\title{
GERENCIAMENTO DA COLETA DE RESÍDUOS SÓLIDOS URBANOS: ESTRUTURAÇÃO E APLICAÇÃO DE MODELO NÃO- LINEAR DE PROGRAMAÇÃO POR METAS
}

\author{
VALERIANA CUNHA
}

Administradora de Empresas

Orientador: Prof. Dr. JOSÉ VICENTE CAIXETA FILHO

Dissertação apresentada à Escola Superior de Agricultura "Luiz de Queiroz", Universidade de São Paulo, para obtenção do título de Mestre em Ciências, Área de Concentração: Economia Aplicada.

PIRACICABA

Estado de São Paulo - Brasil

Setembro - 2001 
Dados Internacionais de Catalogação na Publicação (CIP) DIVISÃO DE BIBLIOTECA E DOCUMENTAÇÃO - ESALQ/USP

\section{Cunha, Valeriana}

Gerenciamento da coleta de resíduos sólidos urbanos : estruturação e aplicação de modelo não-linear de programação por metas / Valeriana Cunha. - - Piracicaba, 2001.

223 p. : il.

Dissertação (mestrado) - - Escola Superior de Agricultura Luiz de Queiroz, 2001.

Bibliografia.

1. Coleta 2. Economịa aplicada 3. Programação não-linear 4. Resíduo sólido I. Título

CDD 628.44

"Permitida a cópia total ou parcial deste documento, desde que citada à fonte - $O$ autor" 
Aos meus pais Weiss e Ana, com todo o meu carinho e gratidâo 


\section{Agradecimentos}

Às forças superiores que satisfazem minha necessidade espiritual.

Ao meu orientador, Prof. Dr. José Vicente Caixeta Filho, por toda a sua competência, dedicação e empenho na orientação do trabalho; pela confiança em mim depositada; pela paciência, sabedoria e tranqüilidade que sempre me transmite.

Aos professores Edson Martins de Aguiar, Luiz Carlos Estraviz Rodriguez e Zilda Paes de Barros Mattos, por todas as contribuições ao longo do desenvolvimento do trabalho e por comporem as bancas de avaliação.

Aos meus pais, Weiss e Ana, por toda dedicação e afeto; pelo incomensurável apoio e por participarem das alegrias e das tristezas, das reclamações e das comemorações, sempre com carinho e paciência.

À minha avó Totonha e às minhas tias, pelo amor à distância.

À minha prima e grande amiga, Raquel, que me acolheu na cidade com muito amor e sempre deu o "apoio logístico" de que eu precisava.

À Valéria, Rosane, Gugu e Fernando, pela torcida constante.

Ao Tiago, pela disponibilidade em ajudar-me.

Ao Nick, pela paz que me transmite.

Às grandes amigas Cínthia, Cristiane e Patrícia, com quem dividi, além dos momentos de concentração e estudo, a minha vida.

Aos colegas do curso, por todos os momentos que tivemos oportunidade de compartilhar.

Aos professores do Departamento de Economia, Administração e Sociologia da USP/ESALQ. 
Aos funcionários do Departamento de Economia, Administração e Sociologia da USP/ESALQ - Álvaro, Cristiane, Fernando, Helena, Elenice, Luciane, Márcia, Maria Helena, Pedro e Valdeci - pelas ajudas indispensáveis, cada um em sua área, mas todas essenciais.

À Maielli que, além de toda a contribuição profissional, é uma pessoa maravilhosa, que sempre tornou os momentos dificeis mais amenos.

À Ligiana, pela grande contribuição prestada na finalização do trabalho.

À Universidade de São Paulo - Campus Piracicaba - pela oportunidade de realização do Curso de Mestrado em Economia Aplicada na instituição.

Ao CNPq, pelo auxílio financeiro recebido.

À Enob Ambiental, especialmente ao Aurélio, pela atenção e presteza no fornecimento dos dados.

À Secretaria de Desenvolvimento do Meio Ambiente da Prefeitura Municipal de Piracicaba e ao Centro de Reabilitação de Piracicaba - SP, especialmente ao Jorge, por fornecerem os dados solicitados. 


\section{SUMÁRIO}

Página

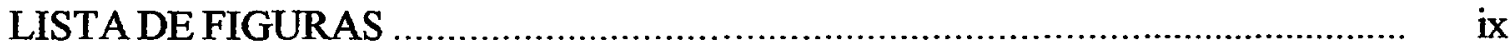

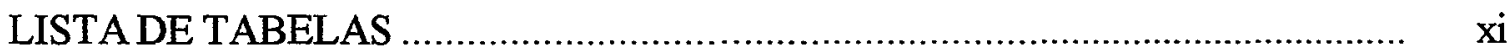

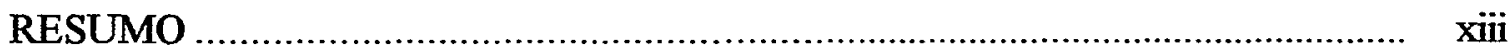

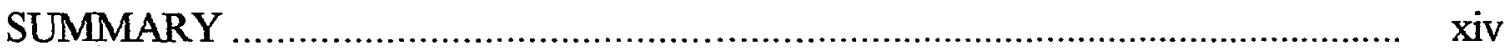

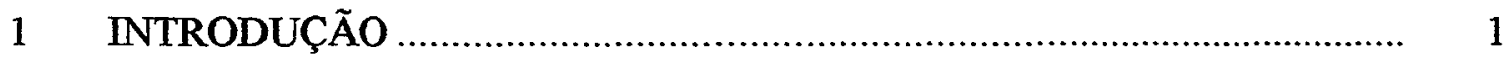

2 REVISÃO DE LITERATURA .......................................................... 4

2.1 Importância do gerenciamento da coleta de resíduos sólidos urbanos ...... 4

2.2 Caracterização dos resíduos sólidos .................................................. 8

2.3 Atividades gerenciais ligadas aos residuos sólidos urbanos .................... 11

2.3.1 Geração .............................................................................. 11

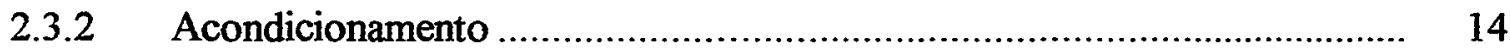

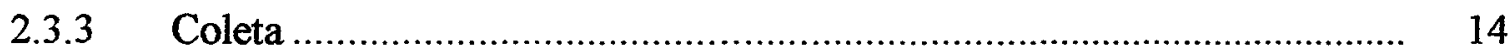

2.3.4 Estação de Transferência ou de Transbordo .......................................... 21

2.3.5 Processamento e recuperação ...................................................... 21

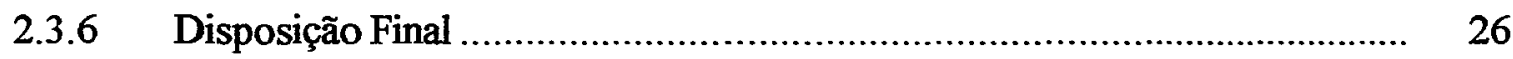

2.4 Custos relacionados ao gerenciamento da coleta de resíduos sólidos

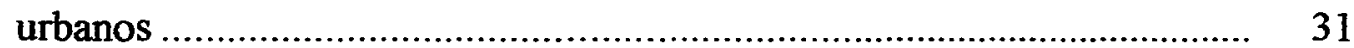

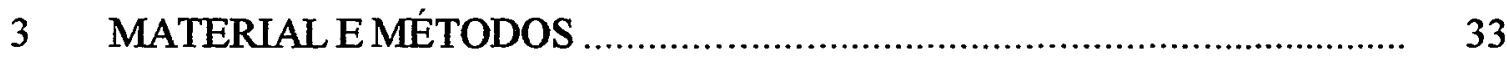

3.1 Modelos de otimização para o gerenciamento de resíduos sólidos

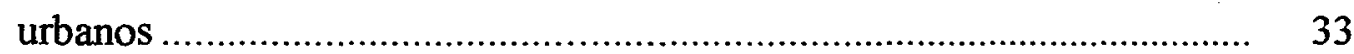

$3.2 \quad$ Programação por Metas ................................................................... 40

3.2.1 Ilustração de programação por metas ............................................... 43 
$3.3 \quad$ O modelo proposto ..................................................................... 47

3.3.1 Especificação das metas ……………………....................................... 47

$3.4 \quad$ Aplicação do modelo ..................................................................... 60

3.4.1 Caracterização do gerenciamento de resíduos sólidos urbanos no município de Piracicaba - SP ........................................................... 60

3.4.2 Especificação dos dados que compõem o modelo ……………………..... 67

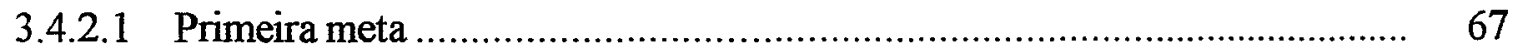

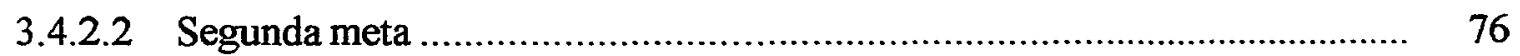

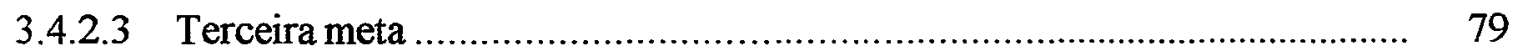

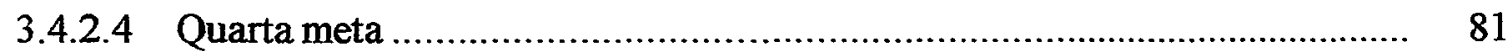

3.4.2.5 Quinta e sexta metas ....................................................................... 81

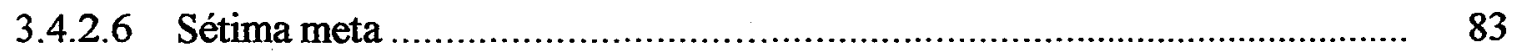

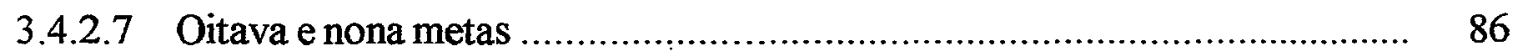

4 RESULTADOS E DISCUSSÃO …...................................................... 91

4.1 Os modelos testados ....................................................................... 91

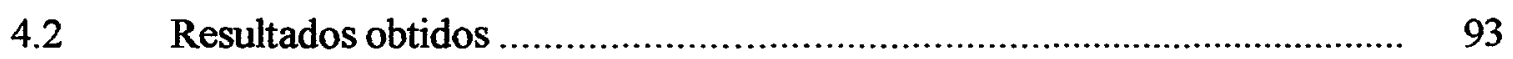

4.2.1 Modelo sem prioridades ................................................................. 94

4.2.2 Modelos com prioridades ............................................................. 100

4.2.2.1 Primeira ordenação das prioridades .................................................... 100

4.2.2.2 Segunda ordenação das prioridades .................................................. 104

4.2.2.3 Terceira ordenação das prioridades .................................................... 108

4.3 Comparação dos valores obtidos com a aplicação dos modelos de programação por metas com os valores praticados em

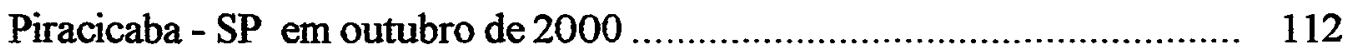

4.3.1 Quantidades coletadas convencionalmente ........................................ 113

4.3.2 Quilometragem percorrida .......................................................... 115

4.3.3 Densidade de coleta ................................................................... 117

4.3.4 Orçamento da coleta seletiva e convencional ....................................... 117

4.3.5 Coleta seletiva .......................................................................... 120

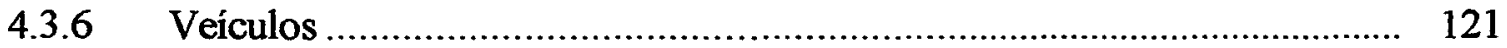


4.3.7 Produtividade …........................................................................ 121

4.4 Considerações finais................................................................. 123

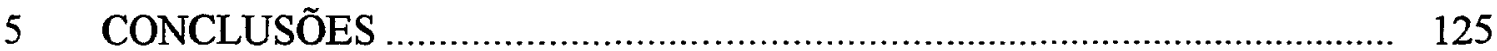

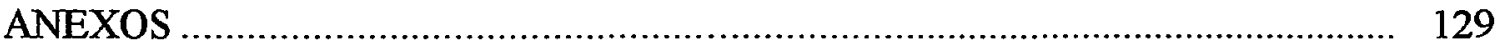

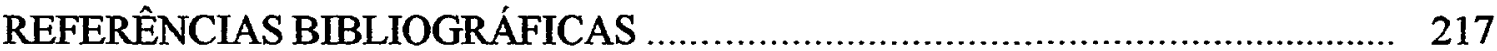




\section{LISTA DE FIGURAS}

Página

1 Caracterização dos resíduos sólidos gerados nos domicílios do Brasil …........... 9

2 Composição dos resíduos sólidos urbanos em algumas cidades Brasileiras,

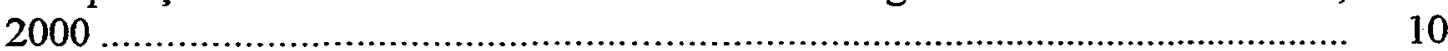

3 O processo da coleta de resíduos sólidos e suas inter-relações .......................... 12

4 Caminhão compactador para lixo domiciliar .................................................. 17

5 Caminhão compactador com dispositivo para basculamento de recipiente estacionário

6 Trator utilizado para a coleta de lixo ........................................................... 17

7 Caminhão de caçamba aberta basculante ........................................................ 17

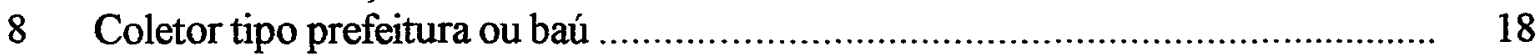

9 Veículo poliguindaste para transporte de caçamba intercambiável ................... 18

10 Veículo com guindaste para coleta em postos de entrega voluntária (coleta seletiva) ou para coleta de podas ................................................................. 18

11 Caminhão multi-caçamba utilizado na coleta seletiva de recicláveis ................. 19

12 Comparação dos custos envolvidos no gerenciamento de resíduos sólidos urbanos entre algumas cidades

13 Fluxo de gerenciamento dos resíduos sólidos ………................................... 38

14 Mapa da cidade de Piracicaba ................................................................ 62

15 Variações relacionadas às quantidades coletadas convencionalmente para a formulação sem prioridades e com densidade média de $195,15 \mathrm{~kg} / \mathrm{km}$, em Piracicaba - SP, 2000

16 Variações relacionadas à quilometragem percorrida na coleta convencional para a formulação sem prioridades e com densidade média de $195,15 \mathrm{~kg} / \mathrm{km}$, em Piracicaba - SP, 2000

17 Variações relacionadas ao Orçamento da Coleta Convencional para a formulação sem prioridades e com densidade média de $195,15 \mathrm{~kg} / \mathrm{km}, \mathrm{em}$ Piracicaba - SP, 2000

18 Variações relacionadas ao Orçamento da Coleta Seletiva para a formulação sem prioridades e com densidade média de $195,15 \mathrm{~kg} / \mathrm{km}$, em Piracicaba - SP, 2000

19 Variações relacionadas à Densidade da Coleta Convencional para a formulação sem prioridades e com densidade média de $195,15 \mathrm{~kg} / \mathrm{km}$, em Piracicaba - SP, 2000 
20 Variações relacionadas à Produtividade da Coleta Convencional para a formulação sem prioridades e com densidade média de $195,15 \mathrm{~kg} / \mathrm{km}$, em Piracicaba - SP, 2000

21 Variações relacionadas à quilometragem percorrida na Coleta Convencional considerando-se a $1^{a}$ ordenação de prioridades, em Piracicaba - SP, 2000.

22 Variações relacionadas ao orçamento da Coleta Convencional considerando-se a $1^{2}$ ordenação de prioridades, em Piracicaba - SP, $2000 \ldots$

23 Variações relacionadas ao orçamento da coleta seletiva considerando-se a $1^{\mathrm{a}}$ ordenação de prioridades, em Piracicaba -SP, $2000 \ldots$.

24 Variações relacionadas à densidade da coleta convencional considerando-se a $1^{\text {a }}$ ordenação de prioridades, em Piracicaba - SP, $2000 \ldots$

25 Variações relacionadas à produtividade da coleta convencional considerando-se a $1^{a}$ ordenação de prioridades, em Piracicaba - SP, $2000 \ldots$

26 Variações relacionadas à quilometragem percorrida na coleta convencional considerando-se a $2^{a}$ ordenação de prioridades, em Piracicaba - SP, 2000

27 Variações relacionadas ao orçamento da coleta convencional considerando-se a $2^{\mathrm{a}}$ ordenação de prioridades, em Piracicaba - SP, $2000 \ldots$

28 Variações relacionadas ao orçamento da coleta seletiva considerando-se a $2^{a}$ ordenação de prioridades, em Piracicaba - SP, $2000 \ldots$

29 Variações relacionadas à produtividade da coleta convencional considerando-se a $2^{a}$ ordenação de prioridades, em Piracicaba - SP, $2000 \ldots$

30 Variações relacionadas à quantidade coletada convencionalmente considerando-se a $3^{a}$ ordenação de prioridades, em Piracicaba - SP, $2000 \ldots$

31 Variações relacionadas à quilometragem percorrida na coleta convencional considerando-se a $3^{\mathrm{a}}$ ordenação de prioridades, em Piracicaba -SP, 2000

32 Variações relacionadas ao orçamento da coleta convencional considerando-se a $3^{\text {a }}$ ordenação de prioridades, em Piracicaba - SP, $2000 \ldots$

33 Variações relacionadas ao orçamento da coleta seletiva considerando-se a $3^{\mathrm{a}}$ ordenação de prioridades, em Piracicaba - SP, $2000 \ldots$

34 Variações relacionadas à densidade da coleta convencional considerando-se a $3^{\mathrm{a}}$ ordenação de prioridades, em Piracicaba - SP, $2000 \ldots$

35 Cálculo do potencial de minimização dos resíduos sólidos urbanos para uma situação hipotética

36 Ganhos financeiros advindos da minimização dos resíduos sólidos urbanos para uma situação hipotética 


\section{LISTA DE TABELAS}

Página

1 Produção de lixo em algumas cidades do mundo ………................................. 5

2 Tempo de decomposição de alguns materiais .................................................. 7

3 Dados sobre geração de resíduos sólidos urbanos em alguns municípios brasileiros, 2000

4 Frequência de coleta e porcentagem da população atendida em alguns municípios brasileiros, 2000 .

5 Veículos utilizados na coleta/transporte do lixo e percurso total de algumas cidades brasileiras, 2000

6 Vantagens e desvantagens dos diferentes tipos de estações de transferências .

7 Métodos utilizados para processamento e recuperação do lixo em alguns municípios brasileiros, 2000 ....

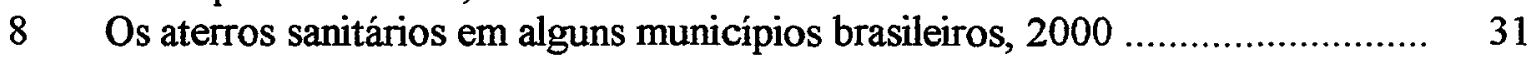

9 Dados do problema ................................................................................ 44

10 Caracterização dos setores de coleta em Piracicaba - SP, $2000 \ldots \ldots \ldots \ldots \ldots \ldots \ldots \ldots \ldots . . .63$

11 Quantidades coletadas de lixo observadas em Piracicaba - SP, por setores, referentes aos meses de agosto e setembro de 2000

12 Dados observados de quantidades coletadas seletivamente em Piracicaba - SP (em kg), por produto reciclável, entre 1999 e 2000 ........

13 Custos de depreciação de bens de capital usados na atividade de coleta seletiva em Piracicaba - SP, outubro de 2000

14 Custos da mão-de-obra operacional e não operacional na atividade de coleta seletiva em Piracicaba - SP, em outubro de 2000

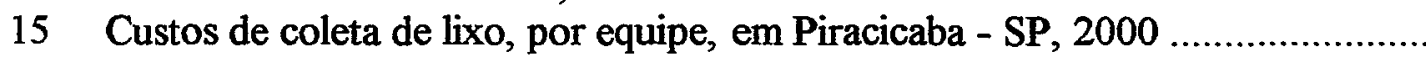

16 Custos mensais de disposição final no aterro sanitário em Piracicaba - SP, 2000

17 Variação da Quantidade coletada de lixo em Piracicaba - SP, em relação à média, para todos os meses do ano

18 Valores médios estimados de geração de lixo por setor, em Piracicaba - SP

19 Valores estimados de geração de lixo, em Piracicaba - SP, em agosto de 2000 
20 Valores de geração de lixo $(\mathrm{kg})$ observados, calculados e variação percentual para o mês de agosto de 2000, em Piracicaba - SP

Geração média de resíduos por habitantes por dia .......................................... 74

22 Valores numéricos da primeira meta do modelo-quantidades mensais a serem coletadas convencionalmente, por setor, em Piracicaba - SP

23 Perímetro dos setores de coleta e distâncias médias dos setores ao aterro sanitário, em Piracicaba - SP, 2000

24 Valores numéricos da segunda meta do modelo - quilometragem mensal a ser percorrida na coleta convencional, por setor, em Piracicaba - SP

25 Valores pagos pela Prefeitura Municipal de Piracicaba para cada tipo de serviço, 2000

26 Valores numéricos da quinta e sexta metas - orçamento mensal, por setor, para a coleta convencional e seletiva em Piracicaba - SP, 2000

27 Quantidades a serem coletadas seletivamente, por setor, em Piracicaba - SP,

27 Quantidades a serem coletadas seletivamente, por setor, em Piracicaba - SP,

28 Participações percentuais observadas por produto reciclável, coletado seletivamente em Piracicaba - SP, entre 1999 e 2000

29 Composição dos resíduos sólidos recicláveis, em Piracicaba - SP

30 Valores numéricos da sétima meta do modelo - quantidades mensais a serem coletadas seletivamente, por setor e por produto reciclável, em Piracicaba - SP, 2000

31 Comparação das quantidades coletadas convencionalmente em Piracicaba SP, em outubro de 2000 , com os valores propostos nas 4 simulações distintas

32 Comparação das quilometragens percorridas na coleta convencional em Piracicaba - SP, em outubro de 2000, com os valores propostos nas 4 simulações distintas

33 Comparação das densidades de coleta na coleta convencional em Piracicaba SP, em outubro de 2000 , com os valores propostos nas 4 simulações distintas

34 Comparação do orçamento da coleta seletiva e convencional em Piracicaba SP, em outubro de 2000 , com os valores propostos nas 4 simulações distintas

35 Comparação das quantidades coletadas seletivamente em Piracicaba - SP, em outubro de 2000 , com os valores propostos nas 4 simulações distintas .......

36 Comparação do número de veículos utilizados na coleta convencional em Piracicaba - SP, em outubro de 2000, com os valores propostos nas 4 simulações distintas

37 Comparação da produtividade dos coletores na coleta convencional em Piracicaba - SP, em outubro de 2000, com os valores propostos nas 4 simulações distintas 


\title{
GERENCIAMENTO DA COLETA DE RESÍDUOS SÓLIDOS URBANOS: ESTRUTURAÇÃO E APLICAÇÃO DE MODELO NÃO-LINEAR DE PROGRAMAÇÃO POR METAS
}

\author{
Autora: VALERIANA CUNHA \\ Orientador: Prof. Dr. JOSÉ VICENTE CAIXETA FILHO
}

\section{RESUMO}

Neste trabalho é desenvolvida e aplicada metodologia para auxiliar a tomada de decisões, nos níveis tático e operacional, do gerenciamento da coleta de resíduos sólidos urbanos. Tal metodologia, baseada em modelo matemático de otimização de Programação Não-Linear por Metas, foi aplicada à cidade de Piracicaba, SP. Pôde-se constatar alguns problemas no gerenciamento tático e operacional na coleta de resíduos sólidos urbanos em Piracicaba, tais como falta de coleta convencional de todos os resíduos gerados em alguns setores, não otimização da frota de veículos existente, produtividades acima das estabelecidas como ótimas na maioria dos setores, densidades abaixo ou acima da média, entre outros. Além disso, verificou-se a necessidade de reestruturação dos setores de coleta para que o gerenciamento se torne mais eficaz. Através da aplicação do modelo, pôde-se concluir que tal ferramenta é útil na tomada de decisão nos níveis tático e operacional, podendo, inclusive, auxiliar na redefinição de estratégias a serem seguidas pelos tomadores de decisão. 


\title{
MANAGEMENT OF SOLID URBAN WASTE COLLECTION: STRUCTURING AND APPLICATION OF A NON-LINEAR GOAL PROGRAMIMING MODEL
}

\author{
Author: VALERIANA CUNHA \\ Adviser: Prof. Dr. JOSÉ VICENTE CAIXETA FILHO
}

\section{SUMMARY}

This work presents a methodology that has been developed and applied to help the decision-making process, at both tactical and operational levels, in solid urban waste management. This methodology, based on an optimization mathematical model of NonLinear Goal Programming, has been applied to Piracicaba, a city in the state of São Paulo. Some problems in tactical and operational management of solid urban waste collection have been found there, such as lack of standard collection of all the waste generated in some areas, non-optimization of fleet of vehicles available, productivity above that established as optimal in most areas, densities below or above average, among others. Furthermore, the need of restructuring collection areas has been noticed so that management can be more effective. Upon applying the model, it was concluded that such tool is useful in tactical and operational decision-making, as well as in helping redefining strategies to be followed by decision-makers. 


\section{INTRODUÇÃo}

Procurando a palavra lixo no dicionário, encontram-se os seguintes significados: "1. Aquilo que se varre da casa, do jardim, da rua, e se joga fora; entulho. 2. Tudo o que não presta e se joga fora. 3. Sujidade, sujeira, imundície. 4. Coisa ou coisas inúteis, velhas, sem valor. 5. Ralé" (Ferreira, 1986).

O próprio significado da palavra transmite a impressão de que lixo é algo sem valor, sem importância e que deve ser jogado fora. Ainda nos dias de hoje, muitas vezes, o lixo é tratado com a mesma indiferença da época das cavernas. Nessa época, o lixo não era verdadeiramente um problema, seja por sua menor quantidade gerada, seja por uma maior facilidade da natureza em reciclá-lo.

Entretanto, em tempos mais recentes, a quantidade de lixo gerada no mundo tem sido grande e o seu mau gerenciamento, além de provocar gastos financeiros significativos, pode provocar graves danos ao meio ambiente e comprometer a saúde e o bem-estar da população.

Existem diversos trabalhos na literatura, tais como os de Canassa (1992), Aguiar (1993), Kulcar (1996), Muttiah et al. (1996), que abordam a questão do gerenciamento de resíduos sólidos urbanos objetivando a sua otimização. Entretanto, cada um destes autores enfoca um único aspecto do gerenciamento, tais como a minimização do percurso de coleta, o dimensionamento da frota e equipes de trabalho ou decisões sobre instalação ou não de uma estação de transferência e locais para disposição final do lixo. Algumas abordagens, como a de Sudhir et al. (1996), enfocam, em um mesmo modelo, vários aspectos do gerenciamento de resíduos sólidos urbanos, tratando cada aspecto como um objetivo a ser atingido. 
Neste estudo, será avaliada a seguinte hipótese: a utilização de modelos matemáticos de otimização que consideram, concomitantemente, diversos objetivos, poderá auxiliar no aprimoramento da gestão tática e operacional da coleta de resíduos sólidos urbanos.

Para tal, pretende-se trabalhar com a abordagem de múltiplos objetivos, tratando o gerenciamento da coleta de lixo de maneira integrada. Assim sendo, a proposta de pesquisa deste trabalho diz respeito à investigação sobre o gerenciamento da coleta de resíduos sólidos urbanos em municípios do Brasil, englobando todas as fases do sistema, tendo em vista a proposição de um modelo matemático de Programação por Metas (Goal Programming). Esse modelo deverá ser aplicado no município de Piracicaba-SP ${ }^{1}$, considerando tanto aspectos relacionados a custos como também ao meio ambiente, saúde e bem-estar da população.

Portanto, o objetivo principal desta pesquisa é o desenvolvimento de um modelo matemático de otimização do gerenciamento da coleta de resíduos sólidos urbanos. Para a consecução desse objetivo, faz-se necessário:

- conhecer os modelos e respectivos algoritmos existentes para solucionar os problemas do gerenciamento da coleta dos resíduos sólidos urbanos;

- definir variáveis e índices explanatórios nos sistemas brasileiros de gerenciamento da coleta de resíduos sólidos;

- propor um modelo tático/operacional de gestão da coleta dos resíduos sólidos urbanos;

- definir variáveis relevantes para a composição do modelo na realidade a ser estudada;

- aplicar o modelo desenvolvido na pesquisa a uma situação real;

- analisar a viabilidade do modelo e suas limitações;

- propor estratégias alternativas que visem à otimização do gerenciamento da coleta de resíduos sólidos urbanos.

\footnotetext{
${ }^{1}$ Piracicaba, cidade do interior de São Paulo, tem uma população de 328.312 habitantes, segundo o Censo do IBGE (2000). Maiores informações sobre o sistema de gerenciamento da coleta de resíduos sólidos na cidade serão dadas no capitulo 3 , seções 3.3 e 3.4 .
} 
O presente trabalho está dividido em cinco capítulos. Este primeiro capítulo introduz o assunto e descreve os objetivos da pesquisa. $O$ segundo capítulo - Revisão de Literatura - descreve a importância do assunto e o processo em estudo, desde a geração do lixo, acondicionamento para coleta, a coleta em si (englobando transferência e transporte, processamento e recuperação) até a disposição final dos resíduos. Nesse capítulo também são apresentados os resultados de um levantamento realizado em cinco municípios brasileiros, caracterizando cada uma das etapas do gerenciamento da coleta de resíduos sólidos urbanos nesses municípios. O terceiro capítulo - Material e Métodos - apresenta, em sua primeira seção, alguns métodos e modelos para otimização do gerenciamento da coleta de resíduos sólidos em diversos contextos nacionais e internacionais. Nas seções seguintes é descrita a metodologia que será utilizada para o desenvolvimento do modelo, o modelo em si e a sua aplicação. No quarto capítulo Resultados e Discussão - a aplicação e os resultados são discutidos enquanto no quinto capitulo - Conclusões - são ressaltadas as contribuições e limitações da pesquisa. 


\section{REVISÃO DE LITERATURA}

Neste capitulo, demonstra-se a importância do gerenciamento da coleta de resíduos sólidos com base nos seguintes pressupostos: a grande quantidade de lixo existente no mundo, os gastos financeiros relativos aos serviços de limpeza, os impactos ao meio ambiente e à saúde da população que o lixo pode causar. Ainda neste capítulo, procura-se descrever o ciclo que envolve os resíduos sólidos, desde a sua geração até a sua disposição final. Para ilustrar as principais características desse ciclo, serão apresentados os resultados de uma pesquisa realizada em Bauru (SP) ${ }^{2}$, Belo Horizonte $(\mathrm{MG})^{3}$, Caxias do Sul (RS) ${ }^{4}$, Juiz de Fora $(\mathrm{MG})^{5}$ e Jundiai $(\mathrm{SP})^{6}$.

\subsection{Importância do gerenciamento da coleta de resíduos sólidos urbanos}

Nos últimos tempos, o interesse em se estudar resíduos sólidos tem se mostrado crescente. $\mathrm{O}$ assunto tem se tornado tópico de debates em diversas áreas do conhecimento e sua importância crescente se dá graças a três fatores principais:

- a grande quantidade de lixo gerada;

\footnotetext{
${ }^{2}$ Bauru tem uma população de 315.835 pessoas, das quais 310.208 residem na área urbana. Possui uma extensão territorial de $673 \mathrm{~km}^{2}$ (IBGE, 2000).

${ }^{3}$ Belo Horizonte é uma cidade com 2.229.697 habitantes, todos residentes na área urbana do município. Possui uma área territorial de $331 \mathrm{~km}^{2}$ (IBGE, 2000).

${ }^{4}$ Caxias do Sul tem uma população de 360.207 habitantes, sendo 333.201 residentes na área urbana. A extensão territorial da cidade é de $1.586 \mathrm{~km}^{2}$ (IBGE, 2000).

${ }^{5}$ Juiz de Fora possui 447.141 habitantes, dos quais 443.359 residem na área urbana. Tem uma extensão territorial de $1.439 \mathrm{~km}^{2}$ (IBGE, 2000).

${ }^{6}$ Jundiaí tem uma população de 322.798 habitantes, dos quais 299.669 residem na área urbana. Sua área territorial é de $432 \mathrm{~km}^{2}$ (IBGE, 2000).
} 
- os gastos financeiros relacionados ao gerenciamento de resíduos sólidos urbanos;

- os impactos ao meio ambiente e à saúde da população.

Em relação à quantidade de lixo gerada, de acordo com dados de Brown (1993), a produção de lixo pode variar de aproximadamente 0,46 a $2,27 \mathrm{~kg} / \mathrm{hab} / \mathrm{dia}$, dependendo da cidade e do país de referência, dados que podem ser visualizados na Tabela 1.

Tabela 1. Produção de lixo em algumas cidades do mundo.

\begin{tabular}{llc}
\hline Cidade & \multicolumn{1}{c}{ País } & $\begin{array}{c}\text { Produção de lixo } \\
(\mathrm{kg} / \mathrm{hab} / \mathrm{dia})\end{array}$ \\
\hline Chicago & Estados Unidos & 2,27 \\
Nova York & Estados Unidos & 1,80 \\
Tóquio & Japão & 1,38 \\
Singapura & Singapura & 0,87 \\
Hong Kong & China & 0,85 \\
Hamburgo & Alemanha & 0,85 \\
Roma & Itália & 0,69 \\
Lahore & Paquistão & 0,60 \\
Tunis & Tunísia & 0,56 \\
Bandung & Indonésia & 0,55 \\
Medelin & Colombia & 0,54 \\
Calcutá & Índia & 0,51 \\
Karachi & Paquistão & 0,50 \\
Manila & Filipinas & 0,50 \\
Kano & Nigéria & 0,46 \\
\hline
\end{tabular}

Fonte: Brown (1993)

Segundo Caixeta Filho (1999), o índice per capita brasileiro está situado em torno de 0,50 a 1,00 kg/hab/dia. Segundo Prandini et al. (1995), são geradas a cada dia no país não menos que 242 mil toneladas de resíduos sólidos urbanos, perfazendo 88,3 
milhões de toneladas anuais, das quais $37 \%$ correspondem a detritos gerados nos domicílios. Por outro lado, o direcionamento da indústria mundial, produzindo cada vez mais bens e utilitários descartáveis, leva a um volume crescente de resíduos gerados. Corson (1996) estima que a geração de resíduos sólidos em todo o mundo cresce em torno de $20 \%$ ao ano.

De acordo com Brasil (2000), em relação aos aspectos financeiros envolvidos no gerenciamento da coleta de resíduos sólidos urbanos, no Brasil, em média, os serviços de limpeza demandam de 7 a $15 \%$ do orçamento dos municípios. Segundo Canassa (1992), a coleta é o processo que engloba, geralmente, a maior parte dos recursos alocados aos serviços de limpeza pública. Segundo Cunha et al. (1995), cerca de $50 \%$ do orçamento municipal destinado aos serviços de limpeza são utilizados na coleta e transporte de resíduos sólidos. Entretanto, grande parte desses recursos é desperdiçada em função da ineficiência dos sistemas adotados, principalmente no que tange à elaboração de rotas de coleta, visto que a maioria das empresas coletora apenas utiliza mapas e experiências dos motoristas para "tentar" otimizar o processo.

, Estudos visando à otimização dos serviços de coleta de lixo apresentam resultados animadores. Canassa (1992) conseguiu reduzir um percurso de 54.182 metros para 47.131 metros (13\%) em Florianópolis (Santa Catarina - Brasil). Eisenstein e Iyer (1997) definiram conjuntos de rotas diferentes das que estavam sendo utilizadas para a coleta em Chicago (Illinois - Estados Unidos), consegüindo diminuir entre 12 e 16\% a capacidade dos caminhões utilizados, o que significa uma redução potencial de US\$ 9 milhões nos custos envolvidos. Vários outros autores, tais como Kulcar (1996), MacDonald (1996) e Muttiah et al. (1996), desenvolveram estudos focados na otimização do gerenciamento da coleta de resíduos sólidos urbanos, cujas abordagens e resultados são discutidos no capítulo 3 .

Outro problema importante relacionado ao gerenciamento da coleta do lixo diz respeito à destinação final dos resíduos, o que pode levar à contaminação do ar, da água, do solo e à proliferação de vetores nocivos à saúde humana. A biosfera tem a capacidade de, ao longo do tempo, transformar o lixo em produtos inofensivos ou em nutrientes que podem ser reutilizados. Entretanto, essa capacidade natural de assimilação pode ser 
facilmente excedida se o lixo, principalmente o advindo de atividades industriais, não for controlado. Além disso, existem alguns materiais que o ambiente tem pouca ou, em alguns casos, nenhuma capacidade de assimilação. Nessas circunstâncias haverá, certamente, aumento da poluição e perda da qualidade ambiental. Na Tabela 2 podem ser observados os tempos aproximados de decomposição de alguns produtos. $\mathrm{O}$ dano ecológico não pode ser quantificado de maneira exata, mas certamente afeta a população.

Tabela 2. Tempo de decomposição de alguns materiais.

\begin{tabular}{ll}
\hline Produto & Tempo de decomposição \\
\hline Papel & 2 a 12 semanas \\
Goma de mascar & 5 anos \\
Lata de conserva & 100 anos \\
Plástico & 450 anos \\
Lata de alumínio & 500 a 1000 anos \\
Pneus & Tempo indeterminado \\
Restos orgânicos & 2 a 12 meses \\
Latas de aço & 10 anos \\
Tetrapak & Mais de 100 anos \\
Vidro & Mais de 10.000 anos \\
Plástico duro & Mais de 100 anos \\
Madeira & Mais de 6 meses \\
Cigarro & 3 meses a vários anos \\
Tecidos de algodão & 1 a 5 meses \\
\hline
\end{tabular}

Fonte: http://www.colegiocci.g12.br/gaia/lixo.htm e Secretaria do Meio Ambiente do Estado de São Paulo.

Obs.: O tempo de decomposição pode variar conforme as condições a que são expostos os materiais.

Brasil (2000) aponta os efeitos maléficos que o lixo pode provocar por meio de três agentes: 
- Agentes físicos - é o caso do lixo acumulado às margens de curso d'água ou de canais de drenagem e em encostas, provocando o seu assoreamento e deslizamentos;

- Agentes químicos - a poluição atmosférica causada pela queima de lixo a céu aberto, a poluição do solo e a contaminação de lençóis d'água por substâncias químicas presentes na massa de resíduos;

- Agentes biológicos - o lixo mal acondicionado ou depositado em local inadequado constitui um foco de proliferação de vetores transmissores de doenças.

\subsection{Caracterização dos resíduos sólidos}

De maneira genérica, segundo Consoni et al. (2000a), o lixo sólido urbano abrange os resíduos domiciliares, os originados em estabelecimentos comerciais, industriais e de prestação de serviços, os decorrentes dos serviços de limpeza pública urbana, os oriundos dos estabelecimentos de saúde (sépticos e assépticos), os entulhos da construção civil e os gerados em terminais rodoviários, ferroviários, portos e aeroportos.

Entretanto, no Brasil, a denominação "resíduos sólidos urbanos", segundo Roth et al. (1999), caracteriza o lixo cuja coleta, transporte e destinação final é, por definição legal, de responsabilidade das Prefeituras Municipais, o que inclui o lixo domiciliar, o comercial e o público. Os resíduos assépticos dos estabelecimentos de saúde e os decorrentes dos terminais rodoviários e ferroviários, bem como os entulhos, podem também compor o conjunto de detritos atendidos pela coleta oficial dos municípios, dependendo do entendimento que cada comunidade adota para a questão. Os demais (industriais, sépticos e produzidos em portos e aeroportos) requerem cuidados especiais quanto ao seu acondicionamento, coleta, transporte e destino final, devido à sua periculosidade à saúde humana e ao meio ambiente. Desta maneira, o descarte e o tratamento destes materiais são de responsabilidade das fontes geradoras e não do poder público municipal. 
Segundo D'Almeida et al. (1995), no Brasil o lixo domiciliar é principalmente constituído de matéria orgânica, conforme mostra a Figura 1. Já segundo Roth et al. (1999), em termos anuais, cada cidadão brasileiro descarta em torno de $45 \mathrm{~kg}$ de plásticos, aproximadamente 90 latas de bebidas e 70 latas de alimentos diversos. Além disso, há que se destacar o descarte de pilhas, lâmpadas fluorescentes, frascos de aerossóis, embalagens de produtos de limpeza doméstica, material eletrônico, entre outros.

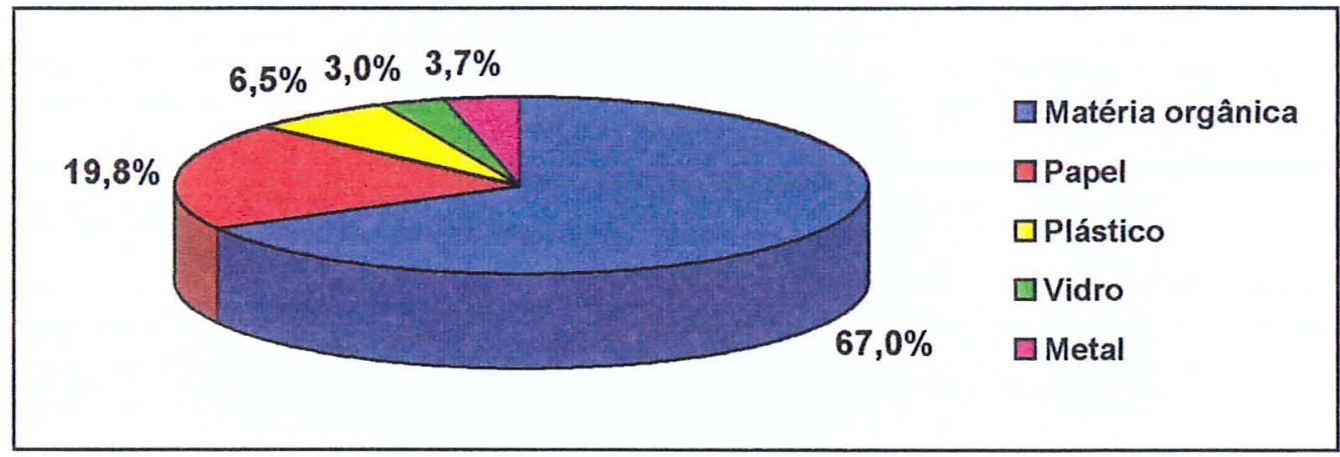

Figura 1 - Caracterização dos resíduos sólidos gerados nos domicílios do Brasil. Fonte: D'Almeida et al. (1995)

Em levantamento realizado em algumas cidades brasileiras ${ }^{7}$, pôde-se verificar a composição dos resíduos sólidos urbanos coletados. Um sumário com os resultados

\footnotetext{
${ }^{7}$ Esse levantamento foi realizado pela autora, nos meses de julho e agosto de 2000, por meio de questionário (vide Anexo A) enviado via e-mail às prefeituras de Bauru (SP), Belo Horizonte (MG), Caxias do Sul (RS), Jundiai (SP) e Juiz de Fora (MG). Essas cidades foram escolhidas por serem de médio porte e se situarem na faixa de 300.000 a 500.000 habitantes. Apesar de Belo Horizonte possuir mais de 2.000.000 habitantes, considerou-se interessante a escolha desse município, pois, segundo Minas Gerais (2000), a gestão de resíduos sólidos urbanos dessa cidade foi premiada internacionalmente através de um trabalho técnico selecionado pelo Conselho Internacional para Iniciativas Ambientais Locais em Toronto, no Canadá, na categoria excelência em Gerenciamento de Resíduos Sólidos, premiação disputada com mais de 200 oîtras cidades de todo o mundo.
} 
é apresentado na Figura 2. Percebe-se que em todos os municípios pesquisados, o percentual de matéria orgânica corresponde à maior parte do lixo coletado, condizendo com a realidade brasileira descrita por D'Almeida et al. (1995) na Figura 1, que aponta o vidro como o material de menor percentual dos resíduos sólidos gerados nos domicílios brasileiros. Comparando esse resultado com os dados da Figura 2, percebe-se que em todos os municípios pesquisados, exceto Caxias do Sul, o vidro também representa o menor percentual dos resíduos coletados.

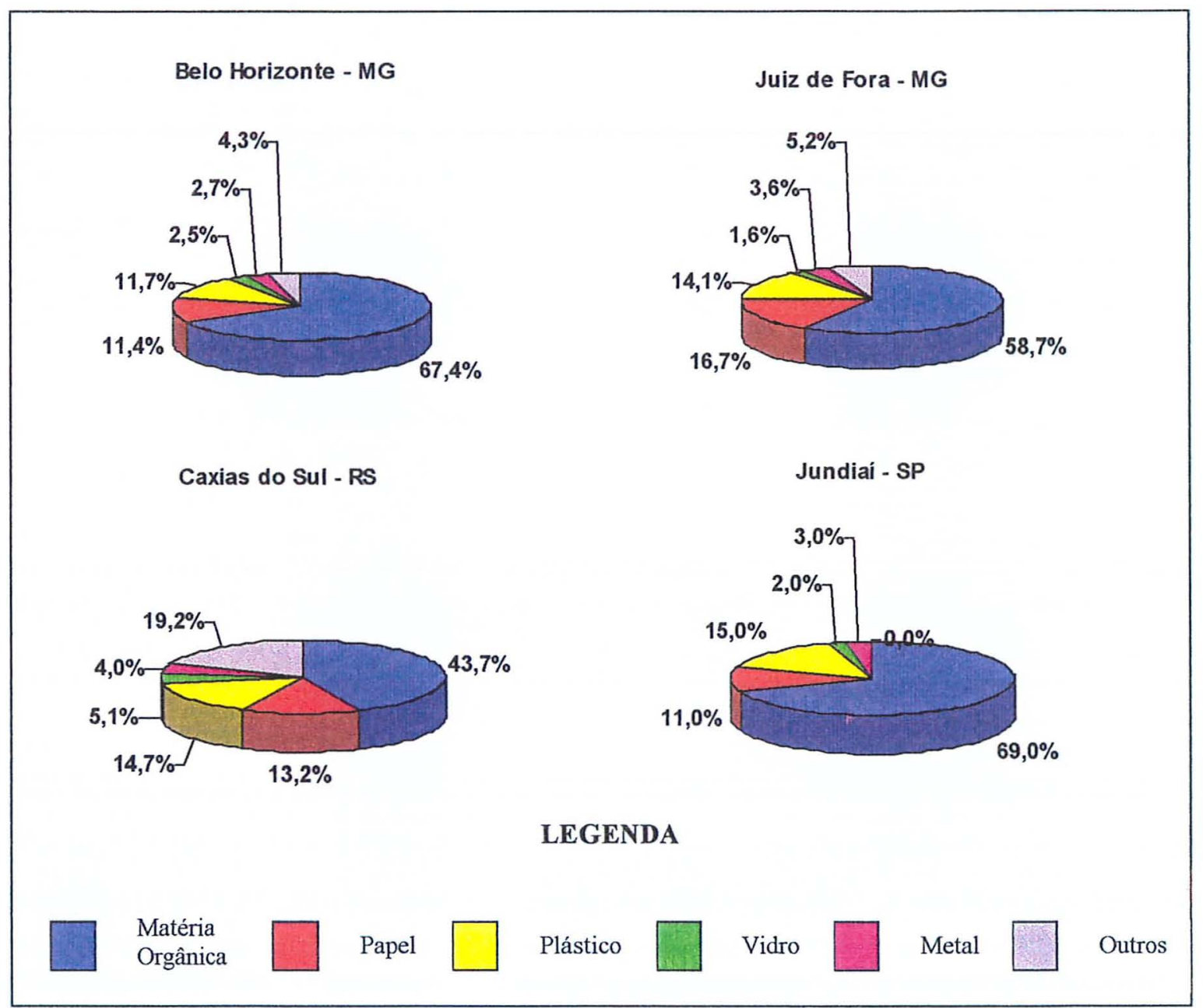

Figura 2 - Composição dos resíduos sólidos em algumas cidades brasileiras, 2000. Fonte: Prefeituras dos municípios pesquisados. 
De acordo com Peral (1989), a composição dos resíduos sólidos urbanos depende de vários fatores, dentre os quais pode-se citar:

- características da população: zonas rurais ou urbanas, áreas residenciais ou de serviço;

- clima e estação: os resíduos coletados no verão apresentam um maior conteúdo de restos de frutas e verduras;

- modo e nível de vida da população: o consumo de produtos alimentícios semi-preparados faz aumentar o conteúdo de embalagens (potes de conserva, vidros, plásticos, papéis e papelão) mas, por outro lado, tem-se uma diminuição dos restos de verduras, carnes etc.

\subsection{Atividades gerenciais ligadas aos Resíduos Sólidos Urbanos}

Tchobanoglous $^{8}$, citado por Canassa (1992), afirma que as atividades gerenciais ligadas aos resíduos sólidos podem ser agrupadas em seis elementos funcionais, conforme ilustra a Figura 3. Cada uma dessas fases será analisada nas próximas seções.

\subsubsection{Geração}

De acordo com Peral (1989), a geração de resíduos, ou seja, a quantidade de resíduos produzidos por uma população, é bastante variável e depende de uma série de fatores, entre eles:

- nível de vida da população: o volume gerado cresce à medida que a renda da população aumenta;

- a época do ano;

- modo de vida da população: é influenciado pela migração diária entre o centro da cidade e da periferia;

${ }^{8}$ TCHOBANOGLOUS, G. Solid Wastes: Engineering Principles and management. Issues. Tokyo: McGraw-Hill, 1977. 


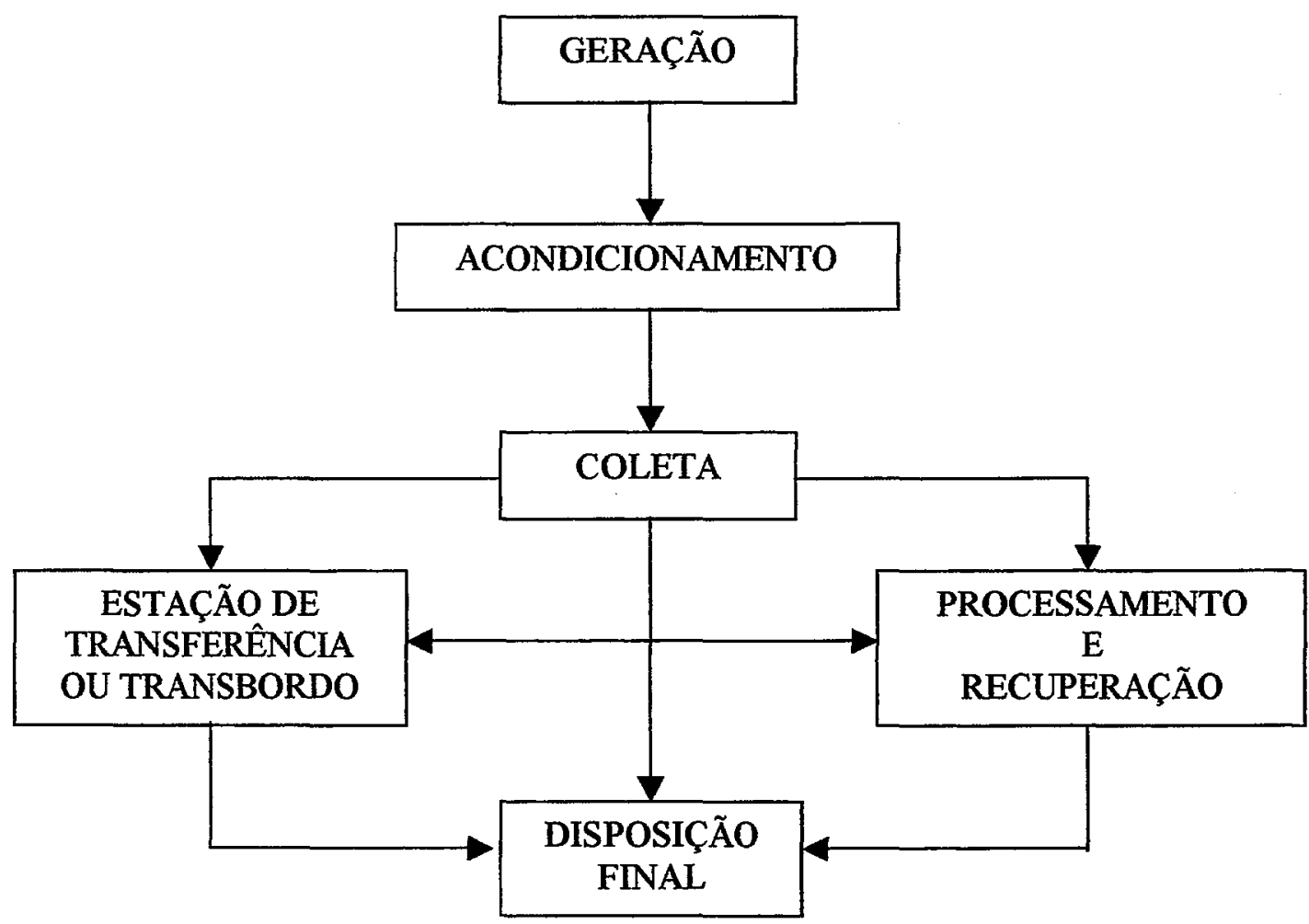

Figura 3 - O processo da coleta de resíduos sólidos e suas inter-relações.

Fonte: Tchobanogloous, citado por Canassa (1992)

- movimento da população durante os períodos de férias, fins de semana e dias festivos;

- os novos métodos de acondicionamento de mercadorias, tais como a utilização de envases e embalagens sem retorno.

As taxas de geração diária de resíduos total e per capita nos municípios pesquisados são descritas na Tabela 3. Percebe-se que a geração per capita nos municípios varia de 0,62 a $1,96 \mathrm{~kg} / \mathrm{hab} / \mathrm{dia}$, sendo Belo Horizonte, a cidade que apresenta o maior valor. 
Tabela 3. Dados sobre geração de resíduos sólidos urbanos em alguns municípios brasileiros, 2000.

\begin{tabular}{lcc}
\hline Cidades & Geração diária & Geração per capita \\
\hline Belo Horizonte & $4.374 \mathrm{t} / \mathrm{dia}$ & $1,96 \mathrm{~kg} / \mathrm{hab} / \mathrm{dia}$ \\
Caxias do Sul & $275 \mathrm{t} / \mathrm{dia}$ & $0,83 \mathrm{~kg} / \mathrm{hab} / \mathrm{dia}$ \\
Juiz de Fora & $273 \mathrm{t} / \mathrm{dia}$ & $0,62 \mathrm{~kg} / \mathrm{hab} / \mathrm{dia}$ \\
Jundiaí & $260 \mathrm{t} / \mathrm{dia}$ & $0,87 \mathrm{~kg} / \mathrm{hab} / \mathrm{dia}$ \\
\hline
\end{tabular}

Fonte: Prefeituras dos municípios pesquisados.

No Brasil, as atividades gerenciais ligadas à fase de geração são pouco efetivas. Já em paises desenvolvidos, é dada grande importância a essa fase, pois é nela que há potencial para a minimização da quantidade dos resíduos sólidos urbanos.

A minimização dessa quantidade pode ser obtida através da redução na própria fonte geradora dos resíduos, a partir da sua reutilização e da reciclagem, uma vez que é nesse momento que se pode proceder a separação do lixo gerado a fim de facilitar a coleta seletiva e reciclagem.

Peral (1989) define a redução na origem como sendo a redução do peso e/ou volume dos resíduos através da alteração de matéria prima, seja pela mudança do tipo de material empregado ou pela composição do mesmo, mudança no desenho da embalagem e/ou produto e troca de material tóxico por materiais menos tóxicos ou não tóxicos.

A redução da fonte e/ou origem, em termos de resíduos sólidos domiciliares, pode ser obtida pela sua não geração, através de alterações de hábitos, ou ainda, através da aquisição de produtos alternativos menos poluentes.

A reutilização consiste no aproveitamento do material nas condições em que é descartado, submetendo-o a pouco ou nenhum tratamento, exigindo apenas operações de limpeza, colocação de etiquetas, entre outras, como é o caso de reutilização de caixas, tambores e garrafas de vidro.

A reciclagem é o processo artesanal ou industrial através do qual os resíduos retornam ao sistema produtivo como matéria prima. Pode ser considerada como uma 
forma de tratamento de parte dos resíduos sólidos gerados. Dada a sua importância, a reciclagem será melhor discutida posteriormente.

Nos Estados Unidos existe um órgão governamental denominado EPA Environmental Protection Agency - que desenvolveu um software para o monitoramento da minimização da geração dos resíduos sólidos urbanos, chamado Reducelt, cujo exemplo de aplicação pode ser visualizado no Anexo B.

\subsubsection{Acondicionamento}

A primeira etapa do processo de remoção dos resíduos sólidos corresponde à atividade de acondicionamento do lixo. Podem ser utilizados diversos tipos de vasilhames, tais como: vasilhas domiciliares, tambores, sacos plásticos, sacos de papel, containers comuns, containers basculantes, entre outros. No Brasil, percebe-se uma grande utilização de sacos plásticos.

De acordo com Brasil (2000), o lixo mal acondicionado significa poluição ambiental e risco à segurança da população, pois pode levar à incidência de doenças tais como: dengue, febre amarela, disenterias, febre tifóide, cólera, leptospirose, giardíase, peste bubônica, tétano, hepatite $\mathrm{A}$ ou infecciosa, malária, esquistossomose etc.

\subsubsection{Coleta}

Após o acondicionamento, os resíduos são depositados em locais apropriados ou nas vias públicas, para serem posteriormente coletados. A operação de coleta engloba desde a partida do veículo de sua garagem, compreendendo todo o percurso gasto na viagem para a remoção dos resíduos dos locais onde foram acondicionados aos locais de descarga até o seu retorno final ao ponto de partida.

Segundo Jardim et al. (2000), em 1997, a taxa de coleta de lixo no Brasil, considerando-se apenas os domicílios urbanos, era de aproximadamente $70 \%$. Esse percentual, embora longe de ser o mais adequado, representa um avanço em relação aos valores de 1990 (64\%) e de 1981 (49\%). A Tabela 4 ilustra os dados relativos à coleta 
para os municípios pesquisados neste trabalho que, por sinal, apresentaram índices de coleta extremamente favoráveis.

Tabela 4. Freqüência de coleta e porcentagem da população atendida em alguns municípios brasileiros, 2000 .

\begin{tabular}{|c|c|c|}
\hline Cidades & $\begin{array}{l}\text { \% da população } \\
\text { urbana atendida }\end{array}$ & Freqüência da coleta \\
\hline Belo Horizonte & $\begin{array}{c}91 \% \\
(2.029 .024)\end{array}$ & $\begin{array}{c}3 \times \text { por semana } \\
\text { (87\% do município) } \\
\text { diária } \\
\text { (13\% do município) }\end{array}$ \\
\hline Caxias do Sul & $\begin{array}{c}100 \% \\
(333.201)\end{array}$ & de diária a quinzenal \\
\hline Jundiaí & $\begin{array}{c}100 \% \\
(299.669)\end{array}$ & não informado \\
\hline Juiz de Fora & $\begin{array}{c}98 \% \\
(434.492)\end{array}$ & $\begin{array}{c}\text { Diária - lixo domiciliar e comercial } \\
\text { ( } 4 \% \text { das rotas) } \\
\text { diária - lixo hospitalar } \\
\text { ( } 4 \% \text { das rotas) } \\
3 \times \text { por semana - lixo domiciliar } \\
\text { ( } 81 \% \text { das rotas) } \\
\text { (11\% das rotas) } \\
2 \times \text { por semana } \\
\text { (coleta seletiva) }\end{array}$ \\
\hline
\end{tabular}

Fonte: Prefeituras dos municípios pesquisados.

A operação de coleta visa a recolher, de forma organizada, segura e econômica, todos os resíduos sólidos gerados pela comunidade e a depositá-los em locais de tratamento, em estações de transbordo ou encaminhá-los para a disposição final.

A coleta normalmente pode ser classificada em dois tipos de sistemas: sistema especial de coleta e sistema de coleta de resíduos não contaminados. Nesse último, a coleta pode ser realizada de maneira convencional ou seletiva. 
No caso do sistema de coleta especial, coletam-se todos os resíduos contaminados, a exemplo dos resíduos dos serviços de saúde, radioativos etc. Neste caso, os resíduos são acondicionados em recipientes específicos e coletados de forma separada. Tal processo utilizado é semelhante ao de coleta por containers, em que o veículo coleta os resíduos armazenados em determinados pontos específicos, os quais, normalmente, preenchem a carga do veículo.

No sistema convencional de coleta dos resíduos não contaminados, em função do tipo de acondicionamento, a coleta pode ser feita ao longo das vias públicas ou por containers. Na coleta ao longo das vias públicas, o veículo coletor percorre todas as ruas, onde os resíduos são colocados, normalmente, em pequenos recipientes. É o processo mais comum, observado na maioria das cidades brasileiras.

Pode-se também coletar os resíduos não contaminados de maneira seletiva. A coleta seletiva viabiliza a reciclagem de matérias primas para a indústria de transformação (plásticos, vidros, latarias e papéis), além de prolongar a vida útil dos aterros em funcionamento, em função da redução da quantidade dos resíduos a eles destinados.

Os tipos de veículos coletores são dos mais diversos. Uma primeira grande classificação os separa entre motorizados e não-motorizados. Os não-motorizados são os que utilizam a tração animal como força motriz. Os motorizados podem ainda ser classificados em compactadores e comuns.

Os veículos compactadores podem possuir ou não dispositivo para basculamento de recipiente estacionário (vide Figuras 4 e 5). Além disșo, de acordo com Querzoli (1988), os compactadores podem ter sistemas de carga descontínua (os mais comuns) ou contínua. Nos primeiros, é preciso parar o sistema de coleta quando o compactador entra em funcionamento, enquanto nos de carga contínua as operações de coleta e compactação podem ser realizadas conjuntamente. Segundo Parra et al. (2000), os veículos compactadores podem reduzir em até $1 / 3$ o volume inicial dos resíduos.

Os veículos coletores comuns podem ser divididos em tratores, coletor de caçamba aberta e coletor com carrocerias tipo prefeitura ou baú, conforme descrito a seguir. 


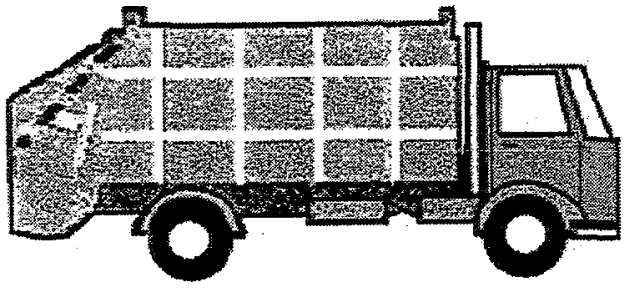

Figura 4 - Caminhão compactador para lixo domiciliar.

Fonte: Parra et al. (2000)

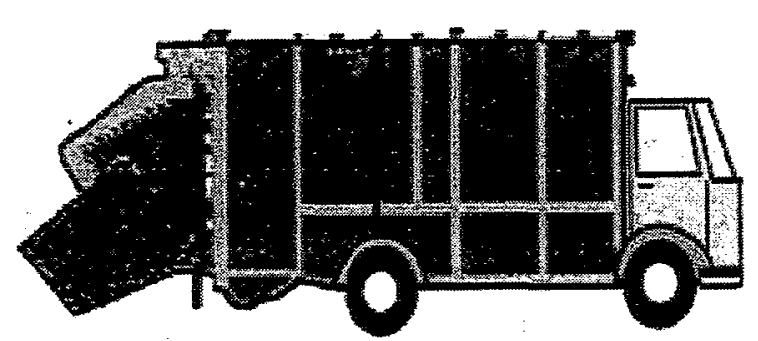

Figura 5 - Caminhão compactador com dispositivo para basculamento de recipiente estacionário.

Fonte: Parra et al. (2000)

- Tratores (vide Figura 6): podem ser utilizados em cidades de pequeno porte e em locais de dificil acesso a outros tipos de veículos.

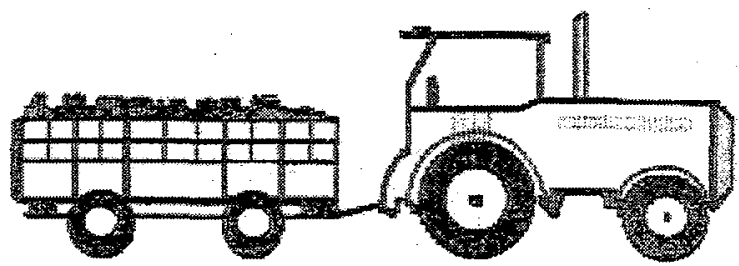

Figura 6 - Trator utilizado para a coleta de lixo. Fonte: Parra et al. (2000)

- Coletor de cacamba aberta (vide Figura 7): segundo Philippi Junior (1986), este modelo tem como característica básica a caçamba construída em chapas de aço, com a parte superior aberta. Sua capacidade é, geralmente, de 5 a $10 \mathrm{~m}^{3}$ de resíduos.

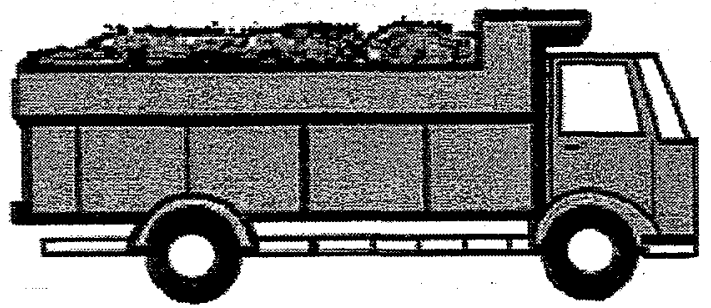

Figura 7 - Caminhão de caçamba aberta basculante.

Fonte: Parra et al. (2000) 
- Coletor tipo prefeitura ou baú (vide Figura 8): de acordo com Querzoli (1988), este veículo coletor, que tem a parte superior fechada, possui uma caçamba construída com chapa de aço, com capacidade variando entre 3,5 a $15,5 \mathrm{~m}^{3}$.

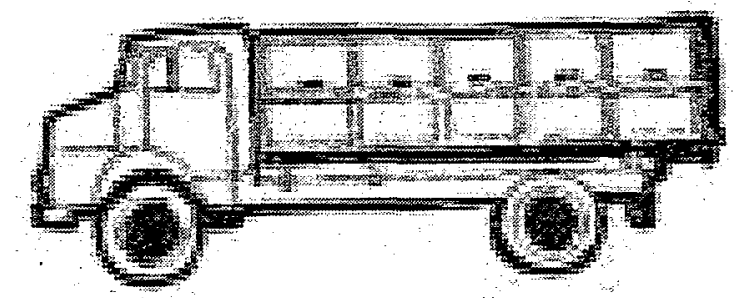

Figura 8 - Coletor tipo prefeitura ou baú.

Fonte: http://www.resol.com.br

Segundo Parra et al. (2000), há ainda o caminhão de carroceria aberta, com um pequeno guindaste móvel, que pode ser utilizado na remoção e transporte de resíduos provenientes de podas de árvores e também na coleta de Postos de Entrega Voluntária $\left(\mathrm{PEV}^{9}\right)$ de materiais recicláveis. (vide Figuras 9 e 10).

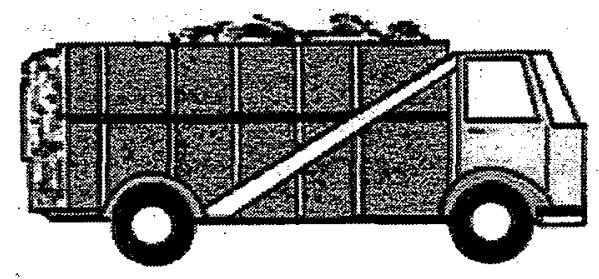

Figura 9 - Veículo poliguindaste para transporte de caçamba intercambiável.

Fonte: Parra et al. (2000)

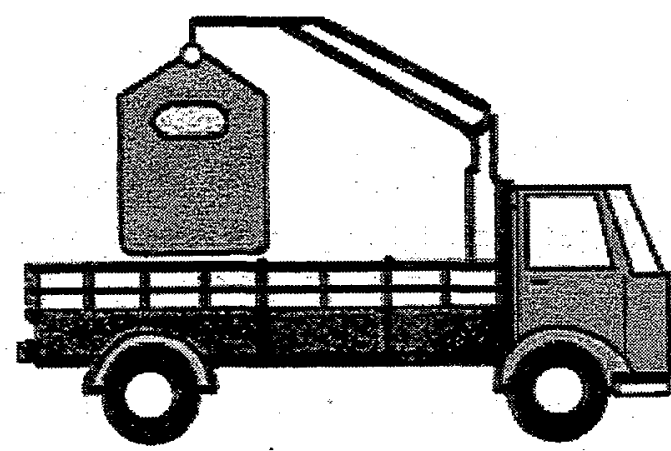

Figura 10 - Veículo com guindaste para coleta em postos de entrega voluntária (coleta seletiva) ou para coleta de podas.

Fonte: Parra et al. (2000)

\footnotetext{
${ }^{9}$ Um PEV consiste de um conjunto de quatro containers de cores diferentes para a coleta seletiva, instalados em locais públicos e de fácil acesso.
} 
Existem também os caminhões multi-caçamba, utilizados na coleta seletiva de recicláveis. Nesse tipo de veículo, metais, vidros, plásticos, papéis e matéria orgânica são alocados separadamente na carroceria do caminhão, como mostra a Figura 11.

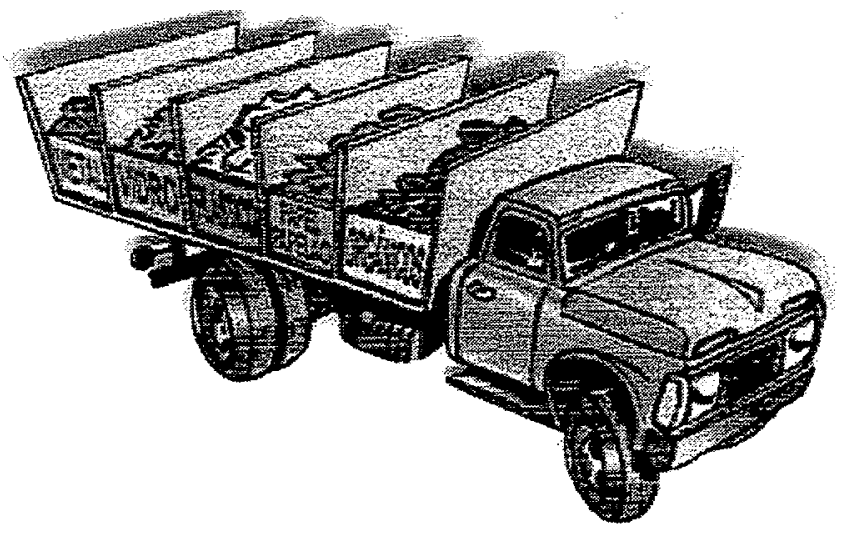

Figura 11 - Caminhão multi-caçamba utilizado na coleta seletiva de recicláveis. Fonte: Guia da coleta... (1999)

De acordo com as empresas de coleta de lixo da cidade de São Paulo, "o perfil básico para que um caminhão se transforme em um catador de lixo ideal é que tenha capacidade para 16 a 17 toneladas, a cara-chata, cabine avançada, motorização entre 180 e $190 \mathrm{HP}$, entre-eixo de aproximadamente $4.500 \mathrm{~mm}$ e transmissão automática. Além disso, deve ter muita robustez no chassis e na suspensão traseira e facilidades para inclusão de um terceiro eixo, entre o dianteiro e o de tração. A transmissão automática nos veículos, apesar de ter um custo inicial maior, proporciona maior regularidade e economia para a operação e inibe constantes erros operacionais que são inevitáveis em uma operação em que se troca de marcha a cada três minutos. $O$ limite de peso para o caminhão toco é de 16 toneladas brutas e nos trucks, 23 toneladas" (Bigarelli, 1997, p.20).

Ainda segundo Bigarelli (1997), existem algumas inovações implantadas pelas próprias oficinas transformadoras ou frotistas que, idealmente, deveriam vir desde a fábrica, tais como cabine dupla, com saídas laterais para os coletores, um escapamento elevado e um sistema pneumático de acionamento do terceiro eixo. 
No Brasil, a escolha do veículo coletor é, ainda, bastante empírica. Ao se pensar em composição ótima de frota, veículos compactadores deveriam atuar em regiões de alta concentração de resíduos e caminhões comuns ou compactadores de baixa capacidade em regiões de concentração mais baixa. Além disso, somam-se situações como a escolha de métodos inadequados e uso de equipamentos incorretos pelos serviços de coleta municipal. Como exemplo, tem-se a utilização de caminhõescaçamba que, por serem abertos, transformam-se em disseminadores dos resíduos coletados, pelas ruas por onde passam.

No levantamento realizado nos municípios brasileiros já citados, identificou-se a caracterização dos veículos, suas capacidades e o tamanho do percurso para as cidades em questão, conforme descrito na Tabela 5. Percebe-se que, em Belo Horizonte e Caxias do Sul, a maioria dos veículos utilizados na coleta são comuns. Já em Bauru e Juiz de Fora, a maioria dos veículos utilizados são compactadores.

Tabela 5. Veículos utilizados na coleta/transporte do lixo e percurso total de algumas cidades brasileiras, 2000 .

\begin{tabular}{lccc}
\hline Cidades & $\begin{array}{c}\text { Quantidade de veículos } \\
\text { Compactadores/capacidade }\end{array}$ & $\begin{array}{c}\text { Quantidade de veículos } \\
\text { comuns/capacidade }\end{array}$ & Percurso diário \\
\hline Bauru & $14 / 15 \mathrm{~m}^{3}$ & $6 / 6 \mathrm{~m}^{3}$ & $1.600 \mathrm{~km}$ \\
Belo Horizonte & $116 / 7 \mathrm{t}$ & $179 / 6 \mathrm{~m}^{3}$ & $21.535 \mathrm{~km}$ \\
& & & \\
& & tipo leme & \\
Caxias do Sul & $6 / 17 \mathrm{~m}^{3}$ & $8 / 13 \mathrm{a} 15 \mathrm{~m}^{3}$ & $2.144 \mathrm{~km}$ \\
& & $\begin{array}{c}\text { caçamba aberta } \\
7 / 40 \mathrm{~m}^{3}\end{array}$ & \\
& & basculantes & \\
& & $14 / 5 \mathrm{~m}^{3}$ & \\
& & caçamba aberta & $3.450 \mathrm{~km}$ \\
Juiz de Fora & & $4 / 20 \mathrm{~m}^{3}$ & \\
& $29 / 13 \mathrm{~m}^{3}$ & poliguindaste \\
& & $3 / 5 \mathrm{~m}^{3}$ & \\
& &
\end{tabular}

Fonte: Prefeituras dos municípios pesquisados. 
Os resíduos coletados podem ser transportados para estações de transferência ou de transbordo, para locais de processamento e recuperação (incineração ou usinas de triagem e compostagem) ou mesmo para o seu destino final (aterros e lixões), conforme descrito nas seções seguintes.

\subsubsection{Estação de transferência ou de transbordo}

Segundo Mansur \& Monteiro (2001), as estações de transferência ou de transbordo são locais onde os caminhões coletores descarregam sua carga dentro de veículos com carrocerias de maior capacidade para que, posteriormente, sejam enviadas até o destino final. $O$ objetivo dessas estações é reduzir o tempo gasto no transporte e, conseqüentemente, os custos com o deslocamento do caminhão coletor desde o ponto final do roteiro até o local de disposição final do lixo. Costuma-se instalar estações de transferência quando as áreas disponíveis para disposição do lixo se encontram muito afastadas dos locais de coleta.

Ainda de acordo com Mansur \& Monteiro (2001), existem duas alternativas para a construção de estações de transferência: sem e com compactação. As estações com compactação podem ter compactador estacionário ou veículo compactador que devem ser complementados por silos ou pátios de acumulação, com a finalidade de permitir o esvaziamento da carga dos carros coletores, sem a eventual presença de carretas na estação de transferência. A Tabela 6 ilustra as vantagens e desvantagens de cada tipo de estação de transferência citado.

\subsubsection{Processamento e recuperação}

Um dos métodos de processamento dos resíduos sólidos urbanos é a incineração. Segundo Roth et al. (1999), o método de incineração dos resíduos sólidos consiste na queima dos detritos em um incinerador ou usina de incineração, a temperaturas superiores a $900^{\circ} \mathrm{C}$. Como vantagens do método, pode-se citar a redução 
Tabela 6. Vantagens e desvantagens dos diferentes tipos de estações de transferências.

\begin{tabular}{lcc}
\hline Tipo & Vantagens & Desvantagens \\
\hline Sem compactação & menor investimento & $\begin{array}{c}\text { Condiciona o } \\
\text { descarregamento à } \\
\text { presença de carretas }\end{array}$ \\
$\begin{array}{l}\text { Com compactador } \\
\text { Estacionário }\end{array}$ & $\begin{array}{c}\text { melhor aproveitamento } \\
\text { da capacidade de carga } \\
\text { das carretas }\end{array}$ & é o tipo mais caro \\
$\begin{array}{l}\text { Com veículo } \\
\text { Compactador }\end{array}$ & $\begin{array}{c}\text { facilita a descarga da } \\
\text { carreta }\end{array}$ & alto custo \\
\hline
\end{tabular}

Fonte: http://www.resol.com.br

significativa do volume dos dejetos municipais (principalmente cinzas de compostos orgânicos e aglomerados inorgânicos solidificados), a diminuição do potencial tóxico dos dejetos e a possibilidade de utilização da energia liberada com a queima (geração de eletricidade, vapor). Os mesmos autores destacam que os principais limitantes ou problemas derivados da incineração são os custos de instalação e de operação do sistema (cerca de US\$20/t de lixo incinerado), a poluição atmosférica (emissão de dioxinas, por exemplo) e a necessidade de mão-de-obra qualificada. Ainda segundo Roth et al. (1999), no Brasil, até 1999, menos de trinta municípios incineravam seus resíduos sólidos.

Como exemplo de método de recuperação dos resíduos, citam-se a reciclagem e a compostagem.

A reciclagem é um processo através do qual materiais que se tornariam lixo são desviados para serem utilizados como matéria prima na manufatura de bens normalmente elaborados com matéria-prima virgem.

A reciclagem pode ser classificada de acordo com o material envolvido. Entre outras, tem-se as seguintes categorias, conforme Peral (1989): 
- reciclagem primária: é o processamento dos resíduos para fabricação de um produto com características similares ao original. Enquadra-se neste grupo a reciclagem que ocorre internamente em uma fábrica (também chamada de reciclagem industrial), com o reaproveitamento de aparas, sobras, peças defeituosas ou fora de especificação. Neste caso, os produtos gerados não são considerados como produtos reciclados, pois, normalmente, há uma mistura com a matéria prima original. Uma característica desta reciclagem é a baixa contaminação do material.

- reciclagem secundária: é o processamento de resíduos com obtenção de produtos diferentes do original. Está associada, em geral, a um nível maior de contaminação. É o caso típico da reciclagem a partir dos resíduos sólidos urbanos, também chamada reciclagem pós-consumo. Os principais aspectos favoráveis da reciclagem secundária são: redução dos impactos ambientais, sanitários e sociais provocados tanto pelo lançamento indiscriminado de resíduos no ambiente, quanto pela implantação e operação de instalações destinadas ao seu tratamento e disposição final; diminuição do consumo de matérias primas virgens, muitas delas não renováveis, cuja exploração também gera impactos e pode tornar-se cada vez mais dificil e cara; redução nos custos de fabricação de alguns produtos, uma vez que o processamento de materiais recicláveis é, geralmente, menos dispendioso, sobretudo em termos energéticos; geração de renda e trabalho, principalmente numa escala que, em função das características de ocorrência e dispersão dos resíduos, favorece as micro e pequenas empresas ou mesmo a constituição de cooperativas.

- reciclagem terciária: implica a obtenção, a partir de um produto, dos componentes químicos básicos do mesmo (no caso dos plásticos, por exemplo, os derivados de petróleo originais). É obtida por diversos processos, tais como pirólise, hidrólise, entre outros. É também denominada reciclagem química. A compostagem de resíduos orgânicos 
(que será melhor descrita a seguir) enquadra-se, de certo modo, nesta categoria.

- reciclagem quaternária: é a utilização do conteúdo energético dos materiais através de sua queima ou incineração. Também conhecida como reciclagem energética, difere das anteriores por não gerar novos produtos que incorporem os materiais já utilizados. Neste sentido, apesar do nome, não é propriamente uma reciclagem, mas sim um reaproveitamento de materiais.

Segundo Brasil (2000), dentre alguns beneficios da reciclagem pode-se citar a preservação dos recursos naturais, a diminuição da poluição do ar e das águas, a diminuição da quantidade de resíduos a serem aterrados e a geração de emprego através da criação de usinas de reciclagem.

Por outro lado, a reciclagem de resíduos sólidos enfrenta obstáculos que podem ser reais ou decorrentes de aspectos indiretos desfavoráveis. A principal dificuldade está associada à diminuição da qualidade técnica do material, em função dos sucessivos ciclos de vida (síntese - transformação - uso - descarte), ao longo dos quais algumas propriedades vão sendo alteradas. Como conseqüência, há uma tendência de que os materiais reciclados sejam usados para a obtenção de produtos com menores exigências técnicas e com menor valor de mercado. Por outro lado, é importante ressaltar que vários materiais (vidro, alumínio, alguns plásticos) mantêm suas características praticamente inalteradas ao serem reciclados.

Um segundo fator relacionado com a qualidade do material diz respeito ao grau de contaminação ${ }^{10}$ que o mesmo apresenta após o uso e, principalmente, após ser coletado da forma tradicional, em que predomina uma mistura bastante intensa dos resíduos. Uma boa separação favorece a recuperação dos materiais a serem reciclados.

De modo geral, segundo Peral (1989), há duas formas de se realizar tal separação:

\footnotetext{
${ }^{10}$ Entende-se por contaminação não somente a ocorrência de "sujeira", mas também a presença conjunta de materiais diferentes. Ambas podem prejudicar a qualidade do produto reciclado, bem como o próprio processamento, acarretando a introdução de etapas adicionais de descontaminação (triagem, lavagem e secagem).
} 
- coleta comum seguida de triagem: os resíduos são coletados sem preocupação quanto à separação, sendo enviados para um ponto de triagem, que pode estar associado a uma unidade de compostagem, de incineração ou a um aterro. A forma mais comum de separação é a visual/manual, realizada por funcionários que ficam ao longo de uma esteira rolante. Procedimentos de separação com eletroímãs ou em função da granulometria ou da densidade também podem ser empregados. A principal característica desse método é que praticamente não há alterações na coleta do lixo (inclusive quanto aos custos), em relação a uma situação sem reciclagem. Por outro lado, os resíduos chegam ao local de separação muito misturados (principalmente quando são coletados utilizando-se veículos compactadores), aumentando bastante a contaminação dos materiais, sobretudo com matéria orgânica. Além disso, a separação manual apresenta baixa eficiência e constitui-se numa atividade insalubre, que pode acarretar em uma alta rotatividade de mão-de-obra.

- coleta seletiva de recicláveis: os resíduos são coletados evitando-se a mistura indesejável e desnecessária dos materiais a serem reciclados, promovendo-se sua coleta em locais e/ou momentos diferentes daqueles da coleta comum. A principal vantagem é uma melhoria significativa na qualidade de tais materiais, cuja contaminação fica bastante reduzida. Acrescente-se a isto, a vantagem de demandar uma participação mais ativa da população, aumentando sua consciência quanto aos resíduos que são gerados por ela.

Um outro fator que pode limitar a reciclagem de resíduos é de natureza financeira e refere-se ao custo comparativamente menor de se utilizar matéria prima virgem na fabricação de determinados produtos. Entretanto, o preço da matéria virgem raramente considera os custos ambientais e sociais decorrentes do consumo de recursos não renováveis e da necessidade de destinação dos resíduos. A incorporação de tais custos pode vir a tornar a comparação financeira mais favorável à reciclagem. 
A compostagem, ou seja, a fabricação de compostos orgânicos a partir do lixo, é um método de decomposição do material orgânico putrescível (restos de alimentos, aparas e podas de jardins, folhas etc.) existente no lixo, sob condições adequadas, de forma a se obter um composto orgânico (húmus) para utilização na agricultura. Apesar de ser considerado um método de tratamento, a compostagem também pode ser entendida como um processo de reciclagem do material orgânico presente no lixo, o que possibilita enorme redução da quantidade de material a ser disposto no aterro sanitário, uma vez que somente será disposto o que for rejeitado no processamento.

Segundo Peral (1989), uma das técnicas de compostagem é a vermicompostagem onde são utilizadas minhocas para a produção do composto, que recebe o nome de vermicomposto. As minhocas ingerem a matéria orgânica previamente compostada, portanto, já anteriormente submetida a um processo de bioestabilização, excretando-a em adiantado estado de humificação, na forma de coprólitos (excrementos fossilizados), com grande disponibilização de nutrientes e capacidade de absorção de umidade.

A partir do levantamento realizado em alguns municípios brasileiros, pôde-se construir a Tabela 7, que ilustra métodos de processamento e recuperação do lixo nos municípios brasileiros pesquisados.

Percebe-se que em todas as cidades há algum tipo de processamento e/ou recuperação dos resíduos sólidos coletados, sendo a coleta seletiva a mais comum.

\subsubsection{Disposição Final}

Em se tratando das alternativas de disposição final do lixo, Consoni et al. (2000b) afirmam que o aterro sanitário é o que reúne as maiores vantagens, considerando a redução dos impactos ocasionados pelo descarte dos resíduos sólidos urbanos. Baseada em critérios de engenharia que permitem a quase total inertização da massa de lixo, tornando-a praticamente "não-reagente" com o meio externo, os autores 


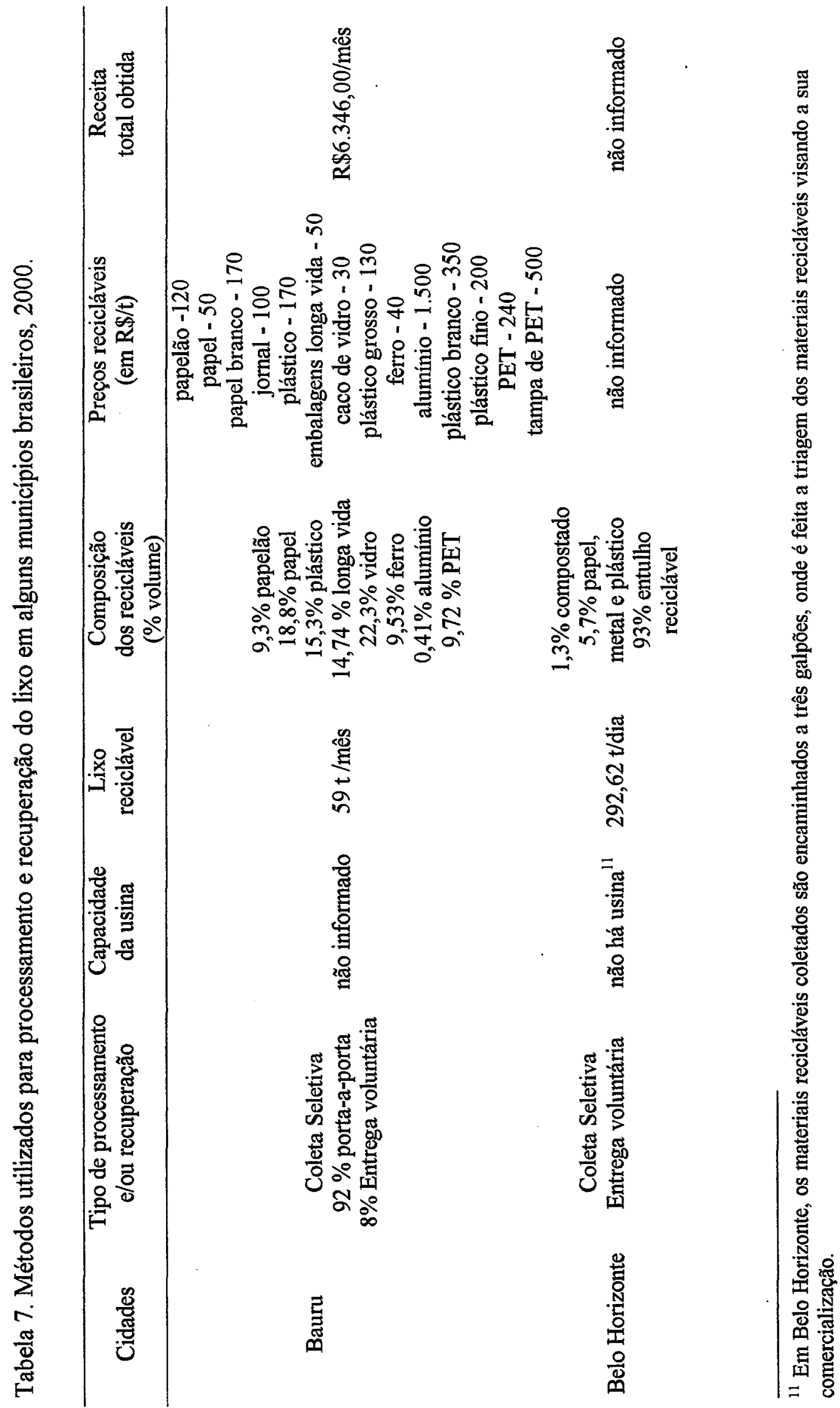




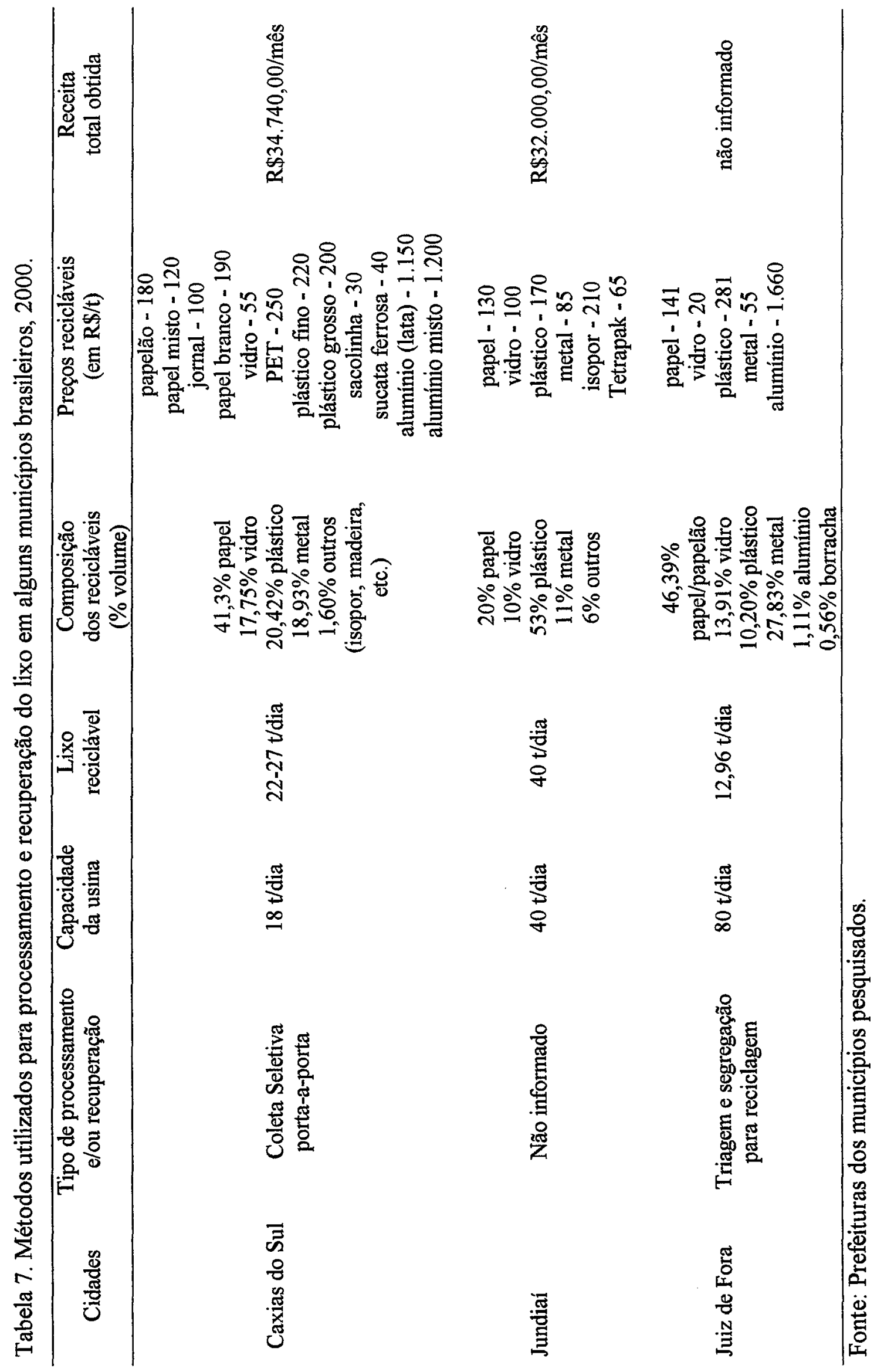


destacam que a instalação de um aterro sanitário apresenta as seguintes características principais: subdivisão da área do aterro em células de colocação de lixo; disposição dos resíduos no solo previamente preparado para que se torne impermeável, impossibilitando o contato dos líquidos residuais (águas das chuvas e chorume ${ }^{12}$ ) com o lençol freático; presença de lagoas de estabilização para a biodegradação da matéria orgânica contida nos líquidos residuais; presença de drenos superficiais para a coleta da água das chuvas; drenos "de fundo" para a coleta do chorume; presença de drenos para a dispersão do metano; coletores dos líquidos residuais em direção às lagoas de estabilização e confinamento do lixo em camadas cobertas com material inerte (solo vegetal).

A eficiência do aterro sanitário, segundo Roth et al. (1999), é dependente tanto da definição correta de sua vida útil, em função das necessidades presentes e futuras (nunca deve ser inferior a 20 anos de uso), quanto da existência e da aplicação de normas operacionais específicas que garantam o preenchimento seqüencial das células de lixo, sua revegetação após o recobrimento e a manutenção do sistema de coleta e tratamento dos líquidos e gases eliminados.

Os aterros continuam existindo até nos países mais desenvolvidos, operando mesmo quando há programas de coleta seletiva e unidades de reciclagem, compostagem e incineração.

Outro método de disposição final dos resíduos é o aterro controlado. Segundo Roth et al. (1999), é menos prejudicial que os lixões pelo fato de os resíduos dispostos no solo serem posteriormente recobertos com terra, o que acaba por reduzir a poluição local. Porém, trata-se de solução com eficácia bem inferior à possibilitada pelos aterros sanitários, pois ao contrário destes, não ocorre a inertização da massa de lixo em processo de decomposição, principalmente por serem geralmente instalados sem que se faça a impermeabilização da base e a instalação de drenos (coleta do chorume e dispersão dos gases resultantes da decomposição). Assim, problemas ambientais

\footnotetext{
${ }^{12}$ Segundo Consoni et al. (2000b), chorume é o líquido preto com alto potencial poluidor do solo e das águas superficiais e subterrâneas, resultante da decomposição da matéria orgânica presente no lixo e a percolação das águas das chuvas ao longo do tempo, o que faz com que o líquido penetrante na massa de resíduos adquira características levemente ácidas, em conseqüência de processos químicos que ali ocorrem.
} 
originados no interior dos aterros controlados podem ser remetidos a longas distâncias, gerando, da mesma forma que no caso dos lixões, impactos negativos.

De acordo com Consoni et al. (2000b), os lixões constituem uma forma inadequada de descarte final dos resíduos sólidos urbanos, sendo porém a mais comum na grande maioria das cidades dos países em desenvolvimento, fazendo com que resíduos inofensivos convivam com produtos tóxicos e perigosos. Problemas e inconvenientes como depreciação da paisagem, odores da decomposição de restos orgânicos, chorume, presença de vetores de doenças (moscas, ratos, baratas, mosquitos), formação de gás metano ${ }^{13}$ e a degradação social de pessoas são fatores comuns a todos os lixões.

Segundo Prandini et al. (1995), a maioria dos resíduos sólidos municipais coletados nas cidades brasileiras (aproximadamente $76 \%$ do total recolhido) não recebe destinação final adequada, sendo despejada em lixões a céu aberto, nos quais não há qualquer espécie de tratamento inibidor ou redutor dos seus efeitos poluidores. Ainda segundo o mesmo autor, apenas $10 \%$ do volume total coletado são depositados em aterros sanitários, $13 \%$ vão para aterros controlados; $0,9 \%$ para usinas de triagem e compostagem e $0,1 \%$ é destinado à incineração.

Os dados referentes aos métodos de disposição final do lixo nas cidades pesquisadas estão descritos na Tabela 8 . Observa-se que os aterros nos municípios pesquisados têm vida útil restante de, no máximo, 4 anos. Percebe-se ainda que em todas as cidades, exceto em Juiz de Fora, o lixo é enviado a aterros sanitários.

\footnotetext{
${ }^{13}$ Metano $\left(\mathrm{CH}_{4}\right)$ é um gás incolor combustivel decorrente da ação das bactérias no material em decomposição. Segundo Consoni et al. (2000b), dentre os seus maleficios estão os incêndios, os riscos de explosões, pela penetração do gás nos solos adjacentes, e também a morte da vegetação das cercanias, pela redução do oxigênio do solo.
} 
Tabela 8. Os aterros sanitários em alguns municípios brasileiros, 2000.

\begin{tabular}{lccccc}
\hline Cidades & $\begin{array}{c}\text { \% enviada ao } \\
\text { aterro sanitário }\end{array}$ & $\begin{array}{c}\% \text { enviada ao } \\
\text { aterro controlado }\end{array}$ & $\begin{array}{c}\text { Área do } \\
\text { aterro }\end{array}$ & $\begin{array}{c}\text { Vida } \\
\text { útil }\end{array}$ & $\begin{array}{c}\text { Vida útil } \\
\text { restante }\end{array}$ \\
\hline Bauru & $\begin{array}{c}100 \% \\
(220 \mathrm{t} / \mathrm{dia})\end{array}$ & - & 4,86 ha & 12 anos & 4 anos \\
Belo Horizonte & $\begin{array}{c}93,3 \% \\
(4.081 \mathrm{t} / \mathrm{dia})\end{array}$ & - & 132,00 ha & 26 anos & 2 anos \\
Caxias do Sul & $278,6 \mathrm{t} / \mathrm{dia}^{14}$ & - & 4,00 ha & 10 anos & 1 ano \\
Jundiaí & $\begin{array}{c}100 \% \\
(260 \mathrm{t} / \mathrm{dia})\end{array}$ & - & $12,80 \mathrm{ha}$ & 15 anos & $\begin{array}{c}1 \text { ano e } \\
6 \text { meses }\end{array}$ \\
Juiz de Fora & - & $98 \%$ & 4,16 ha & 11 anos & $\begin{array}{c}\text { não } \\
\text { informado }\end{array}$ \\
\hline
\end{tabular}

Fonte: Prefeituras dos municípios pesquisados.

\subsection{Custos relacionados ao gerenciamento da coleta de resíduos sólidos urbanos}

A determinação correta dos custos é fundamental para se avaliar o desempenho dos serviços prestados e da empresa como um todo, contribuindo para a melhoria da qualidade da tomada de decisões. No caso das prefeituras, essas informações são necessárias para que a eficiência das empresas prestadoras dos serviços de coleta de lixo possa ser avaliada, auxiliando na determinação da remuneração a ser paga por esses serviços.

A Figura 12 ilustra os custos de coleta, transporte, processamento e disposição final dos resíduos em Belo Horizonte (Minas Gerais - Brasil) e Juiz de Fora (Minas Gerais - Brasil). Os dados completos dos custos nessas cidades estão apresentados no Anexo C. Percebe-se, de acordo com a Figura 12, que os custos da Prefeitura de Belo Horizonte são mais elevados que os da Prefeitura de Juiz de Fora. Para a coleta de lixo

\footnotetext{
${ }^{14}$ Esse valor inclui residuos especiais e podas.
} 
residencial urbano, por exemplo, em Belo Horizonte, o custo é de $\mathrm{R} \$ 39,26 /$ tonelada, enquanto em Juiz de Fora o custo é de $\mathrm{R} \$ 22,15 /$ tonelada.

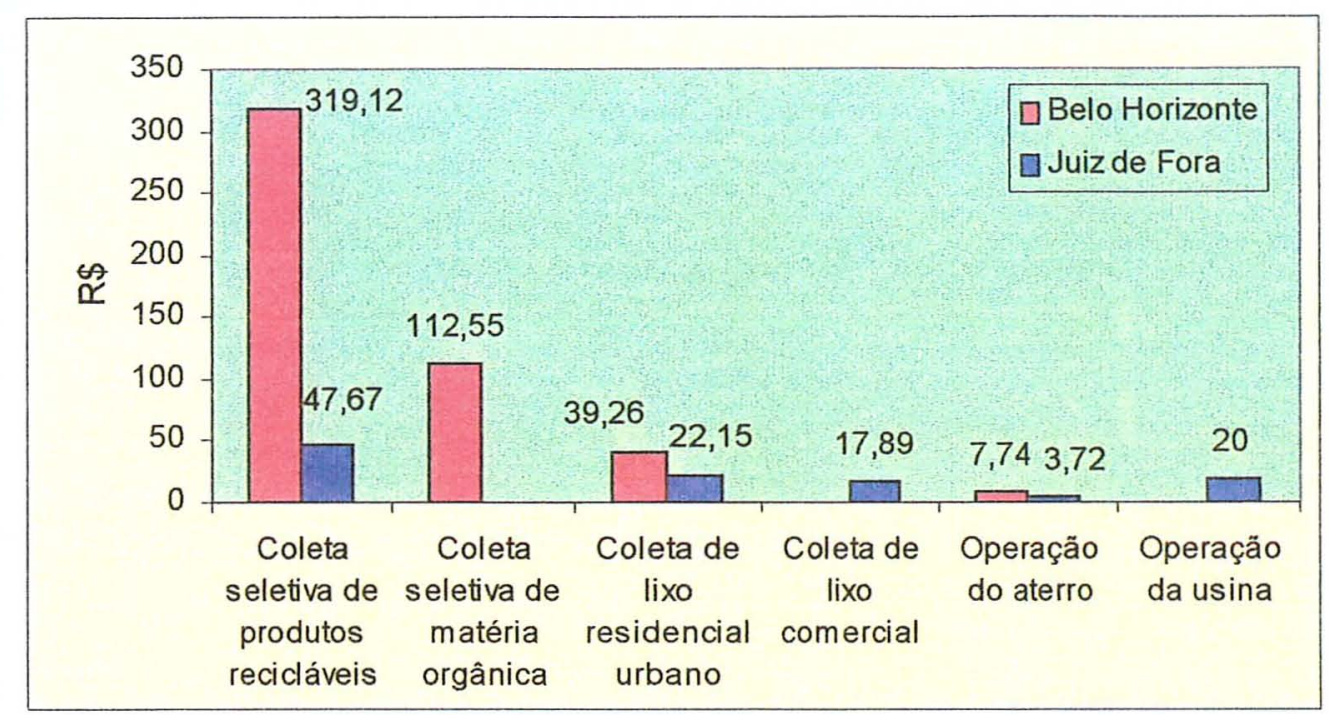

Figura 12 - Comparação dos custos envolvidos no gerenciamento de resíduos sólidos urbanos entre algumas cidades.

Fonte: Prefeituras dos municípios pesquisados.

De acordo com São Paulo (2000), em São Paulo, a maior cidade brasileira, o custo dos serviços de coleta, tratamento e destinação final do lixo em 1997 foi de R \$ 420.922.300,00 para aproximadamente 5.003.174 toneladas de resíduos, o que corresponde a aproximadamente $\mathrm{R} \$ 84,13$ por tonelada.

Este trabalho procurará reunir cada uma das etapas descritas do gerenciamento dos resíduos sólidos urbanos e tratá-las de maneira integrada, conforme detalhado no próximo capítulo. 


\section{MATERIAL E MÉTODOS}

Entende-se por gerenciamento integrado de resíduos sólidos urbanos o conjunto de ações que englobam desde a geração dos resíduos, seu manejo, coleta, tratamento e disposição final dos resíduos. Nesse sentido, pretende-se determinar objetivos a serem alcançados em cada uma destas etapas, visando a otimização do processo como um todo.

Assim sendo, neste capítulo, apresenta-se uma revisão das principais abordagens documentadas na literatura para a otimização do gerenciamento da coleta de resíduos sólidos urbanos, como também descreve-se a metodologia a ser utilizada nesse estudo. Posteriormente, será proposto o modelo a ser aplicado a uma situação real, bem como a caracterização do gerenciamento da coleta de resíduos sólidos urbanos no estudo de caso analisado e a especificação dos dados a serem utilizados no modelo.

É importante ressaltar que neste trabalho serão abordados o sistema convencional de coleta e a coleta seletiva, além da reciclagem secundária.

\subsection{Modelos de otimização para o gerenciamento de resíduos sólidos urbanos}

Encontra-se na literatura uma vasta aplicação de métodos de Pesquisa Operacional para resolução dos mais diversos tipos de problemas relacionados ao gerenciamento de situações que envolvam resíduos sólidos urbanos. 
Mandl (1979) descreve o problema da coleta de lixo em containers, ainda não muito difundido no Brasil, como similar ao do Caixeiro Viajante ${ }^{15}$.

Chaves (1985) apresentou um procedimento heurístico ${ }^{16}$ aplicado a redes mistas para a otimização da coleta de resíduos sólidos em um bairro de Florianópolis.

Costa (1982) realizou o levantamento de algumas restrições associadas a leis de trânsito no Brasil e manobras de veículos. Propôs um modelo de otimização de redes $^{17}$ aplicado a redes orientadas, não-orientadas ou mistas ${ }^{18}$ e efetuou algumas demonstrações destas técnicas utilizando-se de dados reais das cidades de Fortaleza e Aracaju.

Mation (1982) e Gomes (1990), apesar de não proporem nenhum modelo, utilizaram as técnicas de resolução do "problema do carteiro chinês" por exemplo, utilizou-a para redes orientadas na otimização da coleta do bairro de Botafogo no Rio de Janeiro.

Canassa (1992) apresenta um modelo para o planejamento de roteiros de coleta de resíduos sólidos urbanos, objetivando reduzir o tamanho do percurso e melhorar a utilização da capacidade dos veículos coletores. Definiu-se o estabelecimento de um

\footnotetext{
${ }^{15}$ Conforme Gass \& Harris (1996), o problema do Caixeiro Viajante (Traveling Salesman Problem) consiste em determinar a rota mais econômica que comece e termine em um ponto específico, visitando uma única vez cada um dos pontos requerentes de serviços. O problema pode ser descrito da seguinte maneira: se um Caixeiro Viajante deseja passar exatamente uma vez em cada uma de $n$ cidades de uma lista, sendo que os custos de transporte entre as cidades são conhecidos, qual é a rota de menor custo possivel de ser realizada?

${ }^{16}$ Gass \& Harris (1996) definem um procedimento heurístico como um conjunto de regras ou passos que levam a uma solução que pode ou não ser ótima. As regras são baseadas nas características dos problemas e na experiência e intuição do tomador de decisão.

${ }^{17}$ De acordo com Gass \& Harris (1996), os modelos de Otimização de Redes (Network Optimization) podem ser divididos em dois grandes grupos: Planejamento Operacional (Operational Planning) e Estruturação de Sistemas (Design System). No primeiro caso, todas as características da rede são conhecidas e o objetivo é utilizar a rede existente da maneira mais eficiente possível. No segundo caso, estrutura-se a melhor configuração de uma rede, minimizando os custos e fornecendo um nível de serviço eficiente aos clientes. Costa (1982) utilizou um modelo de Planejamento Operacional para otimização de redes.

${ }^{18}$ Segundo Canassa (1992), redes orientadas são aquelas onde as vias que as compõem possuem apenas uma mão de direção. As redes não-orientadas são compostas de vias que possuem duas mãos de direção. Nas redes mistas existem vias com uma ou duas mãos de direção.

${ }^{19}$ Segundo Gass \& Harris (1996), o problema do carteiro chinês (Chinese Postman Problem) consiste em montar uma rota que cubra cada rua de uma determinada zona postal que necessita ser servida pelo carteiro e que leve esse carteiro de volta ao seu ponto de origem. O custo e a distância percorrida deverão ser os menores possiveis.
} 
modelo composto por duas vias principais para a realização do planejamento: a primeira, através de um procedimento que pode ser totalmente informatizado e a segunda, visando ao manuseio de redes que não possibilitam a construção de determinadas etapas no plano bidimensional, através de uma heurística parcialmente informatizada. $\mathrm{O}$ estudo foi aplicado ao planejamento dos roteiros de coleta realizados entre as terças e sextas-feiras, na área central de Florianópolis, SC, com geração média diária, nos dias pré-determinados, de $30 \mathrm{t} /$ dia. Como resultado, além da ferramenta desenvolvida para o planejamento, atingiu-se, no estudo de caso, uma redução de $13 \%$ no comprimento dos percursos iniciais.

Aguiar (1993) realizou um estudo para estimar o tamanho de uma frota de veículos e equipes de trabalho para a coleta e o transporte de resíduos sólidos domiciliares em cidades de pequeno e médio porte. Além disso, seu modelo permite avaliar os custos totais, médios, marginais, assim como a influência de uma ou mais variáveis sobre eles, à medida que as mesmas são alteradas ou que o sistema operacional é modificado (forma geométrica da cidade, densidade populacional, tecnologia utilizada na coleta, taxa de geração e composição dos resíduos sólidos domiciliares da cidade, periodicidade e velocidade de coleta, localização e viabilidade de implantação de estações de transferência de resíduos sólidos, coleta separada do lixo reciclável, localização do pátio de estacionamento dos veículos, distância entre a cidade e o local de disposição final do lixo, entre outras).

Para a elaboração do modelo, Aguiar (1993) dividiu a cidade em setores com densidade populacional e taxa de geração de lixo constantes em toda a sua extensão, além de considerar a malha viária constituída, basicamente, de vias ortogonais e frotas de veículos para coleta de resíduos recicláveis e não recicláveis padronizadas. Com o modelo, consegue-se realizar análises de sensibilidade que possibilitam identificar as características da cidade e da operação que mais contribuem para o acréscimo ou decréscimo nos custos, recursos de equipamento e força de trabalho para os serviços de coleta de resíduos sólidos domiciliares.

Kulcar (1996) desenvolveu um modelo aplicado na cidade de Bruxelas, utilizando métodos de pesquisa operacional para demonstrar como os custos de 
transporte de lixo podem ser minimizados em determinada área. $\mathrm{O}$ trabalho foi dividido em duas fases distintas. Na primeira, utilizou Programação Inteira Mista ${ }^{20}$ com o objetivo de detectar a necessidade da instalação de uma estação de transferência entre as rotas de coleta e o incinerador a fim de minimizar o custo de transporte. Diversas localizações para as estações de transferências foram consideradas. A segunda fase foi proposta a partir de utilização de programação inteira ${ }^{21}$ com vistas à minimização do custo de transporte até os locais de disposição final dos resíduos. Na segunda fase também foram consideradas várias localizações para os depósitos, assim como o impacto da redução do número de depósitos no processo de coleta. Concluiu-se que nenhuma estação de transferência extra deveria ser instalada, pois todas as localizações testadas para tanto levavam a maiores custos de operação. Outra conclusão obtida foi a de que dos treze depósitos existentes, a melhor situação é a que considera apenas quatro deles. A solução proposta pelo problema sinalizava para uma redução potencial de aproximadamente $9 \%$ nos custos iniciais.

Quando se esgota a capacidade dos locais para disposição final do lixo, a busca de um novo local pode consumir tempo. Os métodos existentes para identificar novos locais para disposição do lixo levam em consideração fatores, tais como distâncias das rodovias, propriedades nas proximidades e propensão dos solos a serem contaminados por soluções resultantes de processos industriais. Este tipo de decisão requer conhecimentos em diversas áreas, tais como ciência do solo, sociologia, engenharia e economia. Muttiah et al. (1996) propõem um modelo de localização de depósitos de lixo em Indiana através da utilização das cadeias de Markov²2. Além disso, os autores

\footnotetext{
${ }^{20}$ De acordo com Ackoff (1971), Programação Inteira Mista é um modelo de programação linear com o requisito adicional de que algumas variáveis devem ser inteiras.

${ }^{21}$ Segundo Ackoff (1971), nos modelos de Programação Inteira, todas as variáveis deverão assumir valores inteiros.

${ }^{22}$ Segundo Pinto (2000), as Cadeias de Markov podem ser usadas para processos que envolvam modelos físicos ou econômicos em que o conjunto de sucessos possíveis é finito e a probabilidade do próximo sucesso dependerá apenas do sucesso imediatamente anterior, ou seja, o seu comportamento passado não fornece nenhuma informação relevante na determinação da probabilidade. Além disso, estas probabilidades devem ser constantes no tempo. Os conceitos de Cadeias de Markov são adequados para a análise de problemas probabilísticos, tais como os problemas de estoques e de filas de espera.
} 
propõem o uso de "Simulated Annealing"23 em conjunto com um Sistema de Informação Geográfica (Geographical Information Systems - $\mathrm{GIS}^{\mathbf{2 4}}$ ) para encontrar locais adequados para a disposição final de resíduos sólidos perigosos.

MacDonald (1996) desenvolveu um programa visando a aprimorar o processo de decisão no que tange ao gerenciamento da coleta de resíduos sólidos. $O$ estudo foi denominado "Specific spatial decision support system (SDSS)". A autora alega que o gerenciamento do lixo envolve diversos fatores distintos, tais como: custos, exigências legislativas, uso da terra, geração de poluição, uso de recursos, entre outros. Sendo assim, para se tomarem decisões relacionadas a sistemas de gerenciamento de resíduos sólidos, os trade-offs entre estes fatores devem ser considerados. O SDSS inclui sistemas e modelos para fornecer, organizar e analisar dados relevantes e um GIS (Geographical Information System). Para utilizar o SDSS como uma ferramenta de avaliação de políticas, os planejadores deveriam, primeiramente, desenvolver um conjunto de cenários a serem considerados. Cada um desses cenários seria analisado pelo SDSS e os resultados fornecidos poderiam ser comparados e analisados pelo tomador de decisão. A ferramenta auxilia os planejadores a entenderem como as alternativas de gerenciamento

\footnotetext{
${ }^{23}$ De acordo com Kado (1998), a técnica de Simulated Annealing é derivada do processo de temperagem fisica de um metal. A temperagem objetiva a obtenção de um material sólido no estado tal que os seus átomos assumam padrões regulares. O primeiro passo do processo envolve a fusão do material, seguido de uma redução gradual de temperatura. O estado que o material assume refere-se à configuração de energia mínima de seus átomos. Tal configuração, por sua vez, corresponde ao valor mínimo da função objetivo de um problema de otimização. Uma solução viável para o problema de otimização pode ser considerada como uma possível configuração do material. Para se alcançar o equilíbrio térmico a uma dada temperatura, é necessário que a temperatura se mantenha estável durante um periodo suficientemente longo. Exprimindo em termos de Simulated Annealing, isto implica que o número de soluções viáveis geradas na vizinhança do ponto ótimo, a uma dada temperatura, deve ser suficientemente grande. Uma solução nessa região é a nova solução viável próxima da solução atual, de modo similar a um pequeno deslocamento de um átomo do material produzindo uma nova configuração.

${ }^{24}$ Segundo Deluqui (1998), um GIS (Geographical Information System) pode ser definido como uma coleção organizada de hardware, software, dados geográficos e pessoal, projetado para eficientemente, capturar, armazenar, atualizar, manipular, analisar e apresentar todas as informações referenciadas geograficamente. Constitui-se basicamente em um mapeador temático automatizado, onde as informações obtidas são representadas na forma de "níveis de informação" ou layers e tais características se unem à potencialidade dos bancos de dados automatizados. Os GIS gerenciam e integram banco de dados e arquivos geográficos (linhas, pontos e áreas). Além da possibilidade de lidar com diversas projeções cartográficas, os GIS possuem capacidade de tratar as relações espaciais entre objetos cartográficos (identifica a topologia) e estas podem ser obtidas através de algoritmos. O GIS do estudo continha informações a respeito de uso do solo, rodovias, córregos, rios, entre outros.
} 
dos resíduos sólidos podem afetar a população e o meio ambiente. O fluxo funcionaria conforme ilustrado na Figura 13.

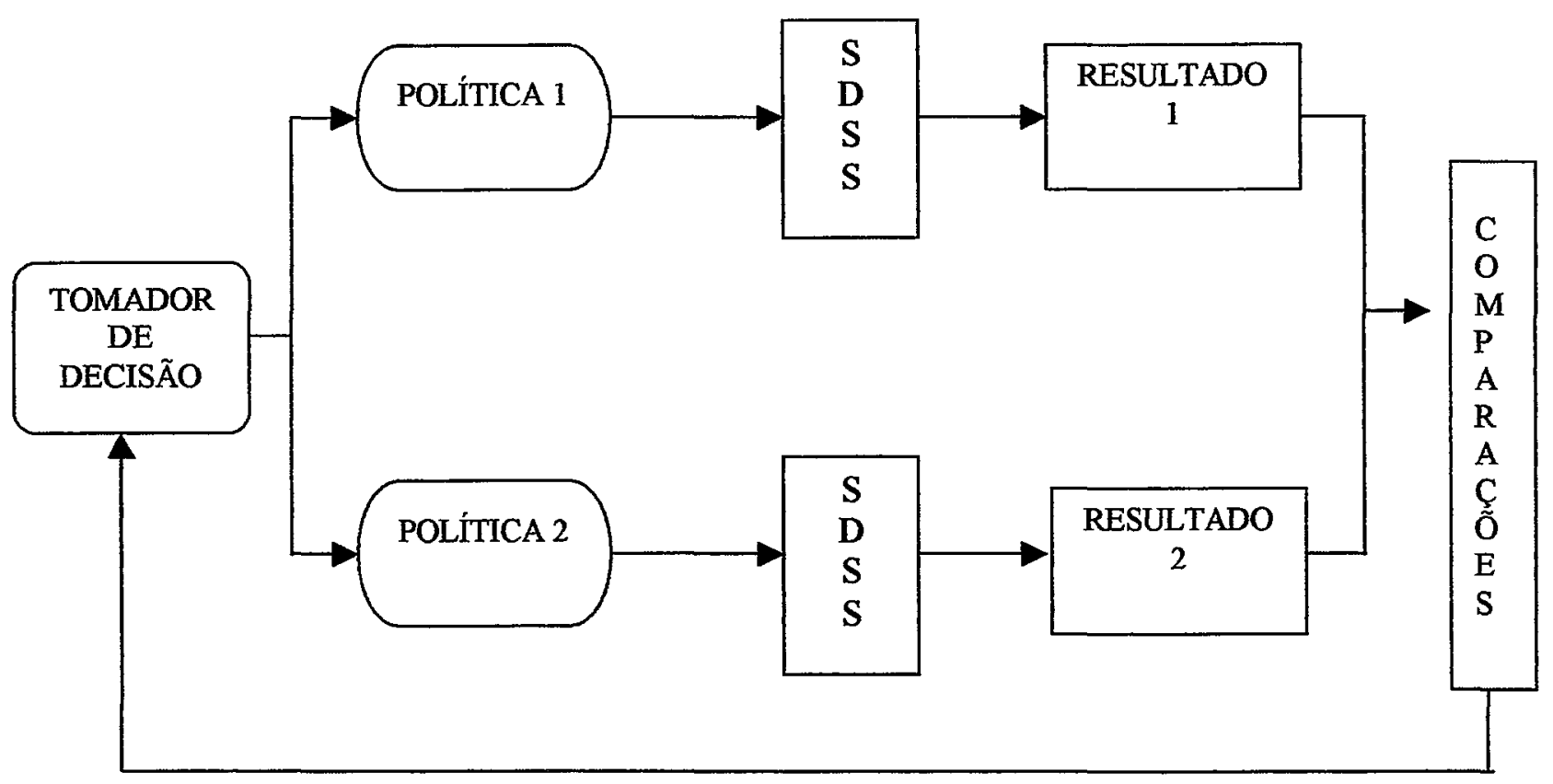

Figura 13 - Fluxo de gerenciamento dos resíduos sólidos.

Fonte: MacDonald (1996)

Posteriormente, através de sugestões dadas pelos responsáveis pelo gerenciamento da coleta do lixo na Filadélfia, MacDonald (1996), modificou o sistema. Esta modificação consistiu no desenvolvimento e inserção de modelos de programação matemática no SDSS para auxiliar os planejadores no desenvolvimento de cenários.

Sudhir et al. (1996) propõem um modelo de gerenciamento integrado da coleta de resíduos sólidos utilizando uma técnica de Pesquisa Operacional denominada Programação por $\mathrm{Metas}^{25}$, com o objetivo de facilitar o consenso entre os diversos objetivos a serem perseguidos simultaneamente, método a ser abordado com detalhes, na

${ }^{25}$ Programação por Metas é um método de tomada de decisão multi-critérios utilizado para resolver problemas que contemplem múltiplos objetivos (Gass \& Harris, 1996). Em Programação por Metas, a função objetivo será sempre uma função de minimização, composta pela soma dos desvios (negativos e/ou positivos) que se pretende minimizar. As metas a serem atingidas serão representadas nos lados direitos das equações (ou Right-Hand-Side - RHS). Em cada lado esquerdo das equações (ou Left-Hand-Side LHS) sempre existirão, além das variáveis, dois termos denominados desvio positivo e desvio negativo. $O$ desvio positivo corresponde ao valor em que a meta ficará acima do nível estabelecido como meta. $\mathrm{O}$ desvio negativo corresponde ao valor que contribui para uma redução no valor estabelecido como meta. Se os desvios negativo e positivo são iguais a zero, a meta foi atingida. 
próxima seção. Os autores propõem um modelo de programação não-linear por metas que abrange seis objetivos, sendo os quatro primeiros de competência do município, o quinto relacionado aos catadores de lixo (reciclantes informais) e o sexto relacionado a empresas privadas engajadas no processo:

1. Minimizar o desvio negativo relacionado aos objetivos da coleta

2. Minimizar o desvio positivo em relação aos objetivos ambientais

3. Minimizar o desvio positivo do orçamento planejado

4. Minimizar a soma dos desvios positivos e negativos do número planejado de veículos

5. Minimizar o desvio negativo do objetivo de empregabilidade

6. Minimizar o desvio negativo do objetivo de receitas das usinas de triagem e compostagem

As restrições consideradas para este problema de Programação Não-Linear por Metas envolviam:

1. Quantidade de lixo coletada - a quantidade de resíduos sólidos coletados pelo municipio e pelos catadores informais não pode exceder a quantidade total de lixo gerada em uma zona.

2. Capacidade de processamento das plantas - a quantidade de resíduos sólidos enviados às usinas de triagem e compostagem não pode exceder a capacidade das mesmas.

3. Capacidade dos locais de disposição final - o volume total de lixo enviado aos locais de disposição final não pode exceder suas capacidades.

4. Quantidade reduzida nos locais de processamento - a quantidade de resíduos sólidos transferida de um local de processamento para um local de disposição final é uma fração do lixo que é recebido pela planta de processamento.

5. Quantidade reciclável - a quantidade reciclável deixada nas ruas é uma função da composição do lixo, dos catadores de lixo e da coleta pelo município (a não linearidade do modelo é conseqüência, unicamente, da especificação matemática adotada para esta restrição). 
Eisenstein \& Iyer (1997) investigaram a programação de caminhões de lixo em Chicago. As análises dos dados coletados mostraram que a cidade é dividida em setores com taxas diversas de geração de lixo. No sistema então vigente, cada caminhão visitava o depósito duas vezes por dia. A abordagem dos autores visava a desenvolver um esquema flexível de rotas, no qual algumas rotas teriam apenas uma ida aos depósitos enquanto outras teriam duas idas diárias, dependendo dos setores designados para cada rota. Utilizaram-se os conceitos de Cadeias de Markov para modelar o impacto na capacidade de usar rotas flexiveis. Os resultados do modelo sugeriram uma redução na capacidade do caminhão de 12 a $16 \%$ para um conjunto de cinco blocos, o que significou uma redução potencial em custos de US\$ 9 milhões por ano.

\subsection{Programação por Metas (Goal Programming)}

De acordo com Lee et al. (1990), o conceito de Programação por Metas, bastante semelhante ao conceito tradicional de Programação Linear, foi originalmente introduzido por A. Charnes e W. W. Cooper e posteriormente desenvolvido por Y. Ijiri, S. M. Lee e outros.

Entretanto, em programação linear, os modelos são desenvolvidos considerando-se apenas um objetivo a ser minimizado ou maximizado. Não é possível encontrar uma solução que, simultaneamente, consiga minimizar custo e maximizar a confiabilidade dos acionistas, por exemplo. $\mathrm{O}$ que se faz em programação linear é uma simplificação da realidade, pois na maioria das situações reais, a solução ótima está relacionada a diversos objetivos. Uma maneira de se tratar múltiplos objetivos é selecionar um deles como principal e os demais como secundários. O principal seria usado como medida de otimização enquanto os secundários seriam tratados como restrições do problema, atribuindo-se valores mínimos e/ou máximos a eles. Entretanto, se os níveis das restrições não forem determinados de maneira cuidadosa, pode não existir uma solução ótima que satisfaça todas as restrições simultaneamente. Desta maneira, para problemas com múltiplos objetivos, o uso da técnica de programação por metas passa a ser uma alternativa interessante. 
De acordo com Ravindran (1986), em programação por metas, para cada objetivo é determinado um nível que deverá ser atingido. A programação por metas trata esses objetivos como metas e não como restrições. É importante destacar a diferença entre a restrição real e a restrição relacionada à meta (ou simplesmente meta). As restrições reais são relacionadas às variáveis de decisão, enquanto as metas são condições que devem ser atingidas, mas que não são obrigatórias ou restritivas. Por exemplo, uma restrição real como a da equação (1),

$$
x_{1}+x_{2}=3
$$

obriga que todos os valores possíveis para $x_{1}+x_{2}$ sejam sempre iguais a 3 .

Por outro lado, uma meta que requer que $x_{1}+x_{2}=3$ não é obrigatória, implicando que a solução pode conter valores maiores ou iguais a 3 , bem como menores ou iguais a 3. Assim sendo, nas metas, são introduzidas variáveis que representam os desvios negativos e positivos do objetivo inicial a ser atingido, como mostra a equação (2).

$$
x_{1}+x_{2}+d_{1}^{-}-d_{1}^{+}=3
$$

sendo

$$
d_{1}^{+}, d_{1}^{-} \geq 0
$$

Perceba-se que se $d_{1}^{-}>0$, então $x_{1}+x_{2}<3$ e se $d_{1}^{+}>0$, então $x_{1}+x_{2}>3$.

Deve-se atribuir pesos adequados a cada um dos desvios para comporem a função objetivo, que deve ser minimizada. Para o exemplo anterior, atribuindo-se pesos $w_{1}^{-}$e $w_{1}^{+}$para $d_{1}^{-}$e $d_{1}^{+}$, respectivamente, tem-se a função objetivo, representada na equação (4).

$$
\min Z=w_{1}^{-} d_{1}^{-}+w_{1}^{+} d_{1}^{+}
$$

Dessa forma, o modelo irá tentar fazer com que a soma $x_{1}+x_{2}$ chegue o mais próximo possível de 3 . Se a meta é satisfazer $x_{1}+x_{2} \geq 3$, então deve ser dado um valor positivo ao peso de $d_{1}^{+}$, enquanto o peso para $d_{1}^{-}$deverá ser igual a zero.

Se os pesos relativos $\left(\begin{array}{lll}w_{1}^{-} & \mathrm{e} & w_{1}^{+}\end{array}\right)$são especificados, o problema de programação por metas se reduz a um problema de programação linear comum. 
Entretanto, muitas vezes os desvios têm unidades diferentes, o que torna uma adequada atribuição de pesos dificil ou até mesmo impossível. Por exemplo, uma empresa que tem dois objetivos, maximizar o lucro e minimizar a emissão de poluentes, apresenta objetivos incomensuráveis, pois o primeiro é medido em unidades monetárias e o segundo, por exemplo, em toneladas de produtos químicos gerados. Para resolver esta incompatibilidade de medidas, a programação por metas define prioridades para os objetivos através de uma classificação ordinal, o que é feito determinando níveis de prioridade a cada objetivo incomensurável e, dentro de cada nível de prioridade, são definidos os pesos dos desvios. A função objetivo ficaria descrita conforme ilustra a equação (5):

$$
\min Z=\sum_{k} P_{k} \sum_{i}\left(w_{i k}^{+} d_{i}^{+}+w_{i k}^{-} d_{i}^{-}\right)
$$

onde $P_{k}$ representa a prioridade $k$, sendo que $P_{k}$ é maior que $P_{k+1}$ e $w_{i k}^{+} e w_{i k}^{-}$são os pesos atribuídos à variável relacionada ao $i$-ésimo desvio na prioridade $k$. Desta maneira, níveis de prioridade mais baixos só serão considerados após os níveis de prioridade mais altos terem sido atingidos.

De acordo com Lee et al. (1990), como o problema de programação por metas é uma forma de programação linear, estes problemas devem ser formulados sob as mesmas hipóteses, limitações e condições da programação linear: linearidade, divisibilidade e característica determinística. Além disso, da mesma maneira que os problemas de programação linear, a programação por metas também poderá ser resolvida utilizando-se o método Simplex ${ }^{26}$.

De acordo com Ravindran et al. (1986), a programação por metas pode ser aplicada em diversos problemas de planejamento nos quais os beneficios são multidimensionais e não diretamente comparáveis. Como exemplos de aplicação podemos citar gerenciamento de florestas, planejamento do uso da terra, recursos

\footnotetext{
${ }^{26} \mathrm{O}$ método Simplex é um algoritmo que, utilizando-se de processos iterativos, leva à solução ótima de um problema. $O$ método Simplex, aplicado aos problemas de programação por metas, é semelhante ao método aplicado à programação linear (Lee et al., 1990).
} 
hídricos, proteção ambiental, seleção de portfólio, transporte, marketing, planejamento da produção, controle de qualidade etc.

O modelo geral de Programação por Metas pode então ser expresso da seguinte maneira:

$$
\min \mathrm{Z}=\sum_{i=1}^{m}\left(w_{i}^{+} d_{i}^{+}+w_{i}^{-} d_{i}^{-}\right)
$$

sujeito a:

$$
\begin{array}{ll}
\sum_{j=1}^{n} a_{i j} x_{j}+d_{i}^{-}-d_{i}^{+}=b_{i} & \text { para todo } i \\
x_{j}, d_{i}^{-}, d_{i}^{+} \geq 0 & \text { para todo } i \mathrm{e} j
\end{array}
$$

A equação (6) representa a função objetivo que minimiza a soma ponderada dos desvios. A equação (7) representa o conjunto de restrições associadas a cada uma das metas. O conjunto de inequações representada pela expressão (8) representa as restrições padrão de não-negatividade de todas as variáveis.

\subsubsection{Iustração de programação por metas}

Para ilustrar o conceito de Programação por Metas será apresentado um exemplo ${ }^{27}$ que contempla as prioridades dadas a cada uma das metas bem como os pesos diferentes que podem ser atribuídos aos desvios dentro de cada prioridade.

Uma usina de triagem e reciclagem de lixo com uma capacidade mensal de recepção de 300 toneladas de lixo por mês processa três tipos de produtos recicláveis: vidro, plástico e papel, utilizando dois tipos de mão-de-obra: a dos separadores, com 500 horas-homem disponíveis, e a dos operadores de máquinas, com 350 horas-homem disponiveis. A quantidade de horas necessárias para cada produto é mostrada na Tabela 9.

${ }^{27}$ Exemplo desenvolvido pela autora. 
Tabela 9. Dados do problema.

\begin{tabular}{lccc}
\hline Funcionários & $\begin{array}{c}\text { Vidro } \\
\text { (horas-homem) }\end{array}$ & $\begin{array}{c}\text { Plástico } \\
\text { (horas-homem) }\end{array}$ & $\begin{array}{c}\text { Papel } \\
\text { (horas-homem) }\end{array}$ \\
\hline Separadores & 9 & 3 & 5 \\
Operadores de máquinas & 5 & 4 & 0 \\
\hline
\end{tabular}

O lucro unitário estimado é de 45, 200 e 230 Unidades Monetárias (U.M.)/tonelada, para vidro, plástico e papel, respectivamente. O salário dos operadores de máquina é duas vezes maior que o salário dos separadores.

Tem-se como metas:

Meta 1 - atingir um lucro de, no mínimo, 20.000 U.M. por mês.

Meta 2 - evitar subutilização da mão-de-obra.

Meta 3 - evitar a utilização de hora-extra.

Meta 4 - evitar subutilização da capacidade de recepção da usina.

Tais metas teriam prioridades $\left(P_{i}\right)$ distintas e, no caso, $P_{1}>P_{2}>P_{3}>P_{4}$.

Desta maneira, a primeira meta reflete o lucro mínimo a ser obtido com a venda dos produtos reciclados, levando-se em consideração o lucro unitário que cada um proporciona (9):

$$
45 x_{1}+200 x_{2}+230 x_{3}+d_{1}^{-}-d_{1}^{+}=20000
$$

onde $x_{1}, x_{2}$ e $x_{3}$ são as quantidades a serem processadas de vidro, plástico e papel, respectivamente. A variável de desvio $d_{1}^{-}$reflete a quantia, em U.M., abaixo do lucro mínimo esperado (20.000 U.M.), enquanto $d_{1}^{+}$representa o lucro acima de 20.000 U.M. A função objetivo seria representada conforme ilustra a expressão (10):

$$
\min \mathrm{Z}=P_{1} d_{1}^{-}
$$

As metas relacionadas às horas-homem disponíveis são dadas pelas equações (11) e (12):

$$
\begin{aligned}
& 9 x_{1}+3 x_{2}+5 x_{3}+d_{2}^{-}-d_{2}^{+}=500 \\
& 5 x_{1}+4 x_{2}+d_{3}^{-}-d_{3}^{+}=350
\end{aligned}
$$


$\mathrm{Na}$ equação (11), $d_{2}^{-}$representa a subutilização da mão-de-obra dos separadores, enquanto $d_{2}^{+}$representa a utilização de horas-extras dos separadores. De maneira análoga, na equação (12), $d_{3}^{-}$representa a subutilização da mão-de-obra dos operadores de máquinas, enquanto $d_{3}^{+}$representa a utilização de horas-extras dos operadores de máquinas. Com essas equações, a segunda e a terceira metas podem ser incorporadas à função objetivo, resultando na seguinte expressão:

$$
\min \mathrm{Z}=P_{1} d_{1}^{-}+P_{2} d_{2}^{-}+2 P_{2} d_{3}^{-}+P_{3} d_{2}^{+}+2 P_{3} d_{3}^{+}
$$

Esses quatro novos termos na função objetivo refletem a segunda e a terceira metas a serem minimizadas. Cada uma das metas tem dois termos, com pesos diferentes, que variam de acordo com o salário de cada tipo de funcionário. Isto significa que a minimização de $d_{3}^{-}$é duas vezes mais importante que a minimização de $d_{2}^{-}$e a minimização de $d_{3}^{+}$é duas vezes mais importante que a minimização de $d_{2}^{+}$. Nesse caso, os pesos são utilizados para diferenciar metas de mesma prioridade, pois o salário dos operadores de máquina é duas vezes maior que o salário dos separadores.

Vale ressaltar que nenhuma das metas associadas à $P_{3}$ (minimização de $d_{2}^{+} \mathrm{e}$ $d_{3}^{+}$) é mais importante que as metas associadas à $P_{2}$ (minimização de $d_{2}^{-}$e $d_{3}^{-}$) que, por sua vez, não são mais importantes que a meta relacionada à $P_{1}$ (minimização de $\left.d_{1}^{-}\right)$

A última meta a ser atingida está relacionada à capacidade mensal de recepção da usina, conforme ilustra a equação (14):

$$
x_{1}+x_{2}+x_{3}+d_{4}^{-}-d_{4}^{+}=300
$$

$\mathrm{Na}$ equação (14),$d_{4}^{-}$representa a subutilização da capacidade de recepção da usina. Ao incluir esta nova meta, a função objetivo ficaria representada conforme a equação (15):

$$
\min \mathrm{Z}=P_{1} d_{1}^{-}+P_{2} d_{2}^{-}+2 P_{2} d_{3}^{-}+P_{3} d_{2}^{+}+2 P_{3} d_{3}^{+}+P_{4} d_{4}^{-}
$$

Portanto, o modelo de programação por metas para este problema seria assim formulado: 


$$
\begin{aligned}
& \min \mathrm{Z}=P_{1} d_{1}^{-}+P_{2} d_{2}^{-}+2 P_{2} d_{3}^{-}+P_{3} d_{2}^{+}+2 P_{3} d_{3}^{+}+P_{4} d_{4}^{-} \\
& 45 x_{1}+200 x_{2}+230 x_{3}+d_{1}^{-}-d_{1}^{+}=20000 \\
& 9 x_{1}+3 x_{2}+5 x_{3}+d_{2}^{-}-d_{2}^{+}=500 \\
& 5 x_{1}+4 x_{2}+d_{3}^{-}-d_{3}^{+}=350 \\
& x_{1}+x_{2}+x_{3}+d_{4}^{-}-d_{4}^{+}=300
\end{aligned}
$$

Resolvendo o problema por programação por metas, chega-se à seguinte solução:

$$
\begin{aligned}
& Z=165 \\
& d_{1}^{-}=0 \quad d_{1}^{+}=8425 \\
& d_{2}^{-}=0 \quad d_{2}^{+}=0 \\
& d_{3}^{-}=0 \quad d_{3}^{+}=0 \\
& d_{4}^{-}=165 \quad d_{4}^{+}=0 \\
& x_{1}=0 \quad x_{2}=87,5 \quad x_{3}=47,5
\end{aligned}
$$

Portanto, tem-se que a meta relacionada à obtenção do lucro de 20.000 U.M foi ultrapassada, pois o desvio positivo relacionado a essa meta $\left(d_{1}^{+}\right)$foi de 8.425 , o que significa que o lucro obtido foi de 28.425 U.M. Os desvios negativos e positivos relacionados à segunda e à terceira meta $\left(d_{2}^{-}, d_{2}^{+}, d_{3}^{-}, d_{3}^{+}\right)$foram todos iguais a zero. Isso significa que foram utilizadas as 500 horas-homem disponíveis dos separadores e as 350 horas-homem disponíveis dos operadores de máquinas. Em relação à quarta meta, o desvio negativo relacionado a ela $\left(d_{4}^{-}\right)$foi de 165 , indicando, assim, que não se está utilizando a capacidade total de recepção mensal da usina (300 ton/mês). Um desvio negativo de 165 indica que a usina está recebendo 135 toneladas de lixo por mês. Ainda de acordo com os resultados obtidos, pôde-se perceber que deverão ser processadas 87,5 toneladas de vidro e 47,5 toneladas de papel. 


\subsection{O modelo proposto}

Como já comentado anteriormente, diversos modelos quantitativos foram desenvolvidos para tratar dos diferentes aspectos do gerenciamento e planejamento de atividades relacionadas a resíduos sólidos urbanos, dentre outras, alocação do lixo dos pontos de coleta aos locais de disposição final, rotas para os veículos de coleta, alternativas de disposição final, localização de usinas de transferência, usinas de triagem e compostagem e locais para disposição final.

O gerenciamento da coleta de resíduos sólidos deve levar em consideração as questões relacionadas à minimização dos custos de operação. É importante que toda a estrutura operacional instalada seja utilizada ao máximo e que as rotas sejam bem trabalhadas a fim de que se obtenha diminuições de percurso e conseqüentemente, reduções em custos. Entretanto, sabe-se dos problemas causados por um mau gerenciamento através, por exemplo, da disseminação de vetores nocivos ao meio ambiente e à saúde, o que leva à conclusão de que, paralelamente ao fator custo, os fatores relacionados ao meio ambiente e à saúde da população devem ser considerados.

Desta maneira, pretende-se propor uma abordagem que englobe múltiplos objetivos contemplando ações integradas ao sistema de coleta do lixo e que seja viável e sustentável, ou seja, que satisfaça objetivos de curto prazo sem acarretar danos que poderão ser percebidos somente no longo prazo.

Deve-se salientar que o modelo a ser proposto é de natureza tática/operacional, não sendo apropriado para definições decorrentes de planejamento estratégico, cabendothe a tentativa de otimização e detecção de falhas na operação, dada a estrutura do sistema de gerenciamento da coleta de resíduos sólidos urbanos vigente na cidade de Piracicaba - SP e que será avaliada neste trabalho.

\subsubsection{Especificação das metas}

A falta de coleta regular do lixo expõe a população ao contato direto com matéria orgânica em decomposição, processo que no Brasil, país de clima tropical, 
ocorre muito rapidamente. A matéria orgânica decomposta constitui excelente meio de proliferação de bactérias patogênicas e de vetores transmissores de doenças.

Sendo assim, a primeira meta ${ }^{28}$ será minimizar a quantidade não coletada mensalmente na cidade. Para isto, tem-se a cidade dividida em $n$ setores $i$ sendo que cada setor tem sua respectiva taxa de geração de lixo mensal, que será definida como meta a ser coletada, representada por $M I_{i}$. A restrição relacionada a esta meta está representada na equação (21).

$$
X_{i}+d c_{i}^{-}-d c_{i}^{+}=M I_{i} \quad \text { para todo } i
$$

onde:

$X_{i}$ é a quantidade transportada de cada setor ( $i$ ) até o aterro sanitário;

$d c_{i}^{-}$e $d c_{i}^{+}$são os desvios negativo e positivo, por setor, da quantidade coletada em relação à quantidade gerada;

$M I_{i}$ é a primeira meta do modelo, que representa a quantidade estimada de geração de resíduos em cada setor $(i)$.

A parcela da função objetivo associada a esta meta é representada pela equação (22).

$$
\min \mathrm{Z}=P_{1} \sum_{i=1}^{n} d c_{i}^{-}
$$

onde:

Z é a variável que representa a soma dos desvios a serem minimizados;

$P_{1}$ é a prioridade associada a essa meta.

Nessa meta, apenas o desvio negativo $\left(d c_{i}^{-}\right)$deverá ser minimizado, pois ele representa a quantidade não coletada nos setores. $\mathrm{O}$ desvio positivo $\left(d c_{i}^{+}\right)$deverá ser igual a zero, pois a quantidade coletada $\left(X_{i}\right)$ não poderá ser maior que a quantidade gerada $\left(M I_{i}\right)$.

\footnotetext{
${ }^{28}$ No decorrer desse trabalho, as metas serão tratadas segundo a ordenação especificada nessa seção. Entretanto, ao aplicar o modelo, serão considerados diferentes tipos de ordenação, que serão descritos em momento apropriado.
} 
A segunda meta do modelo diz respeito ao percurso mensal, por setor, realizado pelos caminhões coletores. A restrição relacionada a esta meta está expressa na equação (23).

$$
2 \times \mathrm{e}_{\mathrm{i}} \times v_{i} \times \operatorname{dias}_{i}+d g \times 2 \times \operatorname{dias}_{i}+\frac{X_{i}}{d e n s_{i}}+d p_{i}^{-}-d p_{i}^{+}=M 2_{i} \text { para todo } i
$$

onde:

$e_{i}$ é a distância média de cada setor $(i)$ ao aterro;

$v_{i}$ é o número de viagens diárias realizadas de cada setor $(i)$ ao aterro;

$d g$ é a distância do aterro à garagem;

dias $_{i}$ é o número de dias em um mês de coleta em cada um dos setores;

dens $_{i}$ é a densidade ${ }^{29}$ de coleta de cada setor (i);

$d p_{i}^{-}$e $d p_{i}^{+}$são os desvios negativo e positivo, por setor, relacionados ao alcance da meta $M 2_{i}$;

$M 2_{i}$ é a segunda meta do modelo, que corresponde à quilometragem a ser alcançada mensalmente em cada setor (i).

$\mathrm{O}$ primeiro termo da equação (23) $-2 \times \mathrm{e}_{i} \times v_{i} \times$ dias $_{i}$ - corresponde à distância percorrida do aterro sanitário a cada um dos setores durante um mês de coleta. Multiplica-se esse termo por 2, porque a cada viagem realizada do aterro ao setor, os caminhões deverão retornar ao aterro para descarregar o lixo coletado. $\mathrm{O}$ segundo termo da equação (23) - $d g \times 2 \times$ dias $_{i}$ - representa a distância mensal percorrida da garagem ao aterro sanitário. A multiplicação por 2 nesse termo é realizada, sobretudo porque, geralmente, o aterro sanitário situa-se entre a garagem e os setores de coleta. Desta maneira, o caminhão sairia no início do dia para iniciar a coleta, passaria pelo local do aterro sanitário e se dirigiria para os setores de coleta. Ao final do serviço, o lixo coletado na última viagem seria depositado no aterro de onde o veículo coletor seguiria

${ }^{29}$ A densidade representa quantos quilogramas são coletados por quilômetro percorrido no setor em questão. 
para a garagem. O terceiro termo da equação (23) - $\frac{X_{i}}{d e n s_{i}}-$ indica a quilometragem percorrida durante um mês de coleta dentro de cada setor.

A função objetivo passaria então a ser representada por:

$\min \mathrm{Z}=P_{1} \sum_{i=1}^{n} d c_{i}^{-}+P_{2} \sum_{i=1}^{n} d p_{i}^{+}$

onde $P_{2}$ é a prioridade associada à meta de minimização de distância percorrida.

Pretende-se coletar a maior quantidade de lixo possível, percorrendo-se a menor distância possível. Sendo assim, o desvio a ser minimizado deverá ser o positivo, que representa a quilometragem percorrida acima da estabelecida como meta.

Ainda em relação à coleta, pretende-se minimizar a sub ou superutilização dos veículos coletores. A restrição relacionada a esta meta é descrita na equação (25).

$$
\frac{\sum_{i=1}^{n} X_{i}}{\sum_{i=1}^{n} v_{i} \times \operatorname{dias} \times \operatorname{cap}}+d v^{-}-d v^{+}=M 3
$$

onde:

cap é a capacidade dos caminhões;

$d v^{-} e d v^{+}$são os desvios negativo e positivo relacionados à sub e à superutilização da frota;

M3 é a terceira meta do modelo, que está relacionada ao número de veículos a serem utilizados no mês.

Deve-se minimizar, na função objetivo, os dois desvios da meta da frota total a ser utilizada, pois nesse caso, interessa-se minimizar a sub e a superutilização de veículos. A nova função objetivo passa a ser representada por:

$$
\min Z=P_{1} \sum_{i=1}^{n} d c_{i}^{-}+P_{2} \sum_{i=1}^{n} d p_{i}^{+}+P_{3} w v_{3} d v^{-}+P_{3} w v_{3}^{\prime} d v^{+}
$$

onde $w v_{3} \quad e \quad w v_{3}^{\prime}$ são os pesos atribuídos aos desvios negativos e positivos, respectivamente, e $P_{3}$ é a prioridade associada à meta do número de veículos a serem 
utilizados no mês. Vale ressaltar que $w v^{\prime}{ }_{3}$ deverá ser maior que $w v_{3}$, visto que a superutilização da frota seria mais prejudicial que a subutilização.

Os aterros sanitários podem ser considerados como sendo a melhor alternativa de disposição final dos resíduos. Entretanto, quanto menos lixo chegar aos aterros, maior será a sua vida útil e menos problemas a cidade enfrentará na procura de novos locais para disposição final dos resíduos. Desta maneira, deve-se tentar utilizar ao máximo a capacidade de usinas de triagem e reciclagem dos municípios para que a menor quantidade possível de resíduos coletados seja levada até o aterro. Sendo assim, a quarta meta diz respeito à minimização da quantidade de resíduos sólidos que é transportada diretamente das zonas ( $i$ ) para o aterro sanitário, representada pela equação (27) ou (28). A utilização de uma ou outra equação dependerá do tipo de resíduos a serem transportados ao local de processamento. A meta relacionada a este objetivo corresponde à capacidade máxima de recepção das usinas de triagem e reciclagem de resíduos sólidos urbanos.

$$
\sum_{t=1}^{T} \sum_{i=1}^{n} Y_{t i}+d a^{-}-d a^{+}=M 4
$$

ou

$$
\sum_{i=1}^{n} B_{i}+d a^{-}-d a^{+}=M 4
$$

onde :

$Y_{t i}$ é a quantidade coletada, seletivamente, dos $T$ materiais recicláveis $t$ por setor $i$

$B_{i}$ é a quantidade de resíduos coletados convencionalmente, por setor, a ser enviada à usina de triagem/compostagem.

$d a^{-} e d a^{+}$são os desvios negativo e positivo relacionados à qualidade ambiental

M4 é a quarta meta do modelo, relacionada à qualidade ambiental e que corresponde à capacidade máxima de recepção das usinas de triagem e reciclagem; 
Desta maneira, é necessário minimizar na função objetivo, o desvio ambiental negativo, pois esse desvio contribui para a não utilização da capacidade máxima de recepção das usinas de triagem e reciclagem, conforme descrito na equação (29).

$$
\min \mathrm{Z}=P_{1} \sum_{i=1}^{n} d c_{i}^{-}+P_{2} \sum_{i=1}^{n} d p_{i}^{+}+P_{3} w v_{3} d v^{-}+P_{3} w v_{3}^{\prime} d v^{+}+P_{4} d a^{-}
$$

onde $P_{4}$ é a prioridade associada à meta de qualidade ambiental.

A quinta meta diz respeito à minimização das despesas com coleta, transferência, tratamento e disposição final do lixo coletado de maneira convencional. A equação (30) representa a restrição relacionada a esta meta.

$$
c_{i}+d o_{i}^{-}-d o_{i}^{+}=M 5_{i} \quad \text { para todo } i
$$

onde:

$c_{i}$ é o custo de coletar, transferir o lixo dos setores $i$ para o aterro, incluindo o custo de disposição no aterro. O custo de coleta é composto por uma parte fixa (depreciação, peças, salários dos motoristas e coletores) e por uma parte variável (gastos com combustível). O custo de disposição no aterro é composto pelo salário dos motoristas, pedreiros e ajudantes; gasto médio com combustivel; gastos com os equipamentos (máquina de esteira, pá carregadeira, caminhões e retroescavadeiras);

$d o_{i}^{-} e d o_{i}^{+}$são os desvios negativo e positivo, por setor, relacionados à meta orçamentária.

$M 5_{i}$ é a meta orçamentária operacional para a coleta convencional em cada setor (i).

O desvio relacionado ao orçamento da coleta convencional que deverá ser minimizado é o positivo, pois ele contribui para um acréscimo nos valores de custos estabelecidos como metas. $O$ desvio negativo relacionado a essa meta indica que os gastos estão sendo menores que os estabelecidos como metas. Nesse caso, ou a meta está sendo superestimada ou houve alguma economia nos gastos com a coleta. A função objetivo ficaria então descrita conforme ilustra a equação (31):

$$
\min \mathrm{Z}=P_{1} \sum_{i=1}^{n} d c_{i}^{-}+P_{2} \sum_{i=1}^{n} d p_{i}^{+}+P_{3} w v_{3} d v^{-}+P_{3} w v_{3}^{\prime} d v^{+}+P_{4} d a^{-}+P_{5} \sum_{i}^{n} d o_{i}^{+}
$$


onde $P_{5}$ é a prioridade associada à meta orçamentária.

A sexta meta associada ao modelo é relacionada ao orçamento destinado à coleta seletiva dos resíduos urbanos, conforme mostra a expressão (32):

$$
m_{i}+\operatorname{dos}_{i}^{-}-\operatorname{dos}_{i}^{+}=M \sigma_{i} \quad \text { para todo } i
$$

onde:

$m_{i}$ é o custo de processar o lixo reciclável dos setores $i$;

$d o s_{i}^{-} e d o s_{i}^{+}$são os desvios negativo e positivo, por setor, relacionados à meta orçamentária;

$M 6_{i}$ é a meta orçamentária operacional da coleta seletiva dos resíduos urbanos em cada setor (i).

Da mesma maneira como acontece com a coleta convencional, o desvio positivo relacionado à meta de custos com a coleta seletiva deverá ser minimizado, conforme ilustra a função objetivo na equação (33):

$$
\begin{aligned}
& \quad \min \mathrm{Z}=P_{1} \sum_{i=1}^{n} d c_{i}^{-}+P_{2} \sum_{i=1}^{n} d p_{i}^{+}+P_{3} w v_{3} d v^{-}+P_{3} w v_{3}^{\prime} d v^{+}+P_{4} d a^{-}+ \\
& +P_{5} \sum_{i=1}^{n} d o_{i}^{+}+P_{6} \sum_{i=1}^{n} d s_{i}^{+}
\end{aligned}
$$

A sétima meta do modelo diz respeito ao alcance de um percentual mínimo de material coletado seletivamente por setor. São poucos os municípios brasileiros que realizam este tipo de coleta e, mesmo naqueles que a realizam, o montante de lixo coletado seletivamente ainda é baixo. De qualquer forma, tal meta é representada pela equação (34).

$$
\sum_{i=1}^{T} Y_{t i}+d s_{i}^{-}-d s_{i}^{+}=M 7_{i} \quad \text { para todo } i
$$

onde:

$M 7_{i}$ é a meta de quantidade ótima a ser coletada seletivamente em cada setor $i$. 
Para essa meta, assim como para a meta relacionada à quantidade a ser coletada convencionalmente, o desvio negativo de coleta é o desvio a ser minimizado, pois a ele corresponde a quantidade não coletada seletivamente. Ao incluir essa meta, a função objetivo passa a ser descrita pela equação (35):

$$
\begin{aligned}
& \quad \min \mathrm{Z}=P_{1} \sum_{i=1}^{n} d c_{i}^{-}+P_{2} \sum_{i=1}^{n} d p_{i}^{+}+P_{3} w v_{3} d v^{-}+P_{3} w v_{3}^{\prime} d v^{+}+P_{4} d a^{-}+ \\
& +P_{5} \sum_{i=1}^{n} d o_{i}^{+}+P_{6} \sum_{i=1}^{n} d o s_{i}^{+}+P_{7} \sum_{i=1}^{n} d s_{i}^{-}
\end{aligned}
$$

A oitava meta do modelo, representada pela equação (36), diz respeito ao alcance de uma densidade média a ser obtida por setor. A densidade representa a quantidade de lixo a ser coletada por quilômetro percorrido.

$$
\text { dens }_{i}+d d_{i}^{-}-d d_{i}^{+}=M 8 \quad \text { para todo } i
$$

onde:

$d d_{i}^{-}$e $d d_{i}^{+}$são os desvios negativo e positivo, por setor, relacionados à meta de densidade $M 8$.

Quanto mais constante for essa densidade em cada um dos setores, melhor distribuídos estão os setores e, conseqüentemente, as equipes de trabalho, já que cada uma delas é responsável por, pelo menos, um setor. Sendo assim, pretende-se minimizar os dois desvios. Entretanto, a minimização de $d d_{i}^{-}$é mais importante que a minimização de $d d_{i}^{+}$, visto que o primeiro contribui para uma diminuição da densidade média a ser atingida, portanto, $w d_{8}$ deverá ser maior que $w d^{\prime}{ }_{8}$.

A função objetivo ficaria então descrita como mostra a equação (37):

$$
\begin{array}{r}
\min \mathrm{Z}=P_{1} \sum_{i=1}^{n} d c_{i}^{-}+P_{2} \sum_{i=1}^{n} d p_{i}^{+}+P_{3} w v_{3} d v^{-}+P_{3} w v_{3}^{\prime} d v^{+}+P_{4} d a^{-}+ \\
+P_{5} \sum_{i=1}^{n} d o_{i}^{+}+P_{6} \sum_{i=1}^{n} d o s_{i}^{+}+P_{7} \sum_{i=1}^{n} d s_{i}^{-}+P_{8} w d_{8} \sum_{i=1}^{n} d d_{i}^{-}+P_{8} w d_{8}^{\prime} \sum_{i=1}^{n} d d_{i}^{+}
\end{array}
$$

A nona meta está relacionada à produtividade dos coletores em cada setor. Quanto mais uniforme for a produtividade, mais bem distribuídas estão as equipes de 
trabalho. Além disso, produtividades abaixo ou acima do padrão estabelecido estarão demonstrando sub ou superutilização da mão-de-obra dos coletores.

A meta de produtividade, ilustrada na equação (38), será medida em termos de quilogramas coletados a mais ou a menos que os quilogramas estabelecidos como meta por coletor por dia.

$$
X_{i}+d p r_{i}^{-}-d p r_{i}^{+}=M 9_{i} \quad \text { para todo } i
$$

onde:

$d p r_{i}^{-} \mathrm{e} d p r_{i}^{+}$são os desvios negativo e positivo, por setor, relacionados à meta de produtividade dos coletores $M 9_{i}$.

Como na meta anterior, pretende-se minimizar os dois desvios. A minimização de $d p r_{i}^{-}$deverá ter preferência em relação à minimização de $d p r_{i}^{+}$, pois o primeiro desvio contribui para uma diminuição da produtividade dos coletores. Sendo assim, $w p r^{\prime}{ }_{9}$ deverá ser maior que $w p r_{9}$.

A função objetivo completa para o modelo em questão fica então representada através da equação (39):

$$
\begin{aligned}
& \min \mathrm{Z}=P_{1} \sum_{i=1}^{n} d c_{i}^{-}+P_{2} \sum_{i=1}^{n} d p_{i}^{+}+P_{3} w v_{3} d v^{-}+P_{3} w v_{3}^{\prime} d v^{+}+P_{4} d a^{-}+ \\
& +P_{5} \sum_{i=1}^{n} d o_{i}^{+}+P_{6} \sum_{i=1}^{n} d o s_{i}^{+}+P_{7} \sum_{i=1}^{n} d s_{i}^{-}+P_{8} w d_{8} \sum_{i=1}^{n} d d_{i}^{-}+P_{8} w d_{8}^{\prime} \sum_{i=1}^{n} d d_{i}^{+}+ \\
& +P_{9} w p r_{9} \sum_{i=1}^{n} d p r_{i}^{+}+P_{9} w p r_{9}^{\prime} \sum_{i=1}^{n} d p r_{i}^{-}
\end{aligned}
$$

As restrições reais que compõem o modelo são:

- Restrição de quantidade coletada

Esta restrição impõe que a quantidade de lixo transferida dos setores para o local de processamento acrescida da quantidade de lixo transferida dos setores para os aterros não totalizem um valor maior que a quantidade gerada em cada zona. 


$$
X_{i}+\sum_{t=1}^{T} Y_{t i}+B_{i} \leq g_{i} \quad \text { para todo } i
$$

onde:

$g_{i}$ é a quantidade de resíduos gerados em cada setor.

- Restrição de capacidade da usina de triagem e compostagem

Esta restrição indica que a capacidade máxima de recepção no local de processamento deve ser respeitada.

$$
\sum_{t=1}^{T} \sum_{i=1}^{n} Y_{t i} \leq C A P A C
$$

ou

$$
\sum_{i=1}^{n} B_{i} \leq C A P A C
$$

onde:

$C A P A C$ é a capacidade máxima de recepção da usina de triagem e compostagem.

As seguintes equações contábeis foram incorporadas ao modelo:

- Cálculo do nível de processamento 1

Esta equação indica a quantidade a que devem ser reduzidos, através do processo de triagem / reciclagem ( índice $_{1 t}$ ), os resíduos coletados convencionalmente e transportados dos setores para o local de processamento. $\mathrm{O}$ valor encontrado $\left(A_{t}\right)$ é igual à quantidade, em toneladas, de cada material reciclável $t$ proveniente desse processo. $\sum_{i=1}^{n} B_{i}-\sum_{t=1}^{T} A_{t}$ deve ser igual à quantidade que será transferida da usina para os aterros. 


$$
\sum_{i=1}^{n} B_{i} \times \text { indice }_{1 t}=A_{t} \quad \text { para todo } t
$$

- Cálculo do nível de processamento 2

Esta equação indica a quantidade a que devem ser reduzidos, através do processo de triagem / reciclagem (índice ${ }_{2 t}$ ), os resíduos coletados seletivamente e transportados dos setores para o local de processamento. $\mathrm{O}$ valor encontrado $\left(R_{t}\right)$ é igual à quantidade, em toneladas, de cada material reciclável $t$ proveniente desse processo. $\sum_{t=1}^{T} \sum_{i=1}^{n} Y_{t i}-\sum_{t=1}^{T} R_{t}$ deve ser igual à quantidade que será transferida do local de processamento para os aterros.

$$
\sum_{t=1}^{T} \sum_{i=1}^{n} Y_{t i} \times \text { índice }_{2 t}=R_{t} \quad \text { para todo } t
$$

Pode-se observar que o total de cada material reciclável $t$ será igual a $A_{t}+R_{t}$.

- Cálculo do nível de compostagem 1

Esta equação indica a quantidade a que devem ser reduzidos, através do processo de triagem / compostagem (índice ${ }_{3}$ ), os resíduos coletados convencionalmente e transportados dos setores para o local de processamento. $\mathrm{O}$ valor encontrado $(W)$ é igual à quantidade, em toneladas, de material resultante da compostagem através desse processo. $\sum_{i=1}^{n} B_{i}-W$ deve ser igual à quantidade que será transferida do local de processamento para os aterros.

$$
\sum_{i=1}^{n} B_{i} \times \text { indice }_{3}=W
$$


- Cálculo do nível de compostagem 2

Esta equação indica a quantidade a que devem ser reduzidos, através do processo de triagem / compostagem ( indice $_{3}$ ), os resíduos coletados seletivamente e transportados dos setores para o local de processamento. O valor encontrado (WW) é igual à quantidade, em toneladas, de material resultante da compostagem através desse processo. $\sum_{t=1}^{T} \sum_{i=1}^{n} Y_{t i}-W W$ deve ser igual à quantidade que será transferida do local de processamento para os aterros.

$$
\sum_{t=1}^{T} \sum_{i=1}^{n} Y_{t i} \times \text { indice }_{4}=W W
$$

Verifica-se que o total de material proveniente da compostagem será igual a $W$ $+W W$

- Cálculo da quantidade de resíduos enviada ao aterro sanitário

$$
\begin{aligned}
& \sum_{i=1}^{n} X_{i}+\left[\sum_{i=1}^{n} B_{i}-\sum_{t=1}^{T} A_{t}\right]+\left[\sum_{t=1}^{T} \sum_{i=1}^{n} Y_{t i}-\sum_{t=1}^{T} R_{t}\right]+\left[\sum_{i=1}^{n} B_{i}-W\right]+ \\
& +\left[\sum_{t=1}^{T} \sum_{i=1}^{n} Y_{t i}-W W\right]=Q A T
\end{aligned}
$$

onde:

$Q A T$ é a quantidade de resíduos encaminhada ao aterro sanitário.

O modelo completo pode ser então representado por:

$\min \mathrm{Z}=P_{1} \sum_{i=1}^{n} d c_{i}^{-}+P_{2} \sum_{i=1}^{n} d p_{i}^{+}+P_{3} w v_{3} d v^{-}+P_{3} w v_{3}^{\prime} d v^{+}+P_{4} d a^{-}+$

$+P_{5} \sum_{i=1}^{n} d o_{i}^{+}+P_{6} \sum_{i=1}^{n} d o s_{i}^{+}+P_{7} \sum_{i=1}^{n} d s_{i}^{-}+P_{8} w d_{8} \sum_{i=1}^{n} d d_{i}^{-}+P_{8} w d_{8}^{\prime} \sum_{i=1}^{n} d d_{i}^{+}+$

$+P_{9} w p r_{9} \sum_{i=1}^{n} d p r_{i}^{+}+P_{9} w p r_{9}^{9} \sum_{i=1}^{n} d p r_{i}^{-}$ 
sujeito a

$$
X_{i}+d c_{i}^{-}-d c_{i}^{+}=M I_{i} \quad \text { para todo } i
$$

$2 \times \mathrm{e}_{\mathrm{i}} \times v_{i} \times \operatorname{dias}_{i}+d g \times 2 \times \operatorname{dias}_{i}+\frac{X_{i}}{d e n s_{i}}+d p_{i}^{-}-d p_{i}^{+}=M 2_{i}$ para todo $i$

$$
\begin{aligned}
& \frac{\sum_{i=1}^{n} X_{i}}{\sum_{i=1}^{n} v_{i} \times \operatorname{dias} \times \operatorname{cap}}+d v^{-}-d v^{+}=M 3 \\
& \sum_{t=1}^{T} \sum_{i=1}^{n} Y_{t i}+d a^{-}-d a^{+}=M 4
\end{aligned}
$$

ou

$$
\begin{array}{ll}
\sum_{i=1}^{n} B_{i}+d a^{-}-d a^{+}=M 4 & \\
c_{i}+d o_{i}^{-}-d o_{i}^{+}=M 5_{i} & \text { para todo } i \\
m_{i}+d o s_{i}^{-}-d o s_{i}^{+}=M \sigma_{i} & \text { para todo } i \\
\sum_{t=1}^{T} Y_{t i}+d s_{i}^{-}-d s_{i}^{+}=M 7_{i} & \text { para todo } i \\
d e n s_{i}+d d_{i}^{-}-d d_{i}^{+}=M 8 & \text { para todo } i \\
X_{i}+d p r_{i}^{-}-d p r_{i}^{+}=M 9_{i} & \text { para todo } i \\
X_{i}+\sum_{i=1}^{T} Y_{t i}+B_{i} \leq g_{i} & \text { para todo } i \\
\sum_{t=1}^{T} \sum_{i=1}^{n} Y_{t i} \leq C A P A C &
\end{array}
$$

ou

$$
\begin{aligned}
& \sum_{i=1}^{n} B_{i} \leq C A P A C \\
& \sum_{i=1}^{n} B_{i} \times \text { indice }_{1 t}=A_{t}
\end{aligned}
$$




$$
\begin{gathered}
\sum_{t=1}^{T} \sum_{i=1}^{n} Y_{t i} \times \text { indice }_{2 t}=R_{t} \quad \text { para todo } t \\
\sum_{i=1}^{n} B_{i} \times \text { indice }_{3}=W \\
\sum_{t=1}^{T} \sum_{i=1}^{n} Y_{t i} \times \text { indice }_{4}=W W \\
\sum_{i=1}^{n} X_{i}+\left[\sum_{i=1}^{n} B_{i}-\sum_{t=1}^{T} A_{t}\right]+\left[\sum_{t=1}^{T} \sum_{i=1}^{n} Y_{t i}-\sum_{t=1}^{T} R_{t}\right]+\left[\sum_{i=1}^{n} B_{i}-W\right]+ \\
+\left[\sum_{t=1}^{T} \sum_{i=1}^{n} Y_{t i}-W W\right]=Q A T
\end{gathered}
$$

\subsection{Aplicação do modelo}

\subsubsection{Caracterização do gerenciamento de resíduos sólidos urbanos no município de Piracicaba - SP}

O modelo proposto foi aplicado à cidade de Piracicaba - SP. Os dados utilizados correspondem a situações reais ocorridas no período de janeiro de 1999 a outubro de 2000. Convém ressaltar que, para alguns dados, como por exemplo, quantidade de recicláveis coletada na cidade, não se tem informações para todo esse período.

O modelo não foi aplicado para um determinado mês. Conforme poderá ser constatado no decorrer desta seção, todos os valores utilizados são valores médios, não representando nenhum mês específico.

De acordo com o IBGE (2000), a população de Piracicaba é de 328.312 habitantes, dos quais 316.518 são residentes na área urbana. É localizada no interior do estado de São Paulo e tem uma área territorial de $1.368 \mathrm{~km}^{2}$.

No período analisado, a coleta de resíduos sólidos urbanos em Piracicaba era feita por 10 veículos coletores com capacidade média de 8,5 toneladas cada um. Além desses 10 veículos, havia mais 2 que faziam parte da frota denominada "reserva técnica". 
Para fins de coleta de lixo, a cidade é dividida em 28 setores, numerados de 1 a 27 e, devido ao grande crescimento dos setores 16 e 17, criou-se um setor intermediário denominado setor 16/17 englobando partes de cada um deles. Tem-se ainda um outro setor que, na verdade, não existe fisicamente, denominado "setor 31 " ou "setor de resgate", cuja equipe é responsável pelo apoio em outros setores que necessitem auxílio ou é acionada em operações de emergência. Na aplicação do modelo, o "setor de resgate" não será considerado. Os setores podem ser visualizados no mapa apresentado à Figura 14, sendo a caracterização desses setores apresentada na Tabela 10.

Cada um desses 28 setores ( 1 a 27 e 16/17) tem uma geração mensal de lixo $g_{i}$. A Tabela 11 ilustra os dados de geração de lixo por setor, referentes aos meses de agosto e setembro de 2000 .

Existem 16 equipes que trabalham na coleta e cada uma dessas equipes é composta por um motorista e 3 ou 4 coletores. Em quatro setores (1, 2, 3 e 16/17), a coleta é realizada por equipes de 3 coletores. Nos setores 1,2 e 3 cada equipe é responsável por um deles. A equipe responsável pelo setor 16/17 é a mesma do "setor de resgate". Como o "setor de resgate" não faz parte do modelo, consideram-se $31 / 2$ equipes de 3 coletores. Além disso, existem 24 setores onde a coleta é realizada por equipes com 4 coletores. Como, nesse caso, cada equipe é responsável por dois setores, consideram-se 12 equipes de 4 coletores. Em suma, em todas as simulações realizadas, são consideradas $31 / 2$ equipes de 3 coletores e 12 equipes de 4 coletores.

Para ser realizada a coleta convencional, são utilizados diferentes percursos (vide Anexo D) em cada um desses setores.

Além da coleta convencional, em Piracicaba existe também a coleta seletiva de resíduos sólidos urbanos, encaminhados para o Centro de Reabilitação de Piracicaba. A coleta seletiva é do tipo “entrega voluntária” e, no periodo da pesquisa, a cidade contava com 130 pontos de coleta (41 condomínios, 7 empresas, 45 residências, 3 órgãos públicos, 6 containers, 18 estabelecimentos comerciais e 10 escolas). Dois caminhões cedidos pela Secretaria de Defesa do Meio Ambiente da Prefeitura Municipal de Piracicaba realizam a coleta nesses 130 pontos da cidade. Na Tabela 12 , têm-se dados mensais da coleta seletiva, por produto, entre 1999 e 2000. 


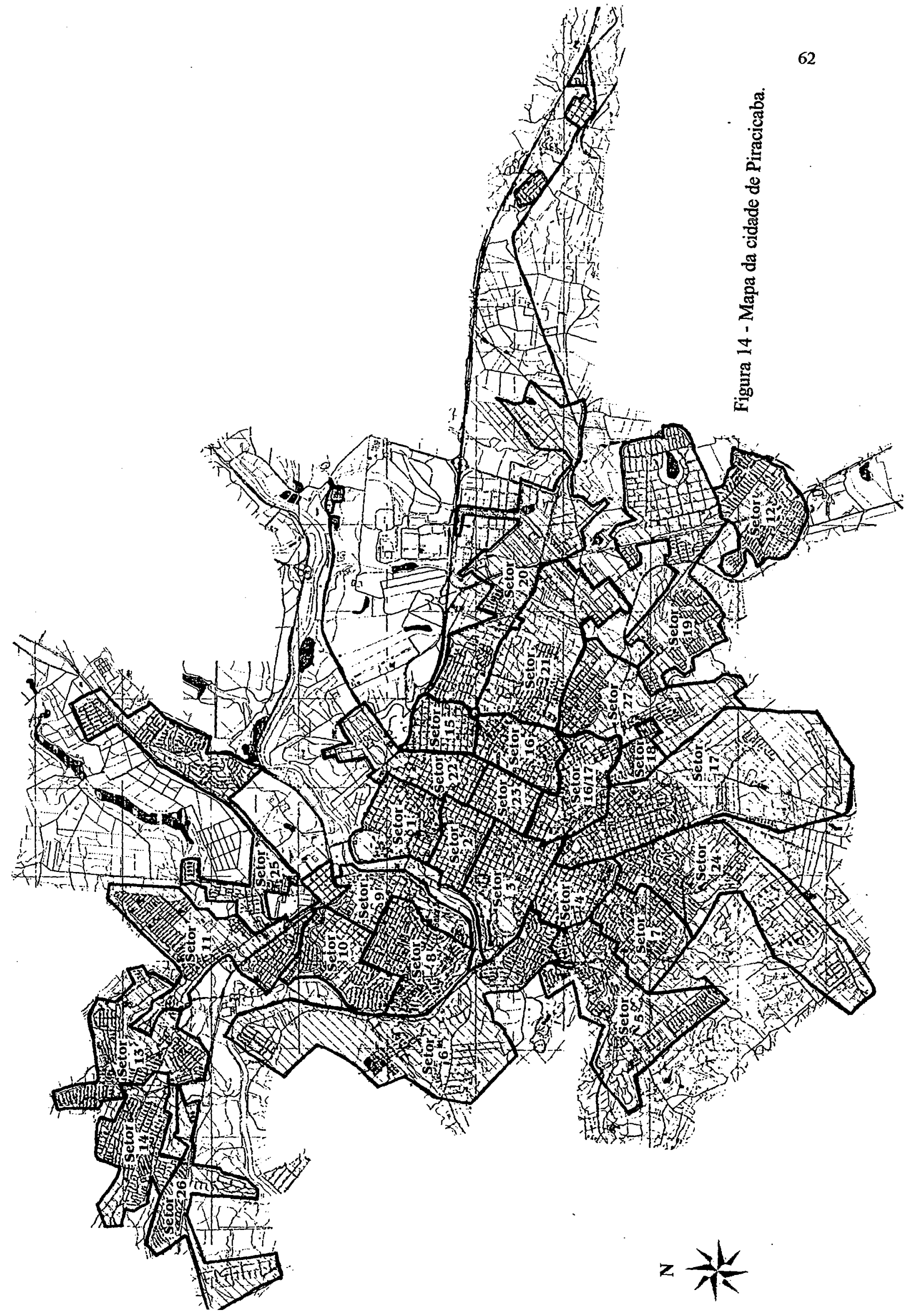


Tabela 10. Caracterização dos setores de coleta em Piracicaba - SP, 2000.

\begin{tabular}{|c|c|c|c|c|}
\hline Setor & Freqüência de coleta & Período & $\begin{array}{l}\text { Número de } \\
\text { Motoristas }\end{array}$ & $\begin{array}{l}\text { Número de } \\
\text { Coletores }\end{array}$ \\
\hline$\overline{1}$ & Diária & Noturno & 1 & 3 \\
\hline 2 & Diária & Noturno & 1 & 3 \\
\hline 3 & Diária & Noturno & 1 & 3 \\
\hline 4 & $2^{a}, 4^{a}$ e $6^{a}$ & Dịurno & 1 & 4 \\
\hline 5 & $2^{a}, 4^{a}$ e $6^{a}$ & Diurno & 1 & 4 \\
\hline 6 & $2^{\mathrm{a}}, 4^{\mathrm{a}}$ e $6^{\mathrm{a}}$ & Diurno & 1 & 4 \\
\hline 7 & $2^{a}, 4^{a}$ e $6^{a}$ & Diurno & 1 & 4 \\
\hline 8 & $2^{a}, 4^{a}$ e $6^{a}$ & Noturno & 1 & 4 \\
\hline 9 & $2^{a}, 4^{a}$ e $6^{a}$ & Noturno & 1 & 4 \\
\hline 10 & $2^{a}, 4^{a}$ e $6^{a}$ & Noturno & 1 & 4 \\
\hline 11 & $2^{a}, 4^{a}$ e $6^{a}$ & Diurno & 1 & 4 \\
\hline 12 & $3^{\mathrm{a}}, 5^{\mathrm{a}}$ e Sáb. & Diurno & 1 & 4 \\
\hline 13 & $2^{a}, 4^{a}$ e $6^{a}$ & Diurno & 1 & 4 \\
\hline 14 & $3^{\mathrm{a}}, 5^{\mathrm{a}}$ e Sáb. & Diurno & 1 & 4 \\
\hline 15 & $3^{a}, 5^{a}$ e Sáb. & Noturno & 1 & 4 \\
\hline 16 & $3^{a}, 5^{a}$ e Sáb. & Noturno & 1 & 4 \\
\hline $16 / 17$ & $3^{a}, 5^{a}$ e Sáb. & Noturno & 1 & 3 \\
\hline 17 & $3^{a}, 5^{a}$ e Sáb. & Noturno & 1 & 4 \\
\hline 18 & $3^{\mathrm{a}}, 5^{\mathrm{a}}$ e Sáb. & Diurno & 1 & 4 \\
\hline 19 & $3^{\mathrm{a}}, 5^{\mathrm{a}}$ e Sáb. & Diurno & 1 & 4 \\
\hline 20 & $3^{\mathrm{a}}, 5^{\mathrm{a}}$ e Sáb. & Diurno & 1 & 4 \\
\hline 21 & $3^{\mathrm{a}}, 5^{\mathrm{a}}$ e Sáb. & Diurno & 1 & 4 \\
\hline 22 & $3^{a}, 5^{a}$ e Sáb. & Diurno & 1 & 4 \\
\hline 23 & $3^{\mathrm{a}}, 5^{\mathrm{a}}$ e Sáb. & Noturno & 1 & 4 \\
\hline 24 & $2^{a}, 4^{a}$ e $6^{a}$ & Noturno & 1 & 4 \\
\hline 25 & $2^{a}, 4^{a}$ e $6^{a}$ & Diurno & 1 & 4 \\
\hline 26 & $2^{a}, 4^{a}$ e $6^{a}$ & Diurno & 1 & 4 \\
\hline 27 & $3^{a}, 5^{a}$ e Sáb. & Diurno & 1 & 4 \\
\hline 31 & Resgate & Diurno & 1 & 4 \\
\hline
\end{tabular}

Fontes: Enob Ambiental (2000) ${ }^{30}$ e Prefeitura Municipal de Piracicaba (2000).

\footnotetext{
${ }^{30}$ Empresa responsável pela coleta e destinação final do lixo em Piracicaba - SP, no periodo da coleta de dados para esta pesquisa.
} 
Tabela 11. Quantidades coletadas de lixo observadas em Piracicaba - SP, por setores, referentes aos meses de agosto e setembro de 2000 .

\begin{tabular}{|c|c|c|}
\hline Setor & $\begin{array}{c}\text { Geração de lixo em agosto de } 2000 \\
(\mathrm{em} \mathrm{kg})\end{array}$ & $\begin{array}{c}\text { Geração de lixo em setembro de } 2000 \\
(\mathrm{em} \mathrm{kg})\end{array}$ \\
\hline 1 & $287.726,70$ & $284.961,96$ \\
\hline 2 & $355.116,70$ & $351.780,62$ \\
\hline 3 & $342.253,30$ & $339.334,01$ \\
\hline 4 & $267.086,70$ & $264.654,32$ \\
\hline 5 & $238.293,30$ & $236.485,67$ \\
\hline 6 & $219.436,70$ & $217.488,21$ \\
\hline 7 & $250.623,30$ & $248.277,20$ \\
\hline 8 & $171.283,30$ & $169.667,00$ \\
\hline 9 & $206.603,30$ & $205.041,59$ \\
\hline 10 & $340.216,70$ & $337.368,75$ \\
\hline 11 & $254.990,00$ & $252.862,79$ \\
\hline 12 & $224.663,30$ & $222.728,89$ \\
\hline 13 & $284.370,00$ & $281.686,53$ \\
\hline 14 & $239.390,00$ & $237.140,76$ \\
\hline 15 & $179.916,70$ & $178.183,11$ \\
\hline 16 & $165.716,70$ & $164.426,32$ \\
\hline $16 / 17$ & $160.563,33$ & $159.185,65$ \\
\hline 17 & $206.610,00$ & $205.041,59$ \\
\hline 18 & $276.313,30$ & $273.825,51$ \\
\hline 19 & $248.023,30$ & $245.656,86$ \\
\hline 20 & $214.740,00$ & $212.902,61$ \\
\hline 21 & $182.036,70$ & $180.148,36$ \\
\hline 22 & $257.690,00$ & $255.483,13$ \\
\hline 23 & $183.023,30$ & $181.458,53$ \\
\hline 24 & $215.433,30$ & $213.557,70$ \\
\hline 25 & $233.340,00$ & $231.244,99$ \\
\hline 26 & $170.776,70$ & $169.011,92$ \\
\hline 27 & $232.040,00$ & $231.244,99$ \\
\hline
\end{tabular}

Fonte: Enob Ambiental (2000). 


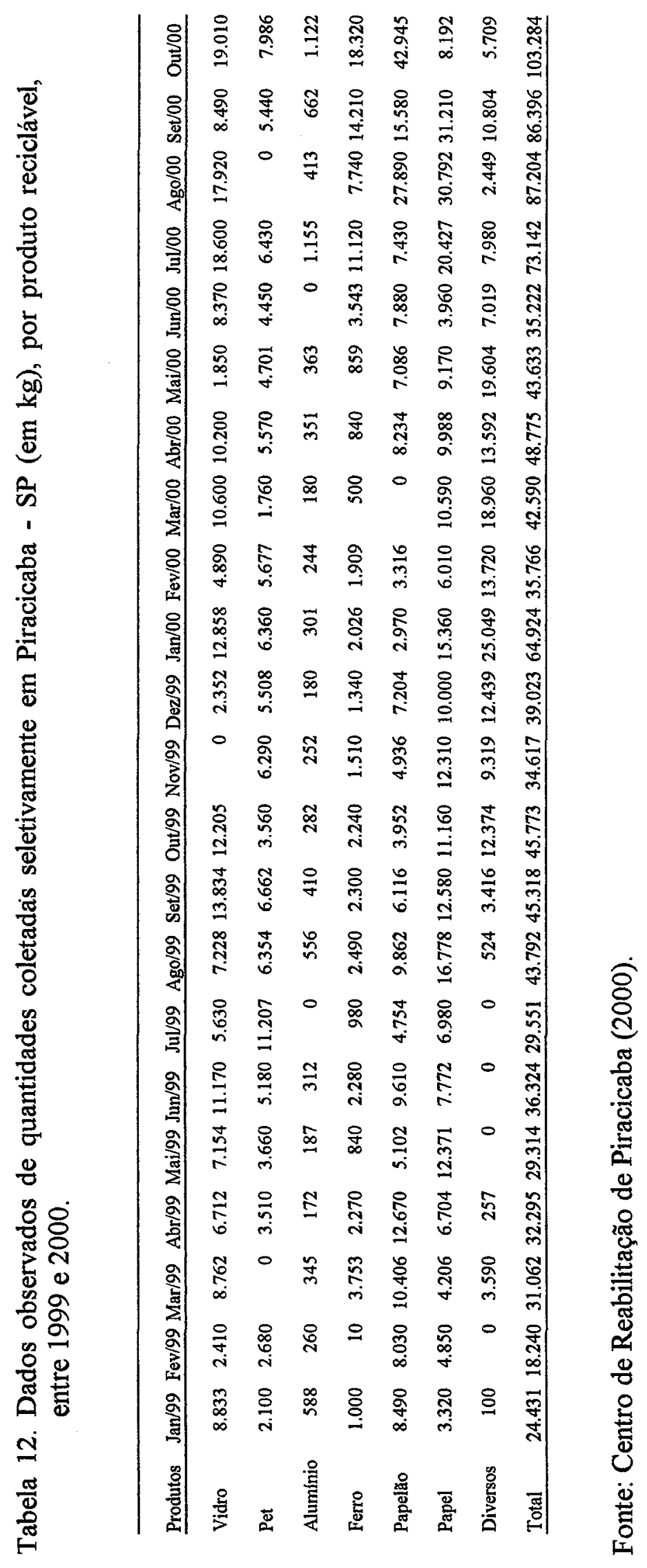


Os custos (referentes ao mês de outubro de 2000) relacionados ao processo de coleta seletiva e reciclagem são apresentados nas Tabelas 13 e 14 .

Tabela 13. Custos de depreciação de bens de capital usados na atividade de coleta seletiva em Piracicaba - SP, outubro de 2000.

\begin{tabular}{lccccc}
\hline Equipamento & Quantidade & $\begin{array}{c}\text { Valor Unitário } \\
\text { (R\$) }\end{array}$ & $\begin{array}{c}\text { Valor Total } \\
(\mathbf{R} \$)\end{array}$ & $\begin{array}{c}\text { Vida útil } \\
\text { (meses) }\end{array}$ & $\begin{array}{c}\text { Depreciação } \\
\text { Mensal }^{31} \text { (R\$) }\end{array}$ \\
\hline Prensa & 3 & $5.500,00$ & $16.500,00$ & 180 & 91,67 \\
Baias & 1 & $2.000,00$ & $2.000,00$ & 180 & 11,11 \\
Balança (200 Kg) & 1 & 180,00 & 180,00 & 180 & 1,00 \\
$\begin{array}{l}\text { Containers } \\
\text { Total }\end{array}$ & 50 & 60,00 & 3000,00 & 180 & 16,67 \\
\hline
\end{tabular}

Fonte: Centro de Reabilitação de Piracicaba (2000).

Tabela 14. Custos da mão-de-obra operacional e não-operacional na atividade de coleta seletiva em Piracicaba - SP, em outubro de 2000.

\begin{tabular}{lcccc}
\hline Funcionários & Quantidade & $\begin{array}{c}\text { Salário } \\
\text { mensal (R\$) }\end{array}$ & $\begin{array}{c}\text { Encargos } \\
\text { mensais (R\$) }\end{array}$ & $\begin{array}{c}\text { Custo total } \\
\text { mensal (R\$) }\end{array}$ \\
\hline Operacional & & & & \\
$\quad$ Ajudante & 2 & 250,00 & 175,00 & 850,00 \\
Separador & 9 & 250,00 & 175,00 & $3.825,00$ \\
$\quad$ Total & & & & $4.675,00$ \\
Não-operacional & 1 & & & \\
Assistente Social & 1 & 986,94 & 690,86 & $1.677,80$ \\
Auxiliar de Escritório & 1 & 250,00 & 175,00 & 425,00 \\
Coordenador & 1 & $1.227,10$ & 858,97 & $2.086,07$ \\
Encarregado & 1 & 700,00 & 490,00 & $1.190,00$ \\
Total & & & & $5.378,87$ \\
Total geral & & & & $10.053,87$ \\
\hline
\end{tabular}

Fonte: Centro de Reabilitação de Piracicaba (2000).

De acordo com informações obtidas no Centro de Reabilitação de Piracicaba, existem ainda "outros custos operacionais", relacionados à coleta seletiva (além dos R\$ $4.675,00$ ilustrados na Tabela 14), que totalizam $R \$ 8.371,89$, fazendo com que o total

\footnotetext{
${ }^{31} \mathrm{O}$ cálculo da depreciação mensal foi realizado tomando-se o valor total do bem dividido por sua vida útil em meses.
} 
dos custos operacionais atinja a cifra de $\mathrm{R} \$ 13.046,89$. Somando-se tal valor aos custos não-operacionais ( $R \$ 5.378,87$ ), chega-se a um total de $R \$ 18.425,76$. Em outubro de 2000 , foi verificado um prejuízo de $\mathrm{R} \$ 3.494,52$ na atividade de coleta seletiva.

As Tabelas 15 e 16 ilustram os dados de custos de coleta e disposição final do lixo no aterro. Em Piracicaba há quatro equipes com 3 coletores e 12 equipes com 4 coletores, perfazendo um custo de coleta convencional de $\mathrm{R} \$ 131.838,08$ mensais.

Tabela 15. Custos de coleta de lixo, por equipe, em Piracicaba - SP, 2000.

\begin{tabular}{cccc}
\hline Recurso utilizado & $\begin{array}{c}\text { Custo unidade } \\
\text { (R\$) }\end{array}$ & $\begin{array}{c}\text { Custo por equipe com } \\
\text { 3 coletores (RS) }\end{array}$ & $\begin{array}{c}\text { Custo por equipe } \\
\text { com 4 coletores (R\$) }\end{array}$ \\
\hline Caminhão + equipamento & & & \\
Depreciação & $1.666,67^{32}$ & $1.666,67$ & $1.666,67$ \\
Combustivel ${ }^{33}$ & $1.785,71$ & $1.785,71$ & $1.785,71$ \\
Peças & 500,00 & 500,00 & 500,00 \\
Mão-de-obra & & & \\
Motorista & $1.100,00$ & $1.100,00$ & $1.100,00$ \\
Coletores & 850,00 & $2.550,00$ & $3.400,00$ \\
Total & & $7.602,38$ & $8.452,38$ \\
\hline
\end{tabular}

Fonte: Enob Ambiental (2000).

\subsubsection{Especificação dos dados que compõem o modelo}

\subsubsection{Primeira meta}

Os dados disponíveis para determinação da primeira meta do modelo (quantidade a ser coletada por setor) são:

- quantidades coletadas de lixo em Piracicaba para os meses de agosto e setembro de 2000 por setor (vide Tabela 11);

\footnotetext{
32 Valor do caminhão, com o equipamento, é de $\mathrm{R} \$ 100.000,00$, depreciado em 60 meses.

${ }^{33}$ Os gastos com combustível da Tabela 15 (R\$ 1.785,71) representam uma média dos gastos com combustível nos setores. Para a aplicação do modelo, o cálculo do valor do combustível gasto é realizado dividindo-se a quilometragem percorrida no setor por 1,5, que é a quilometragem percorrida por litro de óleo diesel consumido. $\mathrm{O}$ valor obtido, correspondente à quantidade de litros de óleo diesel consumidos, é então multiplicado por R\$ 0,803 , que corresponde ao valor médio do litro de óleo diesel nas capitais brasileiras, em novembro de 2000 (Diário Oficial da União, 2000). Tem-se então o gasto com combustível, por setor, de acordo com a quilometragem percorrida pelo veículo coletor.
} 
Tabela 16. Custos mensais de disposição final no aterro sanitário em Piracicaba - SP, 2000.

\begin{tabular}{lcccc}
\hline Recurso utilizado & Unidade & $\begin{array}{c}\text { Quantidade } \\
\text { (mensal) }\end{array}$ & $\begin{array}{c}\text { Custo/unidade } \\
\text { (em R\$) }\end{array}$ & $\begin{array}{c}\text { Custo total mensal } \\
\text { (em R\$) }\end{array}$ \\
\hline $\begin{array}{l}\text { Caminhão + Equipamento } \\
\text { 34 }\end{array}$ & & & & \\
$\quad$ Máquina de esteira & Hora & 400 & 37,00 & $14.800,00$ \\
$\quad$ Pá carregadeiras & Hora & 200 & 26,00 & $5.200,00$ \\
Caminhốes & Hora & 400 & 20,00 & $8.000,00$ \\
Retroescavadeira & Hora & 200 & 20,00 & $4.000,00$ \\
Diesel & & & & $1.785,71$ \\
Mão de obra & & & & \\
$\quad$ Motorista & Pessoa & 1 & $1.100,00$ & $1.100,00$ \\
Pedreiros & Pessoa & 2 & 850,00 & $1.700,00$ \\
$\quad$ Ajudante & Pessoa & 1 & 850,00 & 850,00 \\
$\begin{array}{l}\text { Total } \\
\text { Custo por tonelada aterrada } \\
\text { no mês de setembro de 2000 }\end{array}$ & & & & $37.435,71$ \\
\hline
\end{tabular}

Fonte: Enob Ambiental (2000).

- quantidades agregadas mensais de coleta de resíduos sólidos urbanos em Piracicaba, de janeiro de 1989 a dezembro de 1999 (vide Anexo E) ${ }^{36}$.

De posse desses dados, foram consideradas três alternativas para determinar os valores dessa meta. Na primeira alternativa caberia escolher um dos dois meses para os quais já se obtiveram os dados de quantidades coletadas por setor (agosto ou setembro de 2000). Na segunda, caberia realizar uma média da quantidade coletada nos meses de agosto e setembro de 2000 , enquanto na terceira, utilizar-se-iam os dados por setor de agosto e setembro de 2000 conjuntamente com os dados agregados mensais de 1989 a 1999, calculando-se um valor médio mensal. Dessa maneira, a sazonalidade da geração de resíduos durante todo o ano estaria sendo incluída, o que fez com que esta última alternativa fosse considerada como a mais adequada para um modelo genérico.

Para a realização desse cálculo, tomaram-se os dados anuais de coleta de resíduos sólidos urbanos em Piracicaba de 1989 a 1999 (vide Anexo E). Com base nesses dados, calculou-se a média mensal de geração de resíduos em cada ano (total

\footnotetext{
${ }^{34} \mathrm{O}$ custo dos equipamentos utilizados no aterro sanitário inclui o valor da mão-de-obra necessária.

${ }^{35}$ Apenas este equipamento não tem a mão-de-obra do motorista incluída no valor pago por hora de uso. $O$ valor do salário do motorista está descrito em seguida, na mesma Tabela.

${ }^{36}$ Dados obtidos na Prefeitura Municipal de Piracicaba, em outubro de 2000.
} 
anual de cada ano/12). Por fim, de posse dos dados históricos observados de coleta mensal desses 11 anos, foi feita uma comparação mês a mês em cada ano para verificar a variação do total observado em relação à média mensal calculada (vide Anexo F). Após obtidas todas as variações mensais para os 11 anos, calculou-se a média dessas variações para cada mês $\left(\sum_{i=1}^{11}\right.$ variação percentual em relação à média de cada mês /11), resultado que pode ser visualizado na Tabela 17.

Tabela 17. Variação da quantidade coletada de lixo em Piracicaba - SP, em relação à média, para todos os meses do ano.

\begin{tabular}{lc}
\hline Meses & $\begin{array}{c}\text { Variação percentual média de } 1989 \text { a } 1999 \\
\text { em relação à média mensal coletada. }\end{array}$ \\
\hline Janeiro & 3,051787990 \\
Fevereiro & $-7,812768494$ \\
Março & 0,362266230 \\
Abril & $-5,103515425$ \\
Maio & $-2,061309851$ \\
Junho & $-3,410540040$ \\
Julho & 1,592734591 \\
Agosto & 3,110276108 \\
Setembro & $-0,428611249$ \\
Outubro & 1,539540793 \\
Novembro & $-1,244056077$ \\
Dezembro & 10,404195520 \\
\hline
\end{tabular}

Fonte: Dados da pesquisa.

De acordo com a Tabela 17, percebe-se que no mês de janeiro, a quantidade coletada de lixo é, aproximadamente, $3,05 \%$ superior à média mensal coletada. Por outro lado, pode-se perceber que, em junho, a quantidade coletada é em torno de $3,41 \%$ inferior à média.

É necessário calcular agora o valor médio mensal a ser coletado por setor. Para se realizar esse cálculo, tomaram-se os dados disponíveis do mês de setembro de 2000 (terceira coluna da Tabela 11) e o dado referente a setembro da Tabela 17. Percebe-se, por meio da Tabela 17, que setembro é um mês cuja geração é $-0,428611249 \%$ menor que a média. Consultando a terceira coluna da Tabela 11, percebe-se que, para o setor 1 , 
por exemplo, o valor encontrado é de $284.961,96 \mathrm{~kg}$. Para encontrar o valor médio mensal a ser coletado no setor 1 , considerou-se que o valor de $284.961,96 \mathrm{~kg}$ corresponde à 99,571388751\% (100\%-0,428611249\%). Logo, o valor médio (correspondente a $100 \%$ ) é de $286.188,60 \mathrm{~kg}$. Realizando o mesmo raciocínio para os demais setores, obtêm-se os valores descritos na Tabela 18.

Para mostrar a eficiência da metodologia de cálculo, serão utilizados os valores observados por setor para agosto de 2000 (segunda coluna da Tabela 11), os valores médios mensais estimados (Tabela 18) e o dado referente a agosto, da Tabela 17. De acordo com a Tabela 17, observa-se que no mês de agosto a geração de lixo é $3,110276108 \%$ superior à média. Considerando-se novamente o setor 1 como exemplo, conforme Tabela 18, o valor médio para tal setor é de $286.188,60 \mathrm{~kg}$, correspondente a $100 \%$. Para agosto, o valor deverá ser de 103,110276108\% $(100 \%+3,110276108 \%)$, correspondendo a $295.089,86 \mathrm{~kg}$. Realizando o mesmo procedimento para os demais setores, obtêm-se os valores mostrados na Tabela 19.

A Tabela 20 compara os valores calculados para agosto com base no valor médio encontrado (Tabela 18) com os valores observados para o mês de agosto (segunda coluna da Tabela 11).

Observando a última coluna da Tabela 20 , verifica-se que as diferenças entre os valores observados e calculados para agosto de 2000 não foram significativas. Portanto, considerou-se a metodologia utilizada para estimar a geração em cada mês do ano 2000 como eficiente. Essa estimativa foi realizada para todos os meses do ano (Anexo G).

Ainda para comprovar a qualidade dos dados calculados, será realizada outra comparação. Somando-se os dados médios calculados para cada setor (Tabela 18), observa-se que, na cidade de Piracicaba - SP, com 316.518 pessoas residentes na área urbana, são coletados, em média, por mês, $6.579 .048,08 \mathrm{~kg}$. Sendo assim, a taxa de geração per capita de resíduos sólidos por dia, obtida a partir dos cálculos realizados, considerando-se um mês de 30 dias, é de $0,69 \mathrm{~kg} / \mathrm{hab} / \mathrm{dia}$. 
Tabela 18. Valores médios mensais estimados de geração de lixo por setor, em Piracicaba - SP.

\begin{tabular}{|c|c|}
\hline Setor & Geração de lixo (em kg) \\
\hline 1 & $286.188,60$ \\
\hline 2 & $353.294,88$ \\
\hline 3 & $340.794,69$ \\
\hline 4 & $265.793,54$ \\
\hline 5 & $237.503,64$ \\
\hline 6 & $218.424,40$ \\
\hline 7 & $249.345,92$ \\
\hline 8 & $170.397,34$ \\
\hline 9 & $205.924,20$ \\
\hline 10 & $338.820,97$ \\
\hline 11 & $253.951,25$ \\
\hline 12 & $223.687,64$ \\
\hline 13 & $282.899,07$ \\
\hline 14 & $238.161,55$ \\
\hline 15 & $178.950,11$ \\
\hline 16 & $165.134,10$ \\
\hline $16 / 17$ & $159.870,87$ \\
\hline 17 & $205.924,20$ \\
\hline 18 & $275.004,21$ \\
\hline 19 & $246.714,31$ \\
\hline 20 & $213.819,06$ \\
\hline 21 & $180.923,82$ \\
\hline 22 & $256.582,87$ \\
\hline 23 & $182.239,63$ \\
\hline 24 & $214.476,97$ \\
\hline 25 & $232.240,40$ \\
\hline 26 & $169.739,44$ \\
\hline 27 & $232.240,40$ \\
\hline
\end{tabular}

Fonte: Dados da pesquisa. 
Tabela 19. Valores estimados de geração de lixo, em Piracicaba - SP, em agosto de 2000.

\begin{tabular}{|c|c|}
\hline Setor & $\begin{array}{l}\text { Valores calculados } \\
\text { para ago/2000 }(\mathrm{kg})\end{array}$ \\
\hline 1 & $295.089,85$ \\
\hline 2 & $364.283,33$ \\
\hline 3 & $351.394,35$ \\
\hline 4 & $274.060,45$ \\
\hline 5 & $244.890,66$ \\
\hline 6 & $225.218,00$ \\
\hline 7 & $257.101,27$ \\
\hline 8 & $175.697,17$ \\
\hline 9 & $212.329,02$ \\
\hline 10 & $349.359,24$ \\
\hline 11 & $261.849,84$ \\
\hline 12 & $230.644,94$ \\
\hline 13 & $291.698,01$ \\
\hline 14 & $245.569,03$ \\
\hline 15 & $184.515,95$ \\
\hline 16 & $170.270,23$ \\
\hline $16 / 17$ & $164.843,30$ \\
\hline 17 & $212.329,02$ \\
\hline 18 & $283.557,60$ \\
\hline 19 & $254.387,80$ \\
\hline 20 & $220.469,43$ \\
\hline 21 & $186.551,05$ \\
\hline 22 & $264.563,31$ \\
\hline 23 & $187.907,79$ \\
\hline 24 & $221.147,80$ \\
\hline 25 & $239.463,72$ \\
\hline 26 & $175.018,81$ \\
\hline 27 & $239.463,72$ \\
\hline
\end{tabular}

Fonte: Dados da pesquisa. 
Tabela 20. Valores de geração de lixo $(\mathrm{kg})$. observados, calculados e variação percentual para o mês de agosto de 2000 , em Piracicaba - SP.

\begin{tabular}{|c|c|c|c|}
\hline Setor & $\begin{array}{l}\text { Valores observados } \\
\text { em ago/2000 (kg) }\end{array}$ & $\begin{array}{l}\text { Valores calculados } \\
\text { para ago/2000 (kg) }\end{array}$ & Variação (\%) \\
\hline 1 & $287.726,70$ & $295.089,85$ & 2,56 \\
\hline 2 & $355.116,70$ & $364.283,33$ & 2,58 \\
\hline 3 & $342.253,30$ & $351.394,35$ & 2,67 \\
\hline 4 & $267.086,70$ & $274.060,45$ & 2,61 \\
\hline 5 & $238.293,30$ & $244.890,66$ & 2,77 \\
\hline 6 & $219.436,70$ & $225.218,00$ & 2,63 \\
\hline 7 & $250.623,30$ & $257.101,27$ & 2,58 \\
\hline 8 & $171.283,30$ & $175.697,17$ & 2,58 \\
\hline 9 & $206.603,30$ & $212.329,02$ & 2,77 \\
\hline 10 & $340.216,70$ & $349.359,24$ & 2,69 \\
\hline 11 & $254.990,00$ & $261.849,84$ & 2,69 \\
\hline 12 & $224.663,30$ & $230.644,94$ & 2,66 \\
\hline 13 & $284.370,00$ & $291.698,01$ & 2,58 \\
\hline 14 & $239.390,00$ & $245.569,03$ & 2,58 \\
\hline 15 & $179.916,70$ & $184.515,95$ & 1,03 \\
\hline 16 & $165.716,70$ & $170.270,23$ & 1,03 \\
\hline $16 / 17$ & $160.563,33$ & $164.843,30$ & 1,03 \\
\hline 17 & $206.610,00$ & $212.329,02$ & 1,03 \\
\hline 18 & $276.313,30$ & $283.557,60$ & 1,03 \\
\hline 19 & $248.023,30$ & $254.387,80$ & 1,03 \\
\hline 20 & $214.740,00$ & $220.469,43$ & 1,03 \\
\hline 21 & $182.036,70$ & $186.551,05$ & 1,02 \\
\hline 22 & $257.690,00$ & $264.563,31$ & 1,03 \\
\hline 23 & $183.023,30$ & $187.907,79$ & 1,03 \\
\hline 24 & $215.433,30$ & $221.147,80$ & 1,03 \\
\hline 25 & $233.340,00$ & $239.463,72$ & 1,03 \\
\hline 26 & $170.776,70$ & $175.018,81$ & 1,02 \\
\hline 27 & $232.040,00$ & $239.463,72$ & 1,03 \\
\hline
\end{tabular}

Fonte: Dados da pesquisa.

A Tabela 21 apresenta o resultado do "Programa de Gerenciamento de resíduos Sólidos domiciliares e de serviços de saúde - Prolixo" realizado pela Companhia de Tecnologia de Saneamento Ambiental - CETESB, em 1992. Nesse trabalho, foi 
estimada a geração de lixo por habitante, através de pesquisas em diversos municípios do Estado de São Paulo.

Tabela 21. Geração média de resíduos por habitante por dia.

\begin{tabular}{ll}
\hline Número de habitantes & Geração média per capita \\
\hline Até 100.000 habitantes & $0,4 \mathrm{~kg} / \mathrm{hab} /$ dia \\
De 100.001 a 500.000 habitantes & $0,5 \mathrm{~kg} / \mathrm{hab} / \mathrm{dia}$ \\
De 500.001 a 1.000 .000 habitantes & $0,6 \mathrm{~kg} / \mathrm{hab} / \mathrm{dia}$ \\
Mais de 1.000 .000 habitantes & $0,7 \mathrm{~kg} / \mathrm{hab} / \mathrm{dia}$ \\
\hline
\end{tabular}

Fonte: http://www.mct.gov.br/clima ${ }^{37}$

Portanto, para Piracicaba, de acordo com a Tabela 21, estaria associada uma taxa de $0,5 \mathrm{~kg} / \mathrm{hab} / \mathrm{dia}$, valor muito próximo de $0,69 \mathrm{~kg} / \mathrm{hab} / \mathrm{dia}$, encontrado através dos cálculos realizados.

Além disso, o valor de $0,69 \mathrm{~kg} / \mathrm{hab} /$ dia situa-se dentro da média brasileira citada na literatura por Caixeta Filho (1999), que é de 0,5 a 1,0 kg/hab/dia.

Como será abordado posteriormente, a meta de quantidade a ser coletada seletivamente é de $15,2 \%$ do lixo total produzido. Sendo assim, os valores numéricos da primeira meta do modelo corresponderão aos valores da Tabela 18 diminuídos de $15,2 \%$, dados que podem ser vistos na Tabela 22 .

A metodologia para se calcular o valor da primeira meta pode ser definida de acordo com a estratégia adotada. Existem formas alternativas para se calcular essa meta. Ela pode ser determinada, por exemplo, através de uma estimativa de geração de resíduos per capita em cada cidade, multiplicada pelo valor da população. Pode-se aprimorar essa meta considerando-se diferentes taxas de geração per capita de resíduos, dependendo do nível de renda ou modo de vida da população de cada setor. Além disso, existem outros fatores, tais como época do ano, fins de semana, dias festivos, movimento da população durante os períodos de férias e novos métodos de acondicionamento de mercadorias, que podem ser considerados.

\footnotetext{
${ }^{37}$ O Ministério da Ciência e Tecnologia do Brasil pesquisou diversos índices de geração per capita que utilizam metodologias de cálculo distintas e após a realização de comparações entre eles, concluiu que o indice da CETESB foi o mais próximo da realidade brasileira (Brasil, 2001).
} 
Tabela 22. Valores numéricos da primeira meta do modelo - quantidades mensais a serem coletadas convencionalmente, por setor, em Piracicaba - SP.

\begin{tabular}{|c|c|}
\hline Setor & Geração de lixo (em kg) \\
\hline 1 & $242.687,93$ \\
\hline 2 & $299.594,06$ \\
\hline 3 & $288.993,90$ \\
\hline 4 & $225.392,92$ \\
\hline 5 & $201.403,08$ \\
\hline 6 & $185.223,89$ \\
\hline 7 & $211.445,34$ \\
\hline 8 & $144.496,95$ \\
\hline 9 & $174.623,73$ \\
\hline 10 & $287.320,19$ \\
\hline 11 & $215.350,66$ \\
\hline 12 & $189.687,12$ \\
\hline 13 & $239.898,41$ \\
\hline 14 & $201.960,99$ \\
\hline 15 & $151.749,69$ \\
\hline 16 & $140.033,72$ \\
\hline $16 / 17$ & $135.570,50$ \\
\hline 17 & $174.623 ; 73$ \\
\hline 18 & $233.203,57$ \\
\hline 19 & $209.213,73$ \\
\hline 20 & $181.318,57$ \\
\hline 21 & $153.423,40$ \\
\hline 22 & $217.582,28$ \\
\hline 23 & $154.539,21$ \\
\hline 24 & $181.876,47$ \\
\hline 25 & $196.939,86$ \\
\hline 26 & $143.939,05$ \\
\hline 27 & $196.939,86$ \\
\hline Total & $5.579 .032,80$ \\
\hline
\end{tabular}

Fonte: Dados da pesquisa. 


\subsubsection{Segunda meta}

Utilizando a ferramenta computacional AutoCad, mediu-se o comprimento total do conjunto de vias pertencentes a cada setor, obtendo-se os valores apresentados na Tabela 23 , onde ainda se pode visualizar a distância média de cada setor ao aterro sanitário. Os mapas de cada setor podem ser visualizados no Anexo $\mathrm{H}$.

Tabela 23. Perímetro dos setores de coleta e distâncias médias dos setores ao aterro sanitário, em Piracicaba - SP, 2000.

\begin{tabular}{|c|c|c|}
\hline Setor & Comprimento total das vias & Distância do setor ao aterro (em $\mathrm{km}$ ) \\
\hline 1 & 30,24 & 11,20 \\
\hline 2 & 19,31 & 8,60 \\
\hline 3 & 33,20 & 7,40 \\
\hline 4 & 22,01 & 7,70 \\
\hline 5 & 50,19 & 11,00 \\
\hline 6 & 55,24 & 10,30 \\
\hline 7 & 29,24 & 3,70 \\
\hline 8 & 41,95 & 12,00 \\
\hline 9 & 23,11 & 11,00 \\
\hline 10 & 35,65 & 11,50 \\
\hline 11 & 59,36 & 14,00 \\
\hline 12 & 44,15 & 14,00 \\
\hline 13 & 44,67 & 14,30 \\
\hline 14 & 34,47 & 13,00 \\
\hline 15 & 18,71 & 15,00 \\
\hline 16 & 24,00 & 11,00 \\
\hline $16 / 17$ & 33,21 & 9,00 \\
\hline 17 & 66,42 & 10,00 \\
\hline 18 & 9,49 & 8,70 \\
\hline 19 & 62,38 & 9,30 \\
\hline 20 & 68,87 & 10,70 \\
\hline 21 & 35,31 & 23,30 \\
\hline 22 & 31,59 & 10,30 \\
\hline 23 & 13,78 & 11,50 \\
\hline 24 & 50,76 & 10,00 \\
\hline 25 & 51,47 & 4,50 \\
\hline 26 & 26,42 & 14,50 \\
\hline 27 & 34,39 & 18,00 \\
\hline
\end{tabular}

Fonte: Dados da pesquisa. 
A Tabela 24 mostra os valores associados à segunda meta do modelo.

Tabela 24. Valores numéricos da segunda meta do modelo - quilometragem mensal a ser percorrida na coleta convencional, por setor, em Piracicaba - SP.

\begin{tabular}{|c|c|c|}
\hline Setor & $\begin{array}{l}\text { Quilometragem mensal } \\
\text { percorrida sem o fator de } \\
\text { correção }\end{array}$ & $\begin{array}{c}\text { Quilometragem mensal } \\
\text { percorrida com o fator de } \\
\text { correção de } 40 \%\end{array}$ \\
\hline 1 & $2.350,40$ & $3.290,56$ \\
\hline 2 & $1.775,54$ & $2.485,76$ \\
\hline 3 & $2.002,52$ & $2.803,53$ \\
\hline 4 & 962,65 & $1.347,71$ \\
\hline 5 & $1.552,07$ & $2.172,90$ \\
\hline 6 & $1.570,40$ & $2.198,56$ \\
\hline 7 & 786,24 & $1.100,74$ \\
\hline 8 & $1.512,55$ & $2.117,57$ \\
\hline 9 & $1.200,03$ & $1.680,04$ \\
\hline 10 & $1.396,85$ & $1.955,59$ \\
\hline 11 & $1.874,08$ & $2.623,71$ \\
\hline 12 & $1.676,35$ & $2.346,89$ \\
\hline 13 & $1.703,39$ & $2.384,75$ \\
\hline 14 & $1.482,91$ & $2.076,07$ \\
\hline 15 & $1.413,23$ & $1.978,52$ \\
\hline 16 & $1.211,60$ & $1.696,24$ \\
\hline $16 / 17$ & $1.196,13$ & $1.674,58$ \\
\hline 17 & $1.695,46$ & $2.373,64$ \\
\hline 18 & 867,49 & $1.214,49$ \\
\hline 19 & $1.595,62$ & $2.233,87$ \\
\hline 20 & $1.774,63$ & $2.484,48$ \\
\hline 21 & $2.190,11$ & $3.066,15$ \\
\hline 22 & $1.262,95$ & $1.768,13$ \\
\hline 23 & $1.112,54$ & $1.557,56$ \\
\hline 24 & $1.491,88$ & $2.088,63$ \\
\hline 25 & $1.129,31$ & $1.581,03$ \\
\hline 26 & $1.479,66$ & $2.071,52$ \\
\hline 27 & $1.819,87$ & $2.547,82$ \\
\hline
\end{tabular}

Fonte: Dados da pesquisa. 
Tais valores foram encontrados por meio da equação (67):

$$
\left[\left(v_{i} \times 2 \times e_{i} \times \operatorname{dias}_{i}\right)+\left(2 \times \operatorname{dias}_{i} \times d g\right)+\left(k m_{i} \times \text { dias }_{i}\right)\right] \times 1,40 \text { para todo } i
$$

onde:

$v_{i}$ é a freqüência diária de viagens realizadas de cada setor (i) ao aterro sanitário (2,15 viagens para os setores de coleta diária e 2,6 viagens para os setores de coleta em dias alternados);

$e_{i}$ é a distância de cada setor $i$ ao aterro sanitário, dada na terceira coluna da Tabela 23;

$d g$ é a distância do aterro sanitário à garagem $(6 \mathrm{~km})$;

$k m_{i}$ é o comprimento total das vias de cada setor $i$, dado na segunda coluna da Tabela 23.

O primeiro termo da equação (67) $-v_{i} \times 2 \times e_{i} \times$ dias $_{i}$ - corresponde à distância percorrida do aterro sanitário a cada um dos setores durante um mês de coleta. $\mathbf{O}$ segundo termo da equação $-2 \times$ dias $_{i} \times d g$ - representa a distância mensal percorrida da garagem ao aterro sanitário. A multiplicação por 2 nesse termo é realizada, pois geralmente, o aterro sanitário situa-se entre a garagem e os setores de coleta. Desta maneira, o caminhão sairia no início do dia para iniciar a coleta, passaria pelo local do aterro sanitário e se dirigiria para os setores de coleta. Ao final do serviço, o lixo coletado na última viagem seria depositado no aterro de onde o veículo coletor seguiria para a garagem. O terceiro termo da equação (67) $-k m_{i} x$ dias $_{i}$ - indica a quilometragem percorrida durante um mês de coleta dentro de cada setor.

Essa equação é multiplicada por 1,40 pois está sendo considerado um fator de correção de $40 \%$ para a quilometragem a ser percorrida. O fator de correção se justifica, pois normalmente, não se consegue percorrer apenas a distância correspondente ao perímetro, devido a ruas sem saída ou às mãos de direção de algumas vias. De acordo com Aguiar (1993), tendo em vista que a equipe de coleta quer terminar a tarefa o mais rapidamente possível, é provável que a rota não apresente um nível elevado de 
repetição de passagem em ruas já servidas. Entretanto, nota-se que o uso de um programa de otimização de rotas apresenta uma porcentagem de repetição em torno de $40 \%$.

Deluqui (1998) realizou uma pesquisa para otimizar as rotas de coleta em São Carlos - SP utilizando o software TransCAD e obteve valores de repetição que variaram de $17,23 \%$ a $36,54 \%$.

É importante destacar a diferença entre as equações (23) e (67). A equação (23) compõe o modelo matemático, representado a meta de quilometragem a ser atingida $\left(2^{\mathrm{a}}\right.$ meta). A equação (67) é utilizada para determinar o valor numérico da $2^{a}$ meta. Apesar de existirem semelhanças entre as duas equações, na equação (67) todos os termos devem ser conhecidos, pois eles serão utilizados para se determinar o valor da meta. Por outro lado, na equação (23) nem todos os termos são conhecidos. $X_{i}$ e dens do modelo e seus valores só serão determinados quando o modelo for rodado.

Alternativamente, pode-se determinar essa meta seguindo-se outros critérios, como por exemplo, trabalhando com os valores fornecidos por algum software de roteirização ao invés de se utilizar o valor do comprimento total de todas as vias do setor acrescido do fator de correção.

\subsubsection{Terceira meta}

Determina-se como meta de número de veículos a serem utilizados, aquilo que diz respeito ao tamanho da frota menos a reserva técnica, ou seja, 10 veículos, não devendo haver sub ou superutilização dos mesmos. No modelo teórico, a superutilização terá um peso maior que a subutilização, pois caso a empresa responsável pela coleta necessite de mais veículos do que dispõe, ela deverá alugar ou até mesmo adquirir novos veículos para conseguir realizar a coleta de maneira apropriada.

A expressão (68) é a representação matemática dessa meta: 


$$
\frac{\sum_{i=1}^{n} X_{i}}{\sum_{i=1}^{n} v_{i} \times \operatorname{dias}_{i} \times c a p}+d v^{-}-d v^{+}=M 3
$$

Em cada dia da semana, 10 veículos estarão disponíveis para a realização da coleta. Em Piracicaba, nas $2^{\text {as }}$ feiras, por exemplo, são realizadas as rotas da coleta convencional diária e as rotas dos dias alternados pares. Nas $3^{\text {as }}$ feiras são realizadas as rotas da coleta convencional diária e as rotas dos dias alternados ímpares. Em cada um desses dias, 10 veículos deverão ser suficientes para a conclusão do serviço.

Portanto, nota-se que deverão existir duas equações para essa meta. Em Piracicaba, existe coleta convencional diária, em dias alternados pares $\left(2^{\text {as }}, 4^{\text {as }}\right.$ e $\left.6^{\text {as }}\right)$ e em dias alternados ímpares $\left(3^{\text {as }}, 5^{\text {as }}\right.$ e sábados). Desta maneira, a primeira equação compreenderá os setores da coleta diária (setores 1,2 e 3 ) e das $2^{\text {as }}, 4^{\text {as }}$ e $6^{\text {as }}$ feiras (setores $4,5,6,7,8,9,10,11,13,24,25$ e 26), bem como o número de viagens realizadas diariamente nos setores em questão e o número de dias (em um mês) em que a coleta é realizada. Assim, será obtido o número de veículos necessários para a realização das rotas da coleta diária, das $2^{\text {as }}, 4^{\text {as }}$ e $6^{\text {as }}$ feiras. A segunda equação compreenderá os setores de coleta diária (setores 1,2 e 3 ) e os setores de coleta nas $3^{\text {as }}, 5^{\text {as }}$ e sábados (setores 12,14,15,16,16/17, 17, 18,19, 20, 21, 22, 23, 27), bem como o número de viagens realizadas diariamente nos setores em questão e o número de dias (em um mês) em que é realizada a coleta. Sendo assim, será obtido o número de veículos necessários para a realização das rotas de coleta diária, das $3^{\text {as }}, 5^{\text {as }}$ e sábados. Em cada uma das equações, o valor de $M 3$ deverá ser igual a 10 , que é o número de veículos disponíveis diariamente para a realização da coleta convencional.

$\mathrm{Na}$ aplicação do modelo não foram atribuídos pesos diferentes para a superutilização e subutilização da frota, porém atribuíram-se prioridades diferentes a cada um desses itens.

A meta relacionada a veículos dependerá da estratégia relacionada à composição da frota. Pode-se determinar novos valores de meta de acordo com o tipo de 
veículo coletor utilizado e sua respectiva capacidade. Além disso, pode-se trabalhar com veículos de diferentes tipos ou capacidade nos diferentes setores. Por exemplo, em um setor que gera uma quantidade menor de lixo, pode-se utilizar um veículo comum ou um compactador de baixa capacidade, enquanto nos setores de alta geração seriam necessários veículos compactadores de alta capacidade.

\subsubsection{Quarta meta}

Na cidade de Piracicaba não há usina de triagem e reciclagem. Portanto, o modelo será utilizado excluindo-se a quarta meta que se refere a quantidades a serem encaminhadas à usina de triagem e reciclagem.

\subsubsection{Quinta e sexta metas}

Em relação à meta de orçamento, os valores pagos pela Prefeitura do município de Piracicaba para a coleta convencional ${ }^{38}$, disposição final do $\operatorname{lixo}^{39}$ e coleta seletiva ${ }^{40}$ são aqueles mostrados na Tabela 25. A quinta meta refere-se ao orçamento destinado à coleta convencional e a sexta meta, ao orçamento destinado à coleta seletiva. Sendo assim, admitindo-se que sejam coletados e aterrados $5.579 .032,80 \quad \mathrm{~kg}$ convencionalmente e que $1.000 .015,31 \mathrm{~kg}$ sejam coletados seletivamente por mês na cidade, a meta orçamentária operacional da empresa deverá ser de R\$174.344,78 para a coleta convencional (incluindo aterro) e $R \$ 41.000,63$ para a coleta seletiva. Os orçamentos para a coleta convencional (quinta meta) e coleta seletiva (sexta meta), por setor, podem ser visualizados na Tabela 26.

\footnotetext{
${ }^{38} \mathrm{O}$ custo da coleta convencional corresponde ao custo de coletar e transferir o lixo dos setores para o aterro. Esse custo engloba o salário dos motoristas e coletores, a depreciação dos equipamentos utilizados na coleta, as peças de reposição utilizadas e os gastos com combustivel.

${ }^{39}$ Os custos de disposição no aterro englobam o custo de operação dos equipamentos, os salários dos motoristas e ajudantes e os gastos com combustível.

${ }^{40}$ Em Piracicaba - SP, o custo da coleta seletiva engloba os custos de depreciação dos equipamentos utilizados no processamento dos materiais e os salários dos funcionários envolvidos na coleta seletiva. É importante ressaltar que, na coleta seletiva, não serão considerados os custos de coleta e transferência dos produtos recicláveis ao local de processamento. Só serão considerados os custos relacionados ao processamento dos produtos.
} 
Tabela 25. Valores pagos pela Prefeitura Municipal de Piracicaba para cada tipo de serviço, 2000.

\begin{tabular}{lc}
\hline Serviço & Valor pago (em R\$) \\
\hline Tonelada coletada convencionalmente & 22,00 \\
Tonelada aterrada & 9,25 \\
Tonelada coletada seletivamente & 41 \\
\hline
\end{tabular}

Fonte: Prefeitura Municipal de Piracicaba (2000).

Tabela 26. Valores numéricos da quinta e sexta metas - orçamento mensal, por setor, para a coleta convencional e seletiva em Piracicaba - SP, 2000.

\begin{tabular}{|c|c|c|}
\hline Setor & $\begin{array}{c}\text { Meta orçamentária } \\
\text { da coleta convencional }(R \$)\end{array}$ & $\begin{array}{c}\text { Meta orçamentária } \\
\text { da coleta seletiva }(\mathrm{RS})\end{array}$ \\
\hline 1 & $7.584,00$ & $1.783,53$ \\
\hline 2 & $9.362,31$ & $2.201,73$ \\
\hline 3 & $9.031,06$ & $2.123,83$ \\
\hline 4 & $7.043,53$ & $1.656,43$ \\
\hline 5 & $6.293,85$ & $1.480,12$ \\
\hline 6 & $5.788,25$ & $1.361,22$ \\
\hline 7 & $6.607,67$ & $1.553,92$ \\
\hline 8 & $4.515,53$ & $1.061,92$ \\
\hline 9 & $5.456,99$ & $1.283,32$ \\
\hline 10 & $8.978,76$ & $2.111,53$ \\
\hline 11 & $6.729,71$ & $1.582,62$ \\
\hline 12 & $5.927,72$ & $1.394,02$ \\
\hline 13 & $7.496,83$ & $1.763,03$ \\
\hline 14 & $6.311,28$ & $1.484,22$ \\
\hline 15 & $4.742,18$ & $1.115,22$ \\
\hline 16 & $4.376,05$ & $1.029,12$ \\
\hline $16 / 17$ & $4.236,58$ & 996,32 \\
\hline 17 & $5.456,99$ & $1.283,32$ \\
\hline 18 & $7.287,61$ & $1.713,83$ \\
\hline 19 & $6.537,93$ & $1.537,52$ \\
\hline 20 & $5.666,21$ & $1.332,52$ \\
\hline 21 & $4.794,48$ & $1.127,52$ \\
\hline 22 & $6.799,45$ & $1.599,02$ \\
\hline 23 & $4.829,35$ & $1.135,72$ \\
\hline 24 & $5.683,64$ & $1.336,62$ \\
\hline 25 & $6.154,37$ & $1.447,32$ \\
\hline 26 & $4.498,10$ & $1.057,82$ \\
\hline 27 & $6.154,37$ & $1.447,32$ \\
\hline Total & $174.344,78$ & $41.000,63$ \\
\hline
\end{tabular}

Fonte: Dados da pesquisa.

${ }^{41}$ Este valor é o valor da licitação de 2001 da Prefeitura Municipal de Piracicaba. 
O cálculo dessas metas dependerá dos custos envolvidos, que poderão variar em função da estratégia que vier a ser adotada.

\subsubsection{Sétima meta}

A sétima meta se relaciona à quantidade mínima a ser coletada de cada produto reciclável e está sendo imposta pela Prefeitura Municipal de Piracicaba para 2001. A meta da coleta seletiva deverá alcançar um nível de $15,2 \%$ do lixo total produzido, o que corresponde a, aproximadamente, 1.000 toneladas por mês. Deve-se ressaltar que, em outubro de 2.000, a quantidade coletada seletivamente em Piracicaba foi cerca de $10 \%$ do valor desse patamar estabelecido pela Prefeitura para o ano de 2001. Para se chegar aos valores numéricos para essa meta, primeiramente foram obtidos os valores a serem coletados seletivamente por setor, sem distinguir os produtos. Esses valores correspondem a $15,2 \%$ da geração total estimada de lixo (Tabela 18) e estão apresentados na Tabela 27.

Tomando os dados reais referentes à coleta seletiva (Tabela 12) para o cálculo dos percentuais de cada produto reciclável, obtêm-se os valores mostrados na Tabela 28.

A expressão que representa a sétima meta é:

$$
\sum_{t=1}^{T} Y_{t i}+d s_{i}^{-}-d s_{i}^{+}=M 7_{i}
$$

Em Piracicaba $t$ varia de 1 a 7 , sendo $t=1=$ vidro, $t=2=$ pet , $t=3=$ alumínio, $t=4=$ ferro, $t=5=$-papelão, $=6=$ papel, $t=7=$ diversos). 
Tabela 27. Quantidades a serem coletadas seletivamente, por setor, em Piracicaba - SP, 2000 .

\begin{tabular}{cc}
\hline Setor & Geração de lixo (em kg) \\
\hline 1 & $43.500,67$ \\
2 & $53.700,82$ \\
3 & $51.800,79$ \\
4 & $40.400,62$ \\
5 & $36.100,55$ \\
6 & $33.200,51$ \\
7 & $37.900,58$ \\
8 & $25.900,40$ \\
9 & $31.300,48$ \\
10 & $51.500,79$ \\
11 & $38.600,59$ \\
12 & $34.000,52$ \\
13 & $43.000,66$ \\
14 & $36.200,56$ \\
15 & $27.200,42$ \\
16 & $25.100,38$ \\
$16 / 17$ & $24.300,37$ \\
17 & $31.300,48$ \\
18 & $41.800,64$ \\
19 & $37.500,57$ \\
20 & $32.500,50$ \\
21 & $27.500,42$ \\
22 & $39.000,60$ \\
23 & $27.700,42$ \\
24 & $32.600,50$ \\
25 & $35.300,54$ \\
26 & $25.800,40$ \\
27 & $35.300,54$ \\
Total & $1.000 .015,31$ \\
\hline &
\end{tabular}

Fonte: Dados da pesquisa. 


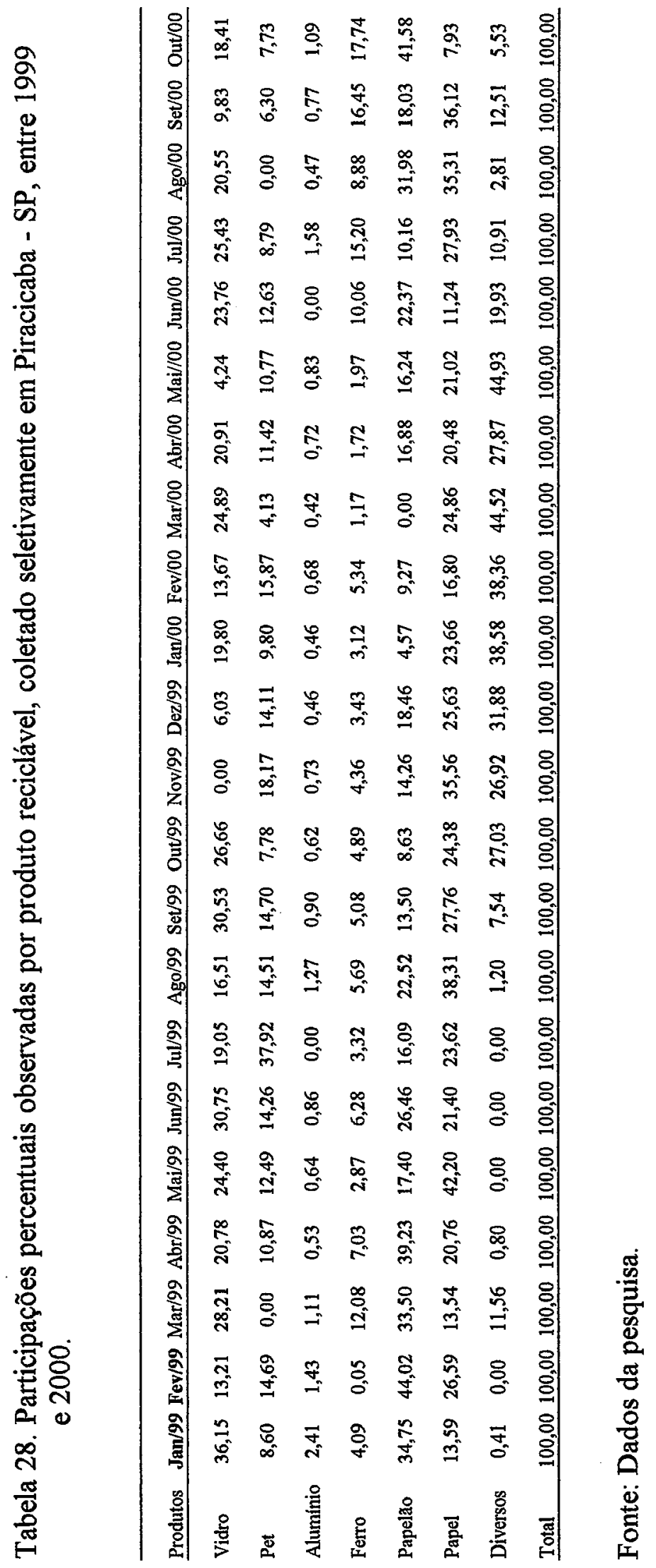


Considerando-se os dados dos 22 meses disponíveis, que abrangem dois anos, obtiveram-se os percentuais médios para cada produto, que estão apresentados à Tabela 29.

Tabela 29. Composição dos resíduos sólidos recicláveis em Piracicaba - SP.

\begin{tabular}{lr}
\hline Material & \multicolumn{1}{c}{$\%$} \\
\hline Vidro & 19,7174 \\
Pet & 11,6159 \\
Alumínio & 0,8172 \\
Ferro & 6,4007 \\
Papelão & 20,9054 \\
Papel & 24,4861 \\
Diversos & 16,0574 \\
Total & 100,0000 \\
\hline
\end{tabular}

Fonte: Dados da pesquisa.

Utilizando-se dos percentuais da Tabela 29, foram estabelecidas as metas de quantidades coletadas seletivamente na cidade por setor, conforme mostra a Tabela 30.

Em Piracicaba - SP, os resíduos coletados seletivamente são encaminhados ao Centro de Reabilitação de Piracicaba, que emprega pessoas portadoras de deficiência física e mental para trabalharem no processo de triagem/segregação e processamento dos materiais coletados para a reciclagem.

\subsubsection{Oitava e nona metas}

Trabalhando-se os dados referentes ao percurso (vide Anexo I), tem-se que a densidade média de todos os setores é de $195,15 \mathrm{~kg} / \mathrm{km}$. Assim sendo, a oitava meta do modelo estabelece que cada equipe de trabalho deve, em média, coletar 195,15 quilogramas de lixo por quilômetro percorrido. A manutenção desse valor médio indicará que as equipes de trabalho estarão tendo, em média, cargas de trabalho semelhantes. 


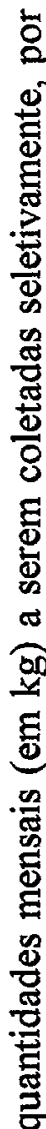

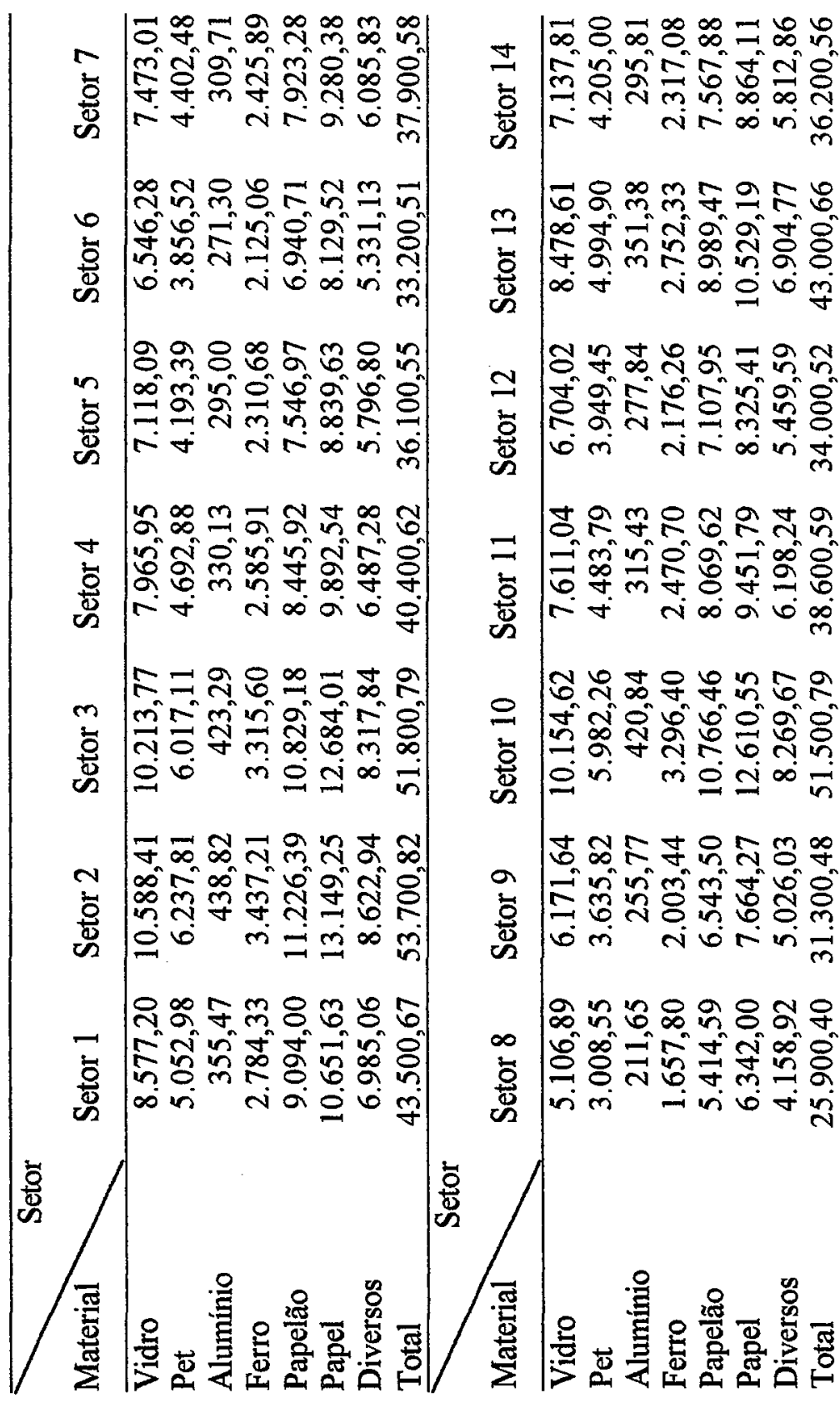

요

营 


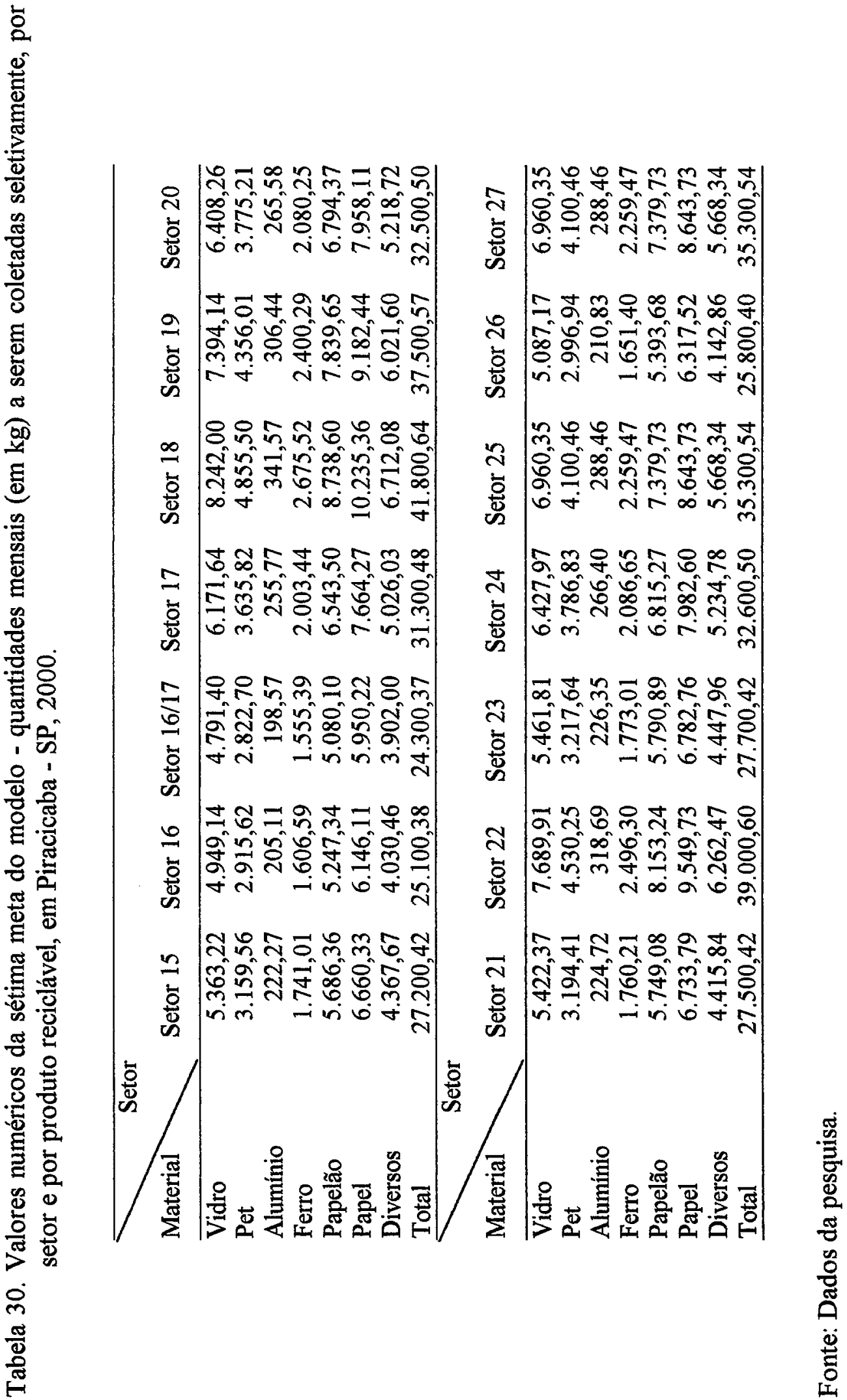


$\mathrm{Na}$ aplicação do modelo não foram atribuídos pesos diferentes para a densidade abaixo da média e para a densidade acima da média. Atribuíram-se prioridades diferentes a cada um desses itens.

A meta relacionada à densidade dependerá da definição da primeira e segunda metas, pois o valor da densidade é o resultado da razão entre a quantidade coletada e a quilometragem percorrida.

A nona meta do modelo é relacionada à produtividade dos coletores. Duarte (1998) realizou uma pesquisa em Florianópolis e concluiu que os coletores de lixo coletam, em média, 2.930 quilogramas de lixo por dia. Anjos et al. (1995) realizaram uma pesquisa semelhante no Rio de Janeiro e os resultados demonstraram que os garis coletavam, em média, 2.860 quilogramas de lixo por dia. Será considerada como valor da produtividade diária de um gari, a média desses dois estudos: 2.900 quilogramas de lixo por dia. A meta de produtividade será medida em termos de quilogramas coletados a mais ou a menos que os 2.900 estabelecidos por coletor por dia. Para os setores de coleta diária $(1,2$ e 3$)$ o valor da meta de produtividade será de $226.200 \mathrm{~kg}$ ( 3 coletores $\mathrm{x} 26$ dias $\mathrm{x}$ produtividade de $2.900 \mathrm{~kg} /$ coletor/dia). Para os setores de coleta em dias alternados $(4,5,6,7,8,9,10,11,12,13,14,15,16,17,18,19,20,21,22,23,24,25$, 26,27 ) o valor da meta de produtividade será de $150.800 \mathrm{~kg}$ (4 coletores x 13 dias x produtividade de $2900 \mathrm{~kg} /$ coletor/dia). Para o setor 16/17, a meta de produtividade será de $113.100 \mathrm{~kg}$ ( 3 coletores $\times 13$ dias $\times 2900 \mathrm{~kg} /$ coletor/dia).

A manutenção dos valores estipulados indicará que os setores estão bem distribuídos com relação à utilização de suas equipes de trabalho, não havendo assim, sub ou superutilização de mão-de-obra.

$\mathrm{Na}$ aplicação do modelo não foram atribuídos pesos diferentes para a produtividade abaixo da média e para a produtividade acima da média. Atribuíram-se prioridades diferentes a cada um desses itens.

Para a aplicação do modelo, as equações (27), (28), (41), (42), (43), (45) e (46) não serão consideradas, pois elas representam situações não vigentes em Piracicaba - SP. Além disso, na equação (40), serão considerados apenas os dois primeiros termos do 
lado esquerdo da equação, pois não há coleta convencional de resíduos a serem encaminhados à usina de triagem/compostagem.

Em relação à equação (44), para o caso específico de Piracicaba - SP, considerou-se que todo o material reciclável que chega ao local de processamento é reaproveitável, ou seja, o índice utilizado para a dedução da quantidade aproveitável é igual a um.

O modelo exposto na seção 3.3 foi então aplicado na cidade de Piracicaba - SP. A discussão sobre a aplicação do modelo e os resultados obtidos fazem parte do próximo capítulo. 


\section{RESULTADOS E DISCUSSÃO}

Inicialmente, neste capítulo será apresentado um breve histórico da aplicação do modelo, destacando-se os principais testes realizados até se chegar ao modelo final. Posteriormente, utilizando-se do modelo escolhido, são descritos os resultados obtidos com uma formulação que não considera as prioridades das metas, bem como os resultados obtidos em três formulações que consideram prioridades distintas para cada uma das metas. Esses resultados são então confrontados com a situação observada em Piracicaba - SP.

\subsection{Os modelos testados}

Antes de se chegar ao modelo final a ser aplicado, foram testadas diversas abordagens para se solucionar 0 problema. Inicialmente, fazendo-se todas as simplificações possíveis, trabalhou-se com um modelo linear e não inteiro. Neste modelo, as variáveis em questão são $X_{i}$ (quantidades de lixo coletada por setor), $Y_{t i}$ (quantidades coletadas seletivamente de cada material $t$ por setor), todas as variáveis representativas dos desvios de cada uma das metas, bem como a variável $Z$ que representa o desvio total do modelo, as quilometragens percorridas dentro de cada setor, o número de veículos utilizados em cada setor, o orçamento utilizado na coleta convencional, o orçamento utilizado na coleta seletiva e a produtividade em cada setor. Neste modelo, considerou-se uma densidade igual a $195,15 \mathrm{~kg} / \mathrm{km}$.

Posteriormente, foi utilizado um modelo de programação linear inteira, cuja única diferença em relação ao anterior foi a imposição de que o número de veículos assumisse valores inteiros. 
Finalmente, foi introduzida a não-linearidade no modelo inicial, fazendo com que a densidade (dens $s_{i}$ ) passasse a ser determinada internamente pelo modelo (variável endógena) ao invés de ser tomada como dada (variável exógena), tal como adotado nos dois primeiros modelos.

É importante ressaltar que não foi testado o modelo de programação não-linear e inteira, dada a maior dificuldade computacional envolvida (e não disponível no ambiente de desenvolvimento deste estudo) para se obter algum tipo de solução consistente.

Após realizadas as devidas avaliações qualitativas das alternativas de modelagem para o problema, acabou-se por optar pela utilização do modelo não-linear, visto que através dele pôde-se determinar o valor da densidade endogenamente, o que em um modelo linear não seria possível. A quantidade de veículos coletores, que deveria ser um número inteiro, deverá ser encontrada por aproximação, já que neste modelo os resultados para ela designados não serão obrigatoriamente inteiros.

É importante ressaltar que os possíveis arredondamentos a serem realizados com o número de veículos não influenciarão os resultados de metas subseqüentes em nenhuma das simulações realizadas. Isso ocorre, pois nas três ordenações realizadas, a quantidade de veículos é definida após a definição das variáveis que a influenciam. Por exemplo, a quantidade a ser coletada convencionalmente está relacionada com o número de veículos. Entretanto, nas ordenações propostas, a quantidade a ser coletada é definida antes de se estabelecer o número de veículos. No caso do orçamento da coleta convencional, onde um dos itens de custo é a depreciação dos veículos, considerou-se a depreciação da frota completa (10 veículos).

Ao introduzir prioridades na resolução do problema de programação por metas, foram testadas três ordenações distintas. A primeira considerou a seguinte ordem das metas: quantidades coletadas convencionalmente $\left(M I_{i}\right)$, percurso realizado $\left(M 2_{i}\right)$, quantidades coletadas seletivamente $\left(M 7_{i}\right)$, veículos super e subutilizados $(M 3)$, orçamento da coleta convencional $\left(M 5_{i}\right)$, orçamento da coleta seletiva $\left(M 6_{i}\right)$, densidade abaixo e acima da estabelecida (M8) e produtividade inferior e superior à estabelecida $\left(M 9_{i}\right)$. 
A segunda testou a seguinte ordenação: quantidades coletadas convencionalmente $\left(M I_{i}\right)$, densidade abaixo e acima da estabelecida $(M 8)$, quantidades coletadas seletivamente $\left(M 7_{i}\right)$, percurso realizado $\left(M 2_{i}\right)$, orçamento da coleta convencional $\left(M 5_{i}\right)$, orçamento da coleta seletiva $\left(M 6_{i}\right)$, veículos super e subutilizados $(M 3)$ e produtividade inferior e superior à estabelecida $\left(M 9_{i}\right)$.

A terceira testou a seguinte ordem de prioridades: produtividade inferior e superior à estabelecida $\left(M 9_{i}\right)$, quantidades coletadas convencionalmente $\left(M I_{i}\right)$, percurso realizado $\left(M 2_{i}\right)$, densidade abaixo e acima da estabelecida $(M 8)$, quantidades coletadas seletivamente $\left(M 7_{i}\right)$, orçamento da coleta seletiva $\left(M 6_{i}\right)$, veículos super e subutilizados (M3) e orçamento da coleta convencional $\left(M 5_{i}\right)$.

É importante destacar que as três ordenações testadas foram determinadas de maneira aleatória, com o intuito de realizar algumas simulações, cabendo ao tomador de decisão ordenar as metas como for conveniente.

Para resolver o modelo que inclui prioridades foi necessário dividir o modelo completo (vide Anexo J) em diversos subproblemas. O primeiro subproblema contém apenas a primeira meta. Nos modelos subseqüentes os resultados de cada subproblema são incluídos como parâmetros do novo subproblema. Por exemplo, ao se considerarem as duas primeiras metas - quantidades coletadas convencionalmente e percurso realizado - processa-se o primeiro modelo contendo apenas as equações e inequações relacionadas à meta de quantidade coletada convencionalmente. Posteriormente, processa-se um novo modelo onde os resultados de quantidades a serem coletadas convencionalmente são inseridos como parâmetros no novo modelo. Além disso, nesse segundo modelo serão inseridas as equações e inequações relacionadas à meta de percurso.

\subsection{Resultados obtidos}

Os modelos matemáticos formulados foram solucionados através da linguagem de otimização GAMS (Brooke et al., 1998), sendo um exemplo de arquivo de entrada reproduzido no Anexo J. 
Nesta seção serão apresentados os resultados para o modelo não-linear sem prioridades e para os três modelos (também não-lineares) que consideram prioridades distintas a cada uma das metas.

\subsubsection{Modelo sem prioridades}

O modelo utilizado foi o não-linear, com a variável dens $s_{i}$, que representa a densidade por setor, sendo determinada endogenamente. Estabeleceu-se que a densidade média deveria ser de 195,15 kg/km.

$\mathrm{O}$ valor da função objetivo (desvio total) foi de $1.226 .375,59$. A quantidade não coletada convencionalmente em todos os setores foi de $450.066,5 \mathrm{~kg}$. A meta de quilometragem foi ultrapassada em $78,81 \mathrm{~km}$. Os orçamentos da coleta convencional e seletiva foram ultrapassados em $\mathrm{R} \$ 6.071,72$ e $\mathrm{R} \$ 3.598,69$, respectivamente. As quantidades coletadas seletivamente foram totalmente atendidas. A densidade e produtividade abaixo da média foram de $294,43 \mathrm{~kg} / \mathrm{km}$ e $23.930,28 \mathrm{~kg}$, respectivamente, enquanto as densidades e produtividades acima da média foram de $294,43 \mathrm{~kg} / \mathrm{km}$ e $741.996,57 \mathrm{~kg}$, respectivamente. Os desvios negativos e positivos do número de veículos foram iguais a zero.

Para essa formulação, as Figuras 15 a 20 ilustram os desvios negativos e positivos de cada uma das metas, por setor, cujos valores exatos podem ser encontrados no Anexo K.

Conforme pode ser visto na Figura 15, para essa formulação, os setores 2, 5, 6, $8,11,12,13,14,16,19,20,24,25,26$ e 27 tiveram toda a quantidade estabelecida coletada (desvios negativos relacionados a $M 1$ iguais a zero). Os desvios positivos para essa meta deverão ser iguais a zero para todos os setores, pois não se pode coletar uma quantidade superior à quantidade gerada, que é a estabelecida como meta. O setor 15 apresentou o menor desvio da quantidade a ser coletada convencionalmente: $949,69 \mathrm{~kg}$ para os $151.749,69 \mathrm{~kg}$ estabelecidos. $\mathrm{O}$ setor 10 apresentou o maior desvio, tendo deixado de coletar $87.839,81 \mathrm{~kg}$ dos $287.320,19 \mathrm{~kg}$ estabelecidos. 


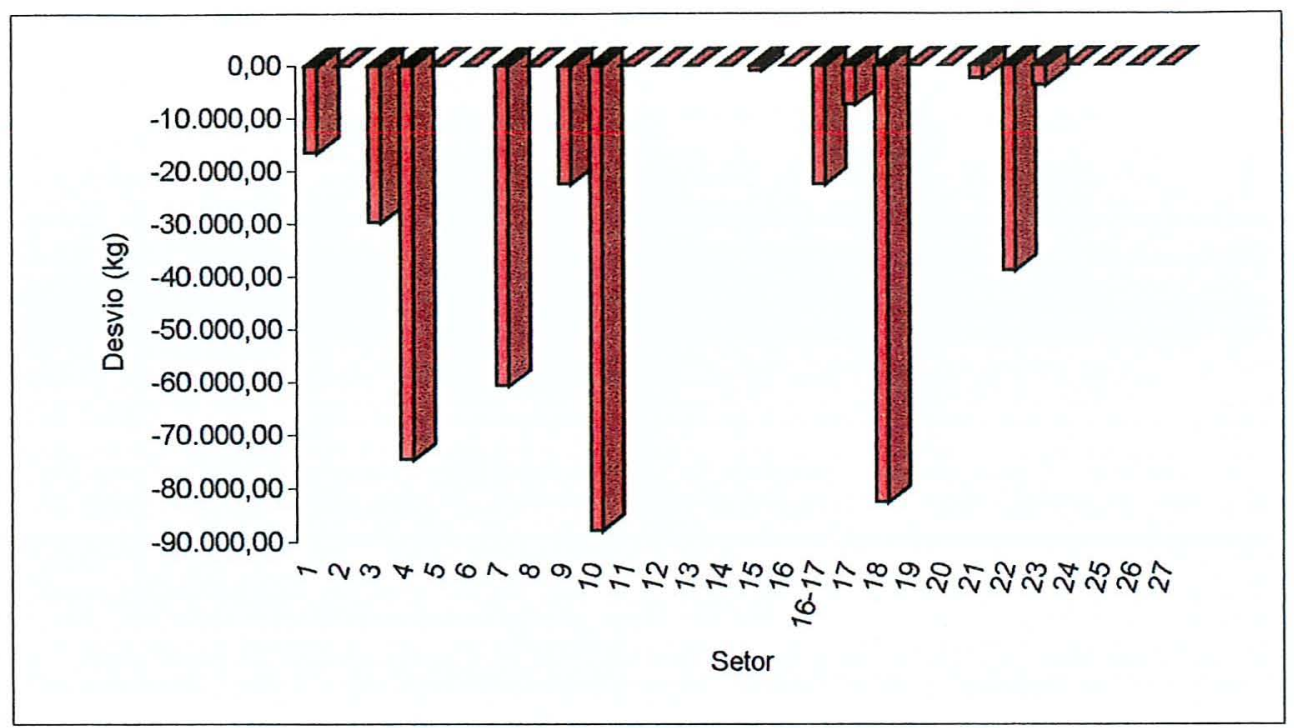

Figura 15 - Variações relacionadas às quantidades coletadas convencionalmente para a formulação sem prioridades e com densidade média de $195,15 \mathrm{~kg} / \mathrm{km}$, em Piracicaba - SP, 2000.

De acordo com a Figura 16, percebe-se que apenas o setor 18 apresentou desvio positivo relacionado à meta de quilometragem (M2). Nesse setor, foram percorridos $78,81 \mathrm{~km}$ a mais do que os estabelecidos como meta. Nos setores 2, 4, 5, 7, $9,10,13,14,22,23,25$ e 27 tal meta foi atingida (desvios positivos e negativos iguais a zero). Em todos os outros setores a quilometragem percorrida ficou abaixo da quilometragem estabelecida como meta. $\mathrm{O}$ setor que mais se distanciou do proposto foi o setor 1, onde seriam percorridos $807,12 \mathrm{~km}$ a menos que os $3.290,56 \mathrm{~km}$ propostos. O setor que menos se distanciou foi o setor 15 , com $57,93 \mathrm{~km}$ a menos que os $1.978,52 \mathrm{~km}$ estabelecidos. É importante ressaltar que os desvios negativos relacionados à meta de quilometragem não são somados na função objetivo.

Em relação aos desvios relacionados à quantidade de veículos utilizados (M3), em todos os dias da semana não houve sub ou superutilização de veículos coletores. A taxa de aproveitamento dos veículos foi de $91,8 \%$ nas $2^{\text {as }}, 4^{\text {as }}$ e $6^{\text {as }}$ e $92,5 \%$ nas $3^{\text {as }}, 5^{\text {as }}$ e sábados (os valores fornecidos pelo modelo foram de 9,18 e 9,25 veículos, respectivamente). 


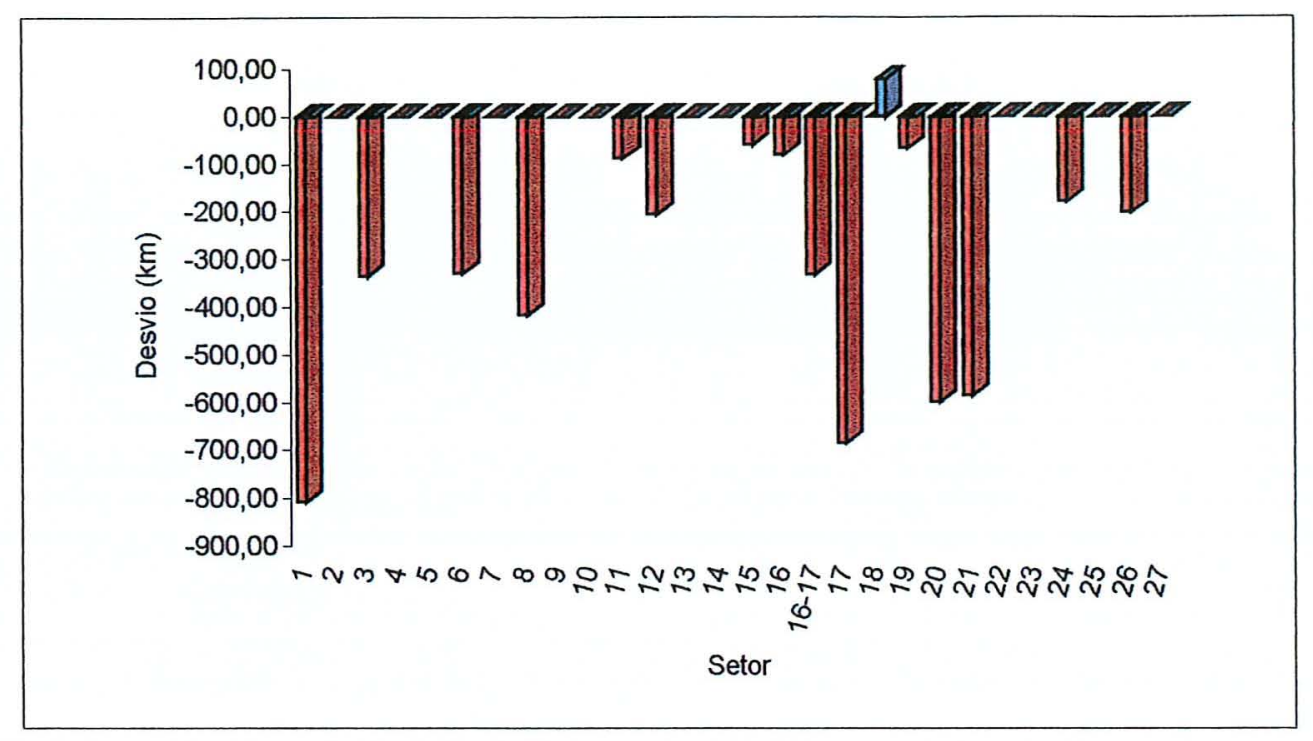

Figura 16 - Variações relacionadas à quilometragem percorrida na coleta convencional para a formulação sem prioridades e com densidade média de 195,15 $\mathrm{kg} / \mathrm{km}$, em Piracicaba - SP, 2000.

De acordo com a Figura 17, percebe-se que os setores $2,4,5,6,7,9,10,11$, $12,13,14,18,19,22,25$ e 27 não utilizaram o total do orçamento disponibilizado para a coleta convencional (desvio negativo M5 diferente de zero), sendo que a maior sobra se deu no setor 10 ( $\mathrm{R} \$ 3.142,54$ dos $\mathrm{R} \$ 8.978,76$ estipulados). A menor sobra ocorreu no setor 27 ( $R \$ 19,66$ dos $R \$ 6.154,37$ disponíveis). Apenas os setores 1, 8, 15, 16, 16/17, 21,23 e 26 ultrapassaram o valor estabelecido, sendo que o maior déficit foi do setor 1 ( $\mathrm{R} \$ 1.213,15$ acima dos $\mathrm{R} \$ 7.584,00$ estabelecidos) e o menor déficit foi o do setor 16/17 ( $\mathrm{R} \$ 216,73$ acima dos $\mathrm{R} \$ 4.236,58$ estabelecidos). 


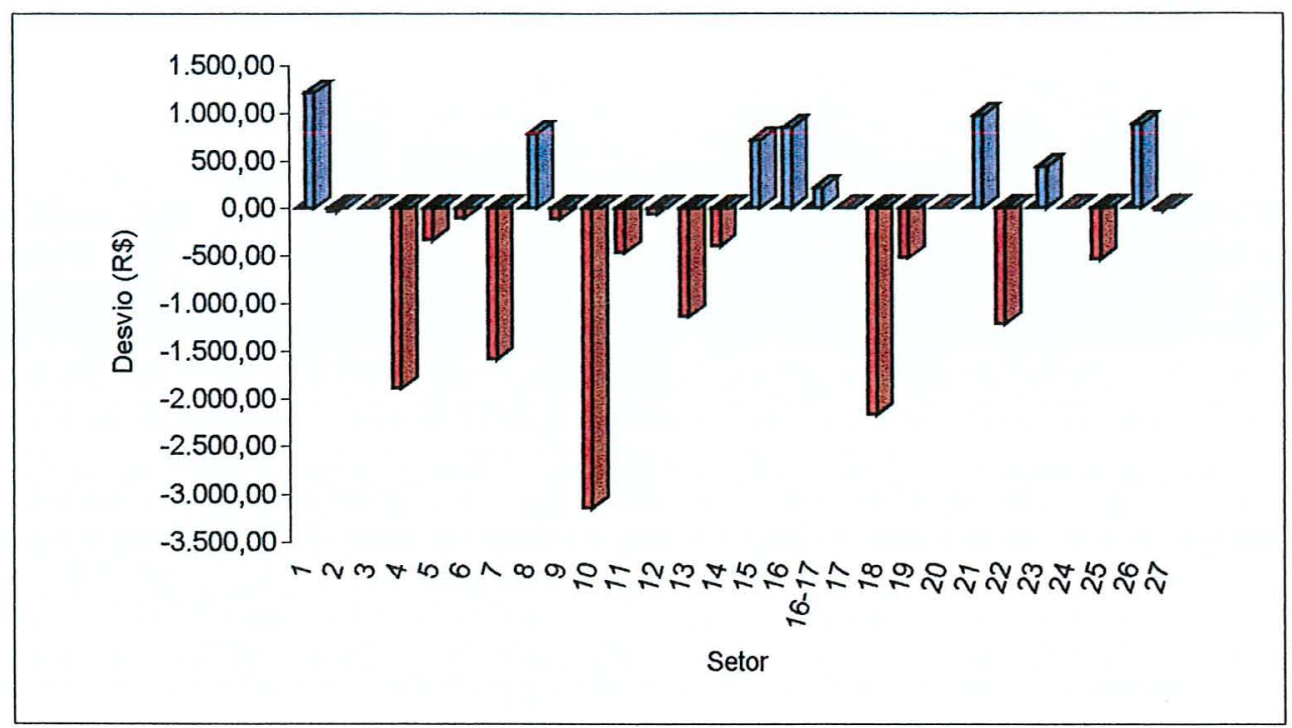

Figura 17 - Variações relacionadas ao Orçamento da Coleta Convencional para a formulação sem prioridades e com densidade média de $195,15 \mathrm{~kg} / \mathrm{km}$, em Piracicaba - SP, 2000.

Conforme a Figura 18, percebe-se que não há valores de desvios negativos para M6 (meta relacionada ao orçamento da coleta seletiva), o que indica que não há sobras de orçamento na coleta seletiva. Nenhum setor conseguiu cumprir o orçamento da coleta seletiva, sendo que o setor que mais ultrapassou o estabelecido foi o setor 2 , superando em R\$ 193,25 o estabelecido de R\$2.201,73. O setor que menos ultrapassou o estabelecido foi o setor $16 / 17$, excedendo em $\mathrm{R} \$ 87,44$ os $\mathrm{R} \$ 996,32$ estabelecidos como meta.

Não há desvios negativos ou positivos relacionados à meta $M 7$ (meta relacionada às quantidades coletadas seletivamente), indicando que toda a quantidade a ser coletada seletivamente estabelecida como meta está sendo respeitada.

Conforme a Figura 19, verifica-se que o valor da variável densidade ficou abaixo do valor estipulado nos setores $5,6,11,12,13,14,19,20,24,25$ e 27, sendo 


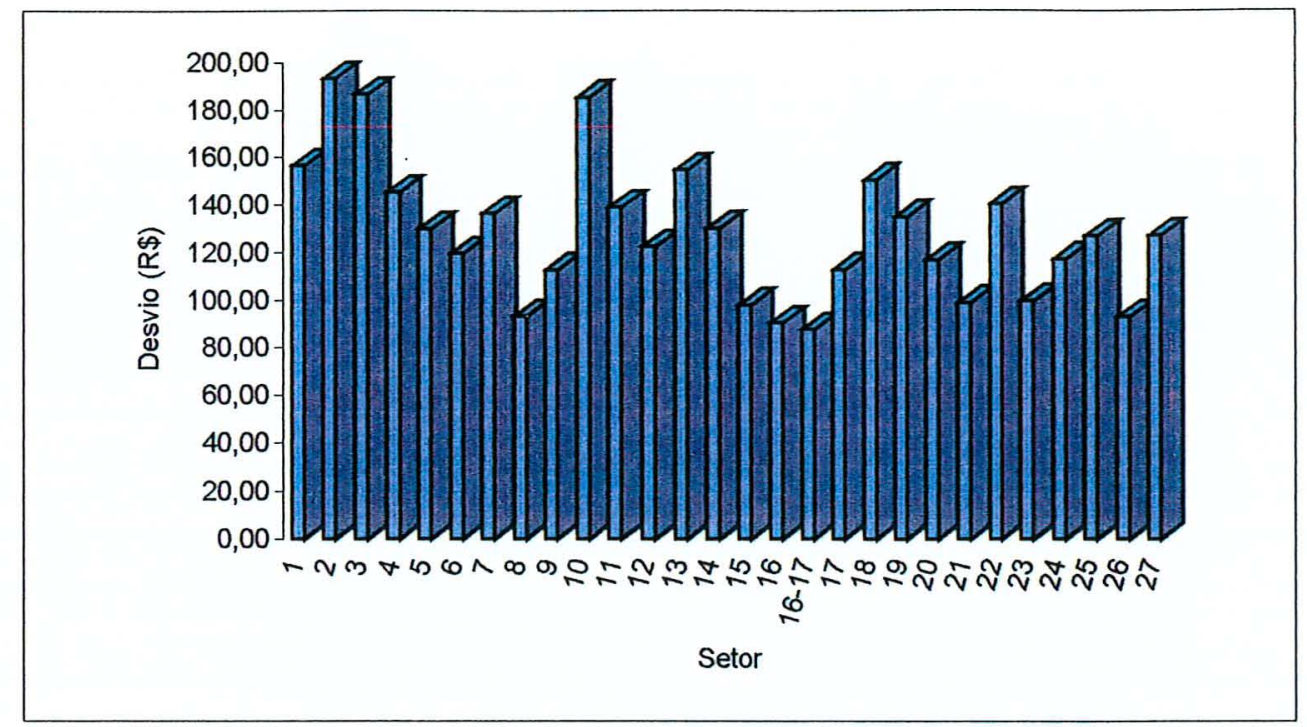

Figura 18 - Variações relacionadas ao Orçamento da Coleta Seletiva para a formulação sem prioridades e com densidade média de $195,15 \mathrm{~kg} / \mathrm{km}$, em Piracicaba SP, 2000.

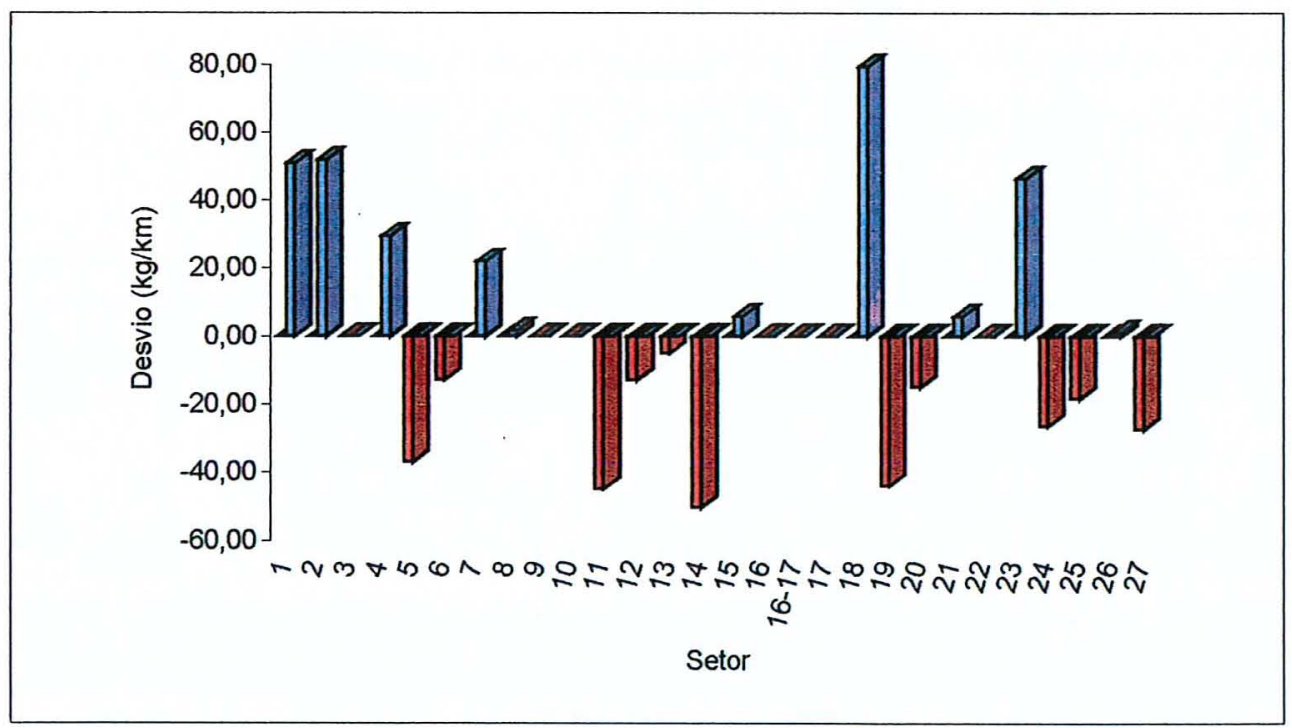

Figura 19 - Variações relacionadas à Densidade da Coleta Convencional para a formulação sem prioridades e com densidade média de $195,15 \mathrm{~kg} / \mathrm{km}$, em Piracicaba - SP, 2000. 
que o setor 13 apresentou o menor desvio para $M 8(5,07 \mathrm{~kg} / \mathrm{km})$ e o setor 14 , o maior $(50,33 \mathrm{~kg} / \mathrm{km})$. Nos setores $1,2,4,7,8,15,18,21,23$ e 26, o valor da variável densidade foi superior aos valores estipulados, sendo que a maior diferença se deu no setor $18(79,44 \mathrm{~kg} / \mathrm{km})$ e a menor, no setor $26(1,14 \mathrm{~kg} / \mathrm{km})$. Os setores $3,9,10,16$, $16 / 17,17$ e 22 atingiram a meta de densidade.

Os desvios da produtividade (M9) são mensurados em termos de quantidades coletadas. De acordo com a Figura 20, percebe-se que os setores 1, 4, 7, 15, 16/17, 18, 21 e 23 apresentaram produtividade de 100\%. Os setores 8, 16 e 26 apresentaram produtividades menores que as estabelecidas, sendo que o setor 8 apresentou o menor desvio negativo, deixando de coletar $6.303,05 \mathrm{~kg}$ dos $150.800 \mathrm{~kg}$ estabelecidos (valor que forneceria uma produtividade de $100 \%$ ). No setor 16 , deixou-se de coletar 10.766,28 $\mathrm{kg}$ dos $150.800 \mathrm{~kg}$ estabelecidos. Os outros setores $(2,3,5,6,9,10,11,12,13,14,17$, $19,20,22,24,25$ e 27 ) apresentaram produtividade acima de $100 \%$, sendo que o setor 13 apresentou o maior desvio, $89.098,41 \mathrm{~kg}$, ou seja, 51.160,99 $\mathrm{kg}$ acima da produtividade de $150.800 \mathrm{~kg}$ estabelecida como meta. O menor desvio positivo foi do setor 9 , com $1502,87 \mathrm{~kg}$ a mais do que a meta de $150.800 \mathrm{~kg}$.

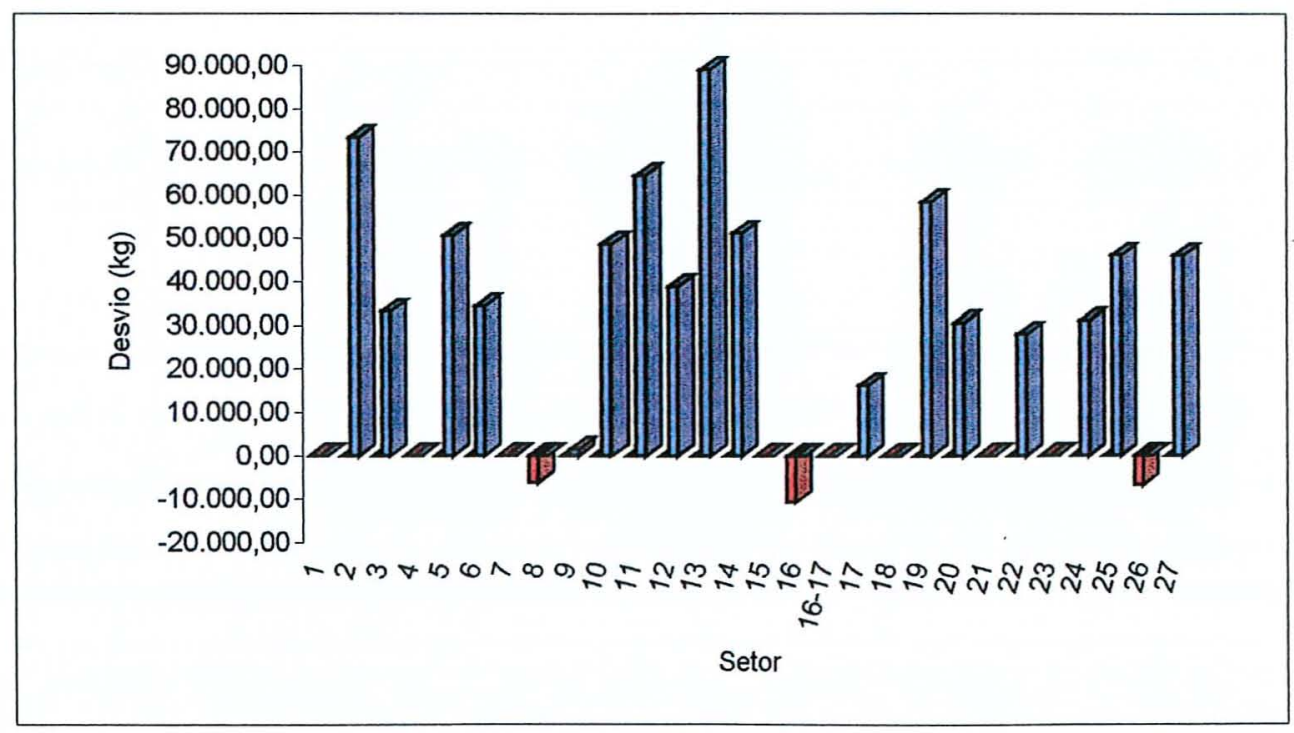

Figura 20 - Variações relacionadas à Produtividade da Coleta Convencional para a formulação sem prioridades e com densidade média de $195,15 \mathrm{~kg} / \mathrm{km}$, em Piracicaba - SP, 2000. 


\subsubsection{Modelos com prioridades}

As prioridades $\left(P_{i}\right)$ foram introduzidas no modelo de Programação por Metas, impondo-se a equação de densidade média. A seguir, são descritas as três ordenações distintas utilizadas.

\subsubsection{Primeira ordenação das prioridades}

A primeira ordenação testada considera a seguinte seqüência de metas: quantidades coletadas convencionalmente $\left(M l_{i}\right)$, percurso realizado $\left(M 2_{i}\right)$, quantidades coletadas seletivamente $\left(M 7_{i}\right)$, veículos super e subutilizados $(M 3)$, orçamento da coleta convencional $\left(M 5_{i}\right)$, orçamento da coleta seletiva $\left(M \sigma_{i}\right)$, densidade abaixo e acima da estabelecida $(M 8)$ e produtividade inferior e superior à estabelecida $\left(M 9_{i}\right)$.

O valor do desvio total para essa ordenação, ponderado pelas prioridades, foi de 1.229.006,69. As Figuras 21 a 25 ilustram os desvios negativos e positivos de cada meta, por setor. No Anexo L, têm-se os valores exatos de tais desvios.

Conseguiu-se coletar toda a quantidade estabelecida como meta para a coleta convencional (desvios nulos para $M I$ ).

Conforme ilustra a Figura 21, todos os setores conseguiram percorrer a quilometragem estabelecida como meta $(M 2)$, exceto o setor 11 , que percorreu $70,01 \mathrm{~km}$ a menos que os $2.623,71 \mathrm{~km}$ estabelecidos, e o setor 20 , que percorreu $68,67 \mathrm{~km}$ a menos que os $2.484,48 \mathrm{~km}$ estabelecidos. Entretanto, os valores de desvio negativo para a meta de quilometragem não são somados na função objetivo.

Houve uma superutilização de 1 veículo nas $2^{\text {as }} 4^{\text {as }}$ e $6^{\text {as }}$, pois se utilizou de 11 veículos (desvio positivo para $M 3$ igual a 1,00). A taxa de aproveitamento dos veículos foi de $92,09 \%$, já que o valor fornecido pelo modelo foi de 10,13 veículos. Nas $3^{\text {as }}, 5^{\text {as }}$ e sábados não houve sub ou superutilização de veículos (desvios para M4 iguais a zero). Foram utilizados os 10 veículos, com taxa de aproveitamento de $98,9 \%$ (o valor fornecido pelo modelo foi de 9,89). 


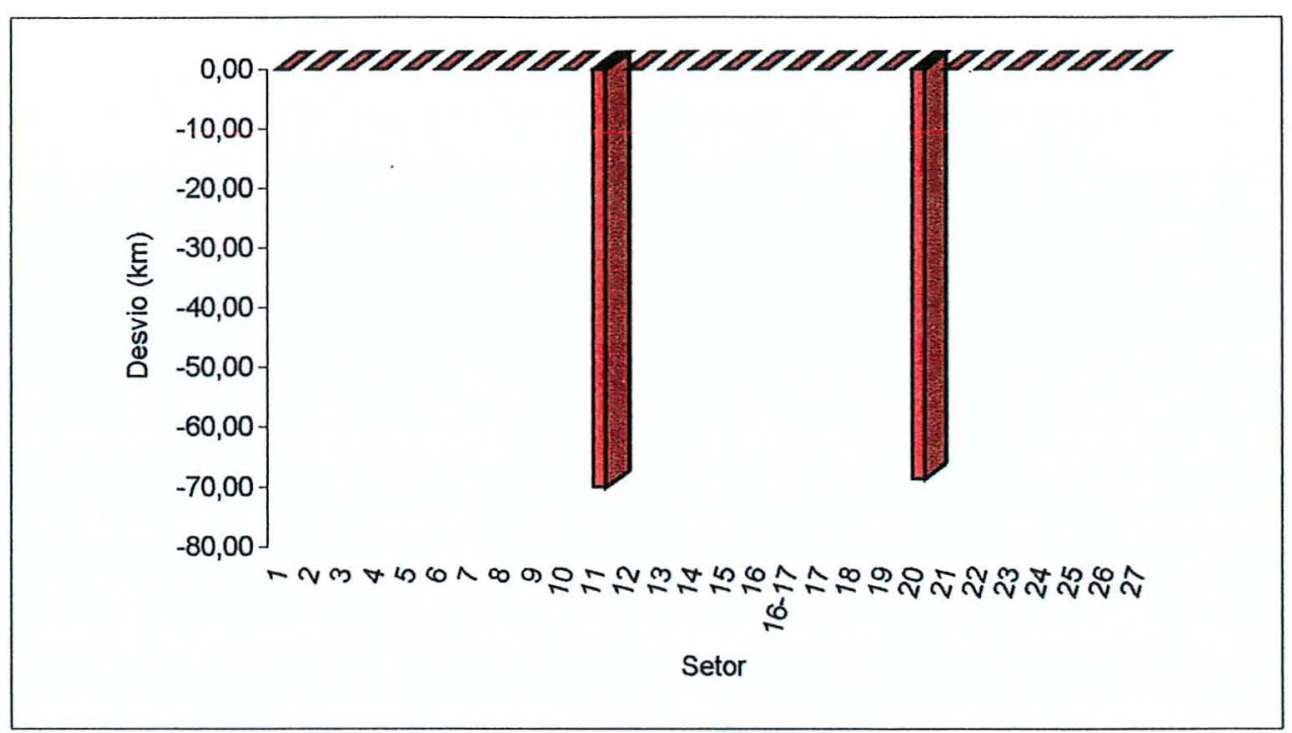

Figura 21 - Variações relacionadas à quilometragem percorrida na Coleta Convencional considerando-se a $1^{\text {a }}$ ordenação de prioridades, em Piracicaba - SP, 2000.

O orçamento da coleta convencional foi ultrapassado nos setores $1,3,8,15$, $16,16 / 17,17,20,21,23$ e 26. O maior desvio positivo para M5 ocorreu no setor 1 (R\$ $1.622,67$ acima dos $\mathrm{R} \$ 7.584,00$ estabelecidos) e o menor, no setor 20 ( $\mathrm{R} \$ 213,82$ acima dos $\mathrm{R} \$ 5.666,21$ estabelecidos). Entretanto, houve sobras (desvios negativos para M5) nos setores $2,4,5,6,7,9,10,11,12,13,14,18,19,22,24,25$ e 27, conforme ilustra a Figura 22. A maior sobra se deu no setor 10 (R $\$ 2.670,59$ utilizados a menos que os R $\$$ $8.978,76$ estabelecidos), enquanto a menor sobra ocorreu no setor 24 ( $\mathrm{R} \$ 11,78$ a menos que os $\mathrm{R} \$ 5.683,64$ estipulados). 


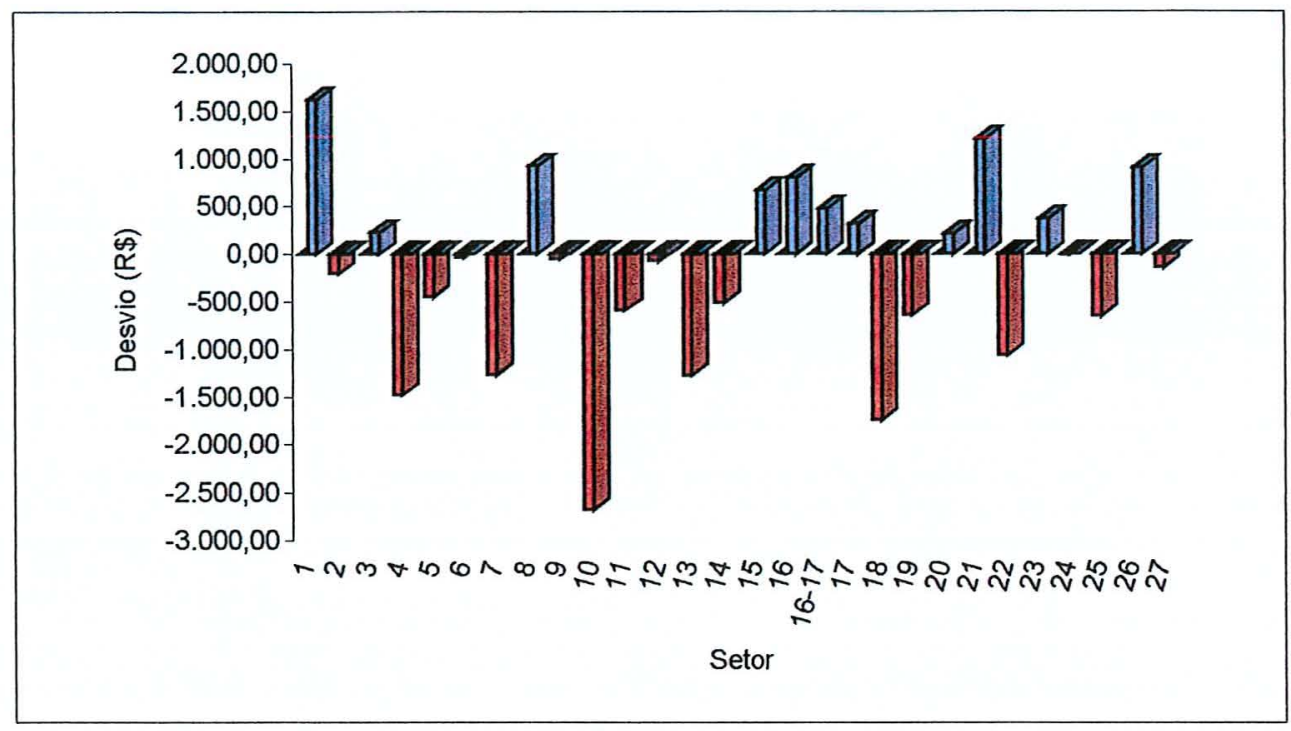

Figura 22 - Variações relacionadas ao orçamento da Coleta Convencional considerandose a $1^{a}$ ordenação de prioridades, em Piracicaba - SP, 2000.

O orçamento da coleta seletiva ultrapassou o estabelecido em $R \$ 3.598,69$, não havendo sobras de orçamento em nenhum dos setores (desvios negativos para M6 iguais a zero), conforme mostra a Figura 23. O setor que mais ultrapassou o valor estabelecido como meta foi o setor 2 ( $\mathrm{R} \$ 193,25$ dos $2.201,73$ estabelecidos), enquanto o setor $16 / 17$ foi o que menos ultrapassou o valor da meta ( $\mathrm{R} \$ 87,44$ dos $\mathrm{R} \$ 996,32$ estabelecidos).

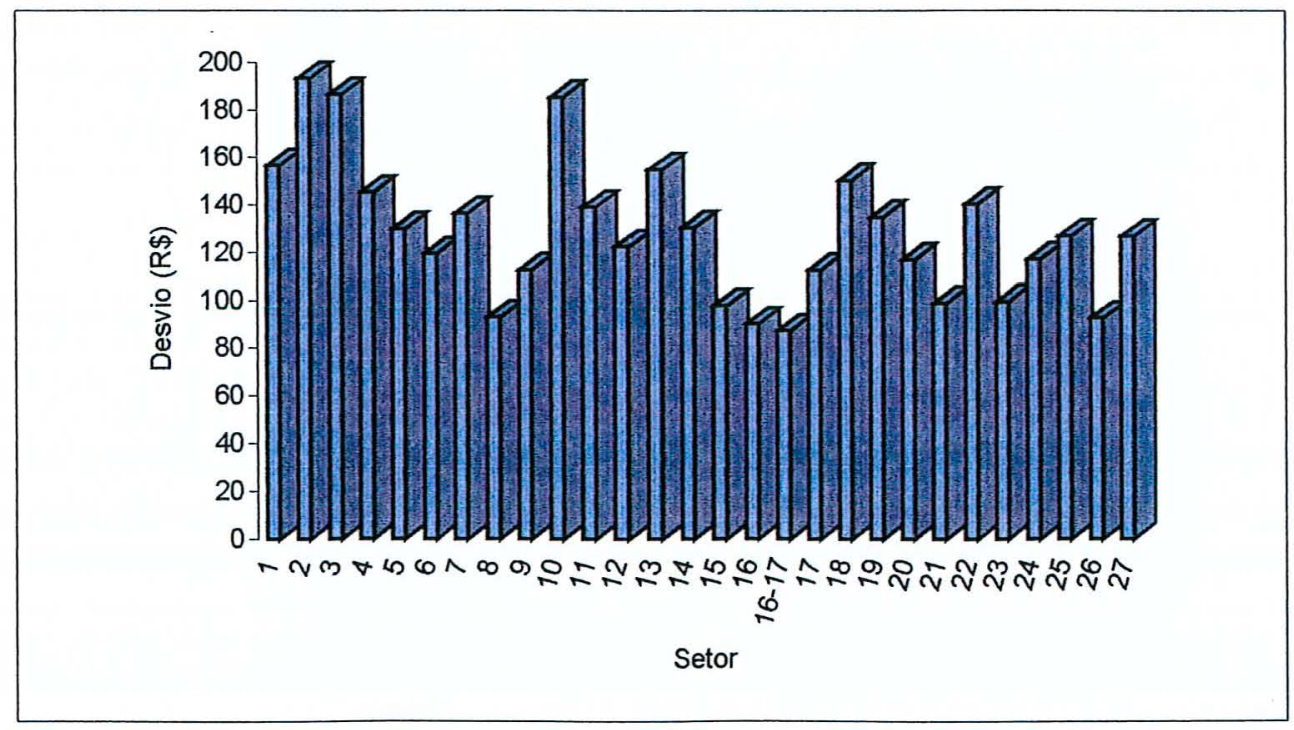

Figura 23 - Variações relacionadas ao orçamento da coleta seletiva considerando-se a $1^{\mathrm{a}}$ ordenação de prioridades, em Piracicaba - SP, 2000. 
A quantidade coletada seletivamente foi alcançada em todos os setores (desvios para $M 7$ iguais a zero).

Nenhum setor alcançou a meta estabelecida de densidade de $195,15 \mathrm{~kg} / \mathrm{km}$. A somatória dos valores de densidade superiores à média estabelecida foi de 833,25. A somatória dos valores de densidade inferiores à média estabelecida também foi de 833,25 . Os setores $2,4,7,9,10,14,18,22$ e 23 apresentaram valores de densidade acima da média estabelecida, conforme ilustra a Figura 24. O maior desvio positivo ocorreu no setor $18(300,64)$ e o menor, no setor $14(21,31)$. Todos os outros setores apresentaram desvios negativos para a meta de densidade. O maior desvio negativo ocorreu no setor $20(82,19)$ e o menor, no setor $13(5,07)$.

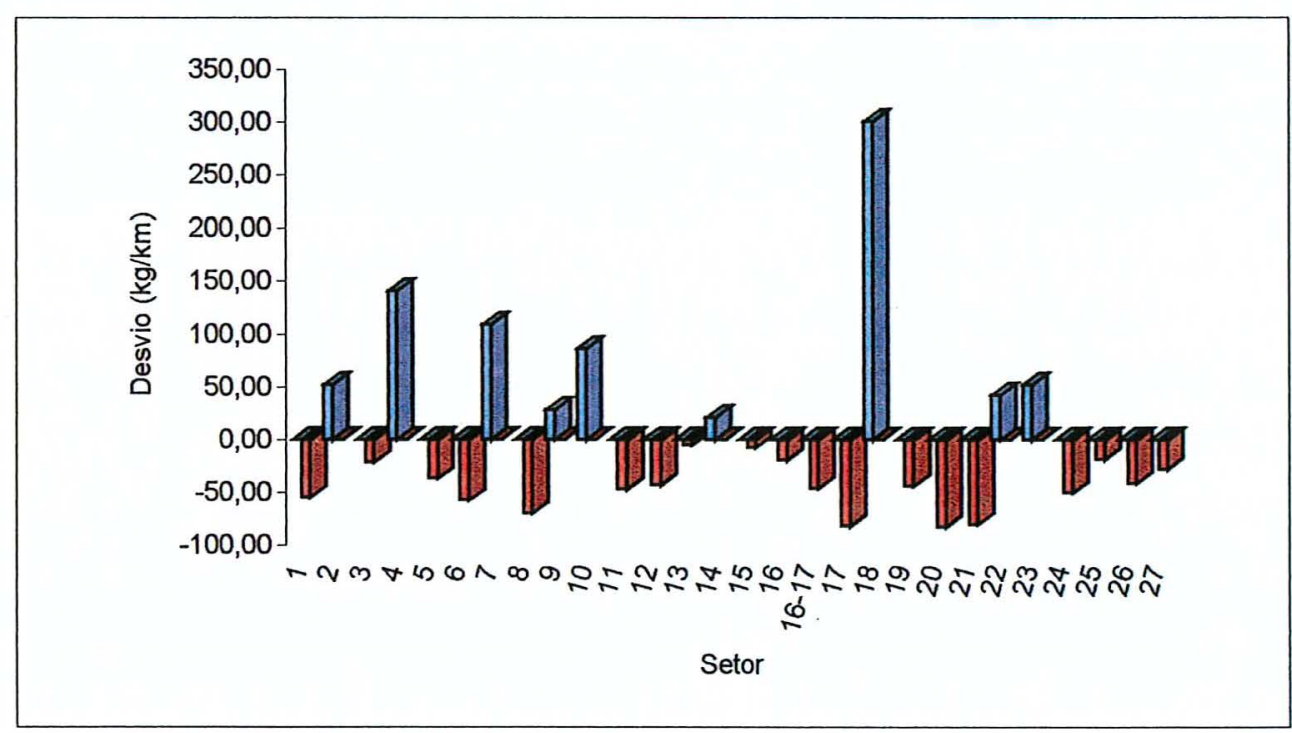

Figura 24 - Variações relacionadas à densidade da coleta convencional considerando-se a $1^{\mathrm{a}}$ ordenação de prioridades, em Piracicaba - SP, 2000.

A meta de produtividade também não foi alcançada em nenhum setor e de acordo com a Figura 25, esta ficou abaixo de 100\% para os setores 8 (faltando 6.303,05 $\mathrm{kg}$ para serem coletados a fim de que a produtividade atingisse $100 \%$ ), 16 (faltando $10.766,28 \mathrm{~kg}$ para serem coletados a fim de que a produtividade atingisse $100 \%$ ) e 26 (faltando $6.860,95 \mathrm{~kg}$ para serem coletados a fim de que a produtividade atingisse $100 \%$ ). A produtividade foi acima de $100 \%$ para todos os outros setores, sendo que 
1.192.063,09 $\mathrm{kg}$ foram coletados graças a valores de produtividade maiores que os $100 \%$ estabelecidos.

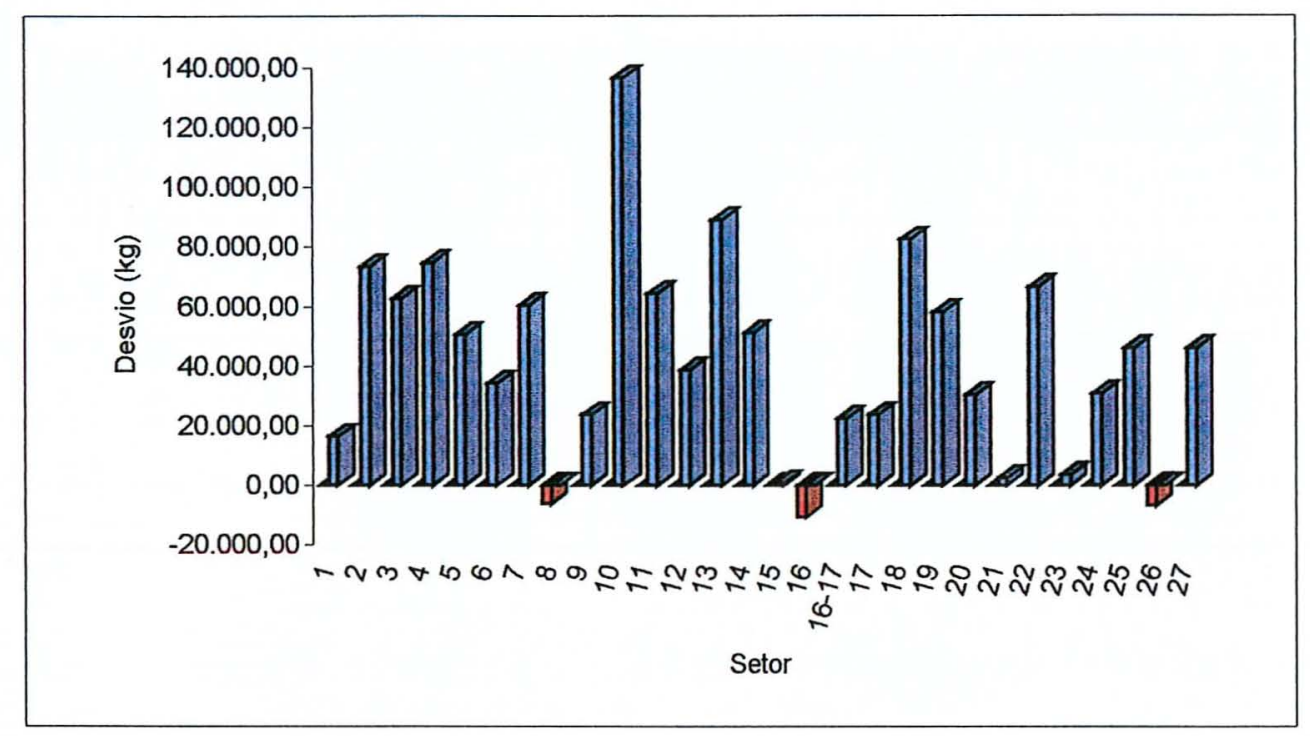

Figura 25 - Variações relacionadas à produtividade da coleta convencional considerando-se a $1^{\text {a }}$ ordenação de prioridades, em Piracicaba - SP, 2000 .

\subsubsection{Segunda ordenação das prioridades}

A segunda ordenação testada considera a seguinte seqüência das metas: quantidades coletadas convencionalmente $\left(M 1_{i}\right)$, densidade abaixo e acima da estabelecida (M8), quantidades coletadas seletivamente $\left(M 7_{i}\right)$, percurso realizado $\left(M 2_{i}\right)$, orçamento da coleta convencional $\left(M 5_{i}\right)$, orçamento da coleta seletiva $\left(M 6_{i}\right)$, veículos super e subutilizados $(M 3)$ e produtividade inferior e superior à estabelecida $\left(M 9_{i}\right)$.

O valor do desvio total, ponderado pelas prioridades, para essa ordenação, foi de $1.230 .305,43$. Houve um aumento de $1.298,74$ da função objetivo dessa ordenação em relação à primeira, graças a um aumento no desvios positivo relacionado às quilometragens percorridas (M2). Houve uma diminuição dos desvios positivos $\mathrm{e}$ negativos da meta relacionada às densidades (M8). Entretanto, essa diminuição foi inferior ao aumento dos desvios positivos de quilometragem. 
As Figuras 26 a 29 ilustram os desvios negativos e positivos, por setor, para cada meta, conforme essa ordenação de prioridades. No Anexo $M$, têm-se os valores detalhados para essa formulação.

Conseguiu-se coletar toda a quantidade estabelecida para a coleta convencional (desvios para $M 1$ iguais a zero).

A quilometragem percorrida foi superior à estabelecida como meta nos setores $2,4,7,9,10,14,18,22$ e 23 . O maior desvio positivo ocorreu no setor $18(724,63 \mathrm{~km} \mathrm{a}$ mais que os $1.214,49 \mathrm{~km}$ estabelecidos como meta). O menor desvio positivo ocorreu no setor 14 (113,70 km percorridos a mais que os 2.076,07 km estabelecidos como meta), conforme ilustra a Figura 26. Em todos os outros setores a quilometragem percorrida foi inferior à estabelecida como meta. O menor desvio negativo ocorreu no setor $15(30,92$ $\mathrm{km}$ percorridos a menos que os $1.978,52 \mathrm{~km}$ estabelecidos) e o maior, no setor 20 (676,04 km a menos que os $2.484,48 \mathrm{~km}$ estabelecidos como meta).

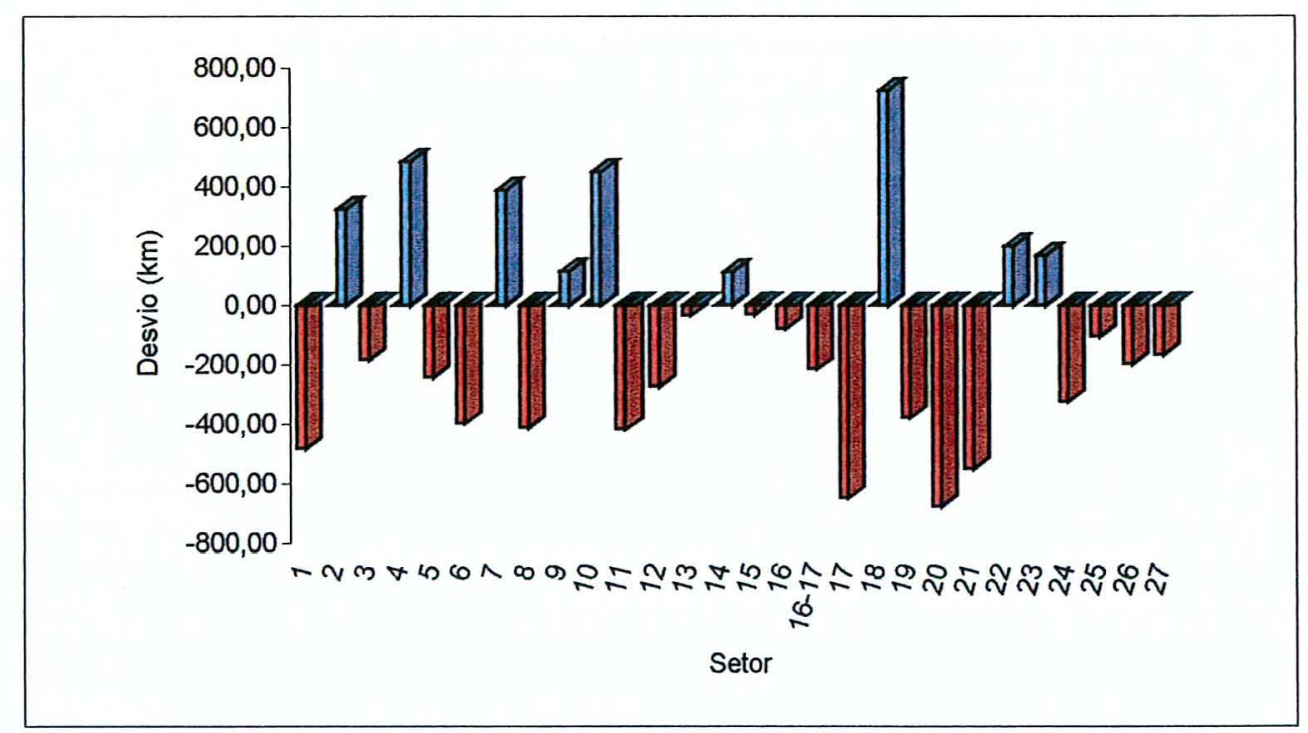

Figura 26 - Variações relacionadas à quilometragem percorrida na coleta convencional considerando-se a $2^{\mathrm{a}}$ ordenação de prioridades, em Piracicaba - SP, 2000.

Além disso, houve uma superutilização de 1 veículo nas $2^{\text {as }} 4^{\text {as }}$ e $6^{\text {as }}$ (desvio positivo $M 3$ ), pois foram utilizados 11 veículos. A taxa de aproveitamento dos veículos 
foi de $92,09 \%$, já que o valor fornecido pelo modelo foi de 10,13 veículos. Nas $3^{\text {as }}, 5^{\text {as }} \mathrm{e}$ sábados não houve sub ou superutilização dos 10 veículos disponíveis. A taxa de aproveitamento foi de $98,9 \%$ (o valor fornecido pelo modelo foi de 9,89 veículos).

Conforme ilustra a Figura 27, o orçamento da coleta convencional foi ultrapassado nos setores $1,3,8,15,16,16 / 17,17,20,21,23$ e 26 . O maior desvio positivo ocorreu no setor 1 ( $R \$ 1.622,67$ a mais que os $R \$ 7.584,00$ estabelecidos) e o menor, no setor 20 ( $R \$ 203,82$ a mais que os $\mathrm{R} \$ 5.666,21$ estabelecidos como meta). Em todos os outros setores houve sobras de orçamento, sendo que a maior sobra ocorreu no setor 10 ( $\mathrm{R} \$ 2670,59$ utilizados a menos que os $\mathrm{R} \$ 8.978,76$ estabelecidos como meta) e a menor, no setor 24 ( $R \$ 11,78$ a menos que os $5.683,64$ estabelecidos).

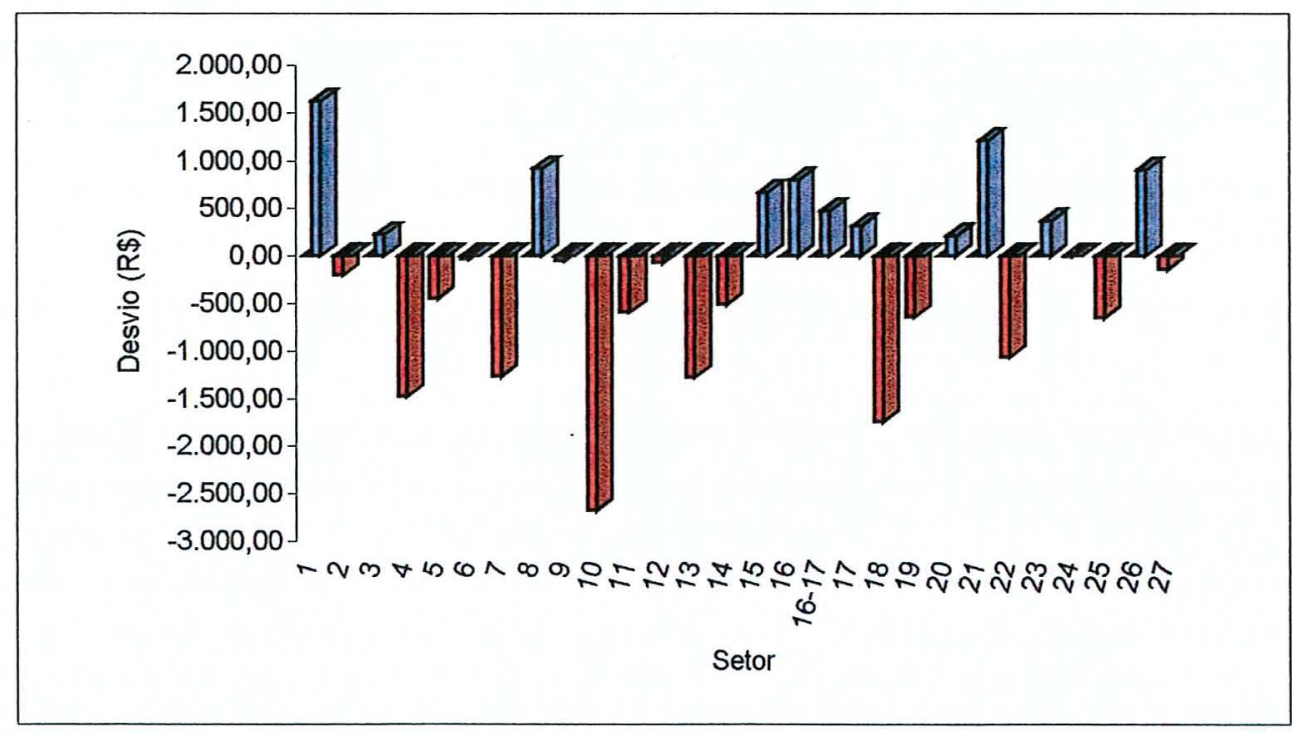

Figura 27 - Variações relacionadas ao orçamento da coleta convencional considerandose a $2^{\mathrm{a}}$ ordenação de prioridades, em Piracicaba - SP, 2000.

O orçamento da coleta seletiva, conforme mostra a Figura 28, foi ultrapassado em $\mathrm{R} \$ 3.598,69$ (somatória dos desvios positivos M6). No caso da coleta seletiva não houve sobras em nenhum setor, sendo que o que mais ultrapassou o valor estabelecido como meta foi o setor 2 ( $R \$ 193,25$ dos $R \$ 2.201,73$ estabelecidos). 


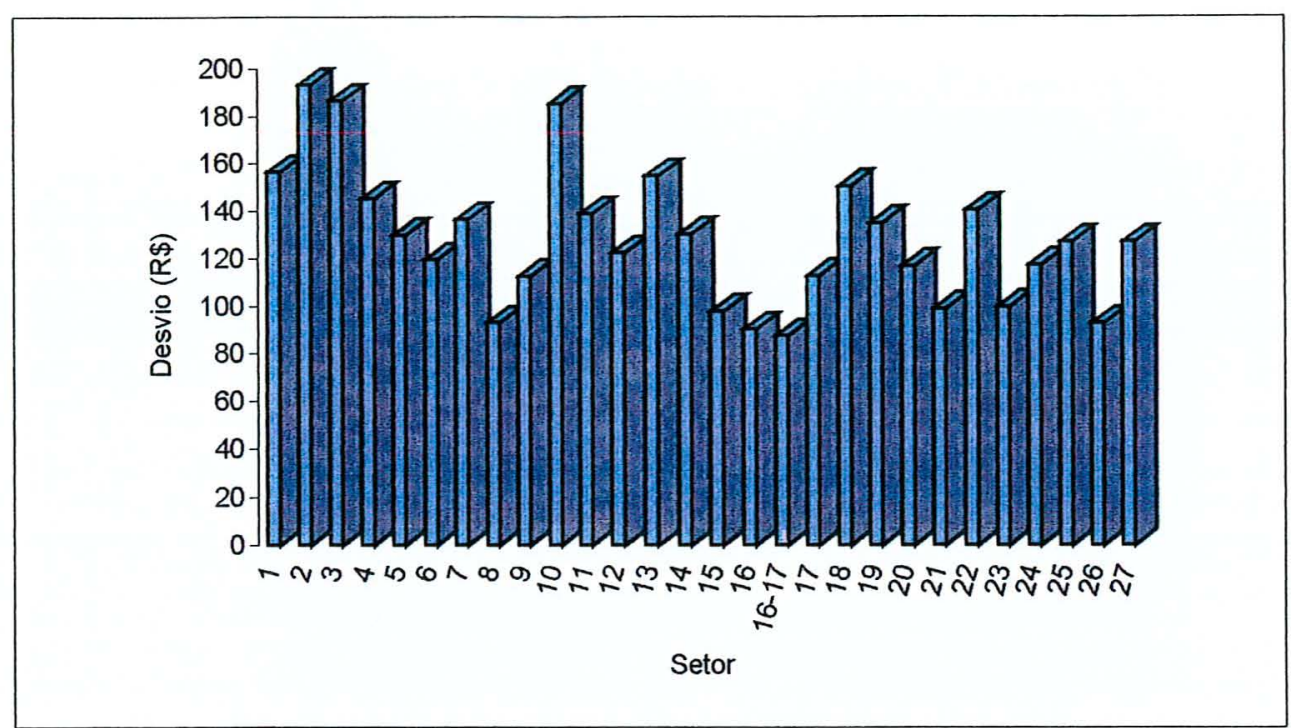

Figura 28 - Variações relacionadas ao orçamento da coleta seletiva considerando-se a $2^{\mathrm{a}}$ ordenação de prioridades, em Piracicaba - SP, 2000.

A quantidade coletada seletivamente foi alcançada em todos os setores (desvios para $M 7$ iguais a zero). A densidade de 195,15 também foi alcançada para todos os setores (desvios para $M 8$ iguais a zero).

Pode-se visualizar na Figura 29 que a produtividade não foi alcançada em nenhum setor, ficando abaixo de $100 \%$ para os setores 8,16 e 26 , ou seja, faltando $6.303,05 \mathrm{~kg}, 10.766,28 \mathrm{~kg}$ e $6.860,95 \mathrm{~kg}$, respectivamente, a fim de que a produtividade atingisse $100 \%$. A produtividade foi acima de $100 \%$ para todos os outros setores, sendo que $1.192 .063,09 \mathrm{~kg}$ foram coletados graças a valores de produtividade maiores que os $100 \%$ estabelecidos. 


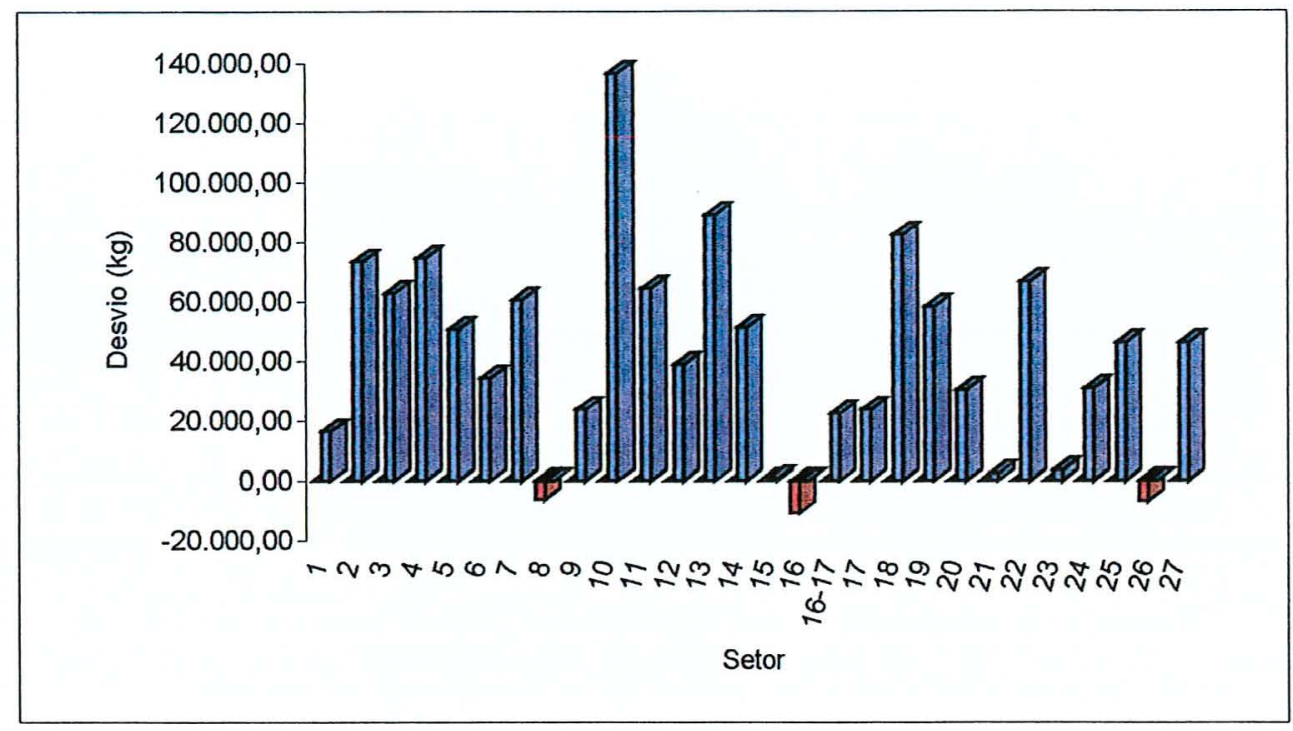

Figura 29 - Variações relacionadas à produtividade da coleta convencional considerando-se a $2^{\mathrm{a}}$ ordenação de prioridades, em Piracicaba - SP, 2000 .

\subsubsection{Terceira ordenação das prioridades}

A terceira ordenação testada considera a seguinte seqüência das metas: produtividade inferior e superior à estabelecida $\left(M 9_{i}\right)$, quantidades coletadas convencionalmente $\left(M 1_{i}\right)$, percurso realizado $\left(M 2_{i}\right)$, densidade abaixo e acima da estabelecida $(M 8)$, quantidades coletadas seletivamente $\left(M 7_{i}\right)$, orçamento da coleta seletiva $\left(M \sigma_{i}\right)$, veículos super e subutilizados $(M 3)$ e orçamento da coleta convencional $\left(M 5_{i}\right)$.

Apesar de um aumento no desvio positivo relacionado ao orçamento da coleta convencional (M5), a função objetivo (desvio total ponderado pelas prioridades) para essa ordenação reduziu-se para $1.206 .750,02$. Essa redução, em relação às duas primeiras ordenações, se deu, principalmente, devido à diminuição dos desvios negativos relacionados à produtividade $(M 9)$.

As Figuras 30 a 34 ilustram os desvios negativos e positivos das metas para todos os setores segundo a terceira ordenação, cujos valores exatos podem ser encontrados no Anexo N. 
De acordo com a Figura 30, não se conseguiu coletar toda a quantidade estabelecida para a coleta convencional, ficando $1.1192 .063,09 \mathrm{~kg}$ sem serem coletados (somatória dos desvios negativos $M I$ ). O maior desvio negativo aconteceu no setor 10 (136.520,19 kg dos 287.320,19 kg não foram coletados). É importante ressaltar que, pelo fato de essa formulação ter como primeira prioridade a produtividade, o primeiro subproblema fornecerá resultados de quantidades a serem coletadas em cada setor que garantam a produtividade de $2.900 \mathrm{~kg} /$ coletor/dia. Dessa maneira, nos setores 8,16 e 26 devem ser coletados $150.800 \mathrm{~kg}$ por mês. Entretanto, nesses setores, as metas de quantidades coletadas são de $144.496,95 ; 140.033,72$ e 143.939,72 kg. Essa diferença levará a valores maiores que zero de desvios positivos para a meta de quantidade coletada convencionalmente para esses setores, valores que devem ser desconsiderados, pois representam valores acima das quantidades estimadas de geração de lixo nesses setores.

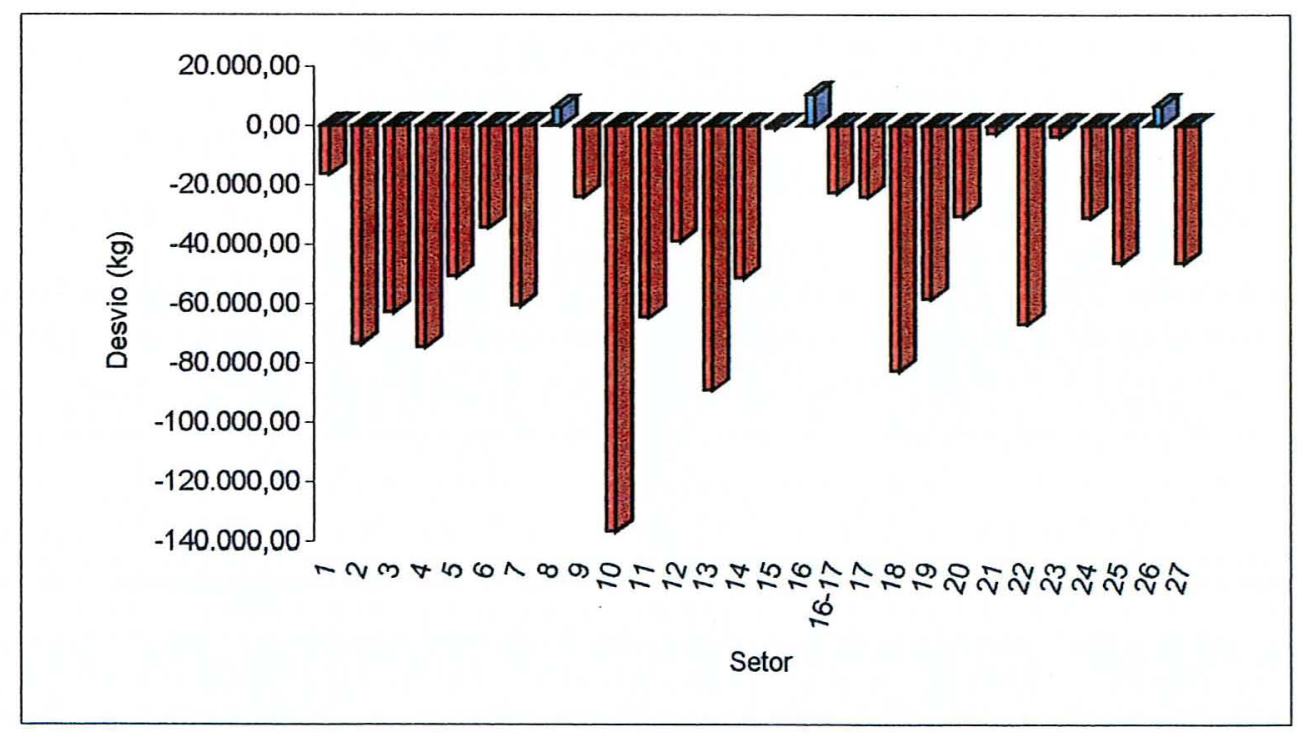

Figura 30 - Variações relacionadas à quantidade coletada convencionalmente considerando-se a $3^{\text {a }}$ ordenação de prioridades, em Piracicaba - SP, 2000 .

Conforme mostra a Figura 31, não houve desvios positivos relacionados à meta de quilometragem (M2). Entretanto, houve desvios negativos, ou seja, em alguns setores 
$(2,3,4,11,13,15,17,20,21,22,25,26$ e 27) a quilometragem percorrida foi inferior à estabelecida como meta. O maior desvio negativo ocorreu no setor $21(845 \mathrm{~km}$ a menos que os $3.066,15 \mathrm{~km}$ estabelecidos como meta), e o menor, no setor $11(13,31 \mathrm{~km} \mathrm{a}$ menos que os $2.623,71 \mathrm{~km}$ estabelecidos). Nos outros setores a meta de quilometragem foi atendida.

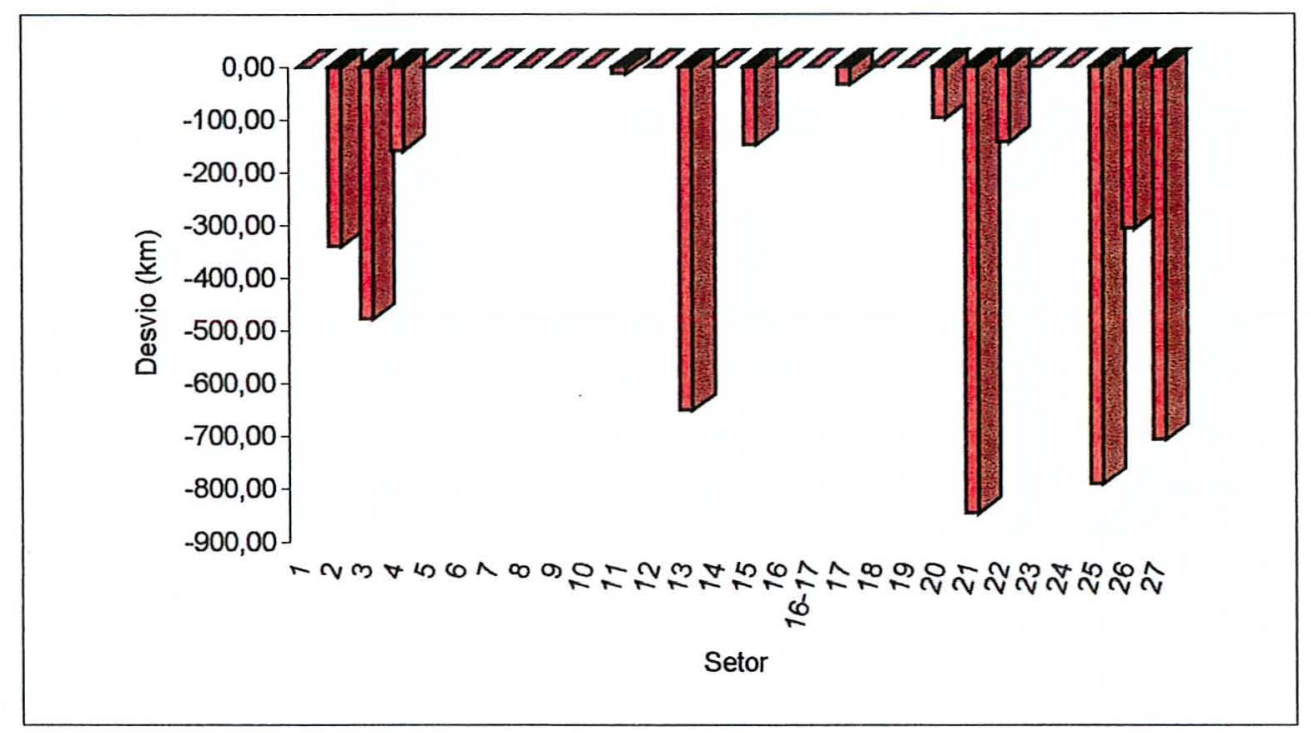

Figura 31 - Variações relacionadas à quilometragem percorrida na coleta convencional considerando-se a $3^{\mathrm{a}}$ ordenação de prioridades, em Piracicaba - SP, 2000.

Houve uma subutilização de 2 veículos nas $2^{\text {as }} 4^{\text {as }}$ e $6^{\text {as }}$, pois se utilizaram 8 veículos, com taxa de aproveitamento de $96,63 \%$, já que o valor fornecido pelo modelo foi de 7,73 veículos. Nas $3^{\text {as }}, 5^{\text {as }}$ e sábados foram utilizados 9 veículos com taxa de aproveitamento de $90,22 \%$, pois o valor fornecido pelo modelo foi de 8,12 veículos.

O orçamento da coleta convencional foi ultrapassado nos setores $1,6,8,9,15$, $16,16 / 17,17,20,21,23,24$ e 26, conforme ilustra a Figura 32. O maior desvio positivo ocorreu no setor 1 ( $\mathrm{R} \$ 1914,00$ a mais que os $\mathrm{R} \$ 7.584,00$ estabelecidos), e o menor, no setor 6 ( $\mathrm{R} \$ 1,91$ a mais que os $\mathrm{R} \$ 5.788,25$ estabelecidos como meta). Entretanto, houve sobras de orçamento em todos os outros setores (ocorrência de desvios negativos). A maior sobra se deu no setor 10 ( $\mathrm{R} \$ 3.318,67$ a menos que os $\mathrm{R} \$ 8.978,76$ estabelecidos) e a menor, no setor 3 ( $R \$ 49,38$ a menos que os $R \$ 9.031,06$ estabelecidos): 


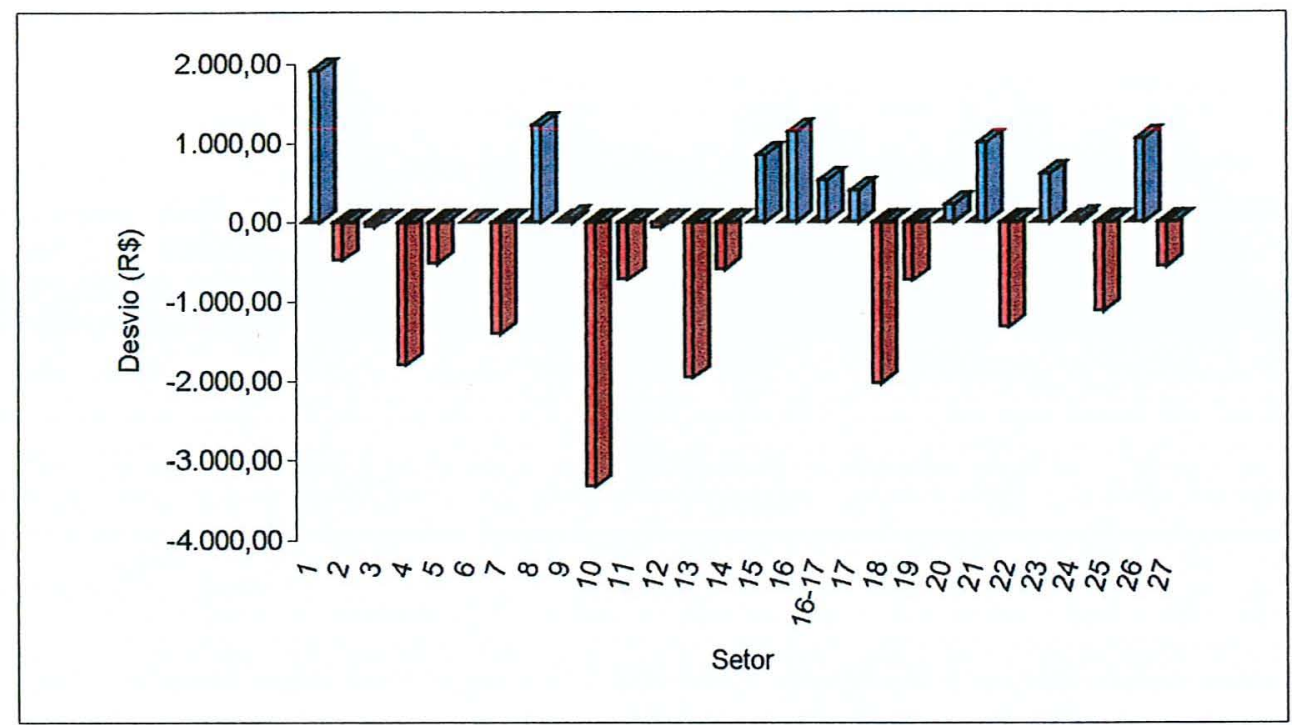

Figura 32 - Variações relacionadas ao orçamento da coleta convencional considerandose a $3^{\mathbf{a}}$ ordenação de prioridades, em Piracicaba - SP, 2000.

O orçamento da coleta seletiva foi ultrapassado em $\mathrm{R} \$ 3.598,69$ (somatória dos desvios positivos $M 6$ ), de acordo com a Figura 33. O maior desvio positivo se deu no setor 2 ( $\mathrm{R} \$ 193,25$ a mais que os $\mathrm{R} \$ 2.201,73$ estabelecidos como meta). Não houve sobras em nenhum dos setores (todos os desvios negativos foram nulos).

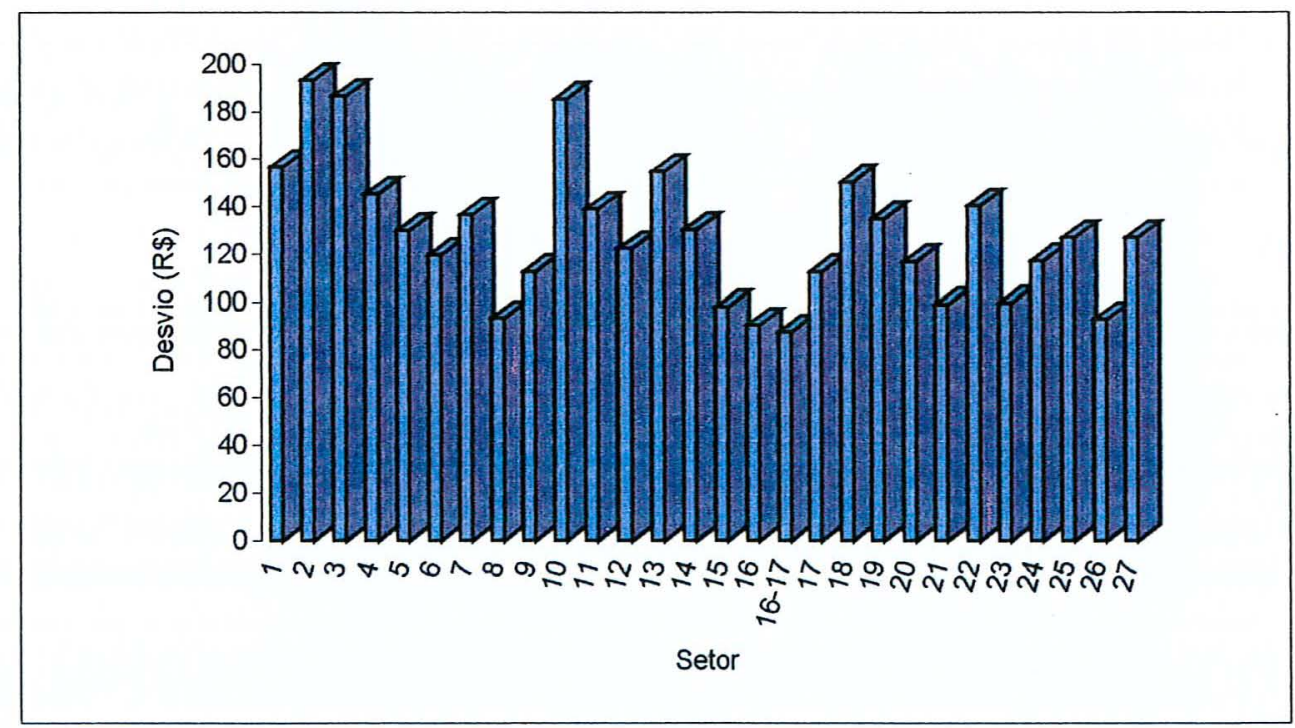

Figura 33 - Variações relacionadas ao orçamento da coleta seletiva considerando-se a $3^{\mathrm{a}}$ ordenação de prioridades, em Piracicaba - SP, 2000. 
A quantidade coletada seletivamente foi alcançada completamente em todos os setores (desvios para $M 7$ iguais a zero).

De acordo com a Figura 34, a somatória dos valores de densidade superiores à média estabelecida foi de 994,88 , correspondente aos desvios positivos para $M 8$ nos setores $2,4,7,13,15,18,21,22,23,25,26$ e 27. A somatória dos valores abaixo da média estabelecida também foi de 994,88 , correspondente aos desvios negativos para M8 em todos os outros setores.

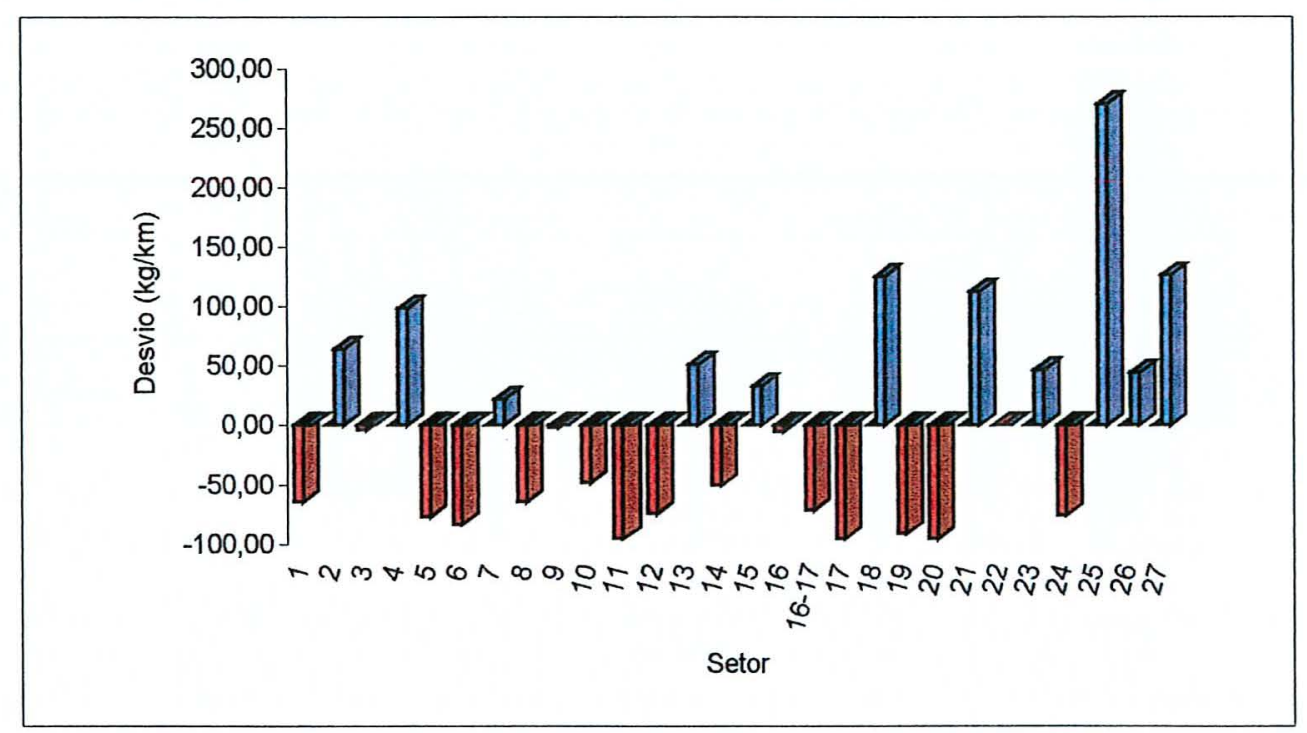

Figura 34 - Variações relacionadas à densidade da coleta convencional considerando-se a $3^{\mathrm{a}}$ ordenação de prioridades, em Piracicaba - SP, 2000.

A produtividade foi de $100 \%$ em todos os setores (desvios para M9 iguais a zero).

\subsection{Comparação dos valores obtidos com a aplicação dos modelos de programação por metas com os valores praticados em Piracicaba - SP em outubro de 2000}

Nas seções seguintes, os resultados de cada simulação serão comparados com os valores praticados em Piracicaba - SP. 


\subsubsection{Quantidades coletadas convencionalmente}

A Tabela 31 mostra os valores reais coletados convencionalmente em Piracicaba, em outubro de 2000, comparando-os com os valores propostos em cada uma das simulações. Em todas as simulações, o valor coletado obtido pelo modelo é menor que o valor coletado em Piracicaba - SP em outubro de 2000. Isso ocorre, pois os valores a serem coletados seletivamente aumentaram de 100 toneladas para 1.000 toneladas por mês, o que diminui a quantidade a ser coletada convencionalmente. Além disso, o valor de outubro é 1,54\% superior ao valor médio, que é o valor considerado no modelo.

$\mathrm{Na} 1^{\mathrm{a}}$ e na $2^{\mathrm{a}}$ ordenações, os valores coletados foram os estabelecidos como meta. Constatou-se que os valores de coleta observados em Piracicaba - SP aproximamse mais dos obtidos nessas formulações.

$\mathrm{Na} 3^{\mathrm{a}}$ ordenação, os valores obtidos foram exatamente iguais aos da produtividade de cada setor. Por exemplo, o setor 1 tem uma equipe com 3 coletores que realizam a coleta 26 dias no mês. Sendo o valor da produtividade igual a 2.900 $\mathrm{kg} /$ coletor/dia, o valor a ser coletado será de $226.200 \mathrm{~kg}$.

No modelo sem prioridades, coletou-se a quantidade possível de acordo com a produtividade máxima de cada setor, pois o modelo considera o alcance de todas as metas ao mesmo tempo. 
Tabela 31. Comparação das quantidades coletadas convencionalmente em Piracicaba SP, em outubro de 2000 , com os valores propostos nas 4 simulações distintas.

\begin{tabular}{cccccc}
\hline Setor & Piracicaba & Sem ordenação & $1^{\text {a } \text { ordenação }}$ & $2^{\text {a } \text { ordenação }}$ & $3^{\text {a } \text { ordenação }}$ \\
\hline 1 & $284.961,96$ & $226.200,00$ & $242.687,93$ & $242.687,93$ & $226.200,00$ \\
2 & $351.780,62$ & $299.594,06$ & $299.594,06$ & $299.594,06$ & $226.200,00$ \\
3 & $339.334,01$ & $259.356,31$ & $288.993,90$ & $288.993,90$ & $226.200,00$ \\
4 & $264.654,32$ & $150.800,00$ & $225.392,92$ & $225.392,92$ & $150.800,00$ \\
5 & $236.485,67$ & $201.403,08$ & $201.403,08$ & $201.403,08$ & $150.800,00$ \\
6 & $217.488,21$ & $185.223,89$ & $185.223,89$ & $185.223,89$ & $150.800,00$ \\
7 & $248.277,20$ & $150.800,00$ & $211.445,34$ & $211.445,34$ & $150.800,00$ \\
8 & $169.667,00$ & $144.496,95$ & $144.496,95$ & $144.496,95$ & $150.800,00$ \\
9 & $205.041,59$ & $152.302,87$ & $174.623,73$ & $174.623,73$ & $150.800,00$ \\
10 & $337.368,75$ & $199.480,38$ & $287.320,19$ & $287.320,19$ & $150.800,00$ \\
11 & $252.862,79$ & $215.350,66$ & $215.350,66$ & $215.350,66$ & $150.800,00$ \\
12 & $222.728,89$ & $189.687,12$ & $189.687,12$ & $189.687,12$ & $150.800,00$ \\
13 & $281.686,53$ & $239.898,41$ & $239.898,41$ & $239.898,41$ & $150.800,00$ \\
14 & $237.140,76$ & $201.960,99$ & $201.960,99$ & $201.960,99$ & $150.800,00$ \\
15 & $178.183,11$ & $150.800,00$ & $151.749,69$ & $151.749,69$ & $150.800,00$ \\
16 & $164.426,32$ & $140.033,72$ & $140.033,72$ & $140.033,72$ & $150.800,00$ \\
$16 / 17$ & $159.185,65$ & $113.100,00$ & $135.570,50$ & $135.570,50$ & $113.100,00$ \\
17 & $205.041,59$ & $167.122,20$ & $174.623,73$ & $174.623,73$ & $150.800,00$ \\
18 & $273.825,51$ & $150.800,00$ & $233.203,57$ & $233.203,57$ & $150.800,00$ \\
19 & $245.656,86$ & $209.213,73$ & $209.213,73$ & $209.213,73$ & $150.800,00$ \\
20 & $212.902,61$ & $181.318,56$ & $181.318,57$ & $181.318,57$ & $150.800,00$ \\
21 & $180.148,36$ & $150.800,00$ & $153.423,40$ & $153.423,40$ & $150.800,00$ \\
22 & $255.483,13$ & $178.728,13$ & $217.582,28$ & $217.582,28$ & $150.800,00$ \\
23 & $181.458,53$ & $150.800,00$ & $154.539,21$ & $154.539,21$ & $150.800,00$ \\
24 & $213.557,70$ & $181.876,47$ & $181.876,47$ & $181.876,47$ & $150.800,00$ \\
25 & $231.244,99$ & $196.939,86$ & $196.939,86$ & $196.939,86$ & $150.800,00$ \\
26 & $169.011,92$ & $143.939,05$ & $143.939,05$ & $143.939,05$ & $150.800,00$ \\
27 & $231.244,99$ & $196.939,86$ & $196.939,86$ & $196.939,86$ & $150.800,00$ \\
\hline & & & & &
\end{tabular}

Fonte: Resultados da pesquisa. 


\subsubsection{Quilometragem percorrida}

A Tabela 32 compara as quilometragens percorridas pelos veículos coletores em cada setor em Piracicaba - SP, em outubro de 2000, com os valores propostos nas quatro simulações.

Em todas as simulações, as quilometragens propostas para os setores 14 e 27 são inferiores às praticadas em Piracicaba - SP. Para os setores 6 e 20, a formulação sem prioridades e a $2^{\mathrm{a}}$ ordenação de prioridades apresentam valores de quilometragem menores que os praticados em Piracicaba - SP. Os setores 21 e 26, para a formulação sem prioridades e para a $1^{\mathrm{a}}$ e a $3^{\mathrm{a}}$ ordenações de prioridades, apresentam valores de quilometragem menores que os valores de Piracicaba - SP. Para o modelo sem prioridades, para a $1^{\mathrm{a}}$ e para a $3^{\mathrm{a}}$ ordenações, o setor 18 apresenta quilometragens inferiores às praticadas em Piracicaba - SP. Para a $3^{\text {a }}$ ordenação, o setor 25 apresenta quilometragem menor que a praticada em Piracicaba - SP nesse setor.

Pôde-se perceber que, em algumas simulações, alguns setores apresentaram valores de quilometragem a ser percorrida maiores que os observados na cidade. Tal fato pode ser explicado pelo motivo de as rotas de coleta realizadas na cidade poderem não abranger todas as ruas de cada setor, o que pode estar acontecendo por dois motivos: ou a coleta não está sendo realizada em todas as vias, ou os caminhões param em determinado ponto e os coletores buscam o lixo das proximidades a pé e o levam para o caminhão que permaneceu estacionado. Como os valores utilizados como metas de quilometragem no modelo incluem todas as ruas de cada setor, esses valores seriam maiores.

Em relação à quilometragem, a formulação sem prioridades foi a que mais se aproximou dos valores praticados em Piracicaba - SP, cabendo à $1^{\text {a }}$ ordenação como sendo a que mais se distanciou dos valores praticados na cidade. 
Tabela 32. Comparação das quilometragens percorridas na coleta convencional em Piracicaba - SP, em outubro de 2000, com os valores propostos nas 4 simulações distintas.

\begin{tabular}{cccccc}
\hline Setor & Piracicaba & Sem ordenação & $1^{\text {a }}$ ordenação & $2^{a}$ ordenação & $3^{\text {a }}$ ordenação \\
\hline 1 & $2.405,00$ & $2.483,44$ & $3.290,56$ & $2.807,76$ & $3.290,56$ \\
2 & $1.989,00$ & $2.485,76$ & $2.485,76$ & $2.808,68$ & $2.146,04$ \\
3 & $2.158,00$ & $2.468,30$ & $2.803,53$ & $2.620,20$ & $2.326,08$ \\
4 & $1.131,00$ & $1.347,71$ & $1.347,71$ & $1.831,93$ & $1.189,80$ \\
5 & $1.352,00$ & $2.172,90$ & $2.172,90$ & $1.931,64$ & $2.172,90$ \\
6 & $2.015,00$ & $2.012,07$ & $2.198,56$ & $1.801,42$ & $2.198,56$ \\
7 & 949,00 & $1.100,74$ & $1.100,74$ & $1.489,62$ & $1.100,74$ \\
8 & $1.469,00$ & $1.701,94$ & $2.117,57$ & $1.707,64$ & $2.117,57$ \\
9 & $1.313,00$ & $1.680,04$ & $1.680,04$ & $1.794,42$ & $1.680,04$ \\
10 & $1.079,00$ & $1.955,59$ & $1.955,59$ & $2.405,70$ & $1.955,59$ \\
11 & $1.872,00$ & $2.442,28$ & $2.553,70$ & $2.205,91$ & $2.610,40$ \\
12 & $1.859,00$ & $2.260,04$ & $2.346,89$ & $2.074,41$ & $2.346,89$ \\
13 & $1.716,00$ & $2.384,75$ & $2.384,75$ & $2.351,98$ & $1.733,73$ \\
14 & $2.236,00$ & $2.076,07$ & $2.076,07$ & $2.189,77$ & $2.076,07$ \\
15 & $1.157,00$ & $1.920,59$ & $1.978,52$ & $1.947,61$ & $1.830,51$ \\
16 & 780,00 & $1.617,17$ & $1.696,24$ & $1.617,17$ & $1.696,24$ \\
$16 / 17$ & 936,00 & $1.343,95$ & $1.674,58$ & $1.459,10$ & $1.674,58$ \\
17 & 858,00 & $1.688,38$ & $2.373,64$ & $1.726,82$ & $2.340,00$ \\
18 & $1.365,00$ & $1.293,30$ & $1.214,49$ & $1.939,12$ & $1.214,49$ \\
19 & $1.365,00$ & $2.021,85$ & $2.165,21$ & $1.856,75$ & $2.233,87$ \\
20 & $2.080,00$ & $1.820,03$ & $2.484,48$ & $1.808,44$ & $2.387,32$ \\
21 & $2.730,00$ & $2.481,67$ & $3.066,15$ & $2.517,26$ & $2.221,15$ \\
22 & $1.469,00$ & $1.768,13$ & $1.768,13$ & $1.967,23$ & $1.624,79$ \\
23 & 871,00 & $1.557,56$ & $1.557,56$ & $1.725,30$ & $1.557,56$ \\
24 & 806,00 & $1.910,60$ & $2.088,63$ & $1.763,98$ & $2.088,63$ \\
25 & 988,00 & $1.581,03$ & $1.581,03$ & $1.476,13$ & 791,08 \\
26 & $1.963,00$ & $1.869,52$ & $2.071,52$ & $1.873,78$ & $1.765,74$ \\
27 & $2.847,00$ & $2.547,82$ & $2.547,82$ & $2.381,97$ & $1.841,81$ \\
\hline & & & & & \\
\end{tabular}

Fonte: Resultados da pesquisa 


\subsubsection{Densidade de coleta}

A Tabela 33 compara as densidades da coleta convencional observadas em cada setor em Piracicaba - SP, em outubro de 2000, com os valores propostos nas quatro simulações.

Em todas as simulações, a densidade média é de $195,15 \mathrm{~kg} / \mathrm{km}$, porém a densidade média em Piracicaba - SP é de 197,04 kg/km. Em relação às densidades de coleta, a $3^{\mathrm{a}}$ ordenação foi a que forneceu valores mais próximos aos observados em Piracicaba, enquanto a $1^{a}$ ordenação apresentou os valores mais distantes dos observados na cidade.

\subsubsection{Orçamento da coleta seletiva e convencional}

A Tabela 34 compara os valores do orçamento destinados às coletas convencional e seletiva em Piracicaba - SP, em outubro de 2000 , com os valores propostos nas quatro ordenações do modelo de Programação por Metas.

Apenas na formulação sem prioridades, os valores de orçamento da coleta convencional propostos pelo modelo são menores que os valores praticados em Piracicaba - SP, em outubro de 2.000. Nas outras formulações, os valores obtidos com o modelo são um pouco maiores que os valores vigentes na cidade.

Os valores para a coleta seletiva de todas as simulações são maiores que os praticados na cidade devido à proposta de um aumento na quantidade coletada de 100 para 1.000 toneladas por mês. 
Tabela 33. Comparação das densidades de coleta na coleta convencional em Piracicaba SP, em outubro de 2000 , com os valores propostos nas 4 simulações distintas.

\begin{tabular}{|c|c|c|c|c|c|}
\hline Setor & Piracicaba & Sem ordenação & $1^{2}$ ordenação & $2^{\mathrm{a}}$ ordenação & $3^{a}$ ordenação \\
\hline 1 & 141,09 & 242,38 & 140,58 & 195,15 & 131,02 \\
\hline 2 & 204,65 & 195,61 & 247,13 & 195,15 & 259,24 \\
\hline 3 & 186,88 & 195,61 & 173,65 & 195,15 & 190,60 \\
\hline 4 & 294,71 & 195,15 & 335,81 & 195,15 & 293,80 \\
\hline 5 & 257,60 & 195,15 & 158,17 & 195,15 & 118,43 \\
\hline 6 & 99,61 & 195,15 & 137,58 & 195,15 & 112,01 \\
\hline 7 & 344,66 & 195,15 & 304,40 & 195,15 & 217,10 \\
\hline 8 & 173,36 & 195,15 & 125,61 & 195,15 & 131,09 \\
\hline 9 & 179,31 & 195,15 & 223,75 & 195,15 & 193,22 \\
\hline 10 & 224,94 & 195,15 & 281,08 & 195,15 & 147,53 \\
\hline 11 & 174,24 & 195,15 & 148,39 & 195,15 & 100,00 \\
\hline 12 & 160,07 & 195,15 & 152,42 & 195,15 & 121,17 \\
\hline 13 & 209,55 & 195,15 & 190,08 & 195,15 & 246,79 \\
\hline 14 & 141,16 & 195,15 & 216,46 & 195,15 & 144,82 \\
\hline 15 & 183,71 & 197,90 & 187,69 & 195,15 & 228,31 \\
\hline 16 & 264,67 & 195,15 & 175,78 & 195,15 & 189,30 \\
\hline $16 / 17$ & 224,86 & 195,15 & 148,95 & 195,15 & 124,26 \\
\hline 17 & 258,64 & 174,65 & 113,27 & 195,15 & 100,00 \\
\hline 18 & 211,81 & 195,15 & 495,79 & 195,15 & 320,60 \\
\hline 19 & 253,33 & 185,96 & 151,55 & 195,15 & 104,06 \\
\hline 20 & 139,88 & 168,43 & 112,96 & 195,15 & 100,00 \\
\hline 21 & 87,00 & 197,90 & 114,92 & 195,15 & 307,71 \\
\hline 22 & 197,17 & 195,15 & 237,57 & 195,15 & 195,21 \\
\hline 23 & 234,18 & 197,90 & 247,60 & 195,15 & 241,61 \\
\hline 24 & 187,10 & 195,15 & 144,73 & 195,15 & 120,00 \\
\hline 25 & 287,24 & 195,15 & 176,78 & 195,15 & 465,26 \\
\hline 26 & 109,54 & 195,15 & 153,89 & 195,15 & 239,54 \\
\hline 27 & 86,07 & 195,15 & 167,61 & 195,15 & 321,53 \\
\hline
\end{tabular}

Fonte: Resultados da pesquisa. 
Tabela 34. Comparação do orçamento da coleta seletiva e convencional em Piracicaba SP, em outubro de 2000 , com os valores propostos nas 4 simulações distintas.

\begin{tabular}{lrrrrr}
\hline Serviço & Piracicaba & Sem ordenação & $1^{\mathrm{a}}$ ordenação & $2^{\mathrm{a}}$ ordenação & $3^{\mathrm{a}}$ ordenação \\
\hline Coleta seletiva & $10.174,32$ & $44.599,32$ & $44.599,32$ & $44.599,32$ & $44.599,32$ \\
Coleta convencional & $128.036,89^{42}$ & $121.007,54$ & $131.826,67$ & $131.826,67$ & $129.380,40$ \\
Destinação final do lixo & $37.435,71$ & $37.435,71$ & $37.435,71$ & $37.435,71$ & $37.435,71$ \\
Total Coleta convencional & & & & & \\
(coleta e destinação final) & $165.472,60$ & $158.443,25$ & $169.262,38$ & $169.262,38$ & $166.816,11$ \\
\hline
\end{tabular}

Fonte: Resultados da pesquisa.

Em Piracicaba - SP, no período da pesquisa, existiam 9 separadores para 100 toneladas mensais de lixo reciclável. Além disso, no quadro de funcionários havia dois ajudantes, uma assistente social, um auxiliar de escritório, um coordenador e um encarregado. Os custos de mão-de-obra somavam R\$ 10.053,87. Além disso, havia o custo de depreciação dos equipamentos. Acredita-se que os equipamentos existentes eram suficientes mesmo com o aumento da coleta, o mesmo acontecendo com relação aos funcionários, excetuando-se os separadores. Proporcionalmente, para 1000 toneladas seriam necessários 90 separadores. Ao comparar esse número com outras cidades, podese acreditar que esteja havendo um exagero de mão-de-obra. Em Uberlândia - MG, por exemplo, segundo a Secretaria do Meio Ambiente ${ }^{43}$, existiam 76 separadores para 3.900 toneladas mensais. Para 1.000 toneladas seriam necessários 20 separadores. Entretanto, as pessoas que trabalham no Centro de Reabilitação em Piracicaba são pessoas portadoras de algum tipo de deficiência física e/ou mental, o que dificulta $o$ trabalho. Na ausência de outros dados foi considerado o número de 90 separadores, por ser um valor proporcional ao único dado disponível (9 separadores para 100 toneladas). $O$ valor da mão-obra seria então de $\mathbf{R} \$ 44.478,87$ e o valor da depreciação dos equipamentos, de $\mathrm{R} \$ 120,45$. O total do orçamento disponível considerado para a coleta seletiva foi de $R \$ 44.599,32$.

\footnotetext{
${ }^{42} \mathrm{O}$ custo da coleta convencional em Piracicaba - SP é de R\$ 131.838,08 mensais. Entretanto, como o "setor de resgate" não fez parte do modelo, considerou-se $3 \frac{1}{2}$ equipes com 3 coletores, o que resultaria num custo de coleta convencional de $\mathrm{R} \$ 128.036,89$.

${ }^{43}$ Comunicação pessoal em 04 de agosto de 2000.
} 
Comparando as simulações com os valores praticados em Piracicaba - SP, percebe-se que, para a coleta convencional, o orçamento que mais se aproxima dos valores de Piracicaba - SP é o referente à $3^{\mathrm{a}}$ ordenação. Em relação à coleta seletiva, a diferença entre os orçamentos é a mesma para as quatro simulações.

\subsubsection{Coleta seletiva}

A Tabela 35 compara as quantidades coletadas seletivamente em Piracicaba SP, em outubro de 2000 , com os valores propostos nas quatro simulações do modelo.

Tabela 35. Comparação das quantidades coletadas seletivamente em Piracicaba - SP, em outubro de 2000 , com os valores propostos nas 4 simulações distintas.

\begin{tabular}{lcccccccc}
\hline $\begin{array}{l}\text { Quantidade coletada } \\
\text { (em kg) }\end{array}$ & Vidro & PET & Alumínio & Ferro & Papelão & Papel & Diversos & Total \\
\hline Piracicaba & $19.010,00$ & $7.986,00$ & $1.122,00$ & $18.320,00$ & $42.945,00$ & $8.192,00$ & $5.709,00$ & $103.284,00$ \\
$\begin{array}{l}\text { Modelo sem } \\
\text { ordenação de } \\
\text { prioridades }\end{array}$ & $197.176,83$ & $116.160,66$ & $8.172,12$ & $64.007,92$ & $209.056,99$ & $244.864,51$ & $160.576,30$ & $1.000 .015,32$ \\
$\begin{array}{l}\text { Modelo da } 1^{\mathrm{a}} \\
\text { ordenação }\end{array}$ & $197.176,83$ & $116.160,66$ & $8.172,12$ & $64.007,92$ & $209.056,99$ & $244.864,51$ & $160.576,30$ & $1.000 .015,32$ \\
$\begin{array}{l}\text { Modelo da } 2^{\mathrm{a}} \\
\text { ordenação }\end{array}$ & $197.176,83$ & $116.160,66$ & $8.172,12$ & $64.007,92$ & $209.056,99$ & $244.864,51$ & $160.576,30$ & $1.000 .015,32$ \\
$\begin{array}{l}\text { Modelo da } 3^{\mathrm{a}} \\
\text { ordenação }\end{array}$ & $197.176,83$ & $116.160,66$ & $8.172,12$ & $64.007,92$ & $209.056,99$ & $244.864,51$ & $160.576,30$ & $1.000 .015,32$ \\
\hline
\end{tabular}

Fonte: Resultados da pesquisa.

Para todas as simulações coletou-se toda a quantidade proposta como meta de coleta seletiva. Essa quantidade é bem superior à quantidade coletada seletivamente em Piracicaba - SP, na época do desenvolvimento do trabalho. 


\subsubsection{Veículos}

A Tabela 36 compara o número de veículos utilizados para a realização da coleta convencional em Piracicaba - SP, em outubro de 2000, com os valores propostos nas quatro simulações do modelo.

Tabela 36. Comparação do número de veículos utilizados na coleta convencional em Piracicaba - SP, em outubro de 2000 , com os valores propostos nas 4 simulações distintas.

\begin{tabular}{lccccc}
\hline Dias da semana & Piracicaba & Sem ordenação & $1^{\text {a }}$ ordenação & $2^{\text {a }}$ ordenação & $3^{\text {a }}$ ordenação \\
\hline $2^{\text {as }}, 4^{\text {as }}, 6^{\text {as }}$ & 10 & 8 & 11 & 11 & 8 \\
$3^{\text {as }}, 5^{\text {as }}$, Sábados & 10 & 9 & 10 & 10 & 9 \\
\hline
\end{tabular}

Fonte: Resultados da pesquisa.

Com relação aos veículos, há 10 deles disponiveis para a coleta em Piracicaba. Além desses, há 2 destinados a emergências. A $1^{\mathrm{a}}$ e a $2^{\mathrm{a}}$ ordenações ultrapassaram o número de 10 veículos nas $2^{\text {as }} 4^{\text {as }}$ e $6^{\text {as }}$. Na $3^{\text {a }}$ ordenação e no modelo sem prioridades houve subutilização de 2 veículos nos dias da semana pares e de um veículo nos dias da semana ímpares.

Em relação à quantidade de veículos utilizados na coleta convencional, a $1^{\mathrm{a}}$ e a $2^{\mathrm{a}}$ ordenações são as que mais se aproximam do observado em Piracicaba - SP.

\subsubsection{Produtividade}

A Tabela 37 compara as produtividades dos coletores em cada setor em Piracicaba - SP, em outubro de 2000 , com os valores de produtividade propostos nas quatro simulações. 
Tabela 37. Comparação da produtividade dos coletores na coleta convencional em Piracicaba - SP, em outubro de 2000 , com os valores propostos nas 4 simulações distintas.

\begin{tabular}{|c|c|c|c|c|c|}
\hline Setor & Piracicaba & Sem ordenação & $1^{\text {a }}$ ordenação & $2^{\mathrm{a}}$ ordenação & $3^{\mathrm{a}}$ ordenação \\
\hline 1 & 126,00 & 100,00 & 107,29 & 107,29 & 100,00 \\
\hline 2 & 156,00 & 100,00 & 132,45 & 132,45 & 100,00 \\
\hline 3 & 150,00 & 100,00 & 127,76 & 127,76 & 100,00 \\
\hline 4 & 176,00 & 100,00 & 149,46 & 149,46 & 100,00 \\
\hline 5 & 157,00 & 100,00 & 133,56 & 133,56 & 100,00 \\
\hline 6 & 144,00 & 100,00 & 122,83 & 122,83 & 100,00 \\
\hline 7 & 165,00 & 100,00 & 140,22 & 140,22 & 100,00 \\
\hline 8 & 113,00 & 95,82 & 95,82 & 95,82 & 100,00 \\
\hline 9 & 136,00 & 100,00 & 115,80 & 115,80 & 100,00 \\
\hline 10 & 224,00 & 100,00 & 190,53 & 190,53 & 100,00 \\
\hline 11 & 168,00 & 100,00 & 142,81 & 142,81 & 100,00 \\
\hline 12 & 148,00 & 100,00 & 125,79 & 125,79 & 100,00 \\
\hline 13 & 187,00 & 100,00 & 159,08 & 159,08 & 100,00 \\
\hline 14 & 157,00 & 133,93 & 133,93 & 133,93 & 100,00 \\
\hline 15 & 118,00 & 100,00 & 100,63 & 100,63 & 100,00 \\
\hline 16 & 109,00 & 92,86 & 92,86 & 92,86 & 100,00 \\
\hline $16 / 17$ & 141,00 & 100,00 & 119,87 & 119,87 & 100,00 \\
\hline 17 & 136,00 & 100,00 & 115,80 & 115,80 & 100,00 \\
\hline 18 & 182,00 & 100,00 & 154,64 & 154,64 & 100,00 \\
\hline 19 & 163,00 & 100,00 & 138,74 & 138,74 & 100,00 \\
\hline 20 & 141,00 & 100,00 & 120,24 & 120,24 & 100,00 \\
\hline 21 & 119,00 & 100,00 & 101,74 & 101,74 & 100,00 \\
\hline 22 & 169,00 & 100,00 & 144,29 & 144,29 & 100,00 \\
\hline 23 & 120,00 & 100,00 & 102,48 & 102,48 & 100,00 \\
\hline 24 & 142,00 & 100,00 & 120,61 & 120,61 & 100,00 \\
\hline 25 & 153,00 & 100,00 & 130,60 & 130,60 & 100,00 \\
\hline 26 & 112,00 & 95,45 & 95,45 & 95,45 & 100,00 \\
\hline 27 & 153,00 & 100,00 & 130,60 & 130,60 & 100,00 \\
\hline
\end{tabular}

Fonte: Resultados da pesquisa. 
A produtividade média em Piracicaba é de $148,75 \%$. Nas duas primeiras ordenações, a produtividade média é de $126,64 \%$. A $3^{\text {a }}$ ordenação tem como primeira meta do modelo as produtividades dos coletores. Dessa maneira, essa formulação apresenta uma produtividade de $100 \%$ para todos os setores. No modelo sem ordenação das prioridades a produtividade foi de $100 \%$ para quase todos os setores, ficando abaixo desse valor para os setores $8(95,82 \%), 16(92,86 \%)$ e $26(95,45 \%)$ e acima desse valor para o setor $14(133,93 \%)$.

Em relação à produtividade, os números da $1^{\mathrm{a}} \mathrm{e}$ da $2^{\mathrm{a}}$ ordenações são os que mais se aproximam dos valores de produtividade praticados em Piracicaba - SP. A $3^{\mathrm{a}}$ ordenação é a que mais se distancia do observado na cidade, o que indica que a estratégia adotada na cidade não se preocupa com o alcance de uma produtividade uniforme entre os coletores. Além disso, a discrepância dos resultados encontrados com esse modelo, em relação à realidade na cidade, pode significar uma superexploração dos coletores, pois sua produtividade na cidade ultrapassa os valores ótimos citados na literatura $(2.900 \mathrm{~kg} /$ coletor $/$ dia $)$.

\subsection{Considerações Finais}

A diversidade das simulações realizadas ilustra como os dados do gerenciamento da coleta de resíduos sólidos urbanos de uma cidade podem ser utilizados para auxiliar a tomada de decisão dos gestores públicos.

Acredita-se que o melhor tipo de modelo seja aquele que considera diferentes ordenações de prioridades a cada uma das metas. Esse modelo apresenta vantagens em relação ao modelo sem prioridades, pois é mais flexível oportunizando ao tomador de decisão enfatizar a variável que for mais importante em cada momento. Ao se trabalhar com modelos sem prioridades, todas as variáveis são consideradas em conjunto, enquanto que no modelo com prioridades, a ordem de importância das variáveis é estabelecida pelo tomador de decisão. Desta maneira, considera-se o modelo com prioridades mais interessante. Entretanto, a ordenação mais adequada dependerá do objetivo pretendido pelo tomador de decisão no período em questão. 
Nas simulações realizadas, percebe-se que, em relação a quantidades coletadas convencionalmente, à quantidade de veículos utilizados e à produtividade de coleta, a estratégia praticada em Piracicaba - SP aproxima-se mais da estratégia incorporada na $1^{\text {a }}$ e na $2^{a}$ ordenações. Já em relação à quilometragem percorrida, a estratégia adotada na cidade aproximou-se mais dos valores obtidos na formulação sem prioridades. Para a densidade e orçamento da coleta convencional, a $3^{\text {a }}$ ordenação foi a que mais se aproximou do que é observado em Piracicaba - SP.

De todas as simulações realizadas, percebe-se que a estratégia praticada em Piracicaba - SP aproxima-se mais das estratégias incorporadas na $1^{\mathrm{a}}$ e na $2^{\mathrm{a}}$ ordenação de prioridades. 


\section{CONCLUSÕES}

O modelo de Programação por Metas desenvolvido e aplicado para a cidade de Piracicaba - SP pode se revelar de grande utilidade para o gerenciamento da coleta de resíduos sólidos urbanos de um município.

É importante ressaltar que a importância do modelo está no fato de se poder utilizar diversas ordenações de prioridades, dependendo do tipo de objetivo que se pretende alcançar.

Ao englobar múltiplos objetivos e tratá-los de acordo com a prioridade de cada um, consegue-se controlar as variáveis consideradas mais importantes pelo gestor público para auxiliá-lo na sua tomada de decisão.

Como foi mostrado no decorrer do trabalho, diversas simulações podem ser realizadas a fim de se verificarem os impactos no gerenciamento da coleta dos resíduos sólidos urbanos em um município. Pode-se alterar o comportamento de algumas variáveis para identificar o seu impacto sobre as outras variáveis, estabelecer ordens de prioridade diferentes às diversas variáveis, assim como definir algumas variáveis como constantes e verificar o impacto dessa ação, entre outras. Caso a meta orçamentária seja prioritária em um determinado ano, o tomador de decisão poderá determinar os valores de todas as outras variáveis de acordo com a restrição orçamentária estabelecida. Sendo assim, provavelmente, uma menor quantidade de residuos seria coletada. $\mathrm{O}$ tomador de decisão deve ficar atento ao trade-off que cada ordenação de prioridades irá originar. No caso do exemplo anterior, se a restrição orçamentária for estabelecida, deverá ser medido o quanto a população estará perdendo por não serem coletados todos os quilogramas de lixo gerados. 
O modelo é útil na tomada de decisão nos níveis tático e operacional, o que confirma a hipótese formulada no início da pesquisa. As características vigentes dos sistemas de gerenciamento da coleta, como por exemplo a divisão de setores existentes e os tipos de veículos utilizados, são consideradas como dadas. Entretanto, apesar de considerar o sistema já estruturado e de tentar otimizar o gerenciamento em um sistema pré-determinado, o modelo não é rígido. Sua flexibilidade está na determinação dos níveis das metas. Durante o desenvolvimento do trabalho, foram sugeridas maneiras distintas de se calcularem as metas, dependendo do tipo de estratégia que será adotada pelo tomador de decisão.

Além disso, ao se utilizar o modelo, podem-se detectar necessidades de mudanças na estrutura do sistema, auxiliando na reestruturação da estratégia. A constatação da necessidade de um redimensionamento dos setores de coleta; a necessidade de reconfiguração da frota utilizada, envolvendo veículos de capacidades diferentes para setores com características distintas, são alguns exemplos de como o modelo tático/operacional pode ser útil para detectar problemas na estratégia adotada.

Considerando-se o que foi exposto, percebe-se que os setores podem estar mal dimensionados. Seria então recomendável o redimensionamento daqueles que não tiveram toda a quantidade estabelecida coletada e que circundam setores que cumpriram essa meta. Tal medida diminuiria não só as defasagens de quantidades coletadas em alguns setores, como também as de produtividade, de densidades, do orçamento disponivel para o setor, entre outras.

A má divisão dos setores leva a uma superexploração da mão-de-obra dos coletores. Duarte (1998) e Anjos (1995) apontam que os coletores devem coletar 2.900 $\mathrm{kg} /$ dia. Entretanto, em Piracicaba, esse valor não foi observado. Para respeitá-lo, seria necessário alocar, em alguns casos, mais que 4 coletores em cada caminhão de coleta, o que se tornaria praticamente inviável em vista do espaço disponível nos caminhões. Esse fato faz com que os coletores trabalhem muito acima da média de produtividade descrita na literatura. Para se respeitar a produtividade de $2.900 \mathrm{~kg} /$ coletor/dia, os setores deveriam ser redimensionados e novas equipes deveriam ser contratadas. 
Acredita-se que a coleta seletiva apresenta um sério problema de produtividade. Por utilizar mão-de-obra de deficientes fisicos/mentais, a produtividade máxima possível não é alcançada, o que leva a um aumento do custo operacional. Entretanto, ocupar os deficientes em um trabalho como este é algo louvável do ponto de vista social.

É preciso também se atentar para a superutilização de veículos. Em nenhuma das simulações foram utilizados mais de 11 veículos, número que, apesar de representar um veículo a mais em relação à meta estabelecida, não ultrapassa o total de veículos disponíveis para a coleta, incluindo a reserva técnica (12 veículos). Caso o número de veículos recomendado ultrapasse o de veículos disponíveis, mais a reserva técnica, a empresa deverá providenciar a compra ou aluguel de outros veículos para que se consiga manter o nível de serviço prestado, o que significará aumento de custos

Em relação à determinação dos valores ótimos para as metas, deve-se salientar que na designação de valores à meta relacionada ao tamanho do percurso a ser realizado pelos veículos coletores, apesar de não se considerar de maneira exata as mãos de direção de cada uma das ruas ou avenidas, bem como a existência de ruas sem saída, atribuiu-se um fator de correção de $40 \%$ para minimizar as distorções que esses problemas podem causar.

Além disso, como já ressaltado anteriormente, o modelo proposto é adequado para os níveis tático e operacional, não sendo, portanto, indicado para a determinação das melhores estratégias a serem adotadas. Por exemplo, no modelo desenvolvido considerou-se como forma de tratamento/processamento/recuperação do lixo, apenas a coleta seletiva de recicláveis, ou seja, o que foi efetivamente observado em Piracicaba SP. Um modelo mais abrangente poderia considerar variáveis, tais como composição química do lixo, características biológicas, teor de matéria orgânica e poder calorífico, buscando auxilio na determinação de métodos ideais de tratamento/processamento/recuperação adequados para cada situação. Variáveis relacionadas a locais disponíveis para a construção de aterros sanitários poderiam também ser relevantes na tomada de decisão em relação ao destino final do lixo. Em uma cidade onde não haja locais disponíveis para a construção de aterros, recomenda-se 
a avaliação de, por exemplo, instalação de incineradores para diminuir a quantidade de lixo a ser aterrada ou, eventualmente, o envio do lixo a municípios vizinhos. 
ANEXOS 


\section{Anexo A - Questionário aplicado em cidades brasileiras visando caracterizar o gerenciamento de resíduos sólidos urbanos nessas cidades}

1. Quanto de resíduos sólidos urbanos é gerado por dia na cidade?

2. Qual é a taxa de geração per capita?

3. Do total de lixo gerado, quanto é coletado?

4. Qual é a freqüência da coleta?

5. Qual é o percurso total realizado diariamente na coleta e transporte do lixo até o processamento e/ou destino final?

6. A coleta atinge toda área urbana do município? Sim ou não?

7. Qual é a composição dos resíduos sólidos urbanos na cidade?

8. Quais são os tipos e respectivas quantidades e capacidades dos veículos envolvidos na coleta e transporte?

9. Como é feita a destinação final do lixo da cidade? (Em aterro sanitário, aterro controlado, lixão, fora do município?). Quantas toneladas são enviadas a cada um dos locais?

10. Especifique a área e respectiva vida útil total e restante de cada local:

11. O lixo da cidade passa por processamento e/ou recuperação? Em caso positivo, qual ou quais?

12. Qual é a capacidade de recepção do incinerador (se houver)?

13. Qual é a capacidade de recepção da usina de reciclagem?

14. Em caso de haver processamento e/ou recuperação, quantas toneladas de lixo "deixam de ir" para o lixão e/ou aterros?

15. Em caso de haver algum tipo de processamento do lixo, após o processamento, quantas toneladas não são aproveitadas e/ou deverão receber destinação final?

16. Caso haja reciclagem quais as quantidades de material reciclável resultante?

17. Em caso de existência de usina de reciclagem e compostagem, quais são as receitas obtidas no processo? 
18. Quanto do orçamento da Prefeitura (em termos relativos e absolutos), se destina aos serviços de limpeza pública como um todo? E quanto vai para o gerenciamento dos resíduos sólidos urbanos? (considerando os serviços de coleta, transporte, processamento, recuperação e destinação final do lixo).

19. Em relação aos gastos, quanto se gasta com os diversos tipos de serviços oferecidos? Observação: Pode-se responder as perguntas abaixo relacionando os gastos com o período (gastos / mês) ou relacionando os gastos com toneladas (gastos / toneladas) ou ainda, se possivel, as duas maneiras.

\section{Por período:}

$\mathrm{R} \$$ /mês com coleta e transporte do lixo urbano

$\mathrm{R} \$$ /mês com incineração do lixo, se houver - manutenção, equipamentos, mão-de-obra, etc (excluir custos dos serviços de limpeza e destinação final)

R\$ /mês com reciclagem do lixo, se houver - manutenção, equipamentos, mão-de-obra, etc (excluir custos dos serviços de limpeza e destinação final)

$\mathrm{R} \$$ /mês com compostagem da matéria orgânica, se houver - manutenção, equipamentos, mão-de-obra, etc (excluir custos dos serviços de limpeza e destinação final)

RS /mês na destinação final do lixo - considerando custos tais como mãode-obra, manutenção, operação, etc.

\section{Por toneladas:}

$\mathrm{R} \$$ /tonelada coletada e transportada do lixo urbano

RS /tonelada reciclada do lixo, incluindo manutenção, equipamentos, mãode-obra, etc (excluir custos dos serviços de limpeza e destinação final)

RS /tonelada que passa pelo processo de compostagem da matéria orgânica, incluindo manutenção, equipamentos, mão-de-obra, etc (excluir custos dos serviços de limpeza e destinação final)

RS /tonelada na destinação final do lixo - considerando custos tais como mão-de-obra, manutenção, operação, etc. 


\section{Anexo B - Demonstração de utilização do software Reducelt}

A Figura 35 ilustra um exemplo de redução potencial na fonte, calculada com o Reducelt. A cidade usada na simulação gera 40.000 toneladas de lixo por ano. Pela figura, percebe-se que as principais fontes de redução são a compostagem (de restos de alimentos e aparas de jardim), a reutilização de roupas, a reciclagem de papel/papelão, a reutilização de paletes de madeira e a reciclagem de toalhas de papel/papelão. $\mathrm{O}$ fator potencial do programa para cada opção de minimização de resíduos é calculado através de uma metodologia descrita no "Source Reduction Program Potencial Manual". O potencial do programa é obtido multiplicando-se a quantidade disponível de resíduos pelo fator potencial do programa em cada categoria.

\begin{tabular}{|c|c|c|c|c|}
\hline \multicolumn{5}{|c|}{ Calculation of Program Potential } \\
\hline \multirow[t]{2}{*}{$\begin{array}{l}\text { Source } \\
\text { Reduction } \\
\text { Option }\end{array}$} & $\begin{array}{l}\text { Waste } \\
\text { Category }\end{array}$ & $\begin{array}{l}\text { Tons of } \\
\text { Waste in } \\
\text { Category }\end{array}$ & $\begin{array}{c}\text { Program } \\
\text { Potential } \\
\text { Factor }\end{array}$ & $\begin{array}{l}\text { Program } \\
\text { Potential }\end{array}$ \\
\hline & & [tons/year] & (\%) & [tons/year] \\
\hline Grasscycling & Yard Trimmings & 6000 & 29,7 & 1740 \\
\hline Home Composting & Food Scraps & 2800 & 26.6 & 728 \\
\hline Home Composting & Yard Trimmings & 4218 & 59.9 & 2489 \\
\hline Clothing Reuse & Dther Waste & 3600 & 8.1 & 288 \\
\hline Office Paper & Paper \& Paperboard & 15600 & 1.6 & 156 \\
\hline Multi-use Pallets & Wood & 2800 & 10,9 & 280 \\
\hline Paper Towel & Paper \& Paperboard & 15600 & 0.3 & 0 \\
\hline \multicolumn{5}{|l|}{ Dther Option } \\
\hline Total & & & & 5681 \\
\hline Help & <Back & & Print & $\mathrm{Next}$ \\
\hline
\end{tabular}

Figura 35 - Cálculo do potencial de minimização dos resíduos sólidos urbanos para uma situação hipotética. 
A Figura 36 destaca os ganhos financeiros provenientes de ações visando reduções nas quantidades de resíduos gerados. As economias são analisadas em termos de impactos nos custos de coleta, impactos nos custos de disposição final, impactos na receita proveniente da reciclagem, impactos na receita proveniente da compostagem e custos do programa para cada categoria.

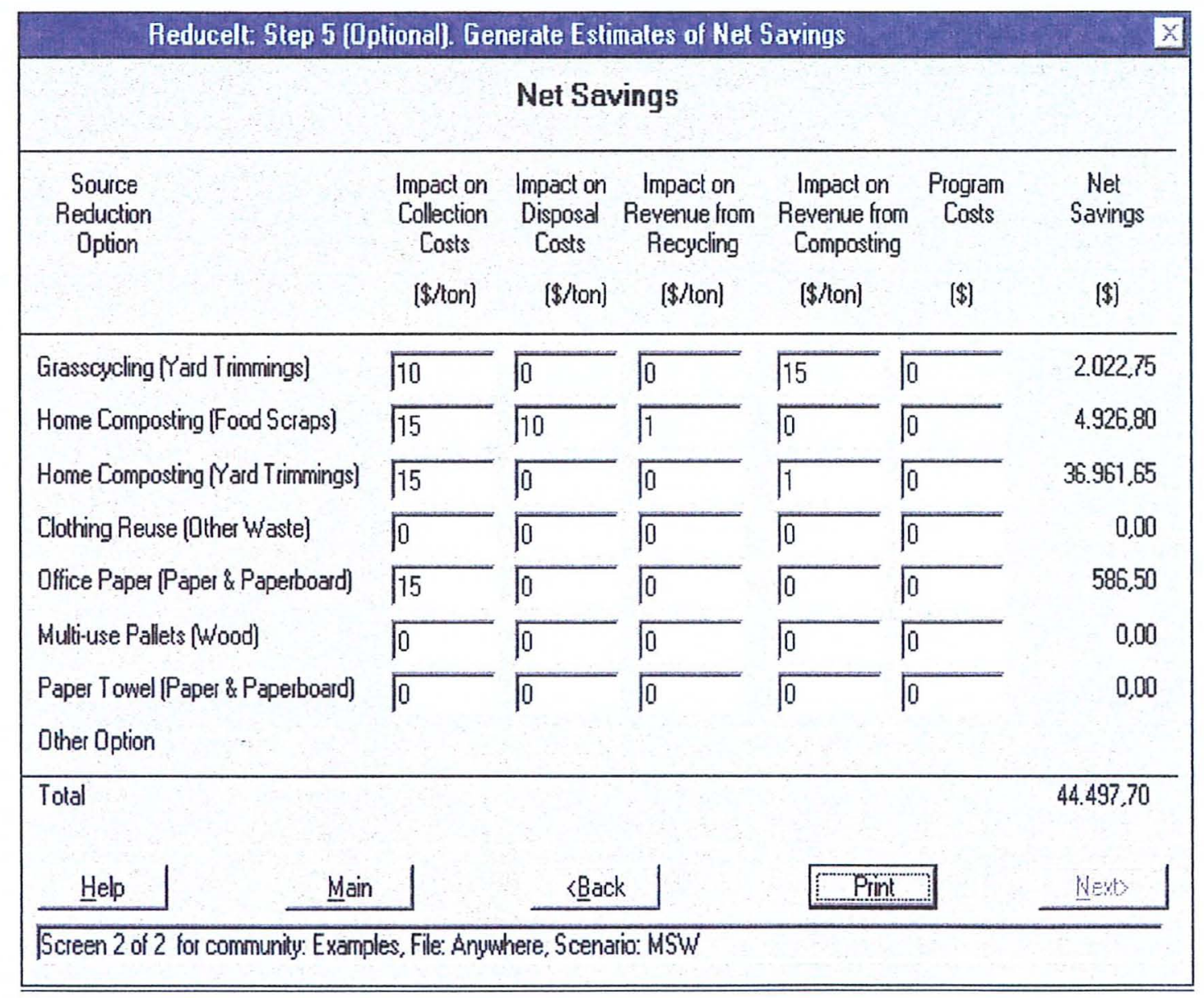

Figura 36 - Ganhos financeiros advindos da minimização dos resíduos sólidos urbanos para uma situação hipotética. 
Anexo $C$ - Tabelas completas de custos das atividades de coleta/transporte, processamento e destinação final dos resíduos sólidos urbanos em Belo Horizonte e Juiz de Fora

Belo Horizonte

\begin{tabular}{lc}
\hline Serviços & $\begin{array}{c}\text { Custo operacional } \\
\text { (em Reais por tonelada) }\end{array}$ \\
\hline Coleta seletiva de produtos recicláveis & $\mathrm{R} \$ 205,83^{44}$ \\
Compostagem & $\mathrm{R} \$ 356,88^{45}$ \\
Coleta e transporte de lixo residencial urbano & $\mathrm{R} \$ 112,55$ \\
Operação do Aterro) & $\mathrm{R} \$ 39,26$ \\
Gastos totais & $\mathrm{R} \$ 7,74$ \\
\hline
\end{tabular}

Fonte: Departamento Municipal de Limpeza Urbana de Belo Horizonte (2000).

Juiz de Fora

\begin{tabular}{cccc}
\hline Serviços & $\begin{array}{c}\text { Custo operacional } \\
\text { (em Reais) }\end{array}$ & $\begin{array}{c}\text { Quantidade } \\
\text { (em toneladas) }\end{array}$ & $\begin{array}{c}\text { Custo operacional } \\
\text { (em Reais por } \\
\text { tonelada) }\end{array}$ \\
\hline Coleta domiciliar & $160.062,99$ & $7.226,21$ & 22,15 \\
Coleta comercial & $10.510,73$ & 587,40 & 17,89 \\
Coleta seletiva & $18.535,15$ & 388,80 & 47,67 \\
Aterro & $29.077,95$ & 7813,61 & 3,72 \\
Usina & $7.775,34$ & 388,80 & 20,00 \\
\hline
\end{tabular}

Fonte: Departamento Municipal de Limpeza Urbana de Juiz de Fora (1998).

${ }^{44}$ Custo de coleta de 1 tonelada de vidro.

${ }^{45}$ Custo de coleta de 1 tonelada de papel ou de metal ou de plástico. 
Anexo D - Os percursos realizados em dois dias de coleta $(04$ e 05 de setembro de 2000) nos diversos setores da cidade de Piracicaba - SP

\begin{tabular}{|lccc|}
\hline Setor 1 - Coleta diária - dia 4 de setembro & Km & Horário & Quantidade \\
Saida & 23620 & $17: 55$ & \\
Av. Carlos Botelho & 23626 & $18: 10$ & \\
Av. Campos Salles & 23639 & $20: 10$ & \\
Balança & 23651 & $20: 42$ & \\
Descarga & 23651 & $20: 45$ & 7360 \\
Rua Dona Eugênia & 23658 & $21: 10$ & \\
Rua do Rosário & 23672 & $23: 00$ & \\
Balança & 23684 & $23: 23$ & \\
Descarga & 23684 & $23: 30$ & 6480 \\
Rua Luiz de Queiroz & 23691 & $23: 50$ & \\
Rua Edu Chaves & 23700 & $01: 15$ & \\
Balança & 23710 & $01: 43$ & \\
Descarga & 23710 & $01: 50$ & 3550 \\
Chegada & 23721 & $02: 15$ & \\
\hline Setor 1 - Coleta diária - dia 5 de setembro & & & \\
Saída & Km & Horário & Quantidade \\
Av. Carlos Botelho & 23893 & $18: 35$ & \\
Rua do Rosário & 23896 & $18: 50$ & \\
Balança & 23923 & $21: 50$ & \\
Descarga & 23935 & $22: 11$ & \\
Rua Luiz de Queiroz & 23935 & $22: 16$ & 6620 \\
Rua Edu Chaves & 23947 & $22: 35$ & \\
Balança & 23952 & $23: 55$ & \\
Descarga & 23962 & $00: 15$ & \\
Chegada & 23962 & $00: 21$ & \\
\hline
\end{tabular}




\begin{tabular}{|lccc|}
\hline Setor 2 - Coleta diária - dia 4 de setembro & Km & Horário & Quantidade \\
Saída & 62045 & $17: 00$ & \\
Rua Santa Cruz & 62048 & $17: 15$ & \\
Rua do Rosário & 62060 & $20: 10$ & \\
Balança & 62068 & $20: 34$ & \\
Descarga & 62068 & $20: 40$ & 7710 \\
Rua do Rosário & 62077 & $21: 00$ & \\
Rua Moraes Barros & 62087 & $22: 40$ & \\
Balança & 62096 & $23: 00$ & \\
Descarga & 62096 & $23: 07$ & 7220 \\
Rua Moraes Barros & 62105 & $23: 35$ & \\
Rua Armando Sales & 62110 & $00: 30$ & \\
Balança & 62118 & $01: 00$ & \\
Descarga & 62118 & $01: 05$ & 5160 \\
Chegada & 62130 & $01: 30$ & \\
\hline Setor 2 - Coleta diária - dia 5 de setembro & & & \\
Saída & 62243 & $17: 00$ & \\
Rua Santa Cruz & 62246 & $17: 15$ & \\
Rua Tiradentes & 62266 & $21: 00$ & \\
Balança & 62276 & $21: 32$ & \\
Descarga & 62276 & $21: 40$ & \\
Rua Tiradentes & 62285 & $21: 55$ & \\
Av. Armando Sales & 62292 & $23: 20$ & \\
Balança & 62300 & $23: 50$ & \\
Descarga & 62300 & $23: 55$ & \\
Chegada & 62311 & $00: 30$ & \\
& & & \\
\hline
\end{tabular}




\begin{tabular}{|lccc|}
\hline Setor 3 - Coleta diária - dia 4 de setembro & $\mathrm{Km}$ & Horário & Quantidade \\
Saída & 61013 & $17: 55$ & \\
São João & 61018 & $18: 05$ & \\
Rua do Rosário & 61028 & $20: 00$ & \\
Balança & 61036 & $20: 20$ & \\
Descarga & 61036 & $20: 24$ & 7250 \\
Rua Riachuelo & 61044 & $20: 35$ & \\
Benjamin Constant & 61058 & $22: 55$ & \\
Balança & 61065 & $23: 12$ & \\
Descarga & 61065 & $23: 18$ & 7390 \\
Av. Paulo de Moraes & 61072 & $23: 25$ & \\
Alferez José Caetano & 61086 & $01: 10$ & \\
Balança & 61093 & $01: 30$ & \\
Descarga & 61093 & $01: 35$ & 5060 \\
Chegada & 61106 & $02: 00$ & \\
\hline & & & \\
\hline Setor 3 - Coleta diária - dia 5 de setembro & Km & Horário & Quantidade \\
Saída & 32905 & $18: 00$ & \\
São João & 32910 & $18: 15$ & \\
Jorge Cury & 32925 & $20: 55$ & \\
Balança & 32933 & $21: 11$ & \\
Descarga & 32933 & $21: 16$ & 6700 \\
Av. Paulo de Moraes & 32940 & $21: 30$ & \\
Alidor Pecorani & 32959 & $23: 45$ & \\
Balança & 32966 & $00: 05$ & \\
Descarga & 32966 & $00: 11$ & 5120 \\
Chegada & 32978 & $00: 40$ & \\
\hline
\end{tabular}




\begin{tabular}{|lccc|}
\hline Setor 4 - Coleta alternada - dia 4 de & Km & Horário & Quantidade \\
setembro & 59682 & $06: 30$ & \\
Saída & 59688 & $06: 42$ & \\
Mercado Municipal & 59701 & $09: 20$ & \\
Rua Capivari & 59708 & $09: 34$ & \\
Balança & 59708 & $09: 42$ & 8810 \\
Descarga & 59715 & $09: 55$ & \\
Av. Capuava & 59727 & $12: 15$ & \\
Av. Dona Jane Conceição & 59734 & $12: 31$ & \\
Balança & 59734 & $12: 38$ & 8550 \\
Descarga & 59741 & $12: 50$ & \\
Rua Santos & 59753 & $15: 00$ & \\
Rua Bogotá & 59762 & $15: 22$ & \\
Balança & 59762 & $15: 27$ & 8280 \\
Descarga & 59769 & $15: 42$ & \\
Chegada & & & \\
\hline Setor 5 - Coleta alternada - dia 04 de & & & \\
setembro & Km & Horário & Quantidade \\
Saída & 11684 & $06: 40$ & \\
Novo Horizonte & 11689 & $07: 00$ & \\
Balança & 11707 & $09: 28$ & \\
Descarga & 11707 & $09: 40$ & 8950 \\
Estrada Lixo & 11709 & $09: 45$ & \\
São Jorge & 11741 & $12: 45$ & \\
Balança & 11745 & $13: 01$ & \\
Descarga & 11745 & $13: 13$ & 9040 \\
São José & 11749 & $13: 30$ & \\
Algodoal & 11769 & $15: 55$ & \\
Balança & 11780 & $16: 23$ & \\
Descarga & 11780 & $16: 31$ & \\
Chegada & 11788 & $16: 50$ & \\
\hline
\end{tabular}




\begin{tabular}{|c|c|c|c|}
\hline $\begin{array}{l}\text { Setor } 6 \text { - Coleta alternada - dia } 4 \text { de } \\
\text { setembro }\end{array}$ & $\mathrm{Km}$ & Horário & Quantidade \\
\hline Saída & 63004 & $06: 30$ & \\
\hline Bairro Ipanema & 63008 & $06: 35$ & \\
\hline Sol Nacente & 63020 & $08: 25$ & \\
\hline Balança & 63031 & $08: 55$ & \\
\hline Descarga & 63031 & $09: 00$ & 7520 \\
\hline Sol Nacente & 63042 & $09: 15$ & \\
\hline Bairro Auto Pompéia & 63054 & $10: 50$ & \\
\hline Balança & 63064 & $11: 18$ & \\
\hline Descarga & 63064 & $11: 23$ & 7920 \\
\hline Bairro Chapadão & 63077 & $11: 40$ & \\
\hline Escola Agrícola & 63139 & $16: 15$ & \\
\hline Descarga & 63149 & $16: 54$ & 7190 \\
\hline Balança & 63149 & $16: 58$ & \\
\hline Chegada & 63159 & $17: 05$ & \\
\hline $\begin{array}{l}\text { Setor } 7 \text { - Coleta alternada - dia } 4 \text { de } \\
\text { setembro }\end{array}$ & $\mathrm{Km}$ & Horário & Quantidade \\
\hline Saída & 61972 & $06: 45$ & \\
\hline Av. Raposo Tavares & 61983 & $07: 20$ & \\
\hline Vila Antunes & 61991 & 09:00 & \\
\hline Balança & 61995 & $09: 19$ & \\
\hline Descarga & 61995 & $09: 25$ & 8010 \\
\hline Jardim Monte Cristo & 62000 & $09: 40$ & \\
\hline Jardim Tabuão & 62011 & $11: 50$ & \\
\hline Balança & 62014 & $12: 04$ & \\
\hline Descarga & 62014 & $12: 08$ & 8570 \\
\hline Jardim Glória & 62018 & $12: 20$ & \\
\hline Jardim Tóquio & 62035 & $15: 10$ & \\
\hline Balança & 62039 & $15: 26$ & \\
\hline Descarga & 62039 & $15: 35$ & 8580 \\
\hline Chegada & 62045 & $15: 45$ & \\
\hline
\end{tabular}




\begin{tabular}{|c|c|c|c|}
\hline $\begin{array}{l}\text { Setor } 8 \text { - Coleta alternada - dia } 4 \text { de } \\
\text { setembro }\end{array}$ & $\mathrm{Km}$ & Horário & Quantidade \\
\hline Saida & 11788 & $17: 50$ & \\
\hline Av.. Ar. Césare Dedini & 11795 & 18:05 & \\
\hline Rua Joana Darc & 11812 & 19:55 & \\
\hline Balança & 11822 & 20:16 & \\
\hline Descarga & 11822 & $20: 22$ & 5540 \\
\hline Av. Bambuta & 11833 & $20: 35$ & \\
\hline Floriano Garnau & 11845 & $22: 20$ & \\
\hline Balança & 11856 & $22: 42$ & \\
\hline Descarga & 11856 & $22: 53$ & 6970 \\
\hline Cristo Redentor & 11866 & $23: 15$ & \\
\hline Silva Jardim & 11880 & 01:50 & \\
\hline Balança & 11895 & 02:05 & \\
\hline Descarga & 11895 & 02:15 & 7080 \\
\hline Chegada & 11901 & $02: 40$ & \\
\hline $\begin{array}{l}\text { Setor } 9 \text { - Coleta alternada - dia } 4 \text { de } \\
\text { setembro }\end{array}$ & $\mathrm{Km}$ & Horário & Quantidade \\
\hline Saída & 59769 & $17: 50$ & \\
\hline Av. Juscelino Kubitschek & 59779 & 18:10 & \\
\hline Av. Manoel Conceição & 59796 & $20: 45$ & \\
\hline Balança & 59808 & $21: 10$ & \\
\hline Descarga & 59808 & $21: 15$ & 9470 \\
\hline Av. Manoel Conceição & 59827 & $21: 35$ & \\
\hline Av. Presidente Kennedy & 59842 & $23: 30$ & \\
\hline Balança & 59852 & $00: 10$ & \\
\hline Descarga & 59852 & $00: 17$ & 8640 \\
\hline Chegada & 59870 & $00: 59$ & \\
\hline
\end{tabular}




\begin{tabular}{|lccc|}
\hline Setor 10 - Coleta alternada - dia 4 de & Km & Horário & Quantidade \\
setembro & 22720 & $17: 55$ & \\
Saída & 22727 & $18: 15$ & \\
Av. Cansaço de Souza & 22741 & $21: 00$ & \\
Av. Manoel Conceição & 22752 & $21: 25$ & \\
Balança & 22752 & $21: 35$ & 10520 \\
Descarga & 22763 & $21: 55$ & \\
Av. Doutor Elálio & 22773 & $23: 40$ & \\
Rua Ana Meri & 22785 & $00: 05$ & \\
Balança & 22785 & $00: 15$ & 8150 \\
Descarga & 22803 & $00: 55$ & \\
Chegada & & & \\
\hline Setor 11 - Coleta alternada - dia 4 de & & & \\
setembro & Km & Horário & \\
Saida & 32594 & $06: 45$ & \\
Bairro Areião & 32601 & $07: 00$ & \\
Bairro Industrial & 32624 & $09: 50$ & \\
Balança & 32638 & $10: 22$ & \\
Descarga & 32638 & $10: 30$ & \\
Bairro Industrial & 32650 & $10: 50$ & \\
Bairro Industrial & 32672 & $14: 10$ & \\
Balança & 32688 & $14: 46$ & \\
Descarga & 32688 & $14: 54$ & \\
Bairro Industrial & 32702 & $13: 13$ & \\
Bairro Algodoal & 32720 & $17: 30$ & \\
Balança & 32732 & $17: 55$ & \\
Descarga & 32732 & $18: 00$ & \\
Chegada & 32738 & $18: 15$ & \\
\hline
\end{tabular}




\begin{tabular}{|c|c|c|c|}
\hline $\begin{array}{l}\text { Setor } 12 \text { - Coleta alternada - dia } 5 \text { de } \\
\text { setembro }\end{array}$ & $\mathrm{Km}$ & Horário & Quantidade \\
\hline Saída & 61106 & $06: 35$ & \\
\hline Cecap I & 61121 & $06: 55$ & \\
\hline Eldorado I & 61134 & $08: 55$ & \\
\hline Balança & 61148 & $09: 26$ & \\
\hline Descarga & 61148 & $09: 32$ & 8240 \\
\hline Eldorado I & 61166 & $10: 30$ & \\
\hline Taquaral & 61175 & $12: 00$ & \\
\hline Balança & 61191 & $12: 28$ & \\
\hline Descarga & 61191 & $12: 34$ & 5970 \\
\hline São Francisco & 61208 & $13: 00$ & \\
\hline Paulicéia & 61235 & $16: 15$ & \\
\hline Balança & 61243 & $16: 44$ & \\
\hline Descarga & 61243 & $16: 48$ & 8680 \\
\hline Chegada & 61249 & $17: 10$ & \\
\hline $\begin{array}{l}\text { Setor } 13 \text { - Coleta alternada - dia } 4 \text { de } \\
\text { setembro }\end{array}$ & $\mathrm{Km}$ & Horário & Quantidade \\
\hline Saída & 23488 & $06: 40$ & \\
\hline Rua José Abílio & 23500 & $07: 05$ & \\
\hline Rua Manoel De Barros Ferraz & 23515 & $09: 35$ & \\
\hline Balança & 23530 & $10: 13$ & \\
\hline Descarga & 23530 & $10: 18$ & 8410 \\
\hline Rua Manoel De Barros Ferraz & 23545 & $10: 50$ & \\
\hline Rua Ricardo Melato & 23557 & $13: 05$ & \\
\hline Balança & 23571 & $13: 42$ & \\
\hline Descarga & 23571 & $13: 50$ & 9390 \\
\hline Parque Olanga & 23586 & $14: 20$ & \\
\hline Rua Nossa Senhora do Carmo & 23600 & $16: 25$ & \\
\hline Balança & 23614 & $17: 00$ & \\
\hline Descarga & 23614 & $17: 10$ & 9860 \\
\hline Chegada & 23620 & $17: 30$ & \\
\hline
\end{tabular}




\begin{tabular}{|c|c|c|c|}
\hline $\begin{array}{l}\text { Setor } 14 \text { - Coleta alternada - dia } 5 \text { de } \\
\text { setembro }\end{array}$ & $\mathrm{Km}$ & Horário & Quantidade \\
\hline Saída & 23721 & $06: 35$ & \\
\hline Mercado Municipal & 23726 & $06: 50$ & \\
\hline Rua 20 Boa Esperança & 23792 & 10:35 & \\
\hline Balança & 23799 & $11: 12$ & \\
\hline Descarga & 23799 & $11: 19$ & 8310 \\
\hline Rua 21 Boa Esperança & 23815 & $11: 52$ & \\
\hline Rua Café Filho & 23827 & $13: 46$ & \\
\hline Balança & 23843 & $14: 20$ & \\
\hline Descarga & 23843 & $14: 27$ & 8480 \\
\hline Rua Café Filho & 23859 & $15: 00$ & \\
\hline Rua da Alegria & 23871 & $17: 25$ & \\
\hline Balança & 23887 & $17: 58$ & \\
\hline Descarga & 23887 & 18:05 & 7490 \\
\hline Chegada & 23893 & $18: 25$ & \\
\hline $\begin{array}{l}\text { Setor } 15 \text { - Coleta alternada - dia } 5 \text { de } \\
\text { setembro }\end{array}$ & $\mathrm{Km}$ & Horário & Quantidade \\
\hline Saída & 60089 & $18: 30$ & \\
\hline Av. Juscelino Kubitschek & 60095 & $18: 40$ & \\
\hline Rua Campos Sales & 60108 & $20: 50$ & \\
\hline Balança & 60123 & $21: 22$ & \\
\hline Descarga & 60123 & $21: 27$ & 9120 \\
\hline Rua Samuel Neves & 60138 & $21: 55$ & \\
\hline Rua Saldanha Marinho & 60150 & $00: 35$ & \\
\hline Balança & 60165 & 01:05 & \\
\hline Descarga & 60165 & $01: 08$ & 7230 \\
\hline Chegada & 60178 & $01: 30$ & \\
\hline
\end{tabular}




\begin{tabular}{|lccc|}
\hline Setor 16 - Coleta alternada - dia 5 de & Km & Horário & Quantidade \\
setembro & 22926 & $19: 00$ & \\
Saída & 22930 & $19: 15$ & \\
Av. André Pendência & 22940 & $21: 00$ & \\
Av. Alberto Volet Sachs & 22951 & $22: 00$ & \\
Balança & 22951 & $22: 12$ & 9600 \\
Descarga & 22962 & $22: 35$ & \\
Rua Casimiro de Abreu & 22969 & $00: 05$ & \\
Av. Alberto Volet Sachs & 22980 & $0: 20$ & \\
Balança & 22980 & $0: 25$ & 6280 \\
Descarga & 22986 & $0: 35$ & \\
Chegada & & & \\
\hline
\end{tabular}

Setor 16/17 - Coleta alternada - dia 5 de setembro

Saída

\begin{tabular}{ccc} 
Km & Horário & Quantidade \\
63159 & $17: 50$ & \\
63167 & $18: 10$ & \\
63184 & $21: 45$ & \\
63193 & $23: 05$ & \\
63193 & $23: 10$ & 8110 \\
63203 & $23: 25$ & \\
63215 & $01: 00$ & \\
63224 & $01: 21$ & \\
63224 & $01: 30$ & 8080 \\
63231 & $01: 50$ & \\
\hline
\end{tabular}

Av. Barão de Valência

Av. Luciano Guidotti

Balança

Descarga

Av. Luciano Guidotti

Rua Visconde do Rio Branco

Balança

Descarga

Chegada

Setor 17 - Coleta alternada - dia 5 de setembro

Saída

Av. Alberto Volet Sachs

Rua General Góis Monteiro

Balança

Descarga

Rua Ragik

Rua Gomes Carneiro

Balança

Descarga
$\mathrm{Km}$

12634

12638

12648

12658

12658

12668

12684

12694

12694

12700
Horário

18:30

18:50

21:20

21:43

22:35

22:50

01:10

01:37

01:50

02:05
Quantidade

Chegada 


\begin{tabular}{|c|c|c|c|}
\hline $\begin{array}{l}\text { Setor } 18 \text { - Coleta alternada - dia } 5 \mathrm{de} \\
\text { setembro }\end{array}$ & $\mathrm{Km}$ & Horário & Quantidade \\
\hline Saída & 32800 & $06: 40$ & \\
\hline Bairro Serra Verde - Av. 1 & 32810 & & \\
\hline Av. Luciano Guidotti & 32825 & 09:34 & \\
\hline Balança & 32835 & 09:58 & \\
\hline Descarga & 32835 & 10:08 & 7300 \\
\hline Bairro Chico & 32841 & $10: 25$ & \\
\hline Rua Fernando Lopes & 32864 & $13: 30$ & \\
\hline Balança & 32874 & $13: 49$ & \\
\hline Descarga & 32874 & $13: 55$ & 7130 \\
\hline Rua Fernando Lopes & 32879 & $14: 10$ & \\
\hline Av. São Paulo & 32893 & $16: 25$ & \\
\hline Balança & 32899 & $16: 53$ & \\
\hline Descarga & 32899 & $16: 59$ & 7810 \\
\hline Chegada & 32905 & $17: 10$ & \\
\hline $\begin{array}{l}\text { Setor } 19 \text { - Coleta alternada - dia } 5 \text { de } \\
\text { setembro }\end{array}$ & $\mathrm{Km}$ & Horário & Quantidade \\
\hline Saida & 22821 & $06: 50$ & \\
\hline Av. Rio das Pedras & 22827 & $07: 05$ & \\
\hline Rua Argentina & 22843 & $10: 20$ & \\
\hline Balança & 22855 & $10: 51$ & \\
\hline Descarga & 22855 & 10:58 & 9830 \\
\hline Rua Equador & 22867 & $11: 20$ & \\
\hline Rua Antônio Arruda & 22881 & $14: 30$ & \\
\hline Balança & 22890 & $14: 56$ & \\
\hline Descarga & 22890 & $15: 00$ & 8690 \\
\hline Rua Domingos Rodrigues & 22900 & $15: 30$ & \\
\hline Av. Luciano Guidotti & 22913 & $18: 15$ & \\
\hline Balança & 22920 & $18: 32$ & \\
\hline Descarga & 22920 & $18: 38$ & 8080 \\
\hline Chegada & 22926 & 19:00 & \\
\hline
\end{tabular}




\begin{tabular}{|c|c|c|c|}
\hline $\begin{array}{l}\text { Setor } 20 \text { - Coleta alternada - dia } 5 \text { de } \\
\text { setembro }\end{array}$ & $\mathrm{Km}$ & Horário & Quantidade \\
\hline Saída & 64213 & $06: 30$ & \\
\hline Av. Bruno Ferraioli & 64217 & $06: 45$ & \\
\hline Rua Clara Nunes & 64230 & 08:50 & \\
\hline Balança & 64240 & $09: 11$ & \\
\hline Descarga & 64240 & $09: 16$ & 8130 \\
\hline Rua Luiz Camulesi & 64253 & 09:50 & \\
\hline Av. Sidney Luiz Brajon & 64263 & $11: 25$ & \\
\hline Balança & 64273 & $11: 40$ & \\
\hline Descarga & 64273 & $11: 47$ & 6740 \\
\hline Rua dos Falcões & 64286 & $12: 15$ & \\
\hline Bairro Monte Alegre & 64344 & $16: 50$ & \\
\hline Balança & 64366 & $17: 35$ & \\
\hline Descarga & 64366 & $17: 40$ & 7510 \\
\hline Chegada & 64373 & 18:00 & \\
\hline $\begin{array}{l}\text { Setor } 21 \text { - Coleta alternada - dia } 5 \text { de } \\
\text { setembro }\end{array}$ & $\mathrm{Km}$ & Horário & Quantidade \\
\hline Saída & 61819 & $06: 40$ & \\
\hline Rua Jardim Brasília & 61826 & $06: 55$ & \\
\hline Rua Jardim Aparete & 61858 & 10:05 & \\
\hline Balança & 61879 & $10: 29$ & \\
\hline Descarga & 61879 & $10: 32$ & 7060 \\
\hline Rua Antônio N. Coelho & 61901 & $11: 05$ & \\
\hline Chácara Modelo & 61934 & $14: 18$ & \\
\hline Balança & 61956 & $14: 49$ & \\
\hline Descarga & 61956 & $14: 53$ & 6510 \\
\hline B. Jardim Bartira & 61981 & $15: 30$ & \\
\hline B. Parque Peória & 61995 & 17:05 & \\
\hline Balança & 62022 & $17: 50$ & \\
\hline Descarga & 62022 & 18:00 & 4700 \\
\hline Chegada & 62029 & 18:09 & \\
\hline
\end{tabular}




\begin{tabular}{|lccc|}
\hline Setor 22 - Coleta alternada - dia 5 de & Km & Horário & Quantidade \\
setembro & 62130 & $06: 45$ & \\
Saída & 62135 & $07: 00$ & \\
Novas Vaz Colinas & 62145 & $08: 30$ & \\
Petrópolis & 62157 & $09: 05$ & \\
Balança & 62157 & $09: 09$ & 7380 \\
Descarga & 62169 & $09: 40$ & \\
Rua Antônio Calar & 62177 & $11: 10$ & \\
Morumbi & 62189 & $11: 39$ & \\
Balança & 62189 & $11: 44$ & 7310 \\
Descarga & 62201 & $12: 10$ & \\
Av. Dois Córregos & 62230 & $15: 10$ & \\
Av. Fernando Lopes & 62237 & $15: 34$ & \\
Balança & 62237 & $15: 43$ & 7590 \\
Descarga & 62243 & $16: 00$ & \\
Chegada & & & \\
\hline & & & \\
Setor 23 - Coleta alternada - dia 5 de & Km & Horário & Quantidade \\
setembro & 13670 & $18: 00$ & \\
Saída & 13678 & $18: 25$ & \\
Av. São João & 13687 & $20: 50$ & \\
Av. Independência & 13698 & $21: 15$ & \\
Balança & 13698 & $21: 24$ & 8490 \\
Descarga & 13709 & $21: 45$ & \\
Silva Jardim & 13718 & $00: 05$ & \\
Regente Feijó & 13730 & $00: 30$ & \\
Balança & 13730 & $00: 37$ & 7200 \\
Descarga & 13737 & $01: 00$ & \\
Chegada & & & \\
& & & \\
\hline
\end{tabular}




\begin{tabular}{|c|c|c|c|}
\hline \multicolumn{3}{|l|}{$\begin{array}{l}\text { Setor } 24 \text { - Coleta alternada - dia } 4 \text { de } \\
\text { setembro }\end{array}$} & \multirow[t]{2}{*}{ Quantidade } \\
\hline Saída & 32738 & $18: 30$ & \\
\hline Voluntários & 32743 & $18: 45$ & \multirow{7}{*}{7520} \\
\hline Av. Independência & 32752 & $21: 00$ & \\
\hline Balança & 32762 & $23: 20$ & \\
\hline Descarga & 32762 & $23: 55$ & \\
\hline Tuquilino Pacheco & 32711 & $00: 20$ & \\
\hline Dom Pedro I & 32778 & $01: 40$ & \\
\hline Balança & 32788 & $02: 10$ & \\
\hline Descarga & 32788 & $02: 17$ & \multirow[t]{2}{*}{4080} \\
\hline Chegada & 32800 & $02: 40$ & \\
\hline $\begin{array}{l}\text { Setor } 25 \text { - Coleta alternada - dia } 4 \text { de } \\
\text { setembro }\end{array}$ & $\mathrm{Km}$ & Horário & \multirow[t]{3}{*}{ Quantidade } \\
\hline Saída & 22643 & $06: 50$ & \\
\hline Rua Marilia (J. Monte Líbano) & 22645 & 07:00 & \\
\hline Rua Estore Galesi (J. Paraíso) & 22660 & $10: 00$ & \multirow{8}{*}{10820} \\
\hline Balança & 22667 & $10: 19$ & \\
\hline Descarga & 22667 & $10: 28$ & \\
\hline Rua Senador Saraiva & 22672 & $10: 45$ & \\
\hline Estrada do Aterro & 22710 & $15: 35$ & \\
\hline Balança & 22712 & $15: 41$ & \\
\hline Descarga & 22712 & $15: 48$ & \\
\hline Chegada & 22719 & $16: 10$ & \\
\hline \multicolumn{4}{|l|}{ Setor 26 - Coleta alternada - dia 4 de } \\
\hline Saída & 60862 & $06: 45$ & Quantidade \\
\hline B. Primavera & 60873 & $07: 00$ & \multirow{7}{*}{8190} \\
\hline B. Vila Fátima & 60889 & $09: 20$ & \\
\hline Balança & 60906 & $09: 51$ & \\
\hline Descarga & 60906 & $10: 00$ & \\
\hline Chácara Santo André & 60923 & $10: 30$ & \\
\hline B. Algodoal & 60994 & $15: 00$ & \\
\hline Balança & 61006 & $15: 24$ & \\
\hline Descarga & 61006 & $15: 28$ & \multirow[t]{2}{*}{8350} \\
\hline Chegada & 61013 & $15: 45$ & \\
\hline
\end{tabular}




\begin{tabular}{|lccc|}
\hline Setor 27 - Coleta alternada - dia 5 de & Km & Horário & Quantidade \\
setembro & 59870 & $06: 30$ & \\
Saída & 59885 & $07: 00$ & \\
Rua Ricardo Meloto & 59946 & $11: 05$ & \\
Rua Guaratim Dueta & 59964 & $11: 38$ & \\
Balança & 59964 & $11: 43$ & 7430 \\
Descarga & 59991 & $12: 15$ & \\
Ártemis & 60018 & $15: 00$ & \\
Rua Angatuba & 60037 & $15: 31$ & \\
Balança & 60037 & $15: 41$ & 7780 \\
Descarga & 60057 & $16: 10$ & \\
Rua Indiana & 60065 & $17: 25$ & \\
Rua da Alegria & 60082 & $17: 52$ & \\
Balança & 60082 & $18: 00$ & 3640 \\
Descarga & 60089 & $18: 25$ & \\
Chegada & & & \\
\hline
\end{tabular}




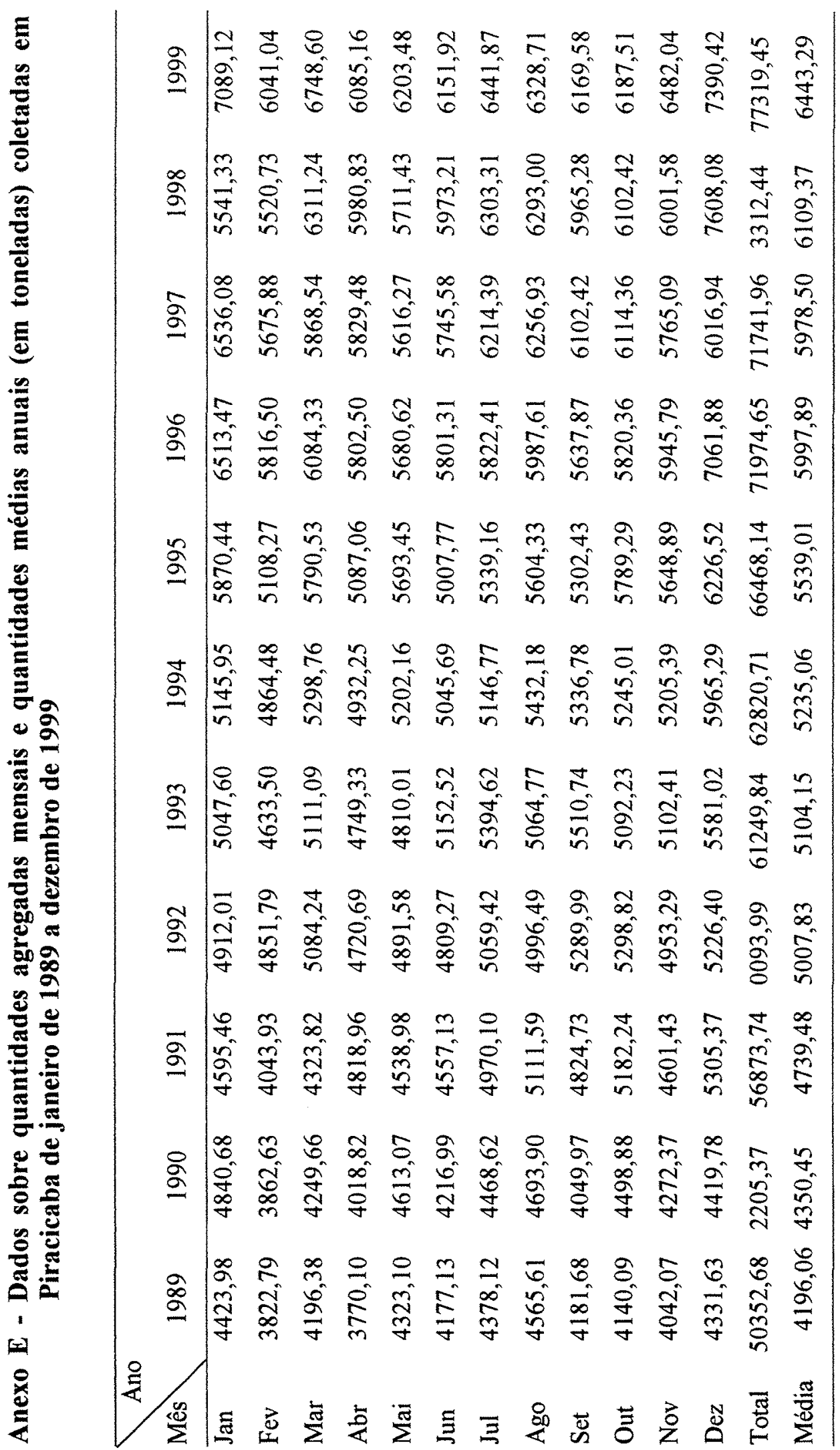




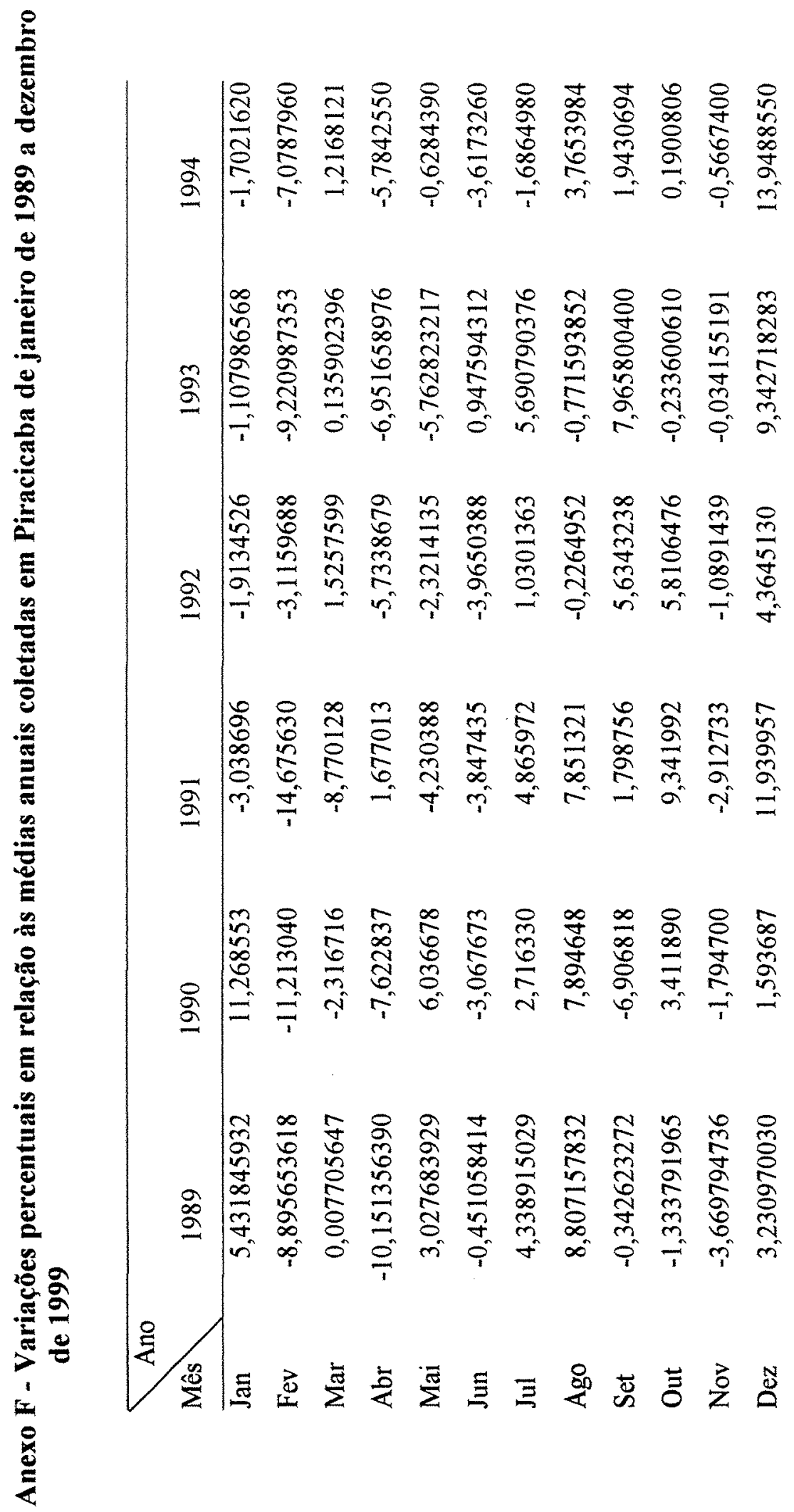




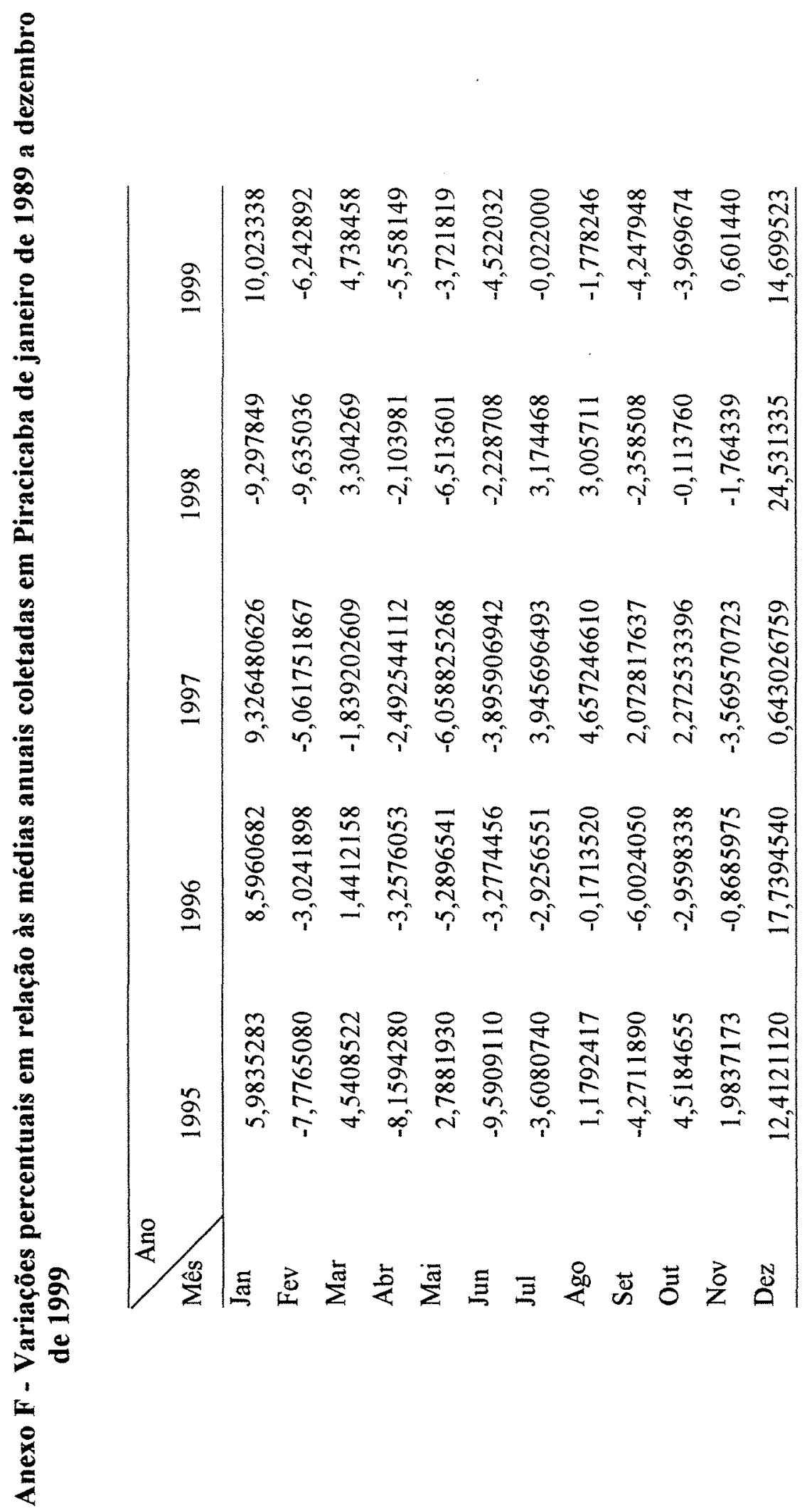




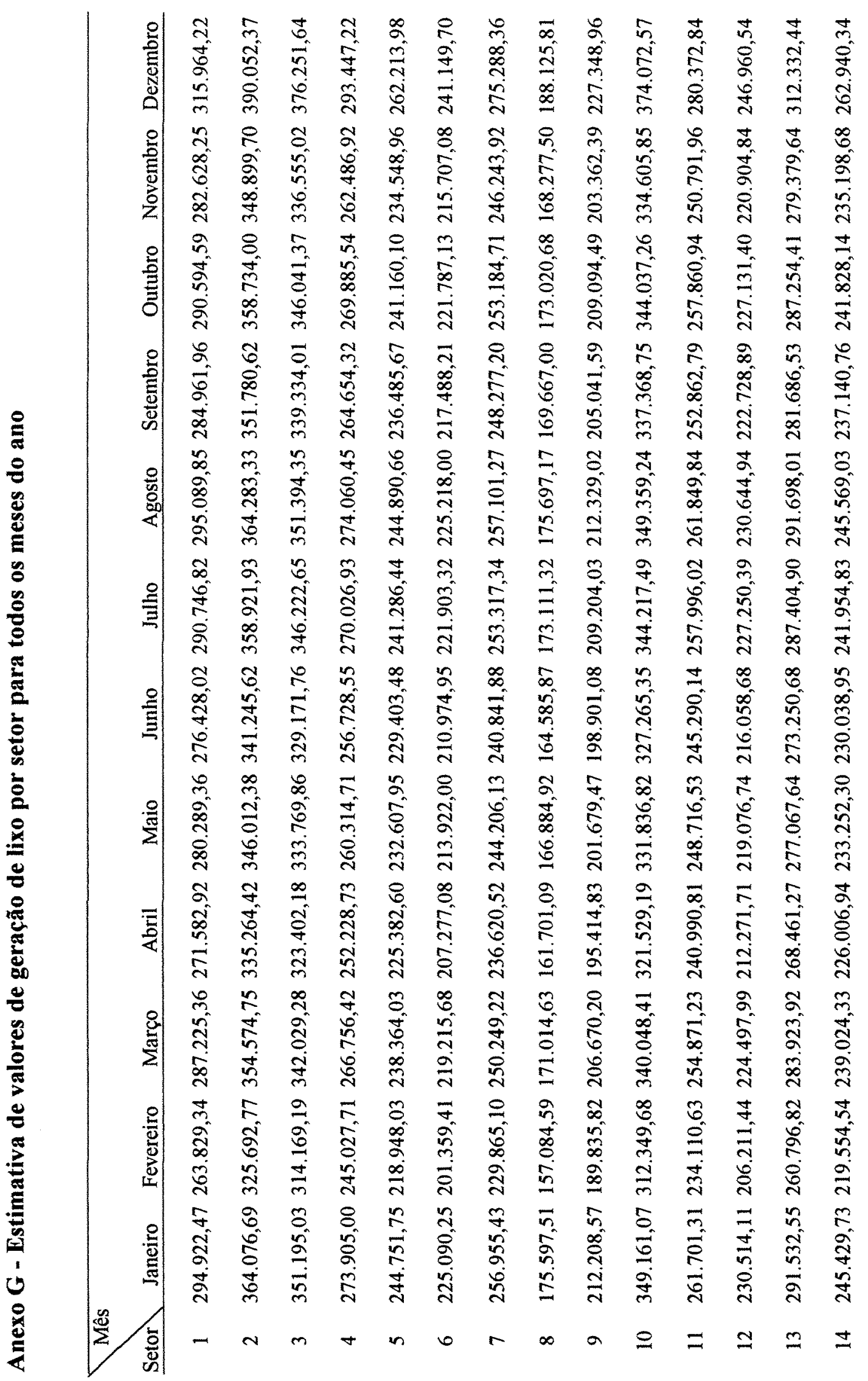




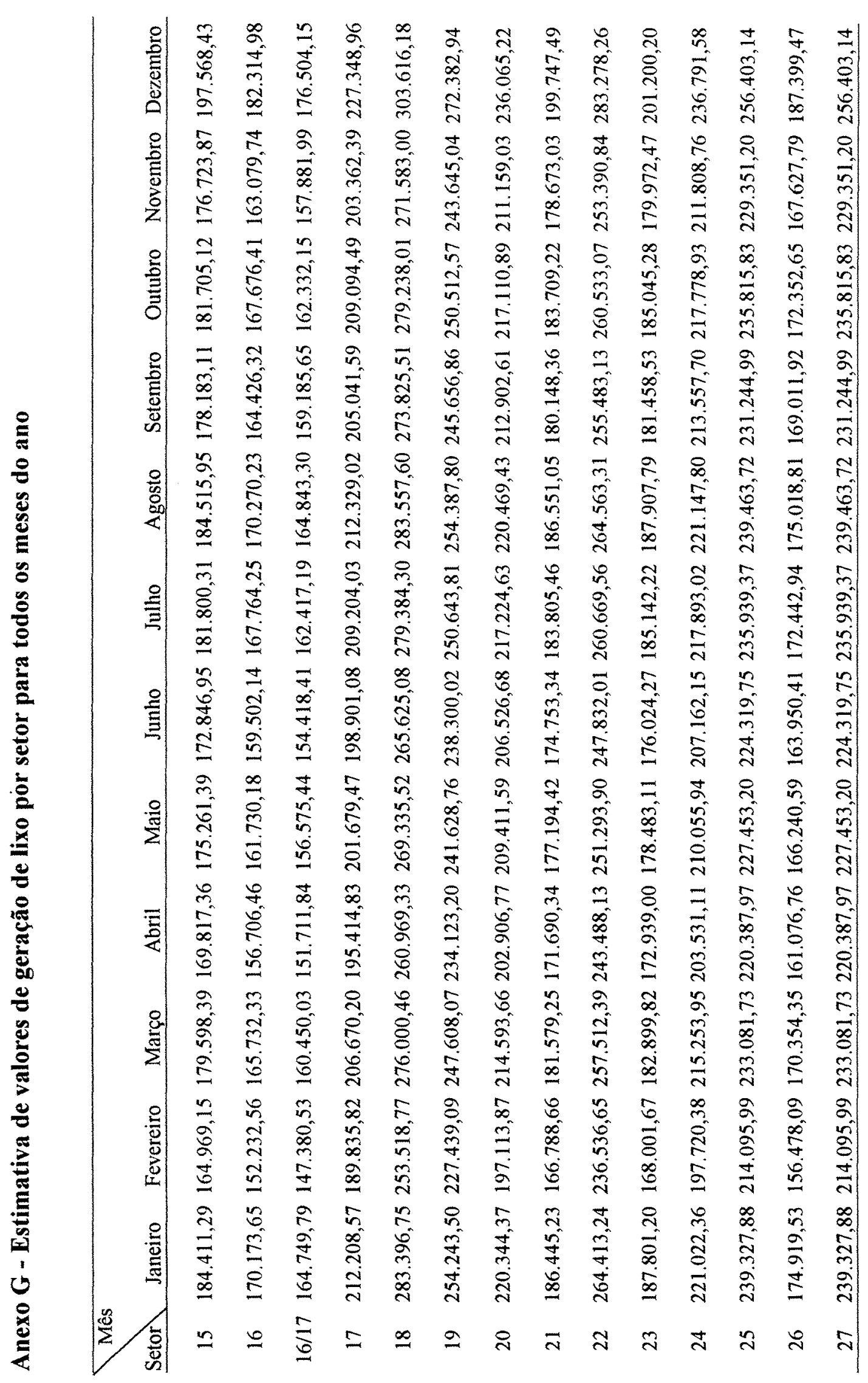


Anexo H - Mapas e perímetros dos setores de coleta, em Piracicaba - SP

\section{$\underline{\text { Setor } 1}$}

Escala 1:15000 Perímetro $-30,24 \mathrm{~km}$

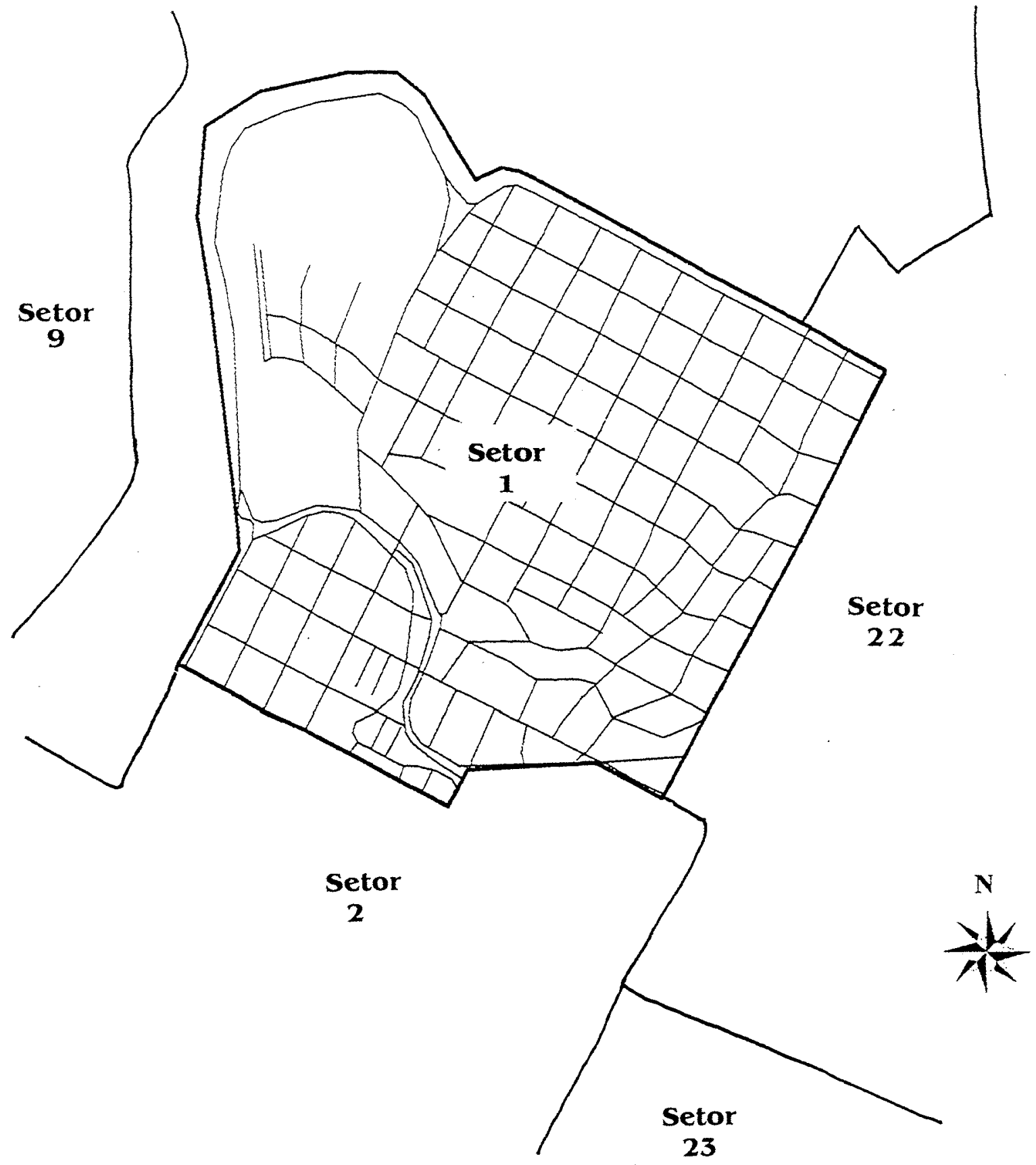


$\underline{\text { Setor } 2}$

Escala 1:15000 Perímetro $-19,31 \mathrm{~km}$

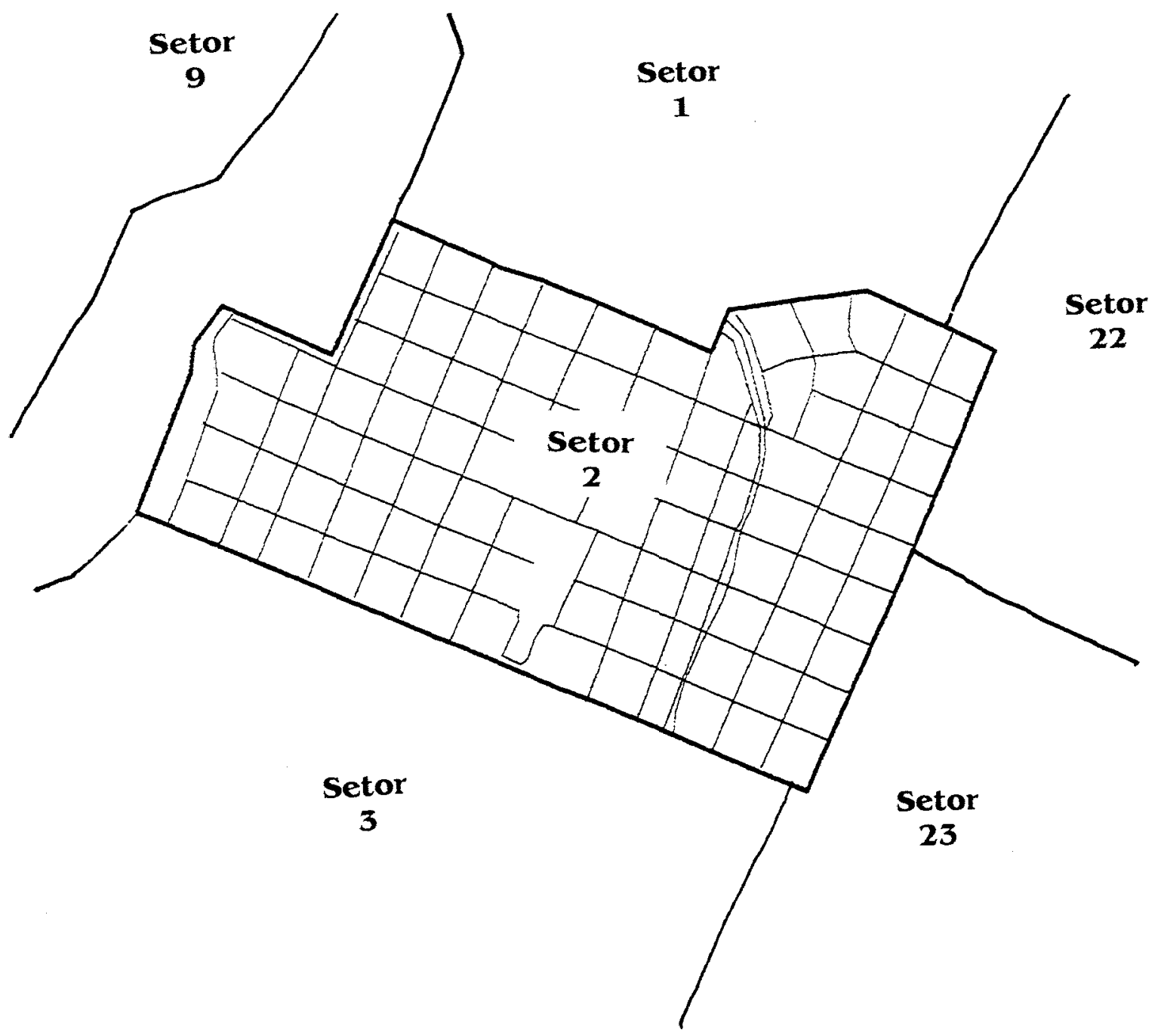


Setor 3

Escala 1:15000

Perimetro $-33,20 \mathrm{~km}$

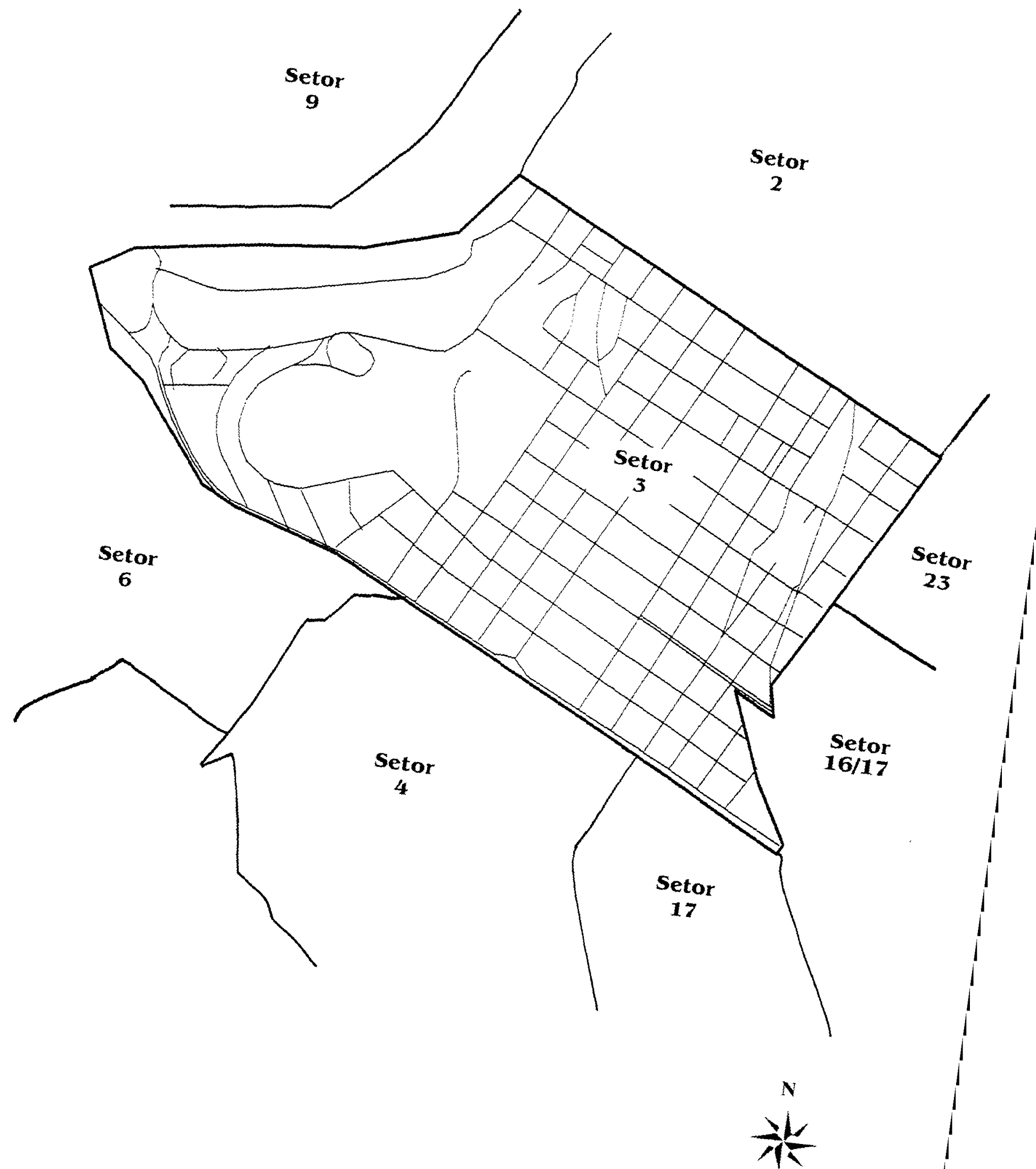


Setor 4

Escala 1:15000 Perímetro-22,01 km

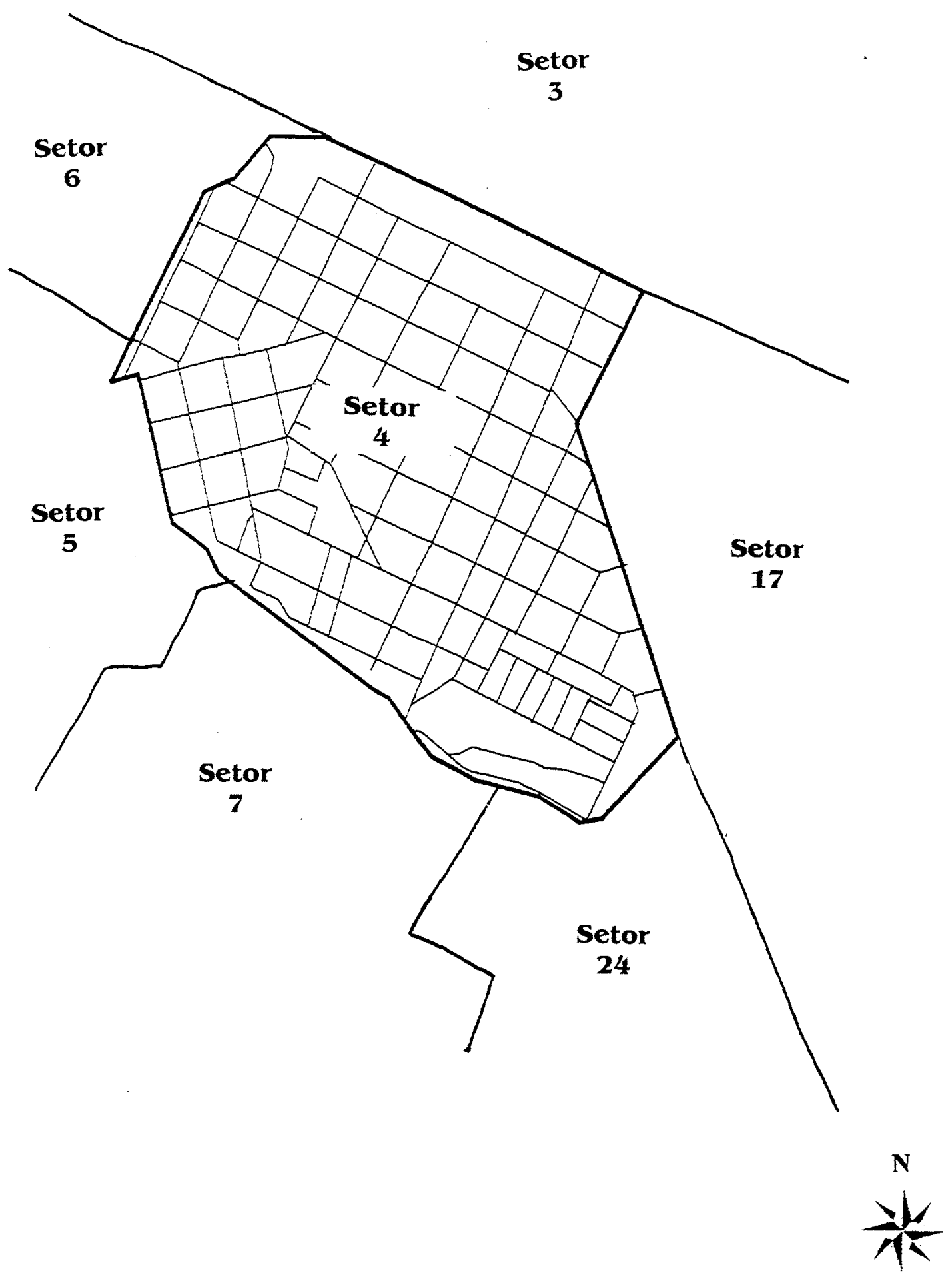




\section{$\underline{\text { Setor } 5}$}

Escala 1:38000 Perimetro - 50,19 km

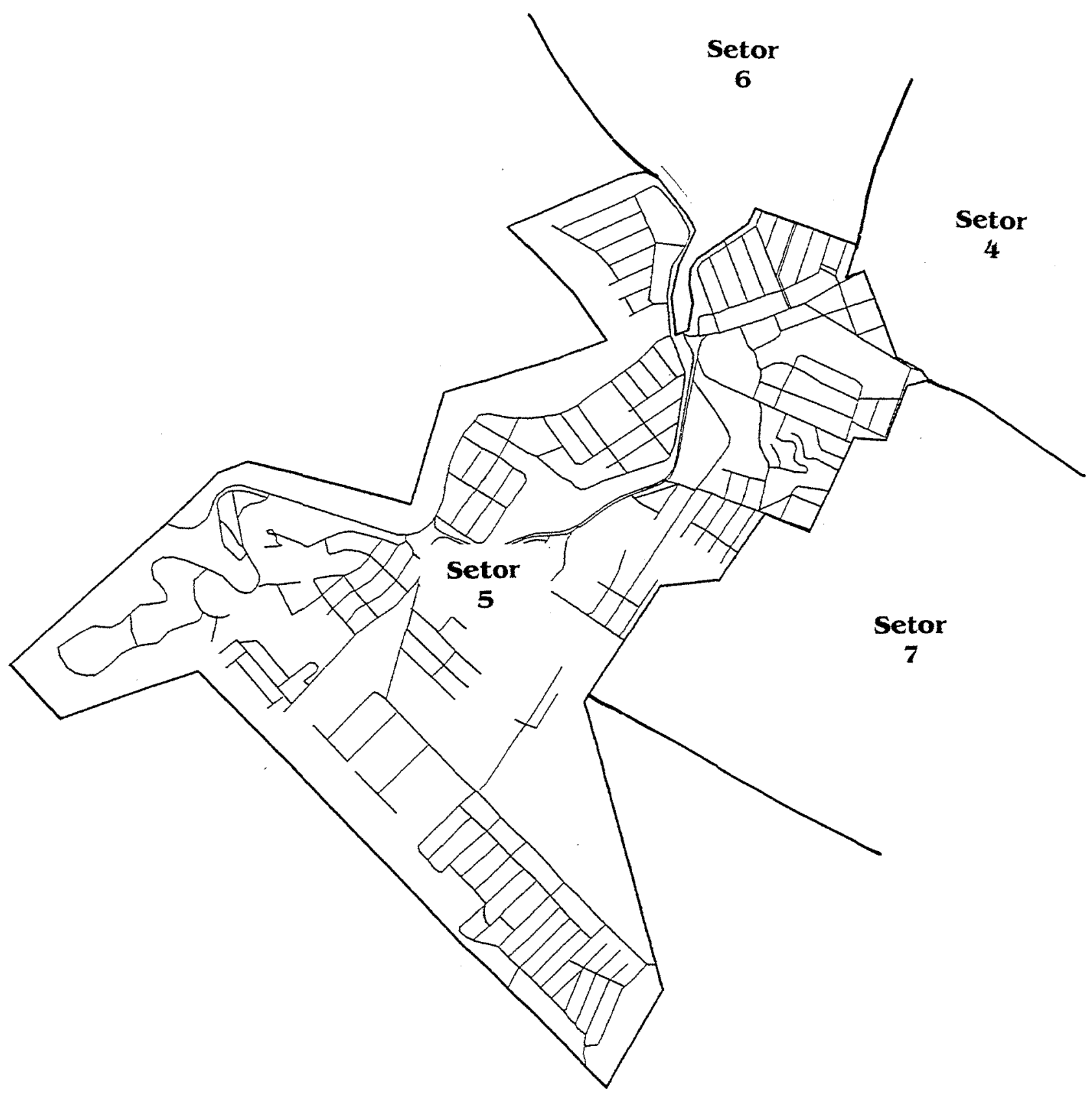


Setor 6

Escala 1:60000 Perímetro $-55,24 \mathrm{~km}$

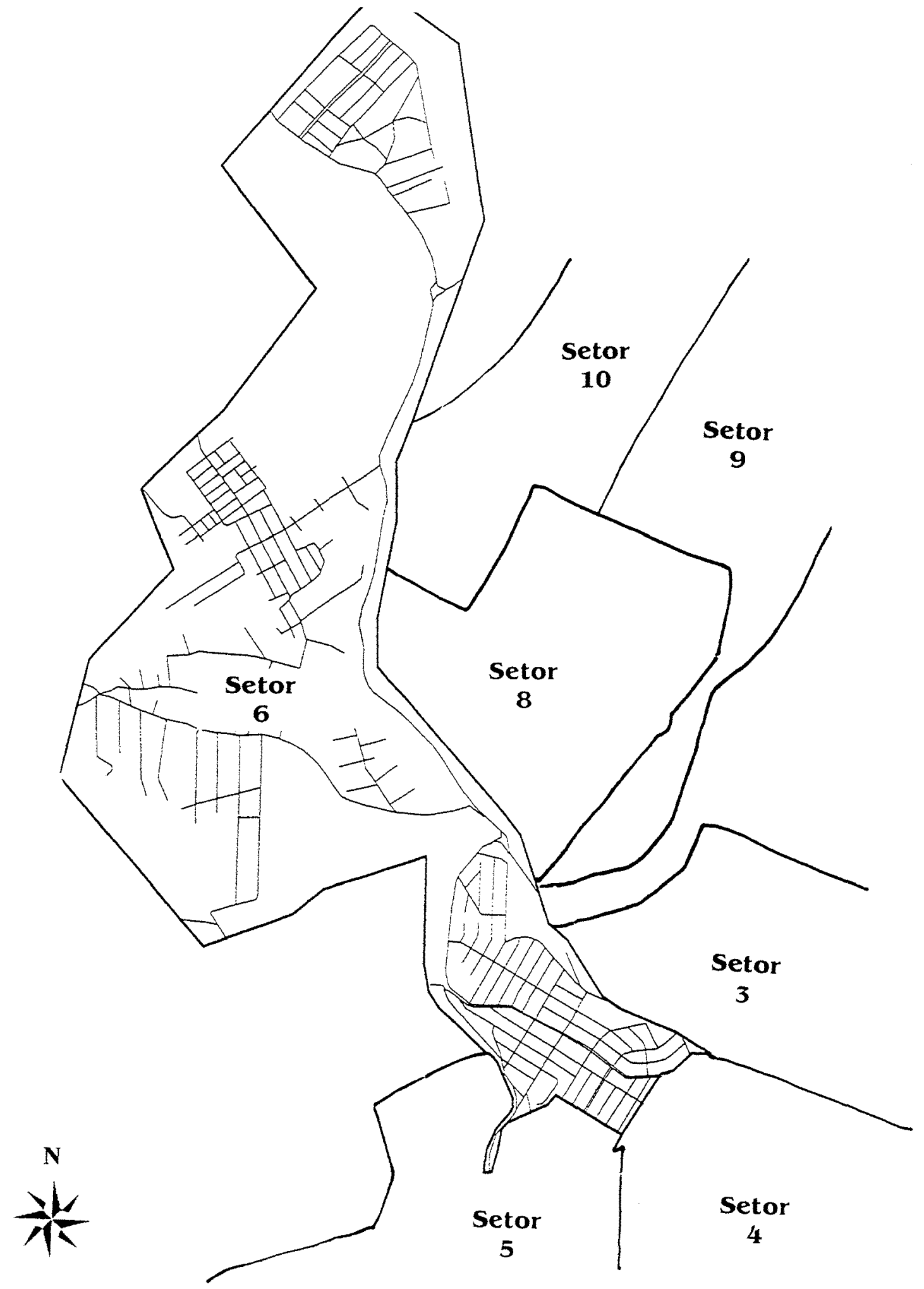




\section{Setor 7}

Escala 1:15000 Perímetro-29,24 km

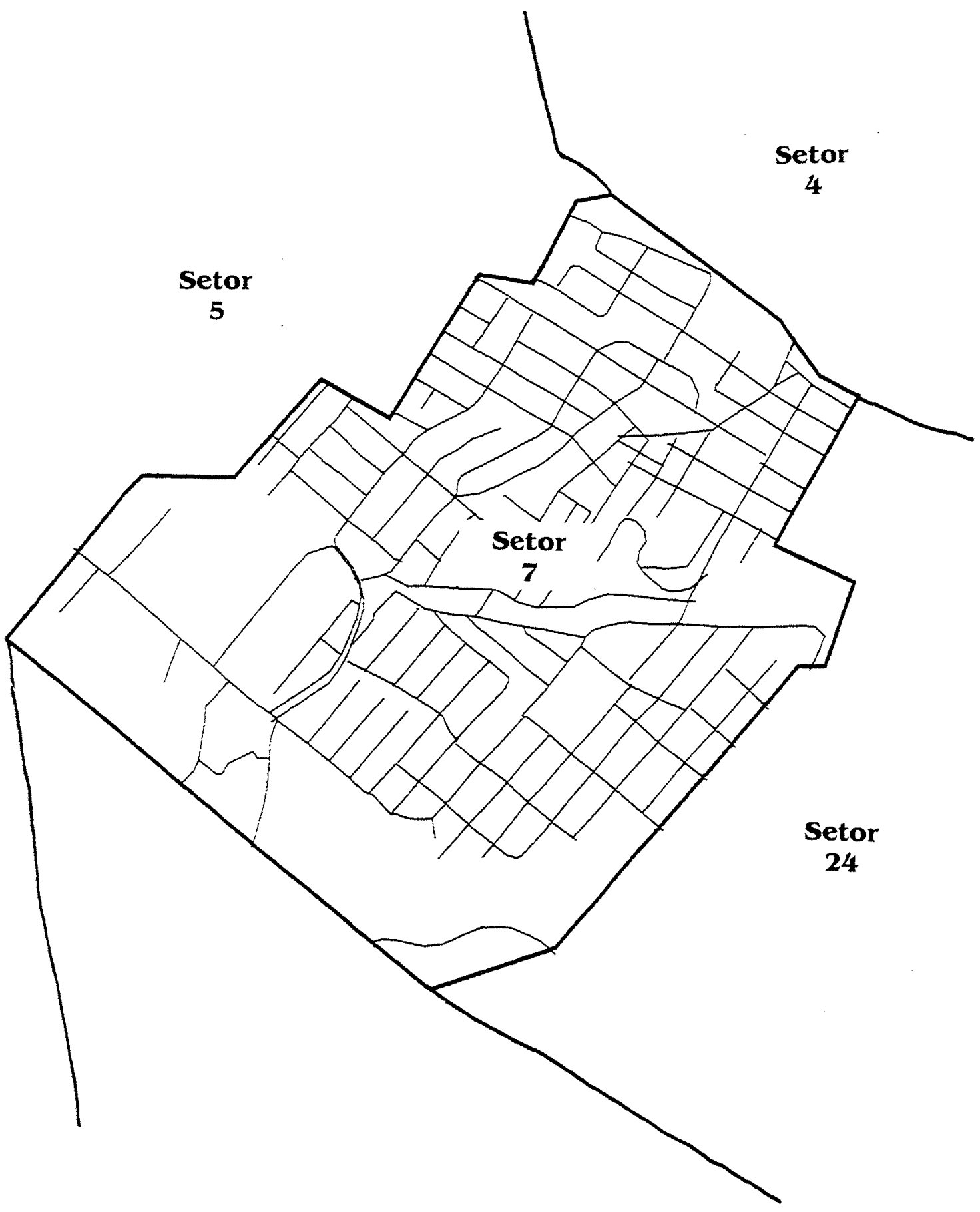


Setor 8

Escala 1:15000

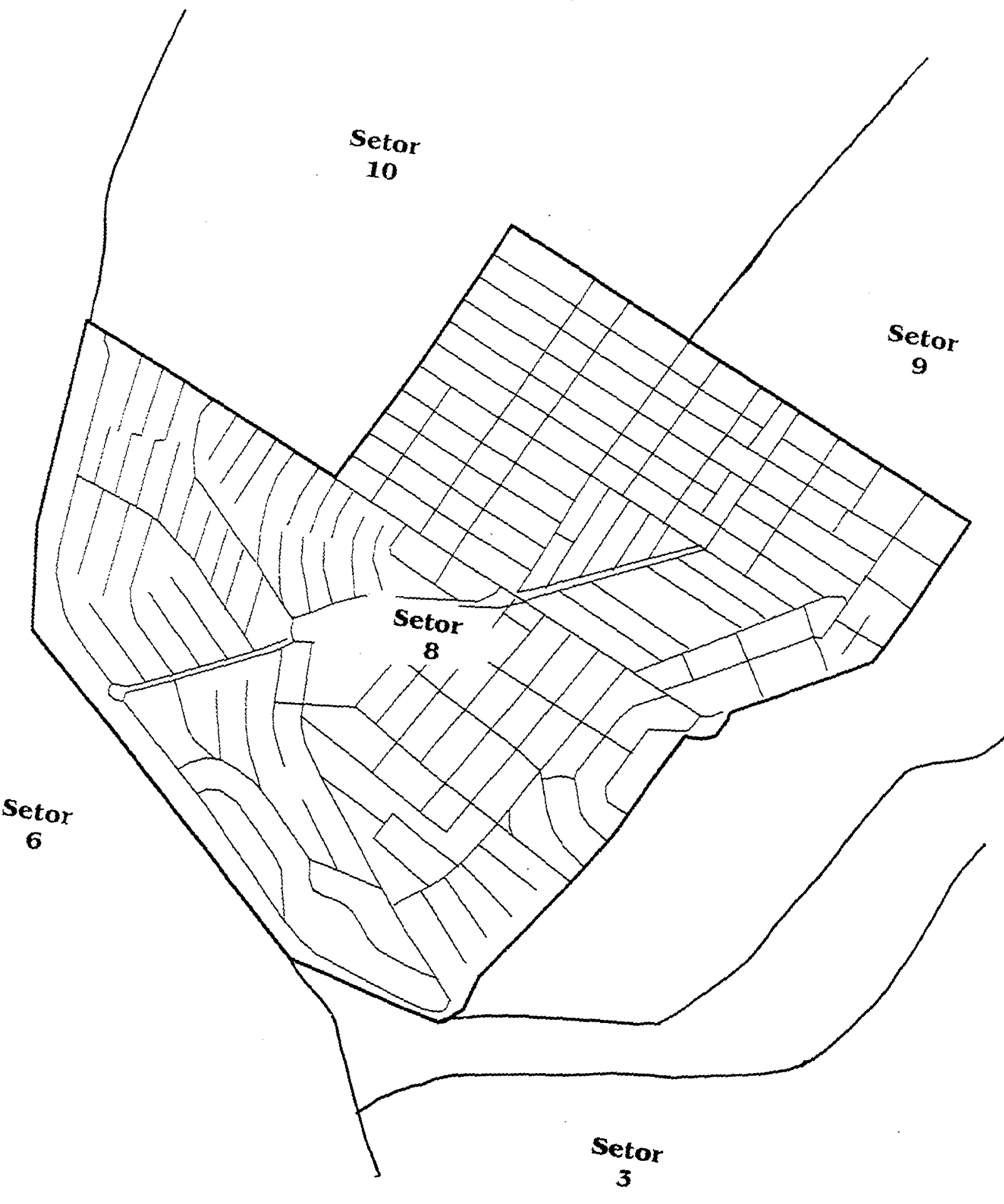

Perimetro $-41,95 \mathrm{~km}$ 
Setor 9

Escala 1:15000 Perímetro $-23,11 \mathrm{~km}$

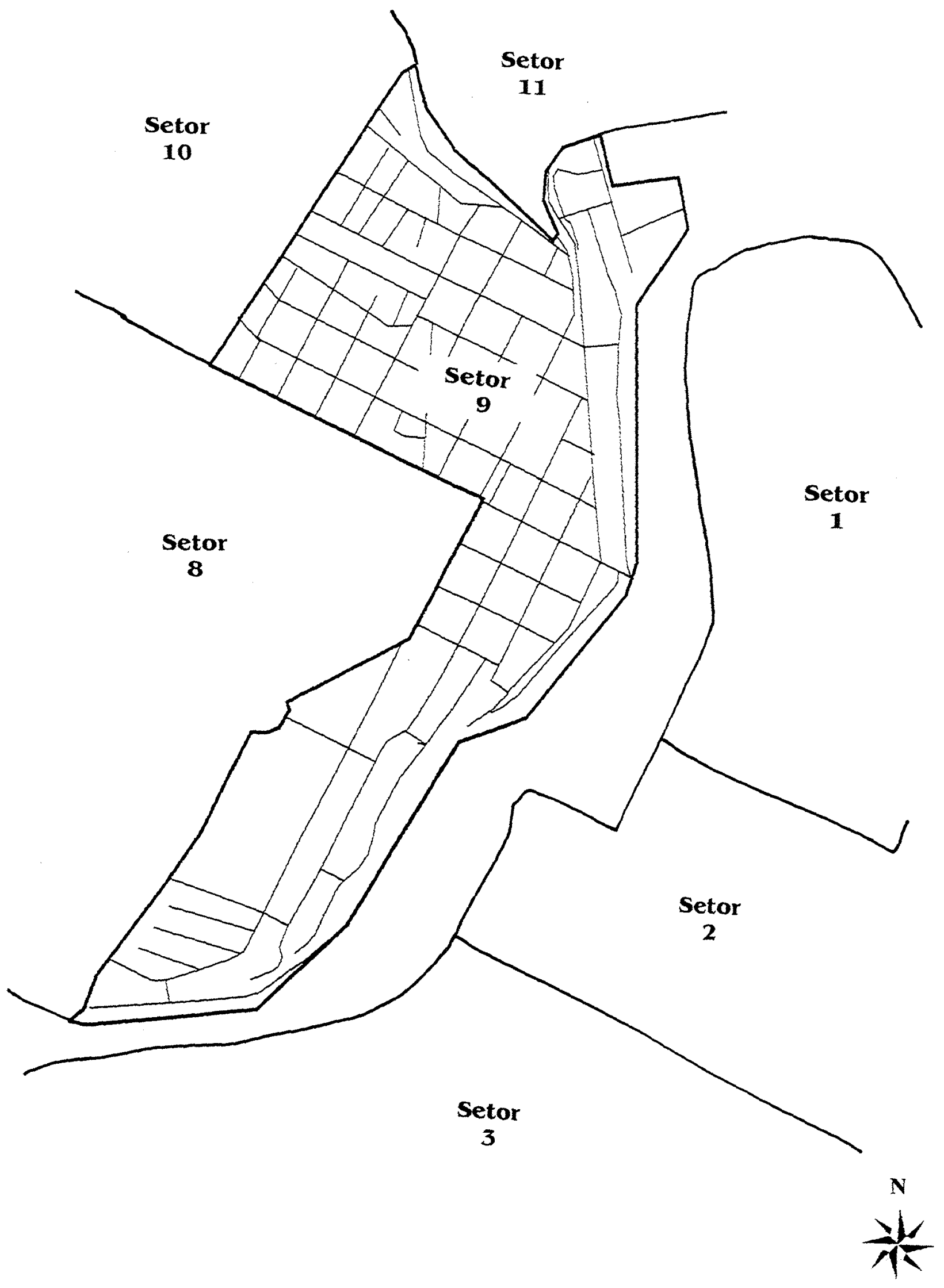


$\frac{\text { Setor } 10}{\text { Escala } 1: 15000 \quad \text { Perimetro }-35,65 \mathrm{~km}}$

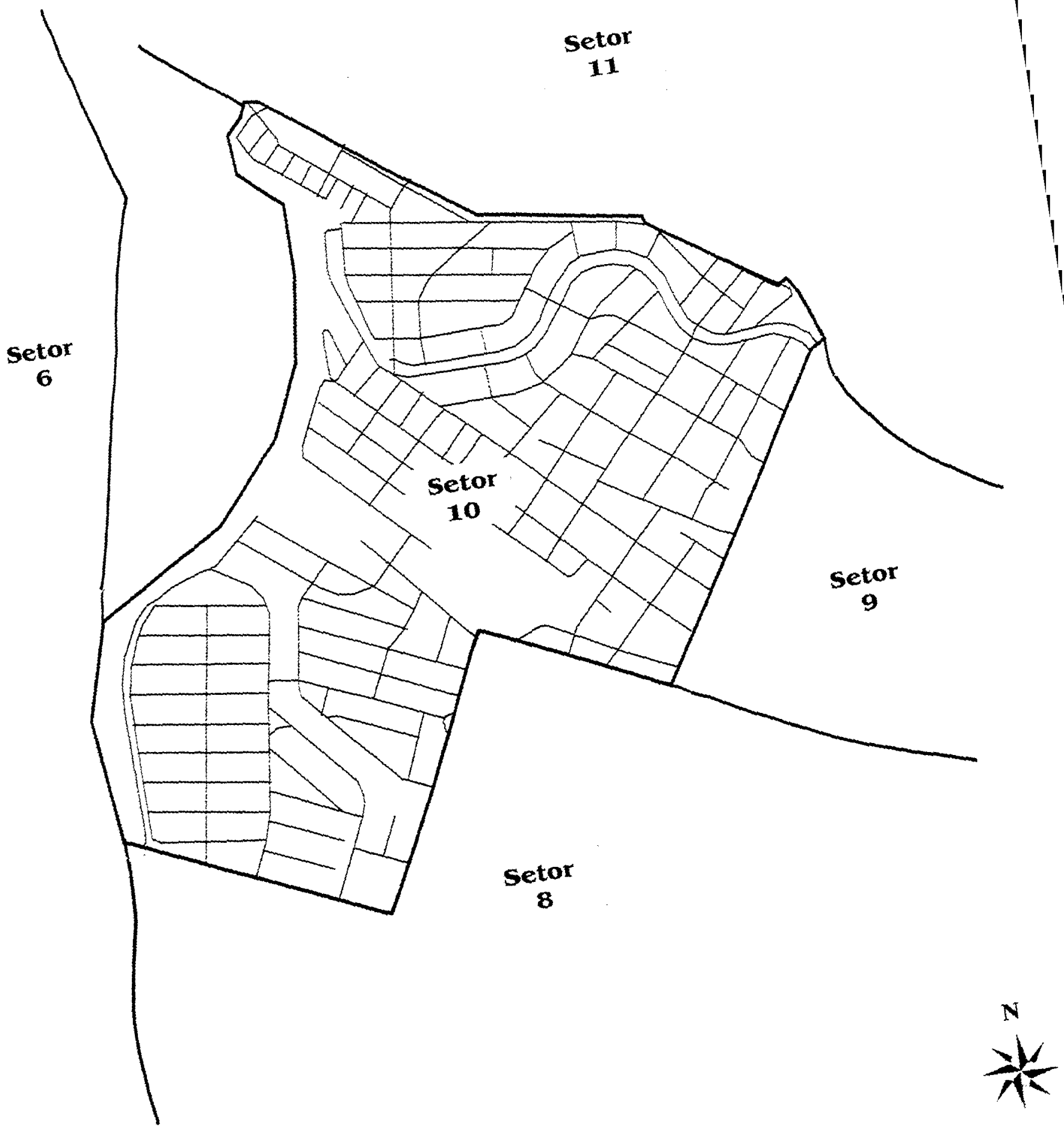


Setor 11

Escala 1:35000 Perímetro $-59,36 \mathrm{~km}$

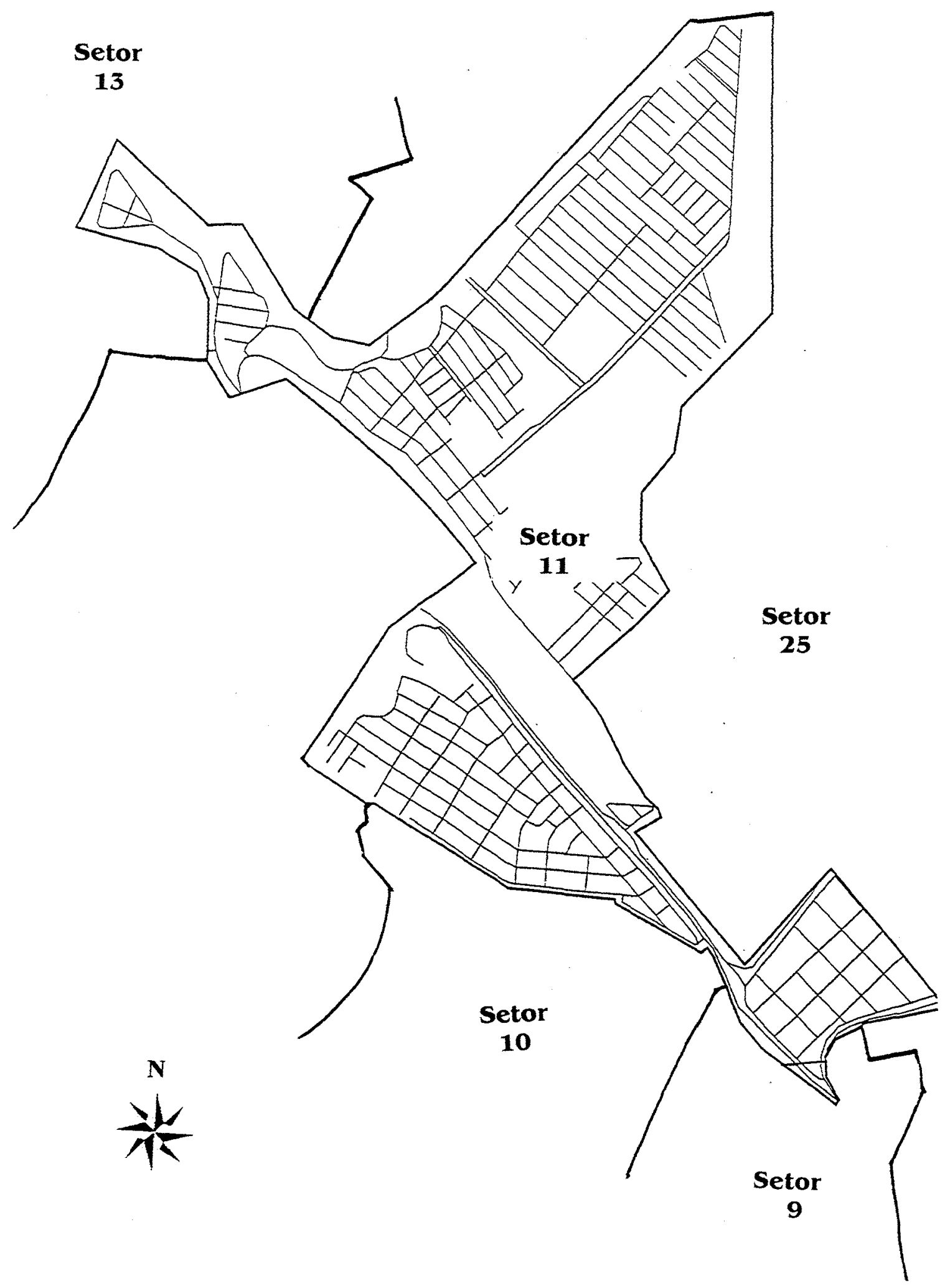


$\underline{\text { Setor } 12}$

Escala 1:15000 Perímetro - 44,15 km

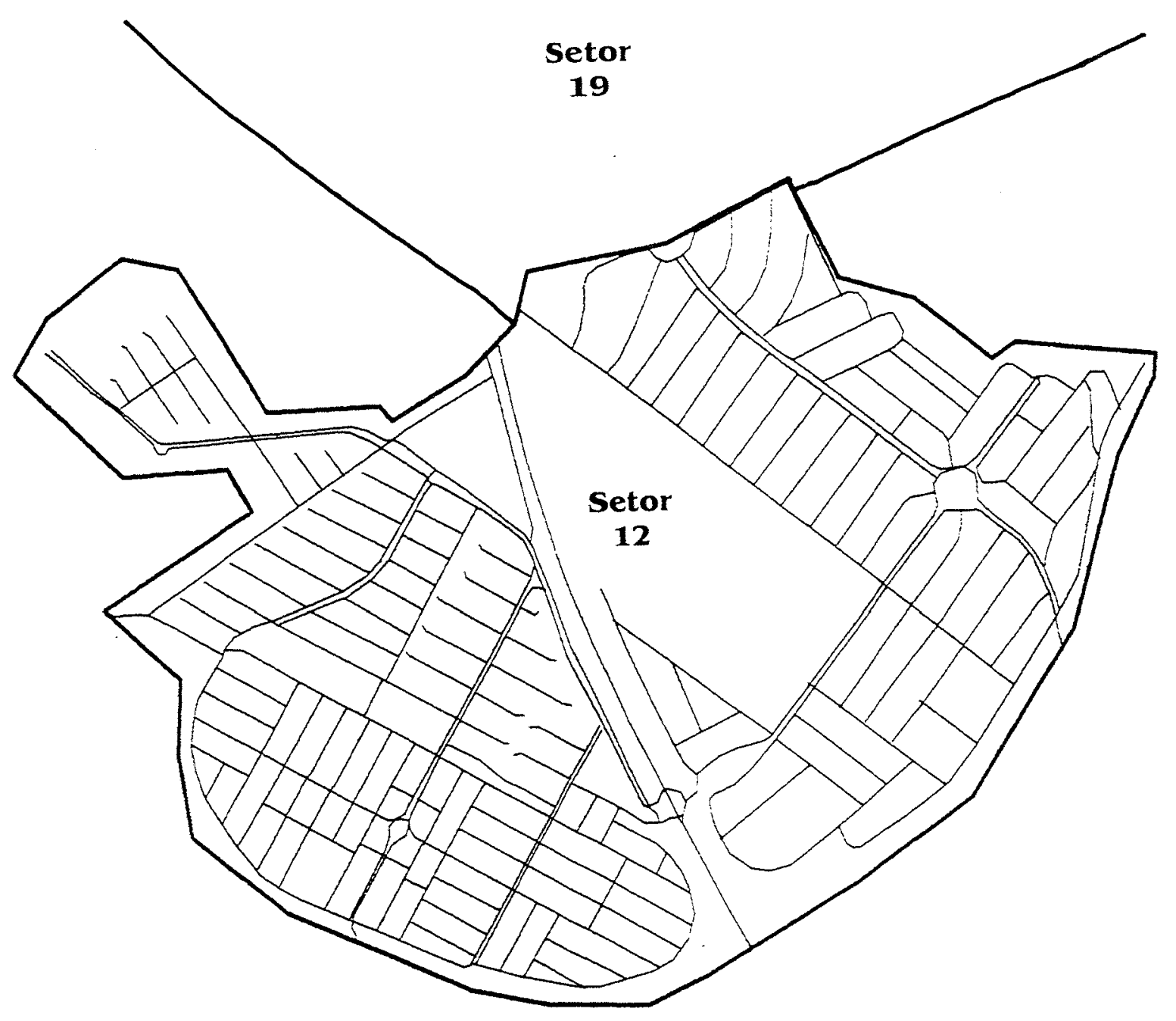

$\frac{2}{12}$ 
Setor 13

Escala 1:15000 Perímetro $-44,67 \mathrm{~km}$

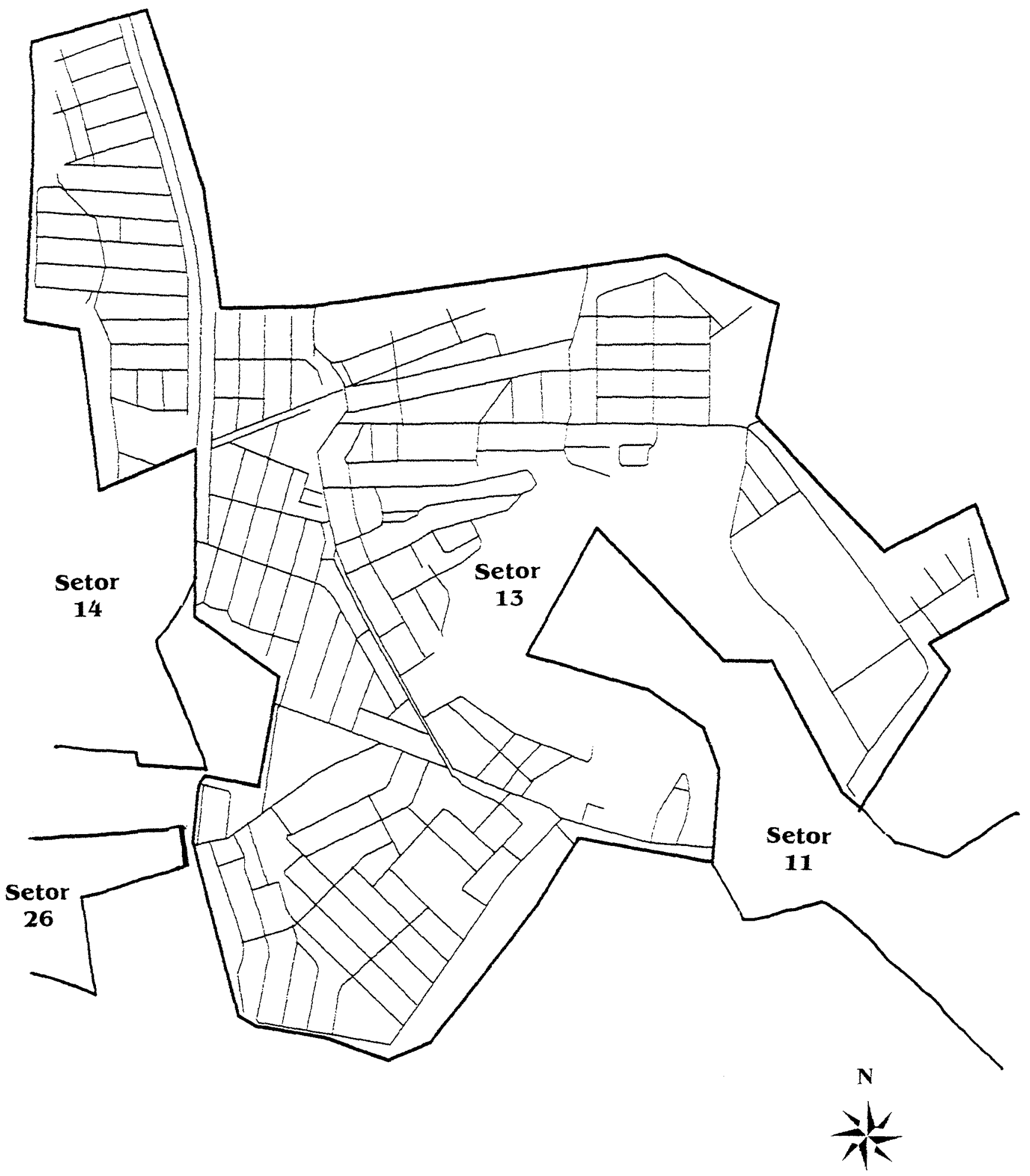




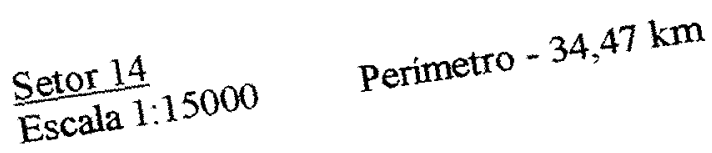

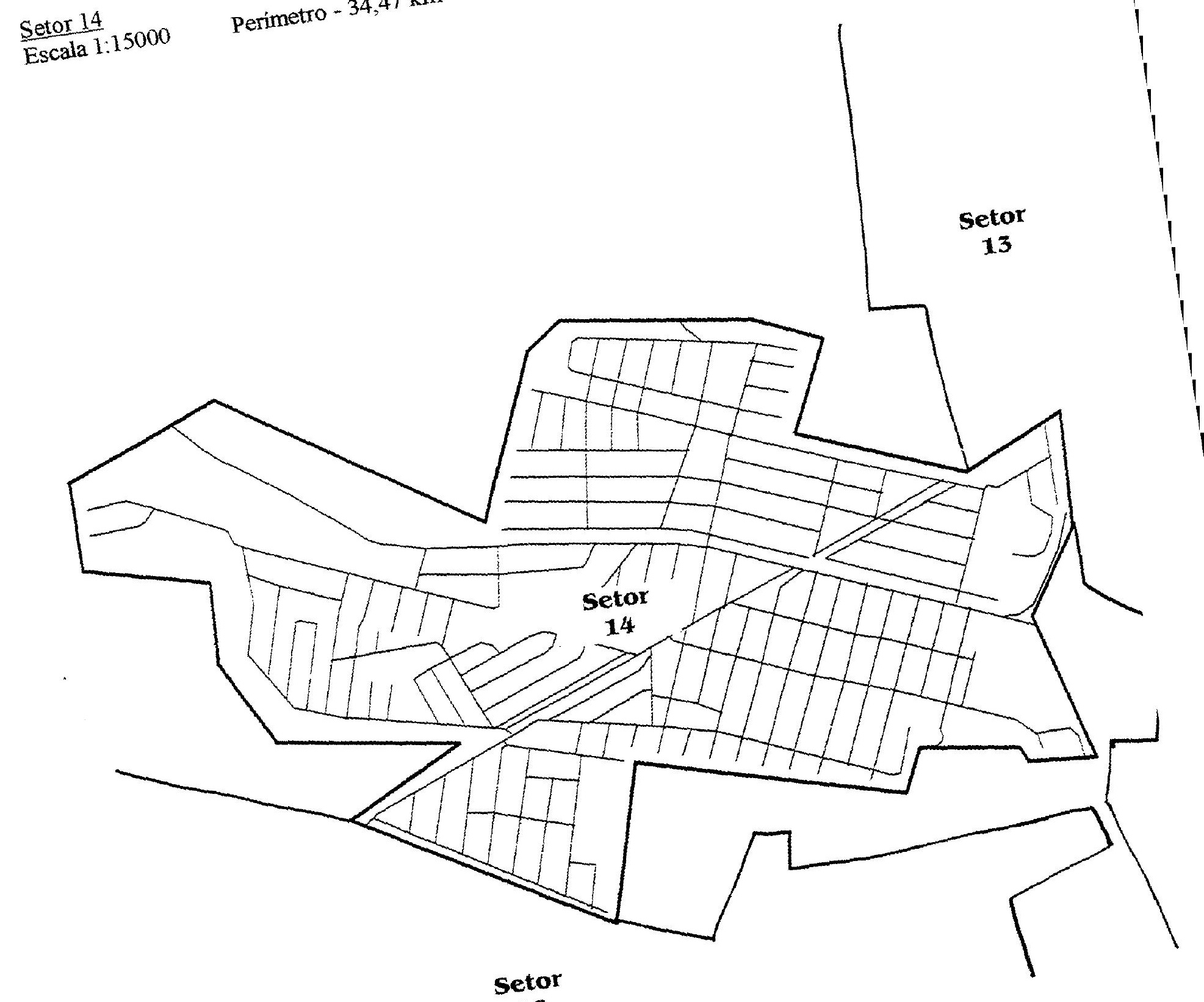

26

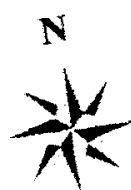


Setor 15

Escala 1:15000 Perimetro $-18,71 \mathrm{~km}$

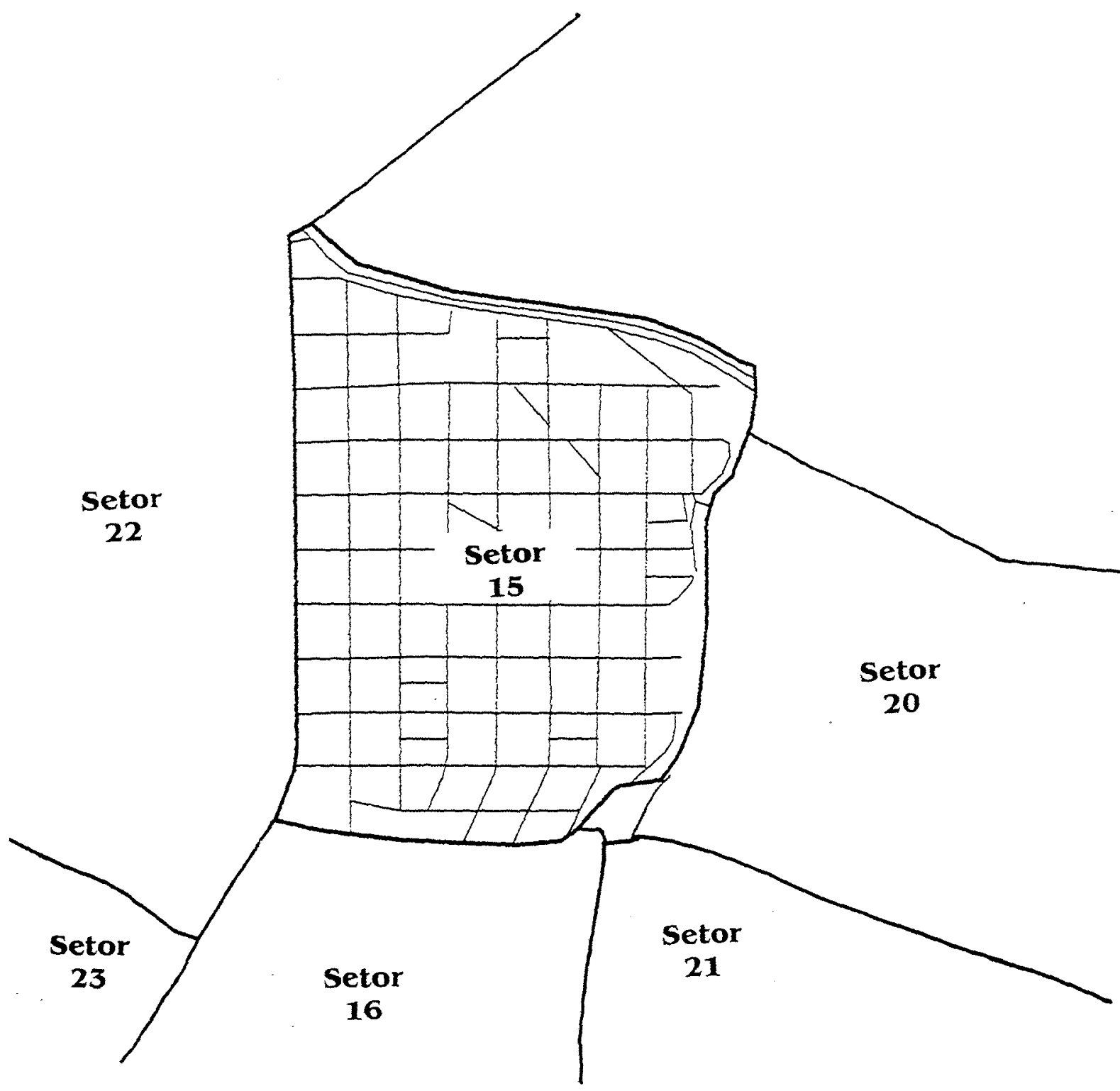


Setor 16

Escala 1:15000 Perímetro $-24,00 \mathrm{~km}$

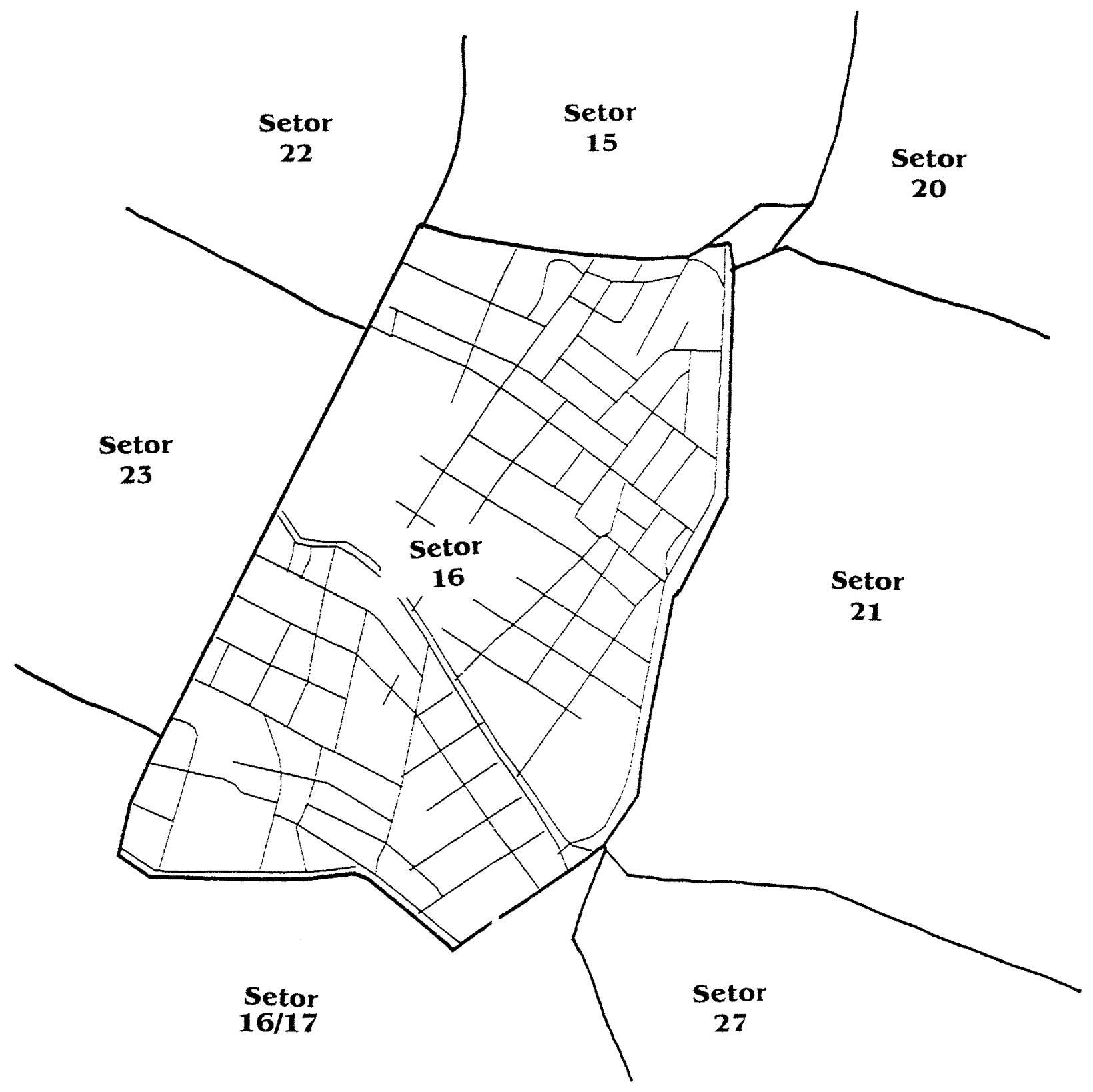


Setor $16 / 17$

Escala 1:15000 Perímetro-33,21 km

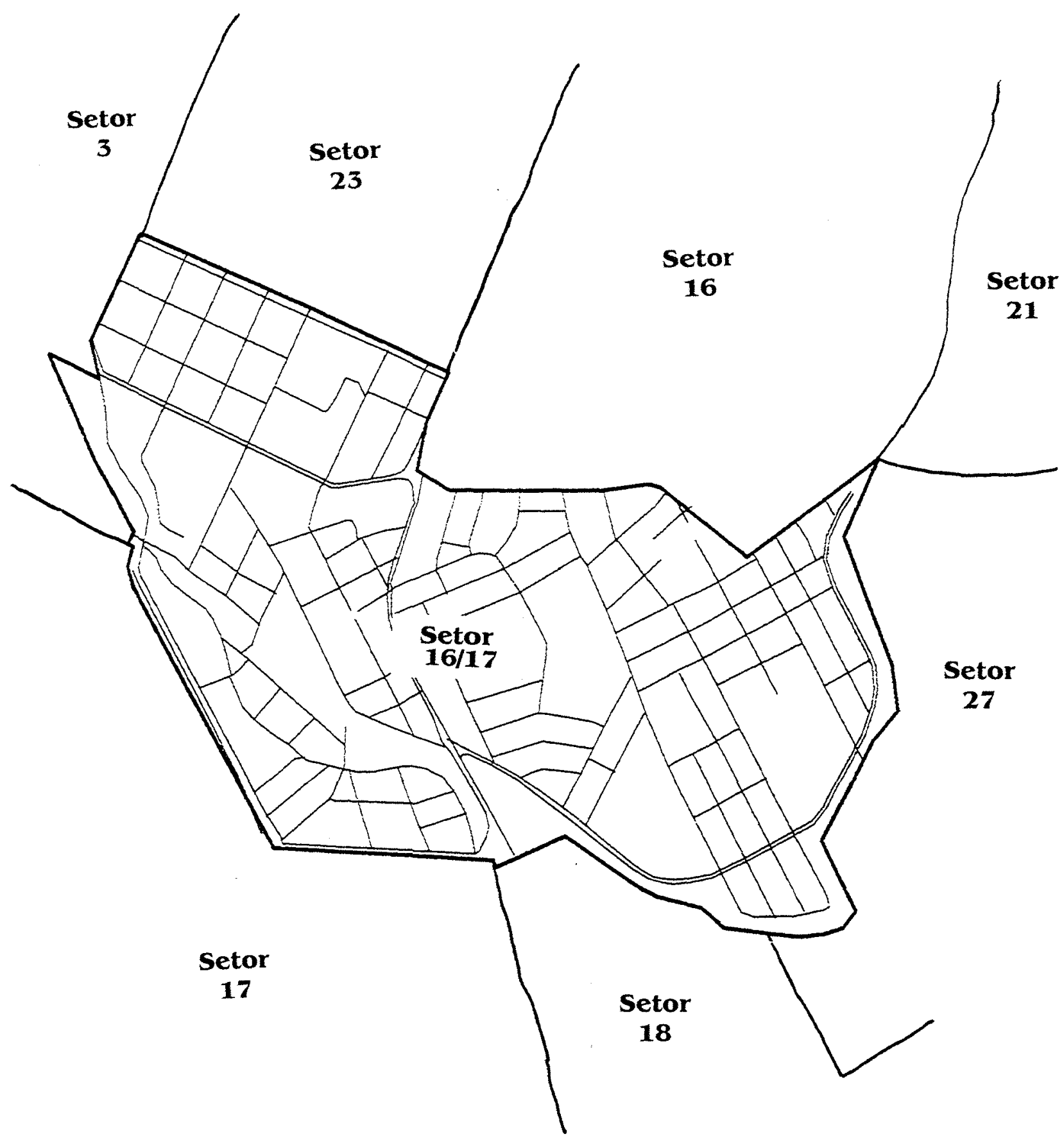

$\frac{1}{12}$ 


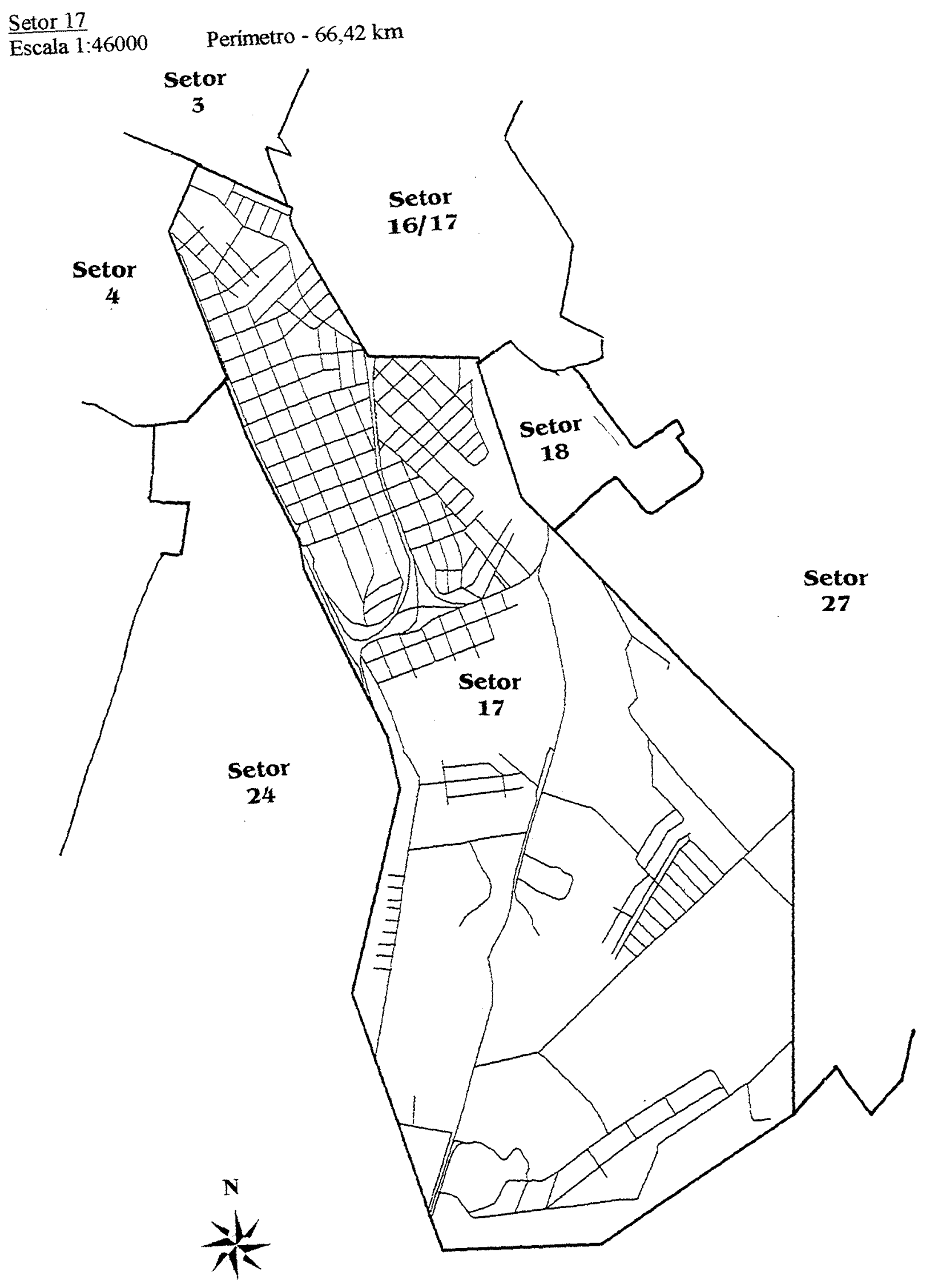




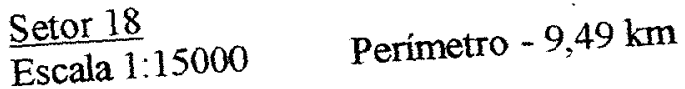

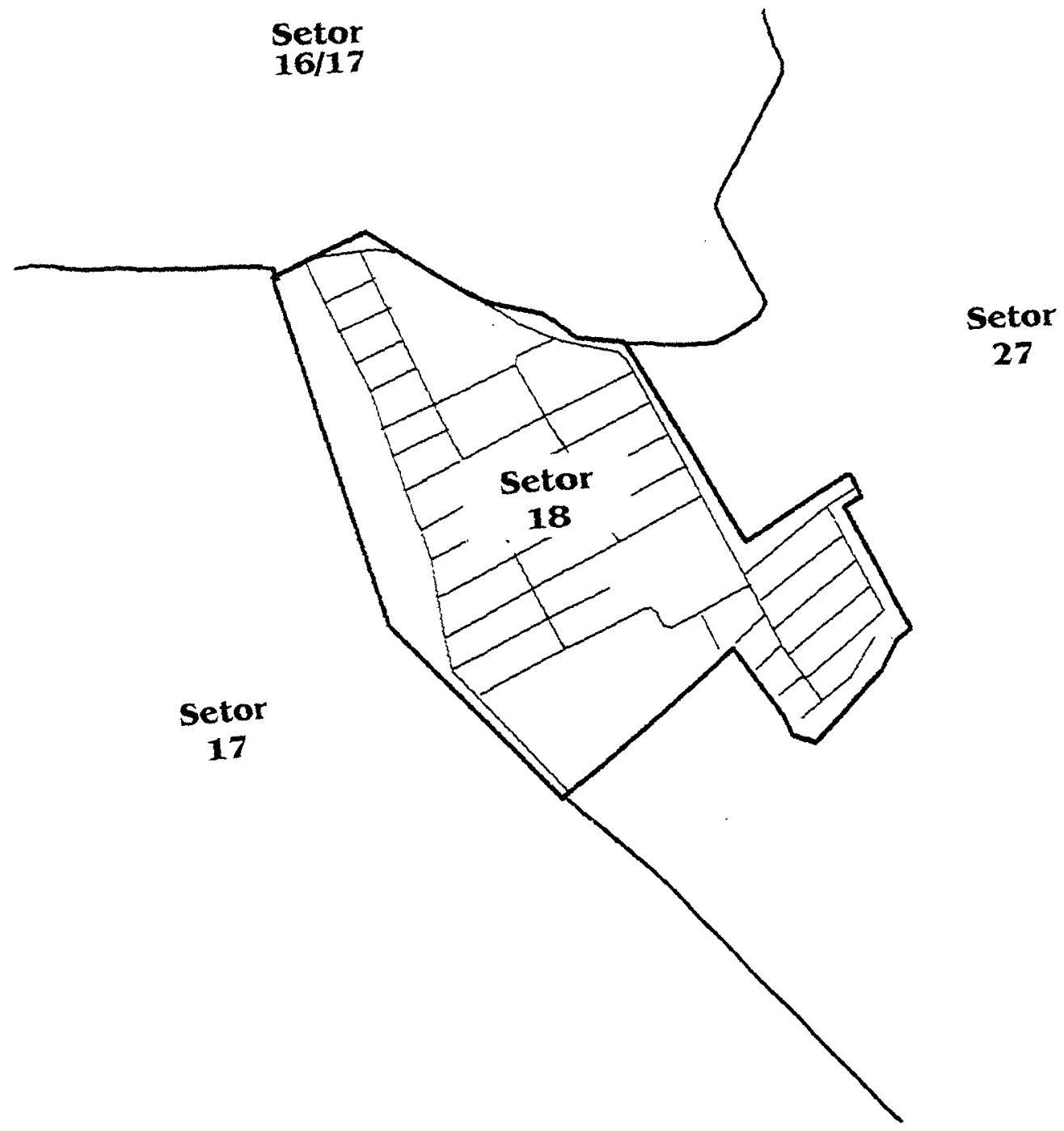


Setor 19
Escala 1:47000 Perimetro $-62,38 \mathrm{~km}$

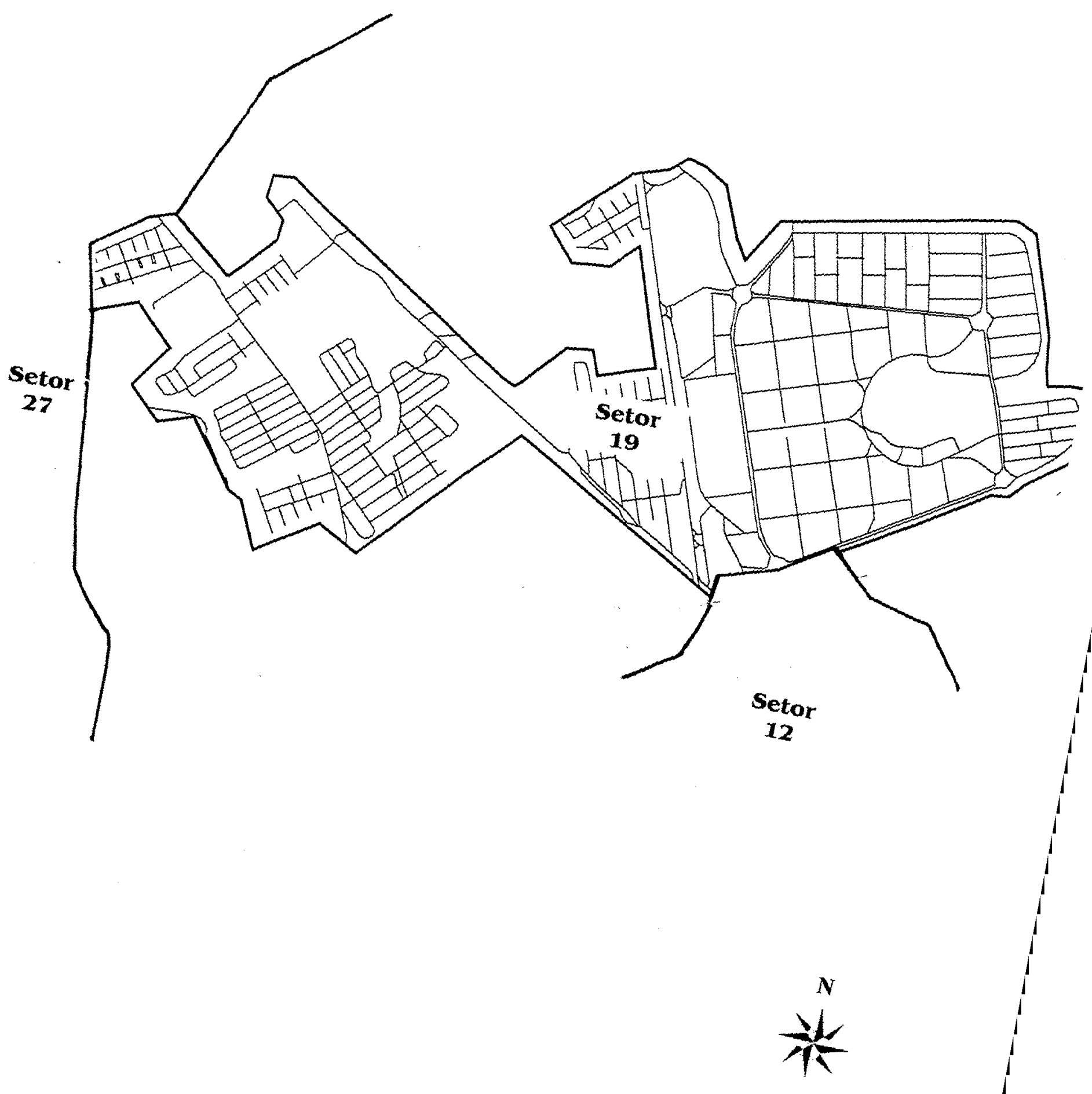


Setor 20

Escala 1:100000 Perímetro $-68,87 \mathrm{~km}$
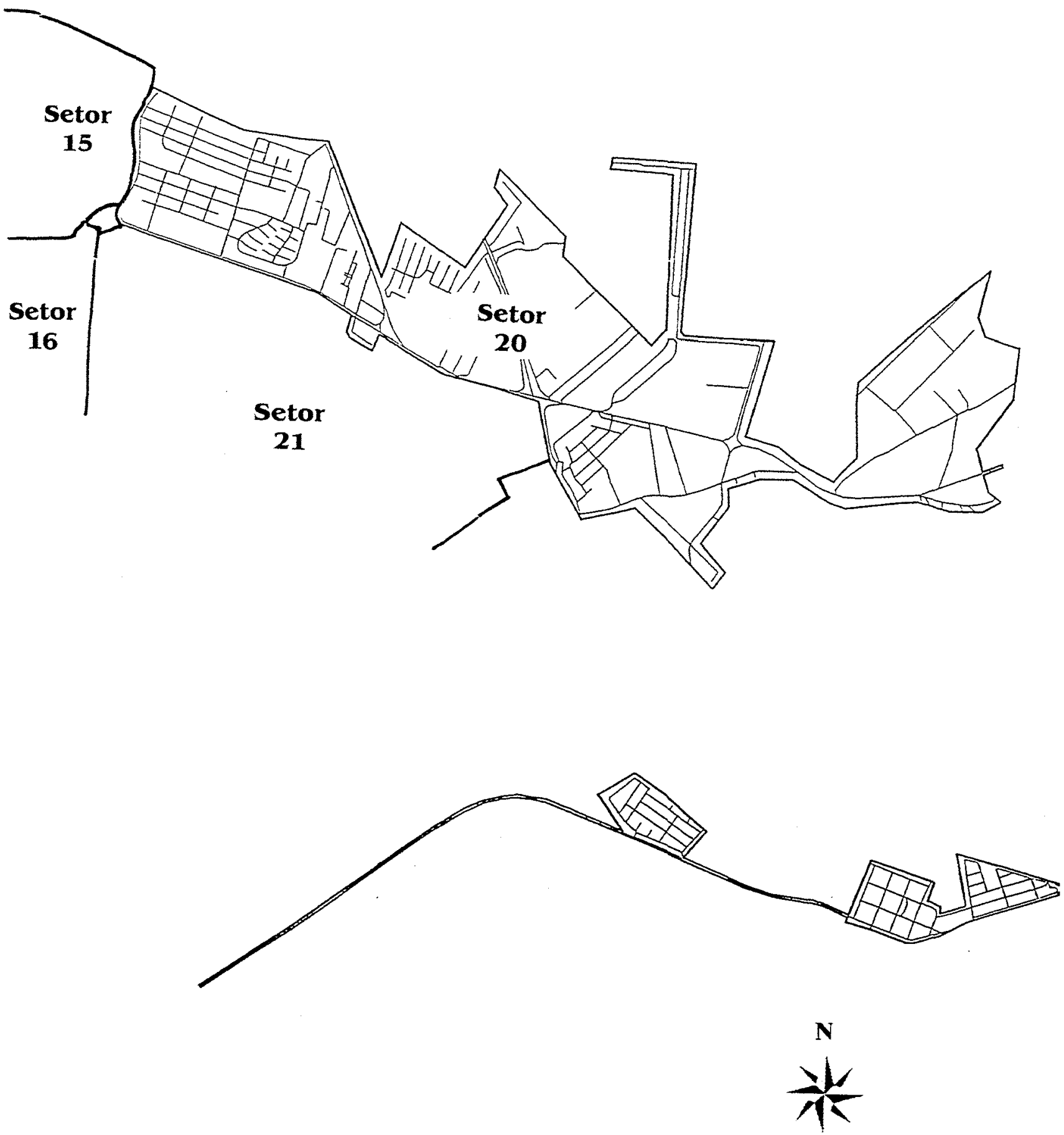
Setor 21

Escala 1:25000 Perímetro $-35,31 \mathrm{~km}$

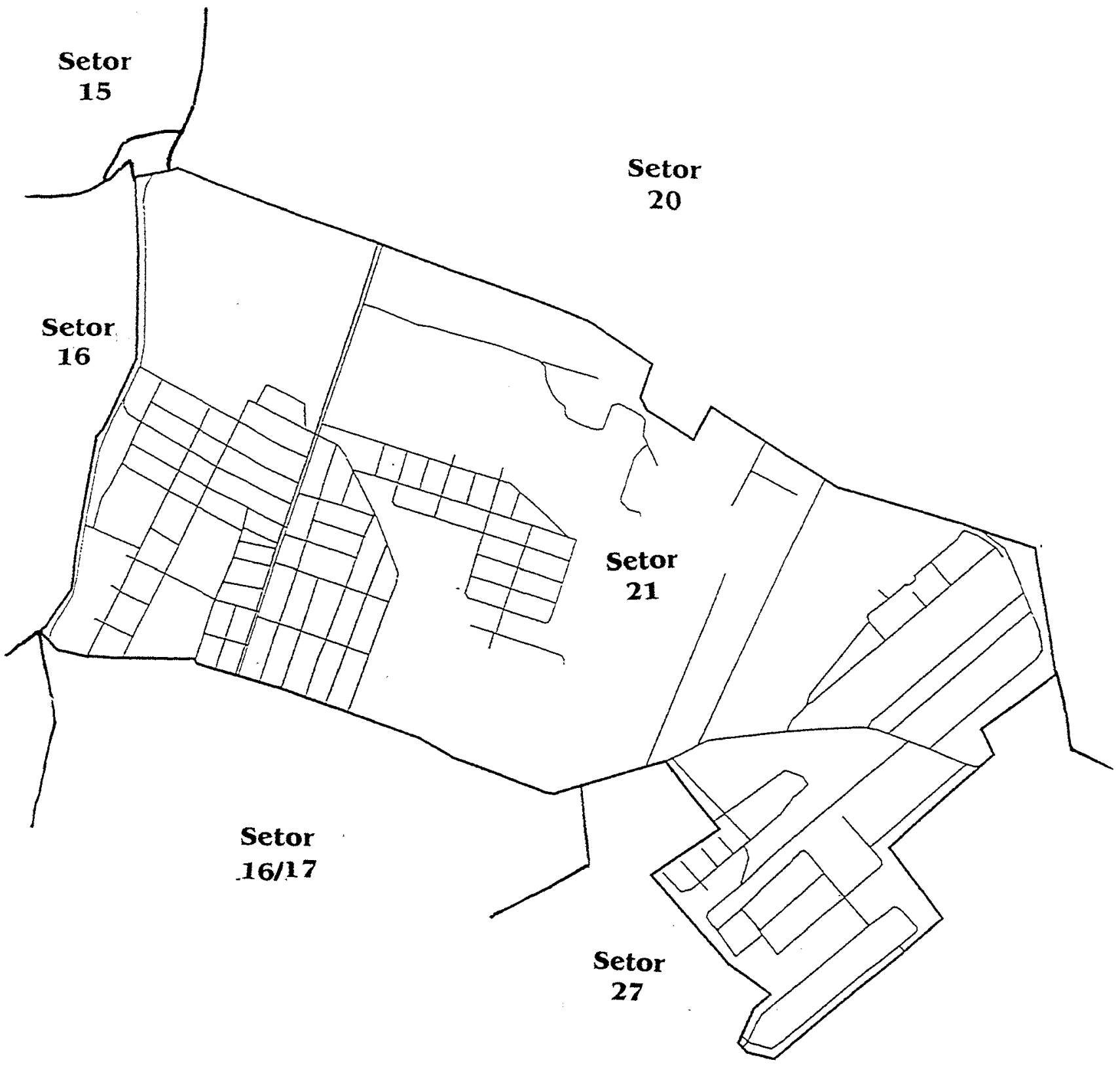


Setor 22

Escala 1:22000 Perímetro $-31,59 \mathrm{~km}$

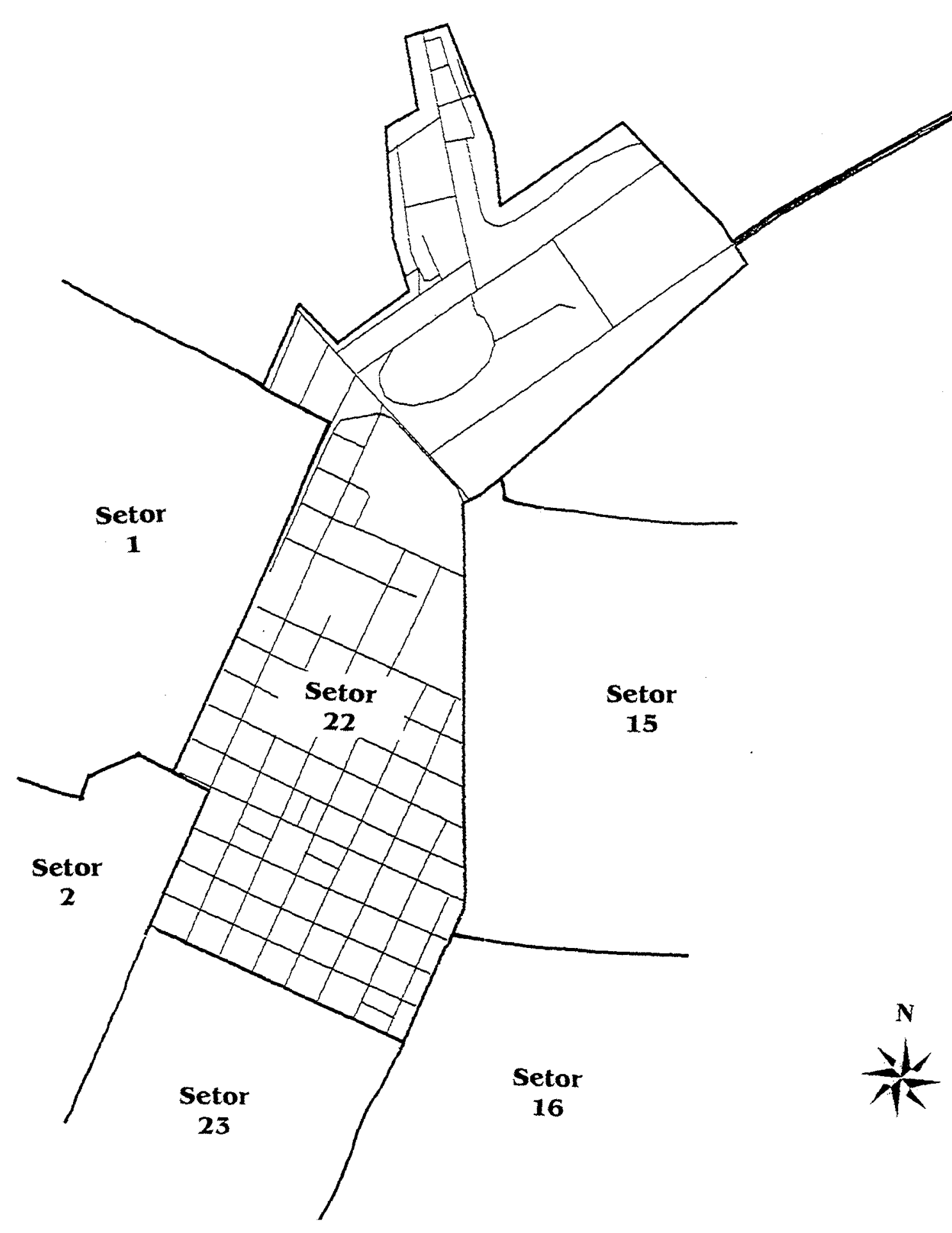




\section{Setor 23}

Escala 1:15000 Perimetro-13,78 km

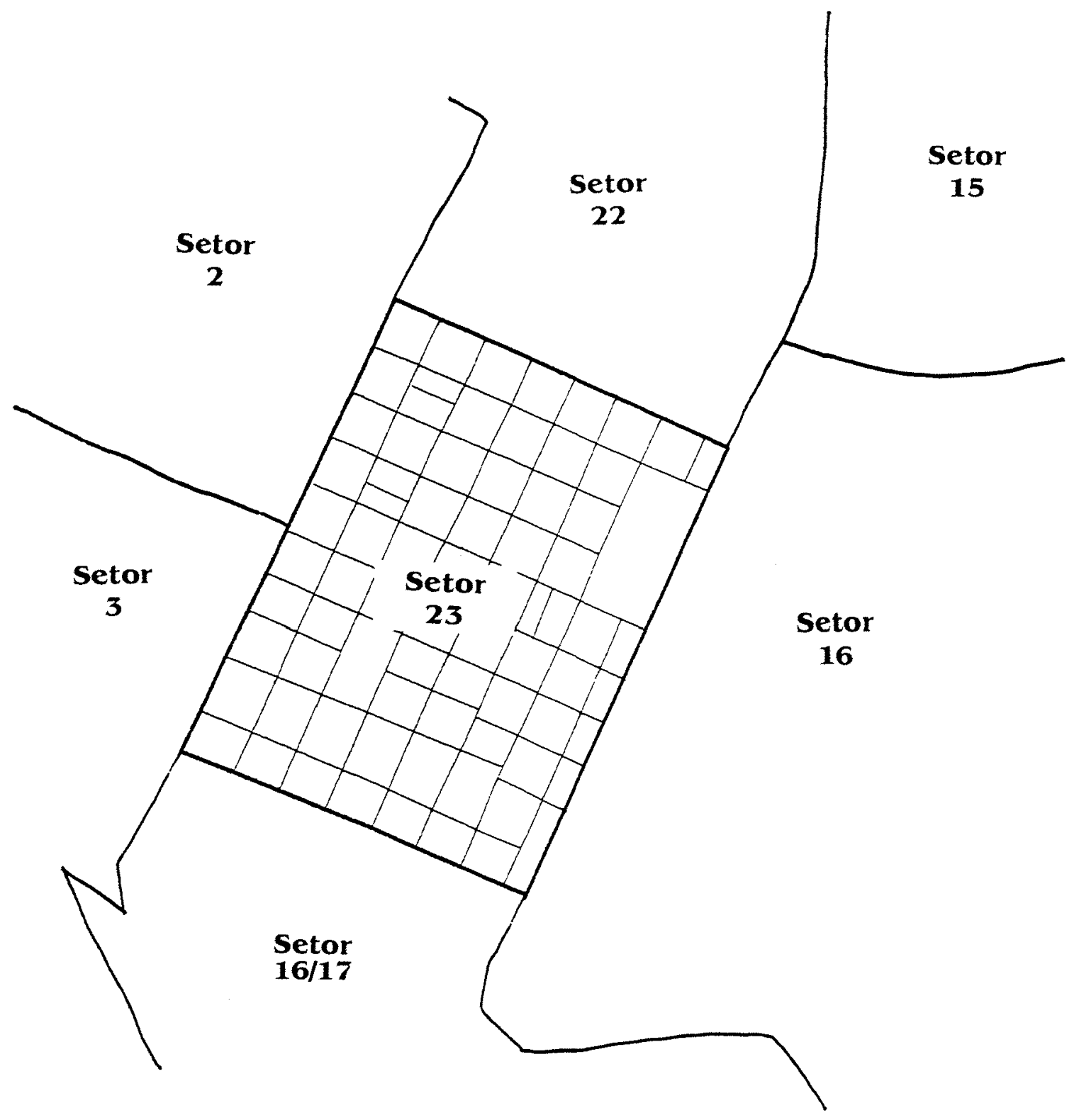




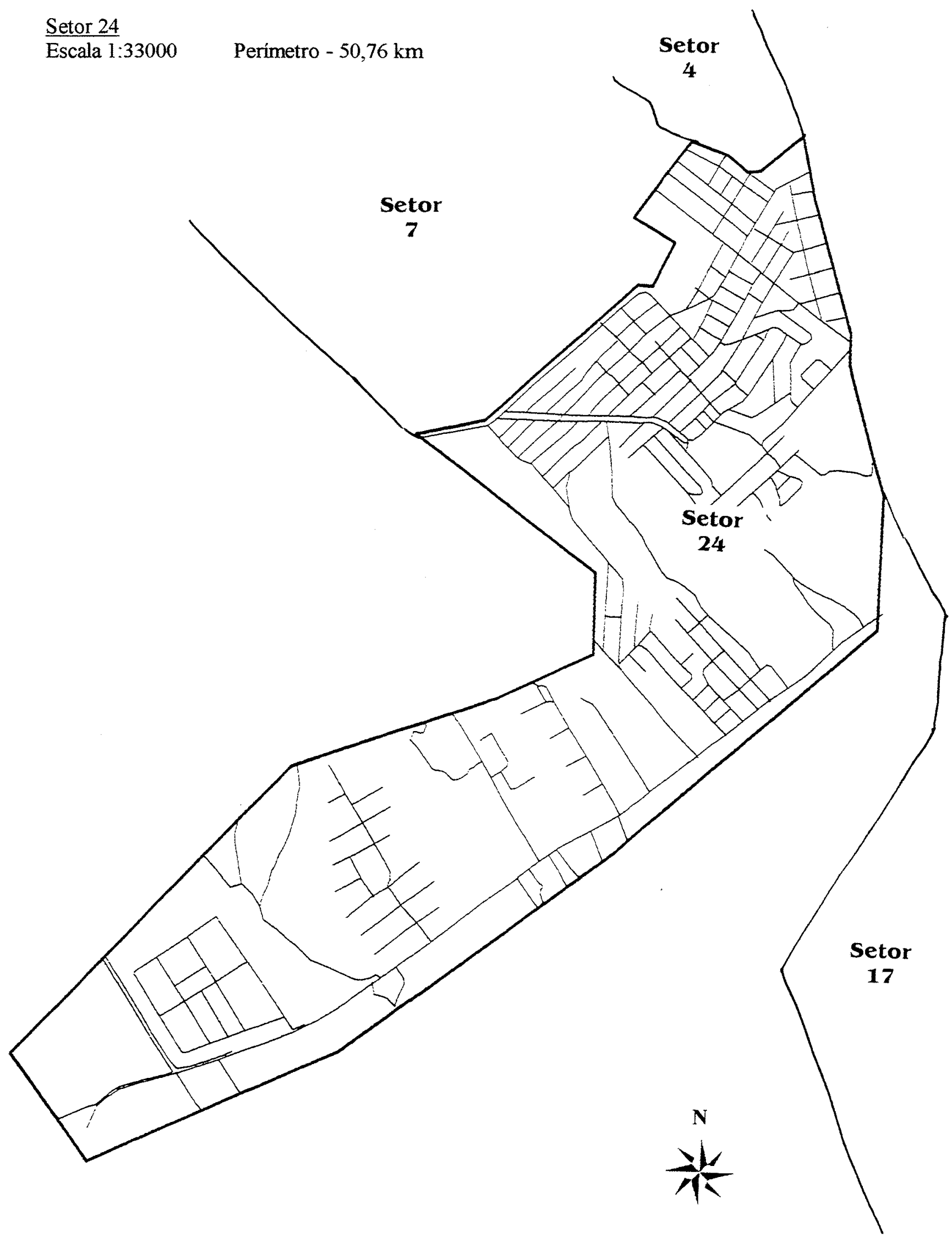


$\underline{\text { Setor } 25}$

Escala 1:45000 Perímetro - 51,47 km
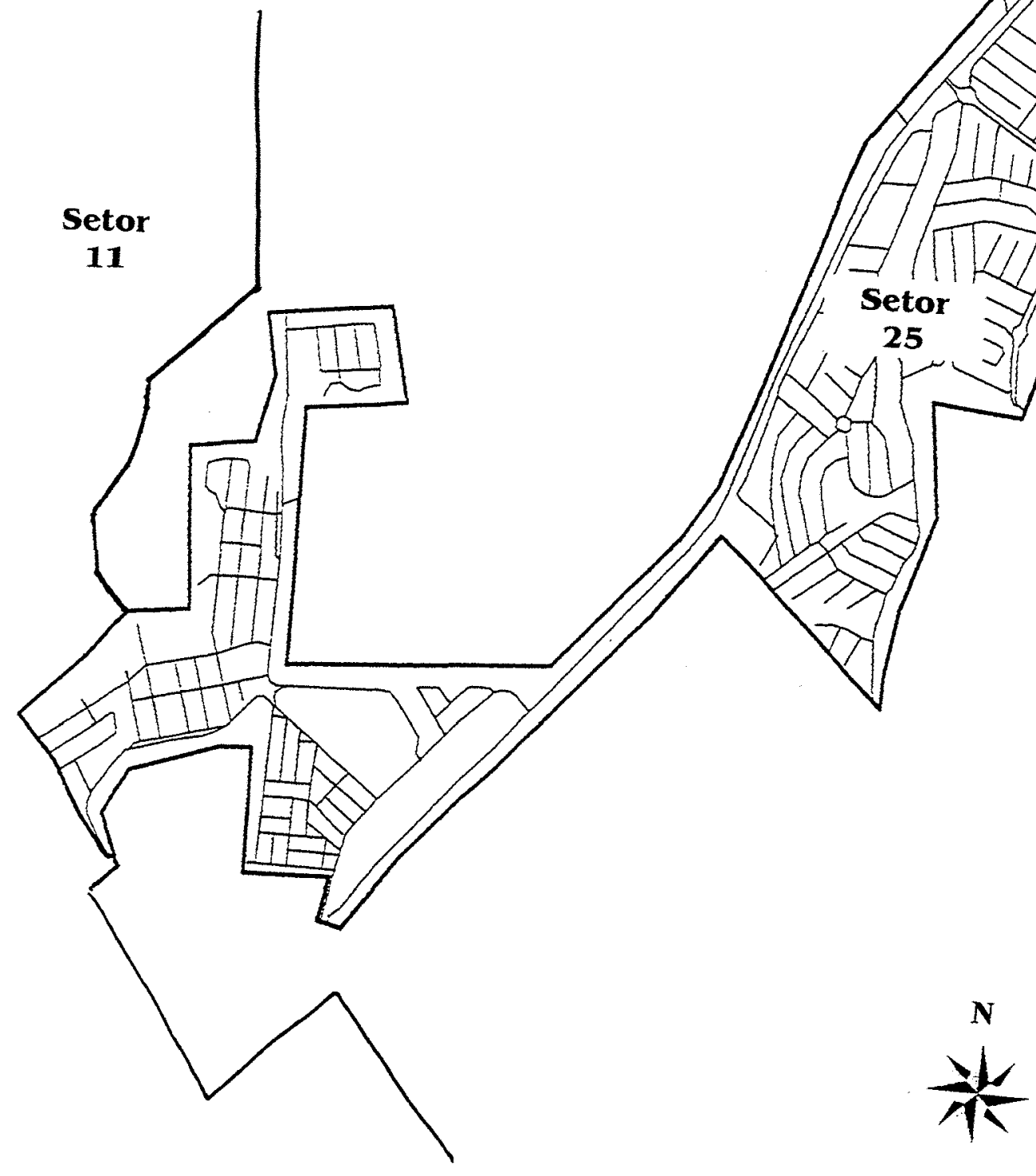
Setor 26

Escala 1:44000

Perímetro-26,42 km

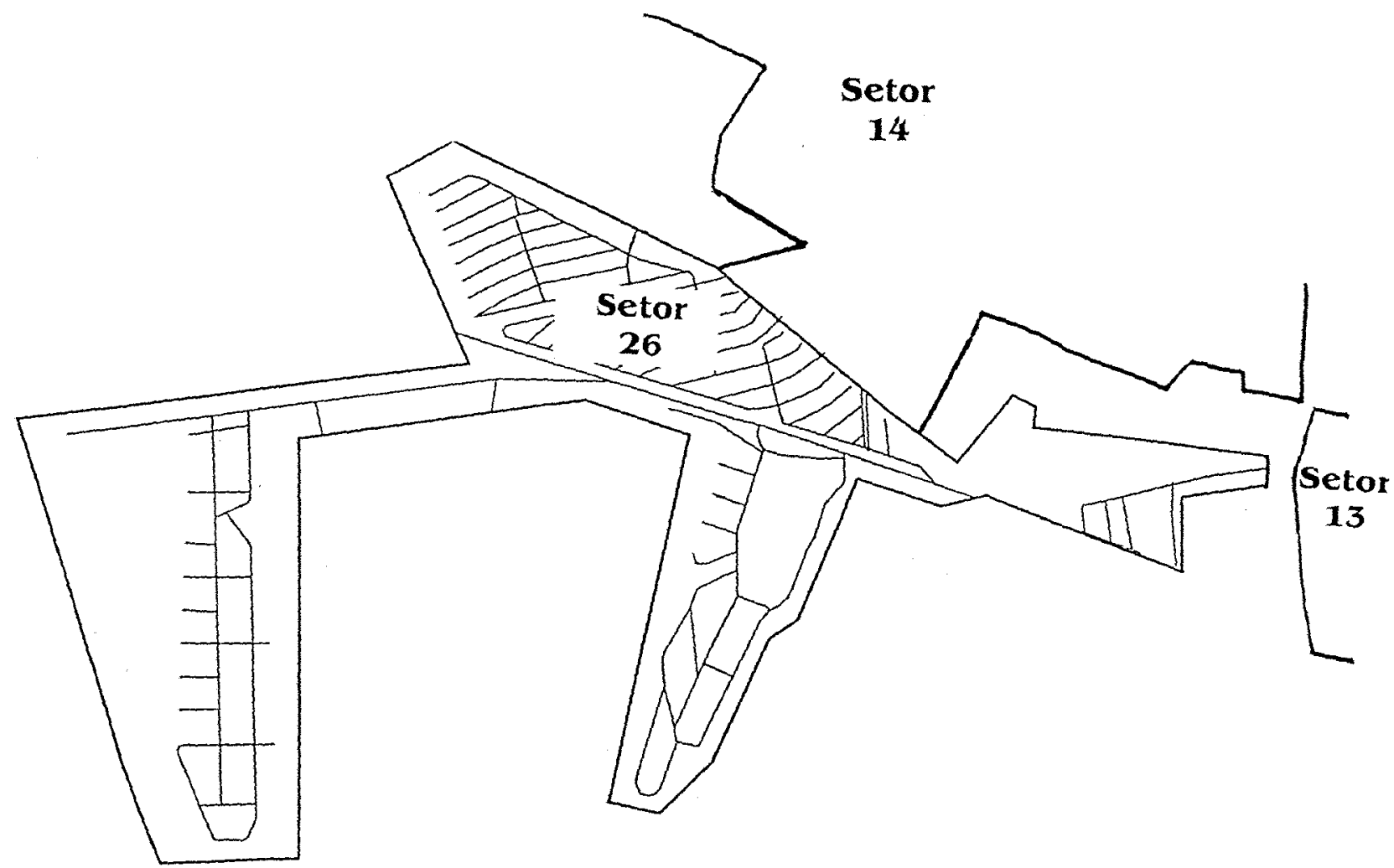

$\frac{N}{12}$ 


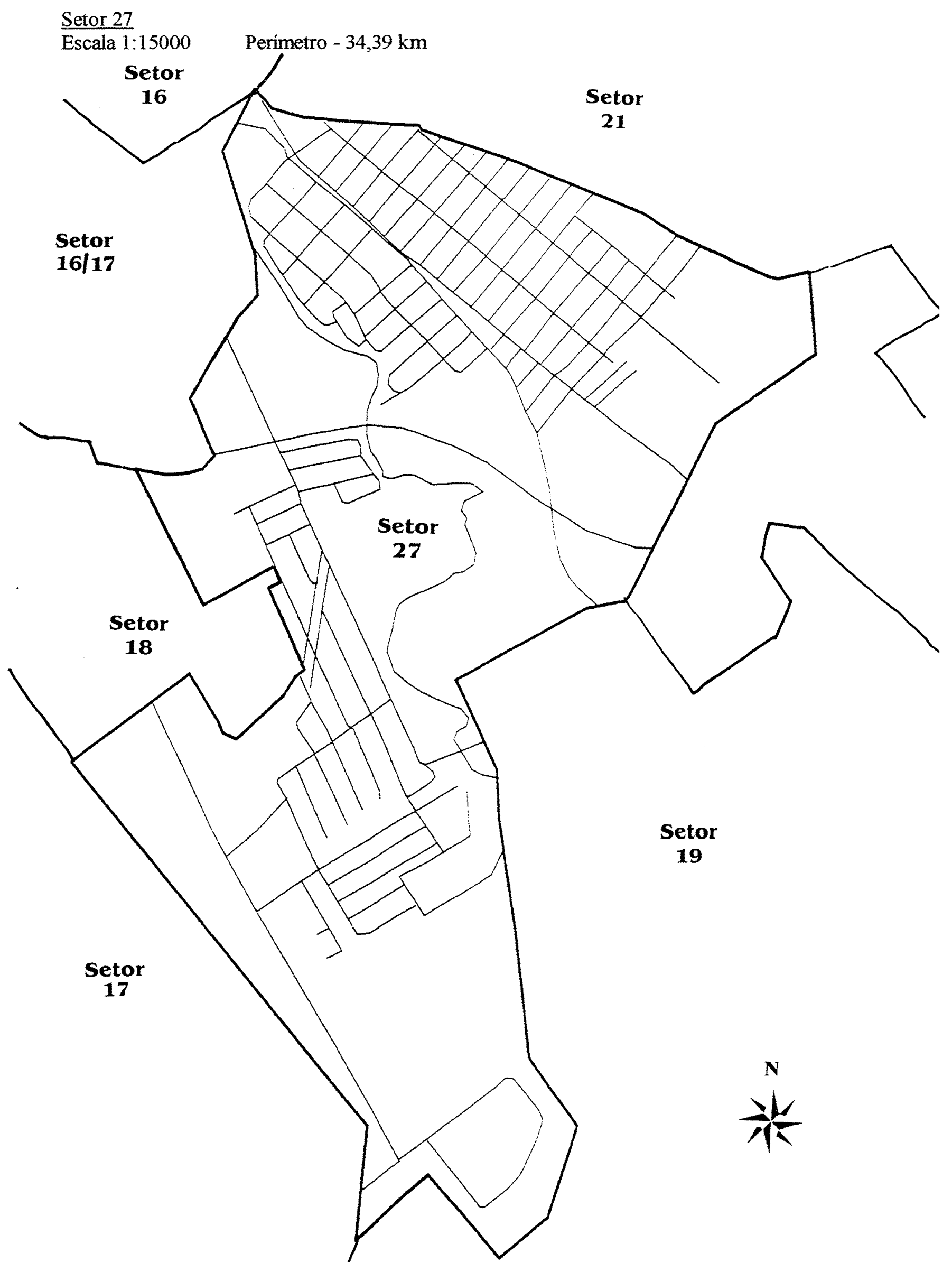




\section{Anexo I - Dados referentes ao percurso dos caminhões coletores por setor}

\begin{tabular}{|c|c|c|c|}
\hline \multirow[t]{2}{*}{ Setor $1^{46}$} & \multicolumn{3}{|l|}{ Dia 4 de setembro } \\
\hline & $\begin{array}{c}\text { Distância percorrida } \\
(\mathrm{em} \mathrm{km})\end{array}$ & $\begin{array}{l}\text { Tempo gasto } \\
\text { (hh:mm) }\end{array}$ & $\begin{array}{c}\text { Quantidade coletada } \\
\text { (em kg) }\end{array}$ \\
\hline $1^{\mathrm{a}}$ viagem & 31 & $02: 50$ & 7.360 \\
\hline $2^{\mathrm{a}}$ viagem & 33 & $02: 45$ & 6.480 \\
\hline$\beta^{\mathrm{a}}$ viagem & 37 & $02: 45$ & 3.550 \\
\hline Totais diários & 101 & $08: 20$ & 17.390 \\
\hline Totais mensais & 2.626 & $33: 20$ & 452.140 \\
\hline Densidade & $(\mathrm{em} \mathrm{kg} / \mathrm{km})$ & & \\
\hline $1^{\text {a }}$ viagem & 237,42 & & \\
\hline $2^{a}$ viagem & 196,36 & & \\
\hline$\beta^{\mathrm{a}}$ viagem & 95,95 & & \\
\hline Média & 172,18 & & \\
\hline Custo/km & $(\mathrm{em} \mathrm{RS)}$ & & \\
\hline & 2,90 & & \\
\hline
\end{tabular}

\begin{tabular}{|lccc|}
\hline Setor 1 & $\begin{array}{c}\text { Dia 5 de setembro } \\
\text { Distância percorrida }\end{array}$ & $\begin{array}{c}\text { Tempo gasto } \\
(\mathrm{hh}: \mathrm{mm})\end{array}$ & $\begin{array}{c}\text { Quantidade coletada } \\
\text { (em kg) }\end{array}$ \\
$1^{\mathrm{a}}$ viagem & $(\mathrm{em} \mathrm{km)}$ & $03: 41$ & 6.620 \\
$2^{\mathrm{a}}$ viagem & 42 & $02: 39$ & 2.620 \\
Totais diários & 42 & $06: 20$ & 9.240 \\
Totais mensais & 84 & $152: 00$ & 240.240 \\
& 2.184 & & \\
Densidade & & & \\
$1^{\mathrm{a}}$ viagem & $(\mathrm{em} \mathrm{kg} / \mathrm{km})$ & \\
$2^{\mathrm{a}}$ viagem & 157,62 & & \\
Média & 62,38 & & \\
& 110 & & \\
Custo $/ \mathrm{km}$ & & & \\
& $(\mathrm{em} \mathrm{R} \$)$ & & \\
\hline
\end{tabular}

\footnotetext{
${ }^{46}$ Nos setores 1,2 e 3 , os totais mensais dos quadros dos dias 04 de setembro correspondem aos totais diários multiplicados por quatro (segundas-feiras). Os totais mensais dos quadros dos dias 05 de setembro correspondem aos totais diários multiplicados por 22 dias (terças a sábados). 0 total geral mensal de cada um desses setores é a soma dos totais mensais dos quadros dos dias 04 e 05 de setembro.
} 


\begin{tabular}{|lccc|}
\hline Setor 2 & $\begin{array}{c}\text { Dia } 4 \text { de setembro } \\
\text { Distância percorrida } \\
(\mathrm{em} \mathrm{km})\end{array}$ & $\begin{array}{c}\text { Tempo gasto } \\
(\mathrm{hh}: \mathrm{mm})\end{array}$ & $\begin{array}{c}\text { Quantidade coletada } \\
\text { (em kg) }\end{array}$ \\
$1^{\text {a }}$ viagem & 23 & $03: 40$ & 7710 \\
$2^{\mathrm{a}}$ viagem & 28 & $02: 27$ & 7220 \\
$3^{\mathrm{a}}$ viagem & 34 & $02: 23$ & 5160 \\
Totais diários & 85 & $8: 30$ & 20.090 \\
Totais mensais & 2210 & $34: 00$ & 522.340 \\
& & & \\
Densidade & $(\mathrm{em} \mathrm{kg} / \mathrm{km})$ & & \\
$1^{\mathrm{a}}$ viagem & 335,22 & & \\
$2^{\mathrm{a}}$ viagem & 257,86 & & \\
$3^{\mathrm{a}}$ viagem & 151,76 & & \\
Média & 236,35 & & \\
& & & \\
Custo $/ \mathrm{km}$ & $(\mathrm{em} \mathrm{R} \$)$ & & \\
& 3,44 & & \\
\hline
\end{tabular}

\begin{tabular}{|c|c|c|c|}
\hline \multirow[t]{2}{*}{ Setor 2} & Dia 5 de setembro & & \\
\hline & $\begin{array}{c}\text { Distância percorrida } \\
\text { (em km) }\end{array}$ & $\begin{array}{l}\text { Tempo gasto } \\
\text { (hh:mm) }\end{array}$ & $\begin{array}{l}\text { Quantidade coletada } \\
(\mathrm{em} \mathrm{kg})\end{array}$ \\
\hline $1^{\text {a }}$ viagem & 33 & $04: 40$ & 7530 \\
\hline $2^{a}$ viagem & 35 & $02: 15$ & 4230 \\
\hline Totais diários & 68 & $06: 55$ & 11.760 \\
\hline Totais mensais & 1768 & $152: 10$ & 305.760 \\
\hline Densidade & $(\mathrm{em} \mathrm{kg} / \mathrm{km})$ & & \\
\hline $1^{\text {a }}$ viagem & 228,18 & & \\
\hline $2^{\mathrm{a}}$ viagem & 120,86 & & \\
\hline Média & 172,94 & & \\
\hline Custo $/ \mathrm{km}$ & $\begin{array}{c}\text { (em RS) } \\
4,30\end{array}$ & & \\
\hline
\end{tabular}




\begin{tabular}{|c|c|c|c|}
\hline \multirow[t]{2}{*}{ Setor 3} & Dia 4 de setembro & & \\
\hline & $\begin{array}{c}\text { Distância percorrida } \\
(\mathrm{em} \mathrm{km})\end{array}$ & $\begin{array}{l}\text { Tempo gasto } \\
\text { (hh:mm) }\end{array}$ & $\begin{array}{c}\text { Quantidade coletada } \\
(\mathrm{em} \mathrm{kg})\end{array}$ \\
\hline $1^{\text {a }}$ viagem & 23 & $02: 29$ & 7250 \\
\hline $2^{\mathrm{a}}$ viagem & 29 & $02: 54$ & 7390 \\
\hline $3^{2}$ viagem & 41 & $02: 42$ & 5060 \\
\hline Totais diários & 93 & $08: 05$ & 19.700 \\
\hline Totais mensais & 2418 & $32: 20$ & 512.200 \\
\hline Densidade & $(\mathrm{em} \mathrm{kg} / \mathrm{km})$ & & \\
\hline $1^{a}$ viagem & 315,22 & & \\
\hline $2^{a}$ viagem & 254,83 & & \\
\hline$\beta^{a}$ viagem & 123,41 & & \\
\hline Média & 211,83 & & \\
\hline Custo/km & $(\mathrm{em} \mathrm{R} \$)$ & & \\
\hline & 3,14 & & \\
\hline
\end{tabular}

\begin{tabular}{|lccc|}
\hline Setor 3 & $\begin{array}{c}\text { Dia 5 de setembro } \\
\text { Distância percorrida } \\
(\mathrm{em} \mathrm{km})\end{array}$ & $\begin{array}{c}\text { Tempo gasto } \\
(\mathrm{hh}: \mathrm{mm})\end{array}$ & $\begin{array}{c}\text { Quantidade coletada } \\
(\mathrm{em} \mathrm{kg})\end{array}$ \\
$1^{\text {a viagem }}$ & 28 & $03: 16$ & 6700 \\
$2^{\text {a viagem }}$ & 45 & $03: 24$ & 5120 \\
Totais diários & 73 & $06: 40$ & 11.820 \\
Totais mensais & 1898 & $146: 40$ & 307.320 \\
& & & \\
Densidade & $(\mathrm{em} \mathrm{kg} / \mathrm{km})$ & & \\
$1^{\text {a } \text { viagem }}$ & 239,29 & & \\
$2^{\mathrm{a}}$ viagem & 113,78 & & \\
Média & 161,92 & \\
& & & \\
Custo $/ \mathrm{km}$ & $(\mathrm{em} \mathrm{R} \$)$ & & \\
& 4,01 & & \\
\hline
\end{tabular}




\begin{tabular}{|lccc|}
\hline Setor 4 & $\begin{array}{c}\text { Dia 4 de setembro } \\
\text { Distância percorrida } \\
(\mathrm{em} \mathrm{km})\end{array}$ & $\begin{array}{c}\text { Tempo gasto } \\
\text { (hh: } \mathrm{mm})\end{array}$ & $\begin{array}{c}\text { Quantidade coletada } \\
\text { (em } \mathrm{kg} \text { ) }\end{array}$ \\
$1^{\mathrm{a}}$ viagem & 26 & $03: 12$ & 8810 \\
$2^{\mathrm{a}}$ viagem & 26 & $02: 56$ & 8550 \\
$3^{\mathrm{a}}$ viagem & 35 & $03: 04$ & 8280 \\
Totais diários & 87 & $09: 12$ & 25.640 \\
Totais mensais & 1131 & $119: 36$ & 333.320 \\
& & & \\
Densidade & $(\mathrm{em} \mathrm{kg} / \mathrm{km})$ & & \\
$1^{\mathrm{a}}$ viagem & 338,85 & & \\
$2^{\mathrm{a}}$ viagem & 328,85 & & \\
$3^{\mathrm{a}}$ viagem & 236,57 & & \\
Média & 294,71 & & \\
& & & \\
Custo/km & $(\mathrm{em} \mathrm{R} \$$ ) & & \\
& 7,47 & & \\
\hline
\end{tabular}

\begin{tabular}{|lccc|}
\hline Setor 5 & $\begin{array}{c}\text { Dia 4 de setembro } \\
\text { Distância percorrida } \\
(\mathrm{em} \mathrm{km})\end{array}$ & $\begin{array}{c}\text { Tempo gasto } \\
(\mathrm{hh}: \mathrm{mm})\end{array}$ & $\begin{array}{c}\text { Quantidade coletada } \\
\text { (em kg) }\end{array}$ \\
$1^{\text {a viagem }}$ & 23 & $03: 00$ & 8.950 \\
$2^{\mathrm{a}}$ viagem & 38 & $03: 33$ & 9.040 \\
$3^{\mathrm{a}}$ viagem & 43 & $03: 37$ & 8.800 \\
Totais diários & 104 & $10: 10$ & 26.790 \\
Totais mensais & 1352 & $132: 10$ & 348.270 \\
& & & \\
Densidade & $(\mathrm{em} \mathrm{kg} / \mathrm{km})$ & & \\
$1^{\mathrm{a}}$ viagem & 389,13 & & \\
$2^{\mathrm{a}}$ viagem & 237,89 & & \\
$3^{\mathrm{a}}$ viagem & 251,43 & & \\
Média & 257,60 & & \\
& & & \\
Custo $\mathrm{km}$ & $(\mathrm{em} \mathrm{R} \$)$ & & \\
& 6,25 & & \\
\hline
\end{tabular}




\begin{tabular}{|c|c|c|c|}
\hline \multirow[t]{2}{*}{ Setor 6} & Dia 4 de setembro & & \\
\hline & $\begin{array}{c}\text { Distância percorrida } \\
\text { (em km) }\end{array}$ & $\begin{array}{l}\text { Tempo gasto } \\
\text { (hh:mm) }\end{array}$ & $\begin{array}{c}\text { Quantidade coletada } \\
\text { (em kg) }\end{array}$ \\
\hline $1^{a}$ viagem & 27 & $02: 30$ & 7520 \\
\hline $2^{a}$ viagem & 33 & $02: 23$ & 7920 \\
\hline$\beta^{a}$ viagem & 95 & $05: 42$ & 7190 \\
\hline Totais diários & 155 & $10: 35$ & 22.630 \\
\hline Totais mensais & 2015 & $137: 35$ & 294.190 \\
\hline Densidade & $(\mathrm{em} \mathrm{kg} / \mathrm{km})$ & & \\
\hline $1^{\text {a }}$ viagem & 278,52 & & \\
\hline $2^{\mathrm{a}}$ viagem & 240,00 & & \\
\hline$\beta^{a}$ viagem & 75,68 & & \\
\hline Média & 99,61 & & \\
\hline Custo/km & $\begin{array}{c}\text { (em RS) } \\
4,19\end{array}$ & & \\
\hline
\end{tabular}

\begin{tabular}{|lccc|}
\hline Setor 7 & $\begin{array}{c}\text { Dia } 4 \text { de setembro } \\
\text { Distância percorrida } \\
(\mathrm{em} \mathrm{km})\end{array}$ & $\begin{array}{c}\text { Tempo gasto } \\
(\mathrm{hh}: \mathrm{mm})\end{array}$ & $\begin{array}{c}\text { Quantidade coletada } \\
(\mathrm{em} \mathrm{kg})\end{array}$ \\
$1^{\text {a }}$ viagem & 23 & $02: 40$ & 8010 \\
$2^{\mathrm{a}}$ viagem & 19 & $02: 43$ & 8570 \\
$3^{\mathrm{a}}$ viagem & 31 & $03: 37$ & 8580 \\
Totais diários & 73 & $09: 00$ & 25.160 \\
Totais mensais & 949 & $117: 00$ & 327.080 \\
& & & \\
Densidade & $(\mathrm{em} \mathrm{kg} / \mathrm{km})$ & & \\
$1^{\mathrm{a}}$ viagem & 348,26 & & \\
$2^{\mathrm{a}}$ viagem & 451,05 & & \\
$3^{\mathrm{a}}$ viagem & 276,77 & & \\
Média & 344,66 & & \\
& & & \\
Custo $/ \mathrm{km}$ & $(\mathrm{em} \mathrm{R} \$)$ & & \\
& 8,91 & & \\
\hline
\end{tabular}




\begin{tabular}{|c|c|c|c|}
\hline \multirow[t]{2}{*}{ Setor 8} & Dia 4 de setembro & & \\
\hline & $\begin{array}{c}\text { Distância percorrida } \\
\text { (em km) }\end{array}$ & $\begin{array}{l}\text { Tempo gasto } \\
\text { (hh:mm) }\end{array}$ & $\begin{array}{l}\text { Quantidade coletada } \\
\text { (em kg) }\end{array}$ \\
\hline $1^{\mathrm{a}}$ viagem & 34 & $02: 32$ & 5540 \\
\hline $2^{3}$ viagem & 34 & $02: 31$ & 6970 \\
\hline $3^{a}$ viagem & 45 & $03: 47$ & 7080 \\
\hline Totais diários & 113 & $08: 50$ & 19.590 \\
\hline Totais mensais & 1469 & $114: 50$ & 254.670 \\
\hline Densidade & $(\mathrm{em} \mathrm{kg} / \mathrm{km})$ & & \\
\hline $1^{\mathrm{a}}$ viagem & 162,94 & & \\
\hline $2^{a}$ viagem & 205,00 & & \\
\hline $3^{a}$ viagem & 157,33 & & \\
\hline Média & 173,36 & & \\
\hline Custo/km & (em RS) & & \\
\hline & 5,75 & & \\
\hline
\end{tabular}

\begin{tabular}{|lccc|}
\hline Setor 9 & $\begin{array}{c}\text { Dia } 4 \text { de setembro } \\
\text { Distância percorrida } \\
(\mathrm{em} \mathrm{km})\end{array}$ & $\begin{array}{c}\text { Tempo gasto } \\
(\mathrm{hh}: \mathrm{mm})\end{array}$ & $\begin{array}{c}\text { Quantidade coletada } \\
(\mathrm{em} \mathrm{kg})\end{array}$ \\
$1^{\mathrm{a}}$ viagem & 39 & $03: 25$ & 9470 \\
$2^{\mathrm{a}}$ viagem & 62 & $03: 44$ & 8640 \\
$3^{\mathrm{a}}$ viagem & & & \\
Totais diários & 101 & $07: 09$ & 18.110 \\
Totais mensais & 1313 & $92: 57$ & 235.430 \\
& & & \\
Densidade & $(\mathrm{em} \mathrm{kg} / \mathrm{km})$ & & \\
$1^{\mathrm{a}}$ viagem & 242,82 & & \\
$2^{\mathrm{a}}$ viagem & 139,35 & & \\
$3^{\mathrm{a}}$ viagem & & & \\
Média & 179,31 & \\
Custo/km & $(\mathrm{em} \mathrm{R} \$)$ & & \\
& 5,79 & & \\
\hline
\end{tabular}




\begin{tabular}{|c|c|c|c|}
\hline \multirow[t]{2}{*}{ Setor 10} & Dia 5 de setembro & & \\
\hline & $\begin{array}{c}\text { Distância percorrida } \\
\text { (em km) }\end{array}$ & $\begin{array}{l}\text { Tempo gasto } \\
\text { (hh:mm) }\end{array}$ & $\begin{array}{c}\text { Quantidade coletada } \\
\text { (em kg) }\end{array}$ \\
\hline $1^{\text {a }}$ viagem & 32 & $03: 40$ & 10520 \\
\hline $\begin{array}{l}2^{a} \text { viagem } \\
3^{a} \text { viagem }\end{array}$ & 51 & $03: 20$ & 8150 \\
\hline Totais diários & 83 & $07: 00$ & 18.670 \\
\hline Totais mensais & 1079 & $91: 00$ & 242.710 \\
\hline Densidade & $(\mathrm{em} \mathrm{kg} / \mathrm{km})$ & & \\
\hline $1^{\text {a }}$ viagem & 328,75 & & \\
\hline$\left\{\begin{array}{l}2^{a} \text { viagem } \\
3^{a} \text { viagem }\end{array}\right.$ & 159,80 & & \\
\hline Média & 224,94 & & \\
\hline Custo/km & $\begin{array}{c}\text { (em R\$) } \\
7,05\end{array}$ & & \\
\hline
\end{tabular}

\begin{tabular}{|c|c|c|c|}
\hline \multirow[t]{2}{*}{ Setor 11} & Dia 4 de setembro & & \\
\hline & $\begin{array}{c}\text { Distância percorrida } \\
(\mathrm{em} \mathrm{km})\end{array}$ & $\begin{array}{l}\text { Tempo gasto } \\
\text { (hh:mm) }\end{array}$ & $\begin{array}{l}\text { Quantidade coletada } \\
(\mathrm{em} \mathrm{kg})\end{array}$ \\
\hline $1^{\mathrm{a}}$ viagem & 44 & $03: 45$ & 7.510 \\
\hline $2^{2}$ viagem & 50 & $04: 24$ & 9.920 \\
\hline $3^{2}$ viagem & 50 & $03: 21$ & 7.660 \\
\hline Totais diários & 144 & $11: 30$ & 25.090 \\
\hline Totais mensais & 1872 & $149: 30$ & 326.170 \\
\hline Densidade & $(\mathrm{em} \mathrm{kg} / \mathrm{km})$ & & \\
\hline $1^{\mathrm{a}}$ viagem & 170,68 & & \\
\hline $2^{a}$ viagem & 198,40 & & \\
\hline$\beta^{a}$ viagem & 153,20 & & \\
\hline Média & 174,24 & & \\
\hline Custo/km & $\begin{array}{c}\text { (em } \mathrm{RS}) \\
4,52\end{array}$ & & \\
\hline
\end{tabular}




\begin{tabular}{|c|c|c|c|}
\hline \multirow[t]{2}{*}{ Setor 12} & Dia 5 de setembro & & \\
\hline & $\begin{array}{c}\text { Distância percorrida } \\
(\mathrm{em} \mathrm{km})\end{array}$ & $\begin{array}{c}\text { Tempo gasto } \\
\text { (hh:mm) }\end{array}$ & $\begin{array}{c}\text { Quantidade coletada } \\
\text { (em kg) }\end{array}$ \\
\hline $1^{a}$ viagem & 42 & $02: 57$ & 8240 \\
\hline $2^{a}$ viagem & 43 & $03: 02$ & 5970 \\
\hline $3^{a}$ viagem & 58 & $04: 36$ & 8680 \\
\hline Totais diários & 143 & $10: 35$ & 22.890 \\
\hline Totais mensais & 1859 & $137: 35$ & 297.570 \\
\hline Densidade & $(\mathrm{em} \mathrm{kg} / \mathrm{km})$ & & \\
\hline $1^{a}$ viagem & 196,19 & & \\
\hline $2^{a}$ viagem & 138,84 & & \\
\hline $3^{2}$ viagem & 149,66 & & \\
\hline Média & 160,07 & & \\
\hline Custo $/ \mathrm{km}$ & $(\mathrm{em} \mathrm{R} \$)$ & & \\
\hline & 4,55 & & \\
\hline
\end{tabular}

\begin{tabular}{|lccc|}
\hline Setor 13 & $\begin{array}{c}\text { Dia 5 de setembro } \\
\text { Distância percorrida } \\
(\mathrm{em} \mathrm{km})\end{array}$ & $\begin{array}{c}\text { Tempo gasto } \\
(\mathrm{hh}: \mathrm{mm})\end{array}$ & $\begin{array}{c}\text { Quantidade coletada } \\
(\mathrm{em} \mathrm{kg})\end{array}$ \\
$1^{\text {a viagem }}$ & 42 & $03: 38$ & 8.410 \\
$2^{\mathrm{a}}$ viagem & 41 & $03: 32$ & 9.390 \\
$3^{\mathrm{a}}$ viagem & 49 & $03: 40$ & 9.860 \\
Totais diários & 132 & $10: 50$ & 27.660 \\
Totais mensais & 1716 & $140: 50$ & 359.580 \\
& & & \\
Densidade & $(\mathrm{em} \mathrm{kg} / \mathrm{km})$ & & \\
$1^{\mathrm{a}}$ viagem & 200,24 & & \\
$2^{\mathrm{a}}$ viagem & 229,02 & & \\
$3^{\mathrm{a}}$ viagem & 201,22 & & \\
Média & 209,55 & & \\
Custo/km & & & \\
& $(\mathrm{em} \mathrm{R} \$)$ & & \\
\hline
\end{tabular}




\begin{tabular}{|lccc|}
\hline Setor 14 & $\begin{array}{c}\text { Dia 5 de setembro } \\
\text { Distância percorrida } \\
(\mathrm{em} \mathrm{km})\end{array}$ & $\begin{array}{c}\text { Tempo gasto } \\
(\mathrm{hh}: \mathrm{mm})\end{array}$ & $\begin{array}{c}\text { Quantidade coletada } \\
(\mathrm{em} \mathrm{kg})\end{array}$ \\
$1^{\mathrm{a}}$ viagem & 78 & $04: 44$ & 8310 \\
$2^{\mathrm{a}}$ viagem & 44 & $03: 08$ & 8480 \\
$3^{\mathrm{a}}$ viagem & 50 & $03: 58$ & 7490 \\
Totais diários & 172 & $11: 50$ & 24.280 \\
Totais mensais & 2236 & $153: 50$ & 315.640 \\
& & & \\
Densidade & $(\mathrm{em} \mathrm{kg} / \mathrm{km})$ & & \\
$1^{\mathrm{a}}$ viagem & 106,54 & & \\
$2^{\mathrm{a}}$ viagem & 192,73 & & \\
$3^{\mathrm{a}}$ viagem & 149,80 & & \\
Média & 141,16 & \\
& & & \\
Custo $/ \mathrm{km}$ & $(\mathrm{em} \mathrm{R} \$)$ & & \\
& 3,78 & \\
\hline
\end{tabular}

\begin{tabular}{|c|c|c|c|}
\hline \multirow[t]{2}{*}{ Setor 15} & Dia 5 de setembro & & \\
\hline & $\begin{array}{l}\text { Distância percorrida } \\
(\mathrm{em} \mathrm{km})\end{array}$ & $\begin{array}{l}\text { Tempo gasto } \\
\text { (hh:mm) }\end{array}$ & $\begin{array}{c}\text { Quantidade coletada } \\
(\mathrm{em} \mathrm{kg})\end{array}$ \\
\hline $1^{\mathrm{a}}$ viagem & 34 & $02: 57$ & 9120 \\
\hline $\begin{array}{l}2^{a} \text { viagem } \\
3^{a} \text { viagem }\end{array}$ & 55 & $04: 03$ & 7230 \\
\hline Totais diários & 89 & $07: 00$ & 16.350 \\
\hline Totais mensais & 1157 & $91: 00$ & 212.550 \\
\hline Densidade & $(\mathrm{em} \mathrm{kg} / \mathrm{km})$ & & \\
\hline $1^{\text {a }}$ viagem & 268,24 & & \\
\hline $\begin{array}{l}2^{\mathrm{a}} \text { viagem } \\
3^{\mathrm{a}} \text { viagem }\end{array}$ & 131,45 & & \\
\hline Média & 183,71 & & \\
\hline Custo/km & $\begin{array}{c}\text { (em } R S) \\
6,57\end{array}$ & & \\
\hline
\end{tabular}




\begin{tabular}{|c|c|c|c|}
\hline \multirow[t]{2}{*}{ Setor 16} & \multicolumn{3}{|l|}{ Dia 5 de setembro } \\
\hline & $\begin{array}{c}\text { Distância percorrida } \\
(\mathrm{em} \mathrm{km})\end{array}$ & $\begin{array}{l}\text { Tempo gasto } \\
\text { (hh:mm) }\end{array}$ & $\begin{array}{c}\text { Quantidade coletada } \\
\text { (em kg) }\end{array}$ \\
\hline $1^{a}$ viagem & 25 & $03: 12$ & 9600 \\
\hline $2^{\mathrm{a}}$ viagem & 35 & $02: 23$ & 6280 \\
\hline \multicolumn{4}{|l|}{$3^{\mathrm{a}}$ viagem } \\
\hline Totais diários & 60 & $05: 35$ & 15.880 \\
\hline Totais mensais & 780 & $72: 35$ & 206.440 \\
\hline Densidade & $(\mathrm{em} \mathrm{kg} / \mathrm{km}))$ & & \\
\hline $1^{2}$ viagem & 384,00 & & \\
\hline $2^{a}$ viagem & 179,43 & & \\
\hline \multicolumn{4}{|l|}{$3^{\mathrm{a}}$ viagem } \\
\hline Média & 264,67 & & \\
\hline Custo $/ \mathrm{km}$ & $(\mathrm{em} \mathrm{RS})$ & & \\
\hline & 9,75 & & \\
\hline
\end{tabular}

\begin{tabular}{|c|c|c|c|}
\hline \multirow[t]{2}{*}{ Setor $16 / 17$} & \multicolumn{3}{|l|}{ Dia 5 de setembro } \\
\hline & $\begin{array}{c}\text { Distância percorrida } \\
(\mathrm{em} \mathrm{km})\end{array}$ & $\begin{array}{l}\text { Tempo gasto } \\
\text { (hh:mm) }\end{array}$ & $\begin{array}{c}\text { Quantidade coletada } \\
\text { (em kg) }\end{array}$ \\
\hline $1^{2}$ viagem & 34 & $05: 20$ & 8110 \\
\hline $2^{a}$ viagem & 38 & $02: 40$ & 8080 \\
\hline \multicolumn{4}{|l|}{$3^{a}$ viagem } \\
\hline Totais diários & 72 & $08: 00$ & 16.190 \\
\hline Totais mensais & 936 & 104:00 & 210.470 \\
\hline Densidade & $(\mathrm{em} \mathrm{kg} / \mathrm{km})$ & & \\
\hline $1^{\mathrm{a}}$ viagem & 238,53 & & \\
\hline $2^{2}$ viagem & 212,63 & & \\
\hline \multicolumn{4}{|l|}{$3^{\mathrm{a}}$ viagem } \\
\hline Média & 224,86 & & \\
\hline Custo/km & $(\mathrm{em} \mathrm{R} \$)$ & & \\
\hline & 8,12 & & \\
\hline
\end{tabular}




\begin{tabular}{|lccc|}
\hline Setor 17 & $\begin{array}{c}\text { Dia 5 de setembro } \\
\text { Distância percorrida } \\
(\mathrm{em} \mathrm{km})\end{array}$ & $\begin{array}{c}\text { Tempo gasto } \\
(\mathrm{hh}: \mathrm{mm})\end{array}$ & $\begin{array}{c}\text { Quantidade coletada } \\
(\mathrm{em} \mathrm{kg})\end{array}$ \\
$1^{\mathrm{a}}$ viagem & 24 & $04: 05$ & 9.580 \\
$2^{\mathrm{a}}$ viagem & 42 & $03: 30$ & 7.490 \\
$3^{\mathrm{a}}$ viagem & & & 17.070 \\
Totais diários & 66 & $07: 35$ & 221.910 \\
Totais mensais & 858 & $98: 35$ & \\
Densidade & & & \\
$1^{\text {a viagem }}$ & $(\mathrm{em} \mathrm{kg} / \mathrm{km})$ & & \\
$2^{\mathrm{a}}$ viagem & 399,17 & & \\
$3^{\mathrm{a}}$ viagem & 178,33 & & \\
Média & & & \\
& 258,64 & & \\
Custo $/ \mathrm{km}$ & $(\mathrm{em} \mathrm{R} \$)$ & & \\
& 8,86 & & \\
\hline
\end{tabular}

\begin{tabular}{|lccc|}
\hline Setor 18 & $\begin{array}{c}\text { Dia 5 de setembro } \\
\text { Distância percorrida } \\
(\mathrm{em} \mathrm{km})\end{array}$ & $\begin{array}{c}\text { Tempo gasto } \\
(\mathrm{hh}: \mathrm{mm})\end{array}$ & $\begin{array}{c}\text { Quantidade coletada } \\
(\mathrm{em} \mathrm{kg})\end{array}$ \\
$1^{\mathrm{a}}$ viagem & 35 & $03: 28$ & 7.300 \\
$2^{\mathrm{a}}$ viagem & 39 & $03: 47$ & 7.130 \\
$3^{\mathrm{a}}$ viagem & 31 & $03: 15$ & 7.810 \\
Totais diários & 105 & $10: 30$ & 22.240 \\
Totais mensais & 1365 & $136: 30$ & 289.120 \\
Densidade & & & \\
$1^{\text {a viagem }}$ & $(\mathrm{em} \mathrm{kg} / \mathrm{km})$ & & \\
$2^{\mathrm{a}}$ viagem & 208,57 & & \\
$3^{\mathrm{a}}$ viagem & 182,82 & & \\
Média & 251,94 & & \\
Custo/km & 211,81 & & \\
& & & \\
\hline
\end{tabular}




\begin{tabular}{|c|c|c|c|}
\hline \multirow[t]{2}{*}{ Setor 19} & Dia 5 de setembro & & \\
\hline & $\begin{array}{c}\text { Distância percorrida } \\
(\mathrm{em} \mathrm{km})\end{array}$ & $\begin{array}{l}\text { Tempo gasto } \\
\text { (hh:mm) }\end{array}$ & $\begin{array}{l}\text { Quantidade coletada } \\
\text { (em kg) }\end{array}$ \\
\hline $1^{\mathrm{a}}$ viagem & 34 & $04: 08$ & 9830 \\
\hline $2^{3}$ viagem & 35 & $04: 02$ & 8690 \\
\hline $3^{a}$ viagem & 36 & $04: 00$ & 8080 \\
\hline Totais diários & 105 & $12: 10$ & 26.600 \\
\hline Totais mensais & 1365 & $158: 10$ & 345.800 \\
\hline Densidade & $(\mathrm{em} \mathrm{kg} / \mathrm{km})$ & & \\
\hline $1^{a}$ viagem & 289,12 & & \\
\hline $2^{\mathrm{a}}$ viagem & 248,29 & & \\
\hline $3^{\mathrm{a}}$ viagem & 224,44 & & \\
\hline Média & 253,33 & & \\
\hline Custo $/ \mathrm{km}$ & $\begin{array}{c}\text { (em RS) } \\
6,19 \\
\end{array}$ & & \\
\hline \multirow[t]{2}{*}{ Setor 20} & Dia 5 de setembro & & \\
\hline & $\begin{array}{c}\text { Distância percorrida } \\
(\mathrm{em} \mathrm{km})\end{array}$ & $\begin{array}{l}\text { Tempo gasto } \\
\text { (hh:mm) }\end{array}$ & $\begin{array}{c}\text { Quantidade coletada } \\
\text { (em kg) }\end{array}$ \\
\hline $1^{\mathrm{a}}$ viagem & 27 & $02: 46$ & 8130 \\
\hline $2^{a}$ viagem & 33 & $02: 31$ & 6740 \\
\hline $3^{a}$ viagem & 100 & $06: 13$ & 7510 \\
\hline Totais diários & 160 & $11: 30$ & 22.380 \\
\hline Totais mensais & 2080 & $149: 30$ & 290.940 \\
\hline Densidade & $(\mathrm{em} \mathrm{kg} / \mathrm{km})$ & & \\
\hline $1^{\mathrm{a}}$ viagem & 301,11 & & \\
\hline $2^{2}$ viagem & 204,24 & & \\
\hline $3^{\mathrm{a}}$ viagem & 75,10 & & \\
\hline Média & 139,88 & & \\
\hline Custo/km & $\begin{array}{c}(\mathrm{em} \mathrm{R}) \\
4,06\end{array}$ & & \\
\hline
\end{tabular}




\begin{tabular}{|cccc|}
\hline Setor 21 & $\begin{array}{c}\text { Dia 4 de setembro } \\
\text { Distância percorrida } \\
(\mathrm{em} \mathrm{km})\end{array}$ & $\begin{array}{c}\text { Tempo gasto } \\
(\mathrm{hh}: \mathrm{mm})\end{array}$ & $\begin{array}{c}\text { Quantidade coletada } \\
(\mathrm{em} \mathrm{kg})\end{array}$ \\
$1^{\text {a }}$ viagem & 60 & $03: 52$ & 7060 \\
$2^{\mathrm{a}}$ viagem & 77 & $04: 21$ & 6510 \\
$3^{\mathrm{a}}$ viagem & 73 & $03: 16$ & 4700 \\
Totais diários & 210 & $11: 29$ & 18.270 \\
Totais mensais & 2730 & $149: 17$ & 237.510 \\
& & & \\
Densidade & $(\mathrm{em} \mathrm{kg} / \mathrm{km})$ & & \\
$1^{\mathrm{a}}$ viagem & 117,67 & & \\
$2^{\mathrm{a}}$ viagem & 84,55 & & \\
$3^{\mathrm{a}}$ viagem & 64,38 & \\
Média & 87,00 & \\
& & & \\
Custo $/ \mathrm{km}$ & $(\mathrm{em} \mathrm{R} \$)$ & & \\
& 3,10 & \\
\hline
\end{tabular}

\begin{tabular}{|c|c|c|c|}
\hline \multirow[t]{2}{*}{ Setor 22} & Dia 4 de setembro & & \\
\hline & $\begin{array}{c}\text { Distância percorrida } \\
(\mathrm{em} \mathrm{km)}\end{array}$ & $\begin{array}{l}\text { Tempo gasto } \\
\text { (hh:mm) }\end{array}$ & $\begin{array}{l}\text { Quantidade coletada } \\
\text { (em kg) }\end{array}$ \\
\hline $1^{2}$ viagem & 27 & $02: 24$ & 7380 \\
\hline $2^{a}$ viagem & 32 & $02: 35$ & 7310 \\
\hline $3^{\mathrm{a}}$ viagem & 54 & $04: 16$ & 7590 \\
\hline Totais diários & 113 & $9: 15$ & 22.280 \\
\hline Totais mensais & 1469 & $120: 15$ & 289.640 \\
\hline Densidade & $(\mathrm{em} \mathrm{kg} / \mathrm{km})$ & & \\
\hline $1^{\text {a }}$ viagem & 273,33 & & \\
\hline $2^{\mathrm{a}}$ viagem & 228,44 & & \\
\hline $3^{\mathrm{a}}$ viagem & 140,56 & & \\
\hline Média & 197,17 & & \\
\hline Custo/km & $\begin{array}{c}(\mathrm{em} \mathrm{RS}) \\
5,75\end{array}$ & & \\
\hline
\end{tabular}




\begin{tabular}{|c|c|c|c|}
\hline \multirow[t]{2}{*}{ Setor 23} & Dia 4 de setembro & & \\
\hline & $\begin{array}{c}\text { Distância percorrida } \\
(\mathrm{em} \mathrm{km})\end{array}$ & $\begin{array}{l}\text { Tempo gasto } \\
\text { (hh:mm) }\end{array}$ & $\begin{array}{l}\text { Quantidade coletada } \\
\text { (em kg) }\end{array}$ \\
\hline $1^{a}$ viagem & 28 & $03: 24$ & 8490 \\
\hline $\begin{array}{l}2^{\mathrm{a}} \text { viagem } \\
3^{\mathrm{a}} \text { viagem }\end{array}$ & 39 & $03: 36$ & 7200 \\
\hline Totais diários & 67 & 07:00 & 15.690 \\
\hline Totais mensais & 871 & $91: 00$ & 203.970 \\
\hline Densidade & $(\mathrm{em} \mathrm{kg} / \mathrm{km})$ & & \\
\hline $1^{a}$ viagem & 303,21 & & \\
\hline $\begin{array}{l}2^{\mathrm{a}} \text { viagem } \\
\beta^{\mathrm{a}} \text { viagem }\end{array}$ & 184,62 & & \\
\hline Média & 234,18 & & \\
\hline Custo $/ \mathrm{km}$ & $\begin{array}{c}\text { (em RS) } \\
8,73 \\
\end{array}$ & & \\
\hline \multirow[t]{2}{*}{ Setor 24} & Dia 5 de setembro & & \\
\hline & $\begin{array}{c}\text { Distância percorrida } \\
(\mathrm{em} \mathrm{km)})\end{array}$ & $\begin{array}{l}\text { Tempo gasto } \\
\text { (hh:mm) }\end{array}$ & $\begin{array}{c}\text { Quantidade coletada } \\
\text { (em kg) }\end{array}$ \\
\hline $1^{a}$ viagem & 24 & $05: 25$ & 7520 \\
\hline $\begin{array}{l}2^{a} \text { viagem } \\
3^{a} \text { viagem }\end{array}$ & 38 & $02: 45$ & 4080 \\
\hline Totais diánios & 62 & $08: 10$ & 11.600 \\
\hline Totais mensais & 806 & $106: 10$ & 150.800 \\
\hline Densidade & $(\mathrm{em} \mathrm{kg} / \mathrm{km})$ & & \\
\hline $1^{2}$ viagem & 313,33 & & \\
\hline $\begin{array}{l}2^{2} \text { viagem } \\
3^{\mathrm{a}} \text { viagem }\end{array}$ & 107,37 & & \\
\hline Média & 187,10 & & \\
\hline Custo $/ \mathrm{km}$ & $\begin{array}{c}\text { (em RS) } \\
9,43\end{array}$ & & \\
\hline
\end{tabular}




\begin{tabular}{|c|c|c|c|}
\hline \multirow[t]{2}{*}{ Setor 25} & \multicolumn{3}{|l|}{ Dia 5 de setembro } \\
\hline & $\begin{array}{l}\text { Distância percorrida } \\
(\mathrm{em} \mathrm{km})\end{array}$ & $\begin{array}{l}\text { Tempo gasto } \\
\text { (hh:mm) }\end{array}$ & $\begin{array}{c}\text { Quantidade coletada } \\
\text { (em kg) }\end{array}$ \\
\hline $1^{a}$ viagem & 24 & $03: 38$ & 10.820 \\
\hline $2^{a}$ viagem & 52 & $05: 42$ & 11.010 \\
\hline \multicolumn{4}{|l|}{$3^{a}$ viagem } \\
\hline Totais diários & 76 & $09: 20$ & 21.830 \\
\hline Totais mensais & 988 & $121: 20$ & 283.790 \\
\hline Densidade & $(\mathrm{em} \mathrm{kg} / \mathrm{km})$ & & \\
\hline $1^{\mathrm{a}}$ viagem & 450,83 & & \\
\hline $2^{a}$ viagem & 211,73 & & \\
\hline \multicolumn{4}{|l|}{$3^{a}$ viagem } \\
\hline Média & 287,24 & & \\
\hline \multirow[t]{2}{*}{ Custo/km } & $(\mathrm{em} \mathrm{R})$ & & \\
\hline & 7,69 & & \\
\hline \multirow[t]{2}{*}{ Setor 26} & Dia 5 de setembro & & \\
\hline & $\begin{array}{c}\text { Distância percorrida } \\
(\mathrm{em} \mathrm{km})\end{array}$ & $\begin{array}{l}\text { Tempo gasto } \\
\text { (hh:mm) }\end{array}$ & $\begin{array}{c}\text { Quantidade coletada } \\
\text { (em kg) }\end{array}$ \\
\hline $1^{\mathrm{a}}$ viagem & 44 & $03: 15$ & 8190 \\
\hline $2^{a}$ viagem & 107 & $05: 45$ & 8350 \\
\hline \multicolumn{4}{|l|}{$\beta^{a}$ viagem } \\
\hline Totais diários & 151 & $09: 00$ & 16.540 \\
\hline Totais mensais & 1963 & $117: 00$ & 215.020 \\
\hline Densidade & $(\mathrm{em} \mathrm{kg} / \mathrm{km})$ & & \\
\hline $1^{a}$ viagem & 186,14 & & \\
\hline $2^{a}$ viagem & 78,04 & & \\
\hline \multicolumn{4}{|l|}{$3^{\mathrm{a}}$ viagem } \\
\hline Média & 109,54 & & \\
\hline \multirow[t]{2}{*}{ Custo/km } & $(\mathrm{em} R \$)$ & & \\
\hline & 3,87 & & \\
\hline
\end{tabular}




\begin{tabular}{|lccc|}
\hline Setor 27 & $\begin{array}{c}\text { Dia 5 de setembro } \\
\text { Distância percorrida } \\
(\text { em } \mathrm{km})\end{array}$ & $\begin{array}{c}\text { Tempo gasto } \\
(\mathrm{hh}: \mathrm{mm})\end{array}$ & $\begin{array}{c}\text { Quantidade coletada } \\
(\mathrm{em} \mathrm{kg})\end{array}$ \\
$1^{\mathrm{a}}$ viagem & 94 & $05: 13$ & 7430 \\
$2^{\mathrm{a}}$ viagem & 93 & $03: 58$ & 7780 \\
$3^{\mathrm{a}}$ viagem & 52 & $02: 44$ & 3640 \\
Totais diários & 219 & $11: 55$ & 18.850 \\
Totais mensais & 2847 & $154: 55$ & 245.050 \\
& & & \\
Densidade & $(\mathrm{em} \mathrm{kg} / \mathrm{km})$ & & \\
$1^{\mathrm{a}}$ viagem & 79,04 & & \\
$2^{\mathrm{a}}$ viagem & 106,58 & & \\
$3^{\mathrm{a}}$ viagem & 70,00 & & \\
Média & 86,07 & & \\
& & & \\
Custo $/ \mathrm{km}$ & $(\mathrm{em} \mathrm{R} \$)$ & & \\
& 2,97 & & \\
\hline
\end{tabular}


Anexo J - O modelo matemático - Input do “GAMS"

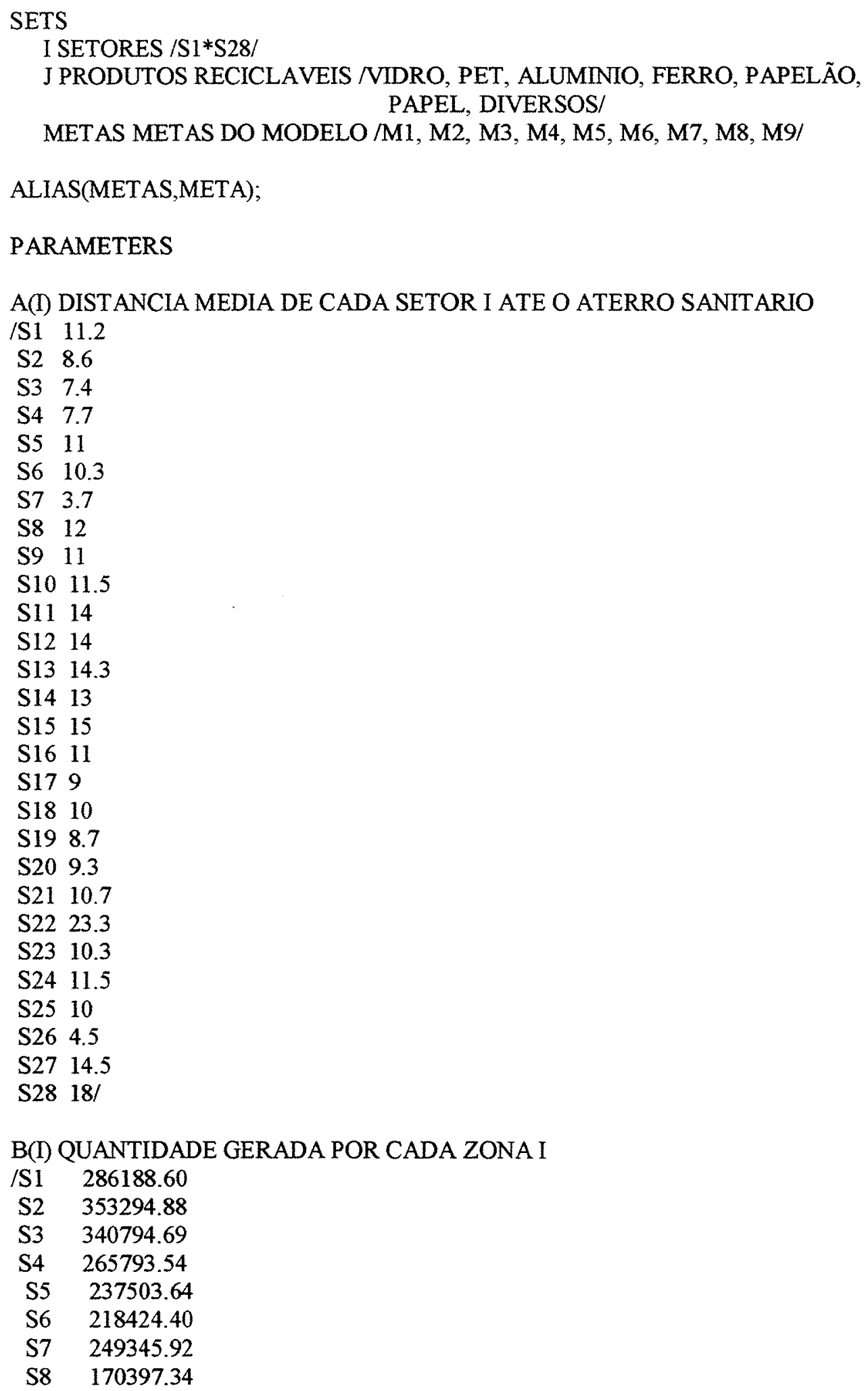


$\begin{array}{ll}\text { S9 } & 205924.20 \\ \text { S10 } & 338820.97 \\ \text { S11 } & 253951.25 \\ \text { S12 } & 223687.64 \\ \text { S13 } & 282899.07 \\ \text { S14 } & 238161.55 \\ \text { S15 } & 178950.11 \\ \text { S16 } & 165134.10 \\ \text { S17 } & 159870.87 \\ \text { S18 } & 205924.20 \\ \text { S19 } & 275004.21 \\ \text { S20 } & 246714.31 \\ \text { S21 } & 213819.06 \\ \text { S22 } & 180923.82 \\ \text { S23 } & 256582.87 \\ \text { S24 } & 182239.63 \\ \text { S25 } & 214476.97 \\ \text { S26 } & 232240.40 \\ \text { S27 } & 169739.44 \\ \text { S28 } & 232240.40 /\end{array}$

OBJ(METAS)

/M3 10

M8 195.15/;

TABLE OBJETIVO(I,METAS)

M2

M5

M6

M7

M9

S1 242687.93

3290.56

$7584 \quad 1783.53$

$43500.67 \quad 226200$

S2 299594.06

$\begin{array}{lll}2485.76 & 9362.31 & 2201.73\end{array}$

2803.53

$9031.06 \quad 2123.83$

$53700.82 \quad 226200$

S3 288993.90

1347.71

$\begin{array}{ll}7043.53 & 1656.43\end{array}$

$51800.79 \quad 226200$

S4 225392.92

2172.90

$6293.85 \quad 1480.12$

40400.62

150800

$\begin{array}{ll}\text { S5 } & 201403.08 \\ \text { S6 } & 185223.89\end{array}$

2198.56

$5788.25 \quad 1361.22$

$36100.55 \quad 150800$

S6 185223.89

1100.74

$6607.67 \quad 1553.92$

33200.51

150800

S8 144496.95

2117.57

$4515.53 \quad 1061.92$

37900.58

150800

S9 174623.73

1680.04

25900.40

150800

S10 287320.19

1955.59

$5456.99 \quad 1283.32$

$31300.48 \quad 150800$

$\begin{array}{llll}8978.76 & 2111.53 & 51500.79 & 150800\end{array}$

S11 215350.66

2623.71

$6729.71 \quad 1582.62$

2346.89

$38600.59 \quad 150800$

S12 189687.12

S13 239898.41

2384.75

$5927.72 \quad 1394.02$

$34000.52 \quad 150800$

S14 201960.99

2076.07

$\begin{array}{ll}7496.83 & 1763.03\end{array}$

43000.66

150800

$\begin{array}{llll}6311.28 & 1484.22 & 36200.56 & 150800\end{array}$

S15 151749.69

1978.52

$4742.18 \quad 1115.22$

$27200.42 \quad 150800$

S16 140033.72

1696.24

$\begin{array}{lll}4376.05 & 1029.12\end{array}$

$25100.38 \quad 150800$

S17 135570.50

1674.58

4236.58

996.32

2373.64

$\begin{array}{ll}5456.99 & 1283.32\end{array}$

$24300.37 \quad 113100$

S18 174623.73

1214.49

7287.61

1713.83

$31300.48 \quad 150800$

S20 209213.73

2233.87

$\begin{array}{ll}6537.93 & 1537.52\end{array}$

41800.64

150800

2484.48

5666.21

1332.52

37500.57

150800

S21 181318.57

3066.15

4794.48

1127.52

32500.50

150800

S23 217582.28

1768.13

6799.45

1599.02

27500.42

150800

1557.56

4829.35

1135.72

39000.60

150800

2088.63

5683.64

1336.62

27700.42

150800

1581.03

6154.37

1447.32

32600.50

150800

S26 196939.86

35300.54

150800 


$\begin{array}{llllll}\text { S27 143939.05 } & 2071.52 & 4498.10 & 1057.82 & 25800.40 & 150800 \\ \text { S28 196939.86 } & 2547.82 & 6154.37 & 1447.32 & 35300.54 & 150800\end{array}$

SCALAR CAPV CAPACIDADE MEDIA DOS VEICULOS /8500/;

VARIABLES

DEVNEG(METAS) DESVIO NEGATIVO DAS METAS M3 E M4

DEVPOS(METAS) DESVIO POSITIVO DAS METAS M3 E M4

PRODUTIV PRODUTIVIDADE DE CADA SETOR I

SOMAXI SOMATORIO DA VARIAVEL XI

SOMAYI SOMATORIO DA VARIAVEL YI

ORCAMENTC ORCAMENTO DA COLETA CONVENCIONAL POR SETOR

DT DESVIO TOTAL DAS METAS

DESVNEG(I,METAS) DESVIO NEGATIVO DAS METAS M1, M2, M5, M6, M7, M8, M9

DESVPOS(I,METAS) DESVIO POSITIVO DAS METAS M1, M2, M5, M6, M7, M8, M9 X(I) QUANTIDADE TRANSPORTADA DE CADA ZONA I AO ATERRO SANITARIO DENS(I) DENSIDADE DE COLETA

CUSTCON(I) CUSTO POR TONELADA DE LIXO COLETADO CONVENC

CUSTSEL(I) CUSTO POR TONELADA DE LIXO COLETADO SELETIVAMENTE

Y(I) QUANT TRANSPORTADA DE RECICLAVEIS DO SETOR I PARA O CENTRO

P(I,J) QUANTIDADE TRANSPORTADA DE CADA PRODUTO J DE CADA SETOR I PARA O CENTRO

QUILOMET (I) QUILOMETROS PERCORRIDOS NA COLETA CONVENCIONAL

VEICDP QUANTIDADE DE VEICULOS UTILIZADOS POR DIA NA COLETA DIARIA E DIAS PARES

VEICDI QUANTIDADE DE VEICULOS UTILIZADOS POR DIA NA COLETA DIARIA E DIAS IMPARES

CUSTCCON CUSTO DA COLETA CONVENCIONAL POR SETOR

CUSTDCON CUSTO DA DISPOSICAO FINAL DO LIXO POR SETOR

CUSTCSEL CUSTO DA COLETA SELETIVA POR SETOR

CUSTTCCON CUSTO TOTAL DA COLETA CONVENCIONAL

CUSTQUILO CUSTO VARIAVEL DA COLETA CONVENCIONAL

POSITIVE VARIABLE CUSTTCCON, CUSTTCSEL, CUSTTD, CUSTQUILO, DEVNEG, DEVPOS, PRODUTIV, SOMAXI, SOMAYI, ORCAMENTC, CUSTCCON, CUSTDCON, CUSTCSEL, DESVNEG, DESVPOS, X(I), DENS(I), Y(I), P(I,J), QUILOMET(I), VEICDP, VEICDI;

EQUATIONS

DESVTOT DEFINE A FUNCAO OBJETIVO

COL_CONV DEFINE A PRIMEIRA META_COLETA CONVENCIONAL

PERC $\bar{C}$ DEFINE A SEGUNDA META_QUTLOMETRAGEM

PERC2 DEFINE A SEGUNDA META_QUILOMETRAGEM

PERC3 DEFINE A SEGUNDA META_QUILOMETRAGEM

PERC4 DEFINE A SEGUNDA META_QUILOMETRAGEM

PERC5 DEFINE A SEGUNDA META_QUILOMETRAGEM

PERC6 DEFINE A SEGUNDA META_QUILOMETRAGEM

PERC7 DEFINE A SEGUNDA META_QULOMETRAGEM

PERC8 DEFINE A SEGUNDA META_QUILOMETRAGEM

PERC9 DEFINE A SEGUNDA META QUILOMETRAGEM

PERC10 DEFINE A SEGUNDA META_QUILOMETRAGEM 
PERC11 DEFINE A SEGUNDA META_QUILOMETRAGEM

PERC12 DEFINE A SEGUNDA META_QUILOMETRAGEM

PERC13 DEFINE A SEGUNDA META_QUILOMETRAGEM

PERC14 DEFINE A SEGUNDA META_QUILOMETRAGEM

PERC15 DEFINE A SEGUNDA META_QUILOMETRAGEM

PERC16 DEFINE A SEGUNDA META_QUILOMETRAGEM

PERC17 DEFINE A SEGUNDA META_QUILOMETRAGEM

PERC18 DEFINE A SEGUNDA META_QUILOMETRAGEM

PERC19 DEFINE A SEGUNDA META QUILOMETRAGEM

PERC20 DEFINE A SEGUNDA META_QUILOMETRAGEM

PERC21 DEFINE A SEGUNDA META_QUILOMETRAGEM

PERC22 DEFINE A SEGUNDA META_QUILOMETRAGEM

PERC23 DEFINE A SEGUNDA META_QUILOMETRAGEM

PERC24 DEFINE A SEGUNDA META_QUILOMETRAGEM

PERC25 DEFINE A SEGUNDA META_QUILOMETRAGEM

PERC26 DEFINE A SEGUNDA META_QUILOMETRAGEM

PERC27 DEFINE A SEGUNDA META_QUILOMETRAGEM

PERC28 DEFINE A SEGUNDA META_QUILOMETRAGEM

VEICULOS DEFINE A PRIMEIRA PARTE DA TERCEIRA META_VEICULOS DIARIOS E DIAS PARES

VEICULO2 DEFINE A SEGUNDA PARTE DA TERCEIRA META_VEICULOS DIARIOS E DIAS IMPARES

COL_SEL DEFINE A SETIMA META_COLETA SELETIVA

RESTGER DEFINE A RESTRICAO DE QUANTIDADE DE RESIDUOS GERADOS POR SETOR

DESVIO DEFINE A RESTRICAO DO DESVIO POSITIVO MI IGUAL A ZERO

DESVIO2 DEFINE A RESTRICAO DO DESVIO POSITIVO M7 IGUAL A ZERO

EQUPERC1 DEFINE O PERCURSO TOTAL REALIZADO NO SETOR

EQUPERC2 DEFINE O PERCURSO TOTAL REALIZADO NO SETOR

EQUPERC3 DEFINE O PERCURSO TOT AL REALIZADO NO SETOR

EQUPERC4 DEFINE O PERCURSO TOT AL REALIZADO NO SETOR

EQUPERC5 DEFINE O PERCURSO TOTAL REALIZADO NO SETOR

EQUPERC6 DEFINE O PERCURSO TOTAL REALIZADO NO SETOR

EQUPERC7 DEFINE O PERCURSO TOT AL REALIZADO NO SETOR

EQUPERC8 DEFINE O PERCURSO TOTAL REALIZADO NO SETOR

EQUPERC9 DEFINE O PERCURSO TOTAL REALIZADO NO SETOR

EQUPERC10 DEFINE O PERCURSO TOTAL REALIZADO NO SETOR

EQUPERC11 DEFINE O PERCURSO TOTAL REALIZADO NO SETOR

EQUPERC12 DEFINE O PERCURSO TOTAL REALIZADO NO SETOR

EQUPERC13 DEFINE O PERCURSO TOTAL REALIZADO NO SETOR

EQUPERC14 DEFINE O PERCURSO TOT AL REALIZADO NO SETOR

EQUPERC15 DEFINE O PERCURSO TOTAL REALIZADO NO SETOR

EQUPERC16 DEFINE O PERCURSO TOTAL REALIZADO NO SETOR EQUPERC17 DEFINE O PERCURSO TOTAL REALIZADO NO SETOR EQUPERC18 DEFINE O PERCURSO TOTAL REALIZADO NO SETOR EQUPERC19 DEFINE O PERCURSO TOTAL REALIZADO NO SETOR EQUPERC20 DEFINE O PERCURSO TOTAL REALIZADO NO SETOR EQUPERC21 DEFINE O PERCURSO TOTAL REALIZADO NO SETOR EQUPERC22 DEFINE O PERCURSO TOTAL REALIZADO NO SETOR EQUPERC23 DEFINE O PERCURSO TOT AL REALIZADO NO SETOR EQUPERC24 DEFINE O PERCURSO TOTAL REALIZADO NO SETOR 
EQUPERC25 DEFINE O PERCURSO TOTAL REALIZADO NO SETOR EQUPERC26 DEFINE O PERCURSO TOTAL REALIZADO NO SETOR EQUPERC27 DEFINE O PERCURSO TOTAL REALIZADO NO SETOR EQUPERC28 DEFINE O PERCURSO TOTAL REALIZADO NO SETOR EQU2 DEFINE A VARIAVEL VEICULO PARA A COLETA DIARIA E DIAS PARES

EQU3 DEFINE A VARIAVEL VEICULO PARA A COLETA DIARIA E DIAS IMPARES

EQU6 DEFINE A VARIAVEL QUANTIDADE DE VIDRO COLETADO

EQU7 DEFINE A VARIAVEL QUANTIDADE DE PET COLETADO

EQU8 DEFINE A VARIAVEL QUANTIDADE DE ALUMINIO COLETADO

EQU9 DEFINE A VARIAVEL QUANTIDADE DE FERRO COLETADO

EQU10 DEFINE A VARIAVEL QUANTIDADE DE PAPELAO COLETADO

EQU11 DEFINE A VARIAVEL QUANTIDADE DE PAPEL COLETADO

EQU12 DEFINE A VARIAVEL QUANTIDADE DE DIVERSOS COLETADO

MEDIA1 DEFINE A DENSIDADE MEDIA DE COLETA

ORC_CONV DEFINE A QUINTA META_ORCAMENTO COL CONVENCIONAL

ORCACON DEFINE O ORCAMENTO TOTAL POR SETOR

CUSTOI DEFINE O CUSTO TOTAL DA COLETA CONVENCIONAL POR SETOR

CUSTO2 DEFINE O CUSTO TOTAL DA COLETA CONVENCIONAL POR SETOR

CUSTO3 DEFINE O CUSTO TOTAL DA COLETA CONVENCIONAL POR SETOR

CUSTO4 DEFINE O CUSTO TOTAL DA COLETA CONVENCIONAL POR SETOR

CUSTO5 DEFINE O CUSTO TOTAL DA COLETA CONVENCIONAL POR SETOR

CUSTO6 DEFINE O CUSTO TOTAL DA COLETA CONVENCIONAL POR SETOR

CUSTO7 DEFINE O CUSTO TOTAL DA COLETA CONVENCIONAL POR SETOR

CUSTO8 DEFINE O CUSTO TOTAL DA COLETA CONVENCIONAL POR SETOR

CUSTO9 DEFINE O CUSTO TOTAL DA COLETA CONVENCIONAL POR SETOR

CUSTO10 DEFINE O CUSTO TOTAL DA COLETA CONVENCIONAL POR SETOR

CUSTO11 DEFINE O CUSTO TOTAL DA COLETA CONVENCIONAL POR SETOR

CUSTO12 DEFINE O CUSTO TOTAL DA COLETA CONVENCIONAL POR SETOR

CUSTO13 DEFINE O CUSTO TOTAL DA COLETA CONVENCIONAL POR SETOR

CUSTO14 DEFINE O CUSTO TOTAL DA COLETA CONVENCIONAL POR SETOR

CUSTO15 DEFINE O CUSTO TOTAL DA COLETA CONVENCIONAL POR SETOR

CUSTO16 DEFINE O CUSTO TOTAL DA COLETA CONVENCIONAL POR SETOR

CUSTO17 DEFINE O CUSTO TOTAL DA COLETA CONVENCIONAL POR SETOR

CUSTO18 DEFINE O CUSTO TOTAL DA COLETA CONVENCIONAL POR SETOR

CUSTO19 DEFINE O CUSTO TOTAL DA COLETA CONVENCIONAL POR SETOR

CUSTO20 DEFINE O CUSTO TOTAL DA COLETA CONVENCIONAL POR SETOR

CUSTO21 DEFINE O CUSTO TOTAL DA COLETA CONVENCIONAL POR SETOR

CUSTO22 DEFINE O CUSTO TOTAL DA COLETA CONVENCIONAL POR SETOR

CUSTO23 DEFINE O CUSTO TOTAL DA COLETA CONVENCIONAL POR SETOR

CUSTO24 DEFINE O CUSTO TOTAL DA COLETA CONVENCIONAL POR SETOR

CUSTO25 DEFINE O CUSTO TOTAL DA COLETA CONVENCIONAL POR SETOR

CUST DEFINE O CUSTO TOTAL DA COLETA CONVENCIONAL POR SETOR

CUST2 DEFINE O CUSTO TOTAL DA COLETA CONVENCIONAL POR SETOR

CUST3 DEFINE O CUSTO TOTAL DA COLETA CONVENCIONAL POR SETOR

SOMATCCC DEFINE O CUSTO TOTAL DA COLETA CONVENCIONAL

SOMATCS

SOMATD

SOMATCQU DEFINE O CUSTO VAR

CUSTODF

SOMA

ORC_SEL 
CUSTO

SOMA3

DENSIDAD DEFINE A OITAVA META_DENSIDADE

PROD COL

PRODUTT DEFINE A NONA META_PRODUTIVIDADE;

DESVTOT(METAS) .. DT =E = SUM(I,DESVNEG(1,'M1')) + SUM (1,DESVPOS(1,'M2')) + SUM(I, DEVPOS(M3')) + SUM(I,DEVNEG('M3')) + SUM(I,DEVPOS('M4')) + SUM(I,DEVNEG(M4')) + SUM(I,DESVPOS(I,'M5')) + SUM(I,DESVPOS(I,'M6')) + SUM(1,DESVNEG(1,'M7')) + SUM(I,DESVNEG(1,'M8')) + SUM(I,DESVPOS(1,'M8')) + SUM(I,DESVNEG(I,'M9')) + SUM(I, DESVPOS(I,'M9'));

COL_CONV(I) .. X (I) + DESVNEG(1,'M1) - DESVPOS(I,'M1) =E= OBJETIVO(I,'M1);

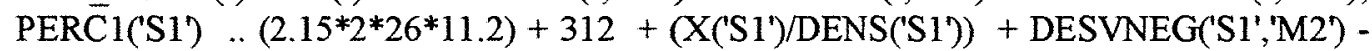
DESVPOS('S1','M2') =E = OBJETIVO('S1','M2');

PERC2('S2) .. (2.15*2*26*8.6) + $312+\left(\mathrm{X}\left(\mathrm{S} 2{ }^{\prime}\right)\right.$ /DENS('S2')) + DESVNEG('S2','M2') DESVPOS('S2','M2') =E= OBJETIVO('S2','M2');

PERC3('S3) .. (2.15*2*26*7.4) + $312+\left(X\left(\right.\right.$ S3 $\left.\left.^{\prime}\right) / \mathrm{DENS}\left(\mathrm{S}^{\prime}\right)\right)+$ DESVNEG('S3','M2') DESVPOS('S3','M2') =E= OBJETIVO('S3','M2');

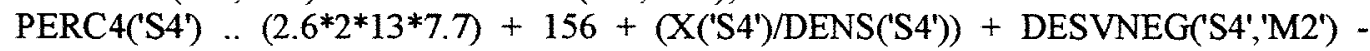
DESVPOS('S4','M2') =E = OBJETIVO('S4','M2');

PERC5(S5) .. $\left(2.6{ }^{*} 2 * 13 * 11\right)+156+\left(\mathrm{X}\left(\mathrm{CS}^{\prime}\right) / \mathrm{DENS}\left(\mathrm{CS}^{\prime}\right)\right)+$ DESVNEG('S5', M2') DESVPOS('S5', 'M2') =E= OBJETIVO('S5', 'M2');

PERC6(S6) .. (2.6*2*13*10.3) + $156+\left(\mathrm{X}\left(\mathrm{CS}^{\prime}\right) / \mathrm{DENS}\left(\mathrm{S} 6^{\prime}\right)\right)+$ DESVNEG(S6',M2') DESVPOS('S6', 'M2') =E = OBJETIVO('S6', M2');

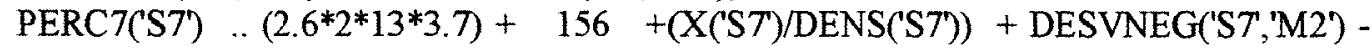
DESVPOS('S7','M2') =E = OBJETIVO('S7', 'M2');

PERC8('S8') .. $\left(2.6{ }^{*} 2^{*} 13^{*} 12\right)+156+\left(\mathrm{X}\left(\mathrm{CS}^{\prime}\right) / \mathrm{DENS}\left(\mathrm{S} 8{ }^{\prime}\right)\right)+$ DESVNEG('S8','M2') DESVPOS('S8','M2') =E= OBJETIVO('S8','M2');

PERC9('S9') .. $\left.\left(2.6^{*} 2^{*} 13^{*} 11\right)+156+\left(\mathrm{X}\left(\mathrm{S}^{\prime}\right) / \mathrm{DENS}(\mathrm{S} 9)^{\prime}\right)\right)+$ DESVNEG(S9', 'M2') DESVPOS('S9','M2') =E = OBJETIVO('S9','M2');

PERC10('S10') .. (2.6*2*13*11.5) + 156 + (X('S10')/DENS('S10'))+ DESVNEG('S10', 'M2') - DESVPOS('S10', 'M2') =E= OBJETIVO('S10','M2');

PERC11('S11') .. (2.6*2*13*14) + 156 + (X('S11)/DENS('S11)) + DESVNEG('S11','M2') DESVPOS('S1 1','M2') =E = OBJETIVO('S11','M2');

PERC12('S12') .. (2.6*2*13*14) + 156 + (X('S12')/DENS('S12')) + DESVNEG('S12', 'M2') DESVPOS('S12','M2) =E = OBJETIVO(S12','M2');

PERC13(S13') .. (2.6*2*13*14.3) + 156+ (X('S13')/DENS('S13')) + DESVNEG('S13','M2) - DESVPOS(S13','M2') =E= OBJETIVO('S13', 'M2');

PERC14(S14') .. (2.6*2*13*13) + $156+\left(\mathrm{X}^{*}\left(\mathrm{CS}^{\prime}\right) / \mathrm{DENS}\left(\mathrm{CS}^{\prime} 4^{\prime}\right)\right)+$ DESVNEG('S14', M2') DESVPOS('S14','M2') =E= OBJETIVO(S14','M2');

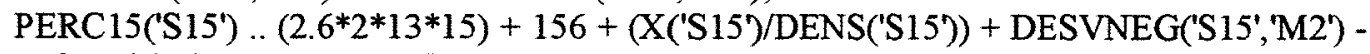
DESVPOS('S15', 'M2') =E= OBJETIVO('S15', 'M2');

PERC16('S16') .. (2.6*2*13*11) + 156 + (X('S16')/DENS('S16')) + DESVNEG('S16', 'M2') DESVPOS('S16,',M2) =E= OBJETIVO('S16','M2);

PERC17('S17') .. (2.6*2*13*9) + 156 + (X('S17)/DENS('S17)) + DESVNEG('S17, M2') DESVPOS('S17,'M2') =E = OBJETIVO(S17', 'M2');

PERC18('S18') .. (2.6*2*13*10) + 156 + (X('S18')/DENS('S18')) + DESVNEG('S18', 'M2') DESVPOS('S18', 'M2') =E= OBJETIVO('S18', 'M2');

PERC19('S19') .. (2.6*2*13*8.7) + 156 + (X('S19')/DENS(S19'))+ DESVNEG(S19', 'M2') DESVPOS('S19','M2') =E= OBJETIVO('S19', 'M2);

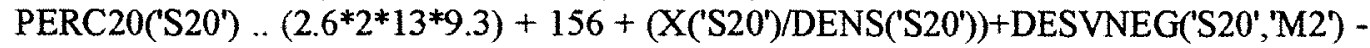
DESVPOS(S20, 'M2) =E = OBJETIVO('S20', 'M2); 
PERC21('S21') .. (2.6*2*13*10.7) + 156+(X('S21')/DENS('S21'))+ DESVNEG('S21','M2') - DESVPOS(S21','M2') =E= OBJETIVO('S21','M2');

PERC22('S22') .. (2.6*2*13*23.3) + 156 + (X('S22')/DENS('S22'))+ DESVNEG('S22','M2') - DESVPOS('S22','M2') =E= OBJETIVO('S22','M2');

PERC23('S23') .. (2.6*2*13*10.3) + 156 + (X('S23')/DENS('S23'))+ DESVNEG('S23', 'M2') - DESVPOS('S23','M2') =E= OBJETIVO('S23','M2');

PERC24('S24') .. (2.6*2*13*11.5) + $156+\left(\mathrm{X}\left(\mathrm{C}^{*} 24\right)\right.$ /DENS('S24')) + DESVNEG('S24','M2')

- DESVPOS('S24','M2') =E= OBJETIVO('S24','M2');

PERC25('S25') .. (2.6*2*13*10) + 156 + (X('S25')/DENS('S25') + DESVNEG('S25','M2') DESVPOS('S25','M2') =E= OBJETIVO(S25', $\mathrm{M} 2$ ');

PERC26('S26') .. (2.6*2*13*4.6) + $156+\left(\mathrm{X}\left(\mathrm{CS}^{\prime} 6^{\prime}\right) / \mathrm{DENS}\left(\mathrm{S} 26^{\prime}\right)\right)+$ DESVNEG('S26', 'M2) - DESVPOS('S26,'M2') =E= OBJETIVO('S26,' 'M2');

PERC27('S27') .. (2.6*2*13*14.5) + 156 + (X('S27)/DENS('S27))+ DESVNEG('S27,'M2')

- DESVPOS('S27', 'M2') =E= OBJETIVO('S27', 'M2');

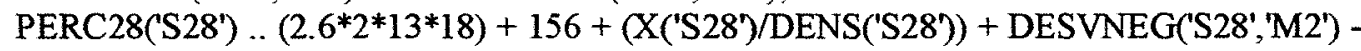
DESVPOS('S28', 'M2') =E = OBJETIVO('S28', 'M2');

VEICULOS(I) .. (X(S1')/CAPV) $/(2.15 * 26)+(\mathrm{X}(\mathrm{S} 2) / \mathrm{CAPV}) /(2.15 * 26)+$ $\left(\mathrm{X}\left(\mathrm{S}^{\prime}\right) / \mathrm{CAPV}\right) /\left(2.15^{*} 26\right)+\left(\mathrm{X}\left(\mathrm{S}^{\prime}\right) / \mathrm{CAPV}\right) /\left(2.6^{*} 13\right)+\left(\mathrm{X}\left(\mathrm{S}^{\prime}\right) / \mathrm{CAPV}\right) /\left(2.6^{*} 13\right)+$ $\left(\mathrm{X}\left(\right.\right.$ ('S6') $\left.^{\prime} / \mathrm{CAPV}\right) /\left(2.6^{*} 13\right)+\left(\mathrm{X}\left(\mathrm{CS}^{\prime}\right) / \mathrm{CAPV}\right) /\left(2.6^{*} 13\right)+\left(\mathrm{X}\left(\mathrm{S} 8^{\prime}\right) / \mathrm{CAPV}\right) /\left(2.6^{*} 13\right)+$ $\left(\mathrm{X}\left(\mathrm{(SO}^{\prime}\right) / \mathrm{CAPV}\right) /\left(2.6^{*} 13\right)+\left(\mathrm{X}\left(\mathrm{S} 10^{\prime}\right) / \mathrm{CAPV}\right) /\left(2.6^{*} 13\right)+(\mathrm{X}(\mathrm{S} 11) / \mathrm{CAPV}) /\left(2.6^{*} 13\right)+$ $\left(\mathrm{X}\left(\mathrm{S} 13^{\prime}\right) / \mathrm{CAPV}\right) /\left(2.6^{*} 13\right)+\left(\mathrm{X}\left(\mathrm{S} 25^{\prime}\right) / \mathrm{CAPV}\right) /\left(2.6^{*} 13\right)+\left(\mathrm{X}\left(\mathrm{S} 26^{\prime}\right) / \mathrm{CAPV}\right) /\left(2.6^{*} 13\right)+$ $\left(\mathrm{X}\left(\mathrm{C}^{\mathrm{S}} 2 \mathrm{~T}^{\prime}\right) / \mathrm{CAPV}\right) /\left(2.6^{*} 13\right)+\mathrm{DEVNEG}\left(\mathrm{M}^{\prime}\right)$ - DEVPOS('M3') $=\mathrm{E}=\mathrm{OBJ}\left(\mathrm{CM}^{\prime}\right)$;

VEICULO2(I) .. (X('S1')/CAPV)/(2.15*26) $+(\mathrm{X}(\mathrm{S} 2) / \mathrm{CAPV}) /(2.15 * 26)+$ $\left(\mathrm{X}\left(\mathrm{S} 3^{*}\right) / \mathrm{CAPV}\right) /\left(2.15^{*} 26\right)+\left(\mathrm{X}\left(\mathrm{S} 12^{\prime}\right) / \mathrm{CAPV}\right) /\left(2.6^{*} 13\right)+\left(\mathrm{X}\left(\mathrm{S} 14^{\prime}\right) / \mathrm{CAPV}\right) /\left(2.6^{*} 13\right)+$ $\left(\mathrm{X}\left(\mathrm{CS}^{\prime} 5^{\prime}\right) / \mathrm{CAPV}\right) /\left(2.6^{*} 13\right)+\left(\mathrm{X}\left(\mathrm{S} 16^{\prime}\right) / \mathrm{CAPV}\right) /\left(2.6^{*} 13\right)+\left(\mathrm{X}\left(\mathrm{S} 17^{7}\right) / \mathrm{CAPV}\right) /\left(2.6^{*} 13\right)+$ $\left(\mathrm{X}\left(\mathrm{S} 18^{7}\right) / \mathrm{CAPV}\right) /\left(2.6^{*} 13\right)+\left(\mathrm{X}\left(\mathrm{S} 19^{\prime}\right) / \mathrm{CAPV}\right) /\left(2.6^{*} 13\right)+\left(\mathrm{X}\left(\mathrm{S} 20^{\prime}\right) / \mathrm{CAPV}\right) /\left(2.6^{*} 13\right)+$ $\left(\mathrm{X}\left(\mathrm{S} 21^{\prime}\right) / \mathrm{CAPV}\right) /\left(2.6^{*} 13\right)+(\mathrm{X}(\mathrm{S} 22) / \mathrm{CAPV}) /\left(2.6^{*} 13\right)+(\mathrm{X}(\mathrm{S} 23) / \mathrm{CAPV}) /\left(2.6^{*} 13\right)+$ $\left(\mathrm{X}\left(\mathrm{S}^{2} 24^{\prime}\right) / \mathrm{CAPV}\right) /\left(2.6^{*} 13\right)+\left(\mathrm{X}\left(\mathrm{CS}^{2} 8^{\prime}\right) / \mathrm{CAPV}\right) /\left(2.6^{*} 13\right)+\mathrm{DEVNEG}\left(\mathrm{C}^{\prime} 4^{\prime}\right)-\mathrm{DEVPOS}\left(\mathrm{M}^{\prime}\right)$ $=\mathrm{E}=\mathrm{OBJ}\left(\mathrm{M} 33^{\prime}\right)$;

COL_SEL(I) .. SUM(J, P(I,J) + DESVNEG(I,'MT) $-\operatorname{DESVPOS}\left(I,{ }^{\prime} M 7^{\prime}\right)=E=$ OBJETIVO(I,'MT);

RESTGER(I) .. X (I) + SUM(J,P(I,J) $=\mathrm{L}=\mathrm{B}(\mathrm{I})$;

DESVIO(I,METAS) .. DESVPOS $\left(1,{ }^{\prime} M 1{ }^{\prime}\right)=E=0$;

DESVIO2(I,METAS) .. DESVPOS $(1, \mathrm{M} 7)=\mathrm{E}=0$;

EQUPERC1('S1') .. $(2.15 * 2 * 26 * 11.2)+312+\left(\mathrm{X}\left(\mathrm{S} 1{ }^{\prime}\right) / \mathrm{DENS}\left(\mathrm{S}^{\prime}{ }^{\prime}\right)\right)=\mathrm{E}=$ QULLOMET('S1);

EQUPERC2(S2') .. $(2.15 * 2 * 26 * 8.6)+312+\left(\mathrm{X}\left(\mathrm{CS}^{\prime}\right) / \mathrm{DENS}(\mathrm{S} 2)\right)=\mathrm{E}=$

QUILOMET('S2);

EQUPERC3('S3') .. $(2.15 * 2 * 26 * 7.4)+312+\left(\mathrm{X}\left(\mathrm{CS}^{\prime}\right) / \mathrm{DENS}\left(\mathrm{S}^{\prime}\right)\right)=\mathrm{E}=$

QUILOMET('S3');

EQUPERC4('S4') .. $(2.6 * 2 * 13 * 7.7)+156+\left(\mathrm{X}(\mathrm{S} 4) / \mathrm{DENS}\left(\mathrm{S}^{\prime}\right)\right)=\mathrm{E}=$

QUILOMET(S4);

EQUPERC5('S5') .. $\left(2.6^{*} 2 * 13^{*} 11\right)+156+\left(\mathrm{X}\left(\mathrm{S}^{\prime}\right) / \mathrm{DENS}\left(\mathrm{S} 5^{\prime}\right)\right)=\mathrm{E}=$

QULLOMET(S5);

EQUPERC6('S6') .. $(2.6 * 2 * 13 * 10.3)+156+\left(\mathrm{X}^{\prime}\left(\mathrm{S} 6^{\prime}\right) / \mathrm{DENS}\left(\mathrm{S} 6{ }^{\prime}\right)\right)=\mathrm{E}=$

QUILOMET('S6);

EQUPERC7('S7) $. .(2.6 * 2 * 13 * 3.7)+156+\left(\mathrm{X}\left(\mathbf{S}^{\mathrm{S} 7}\right) / \mathrm{DENS}(\mathrm{S} 7)\right)=\mathrm{E}=$

QUILOMET(ST);

EQUPERC8('S8) $\left.. .\left(2.6^{*} 2 * 13^{*} 12\right)+156+\left(\mathrm{X}^{\prime} \mathrm{S}^{\prime}\right) / \mathrm{DENS}\left(\mathrm{S}^{\prime}\right)\right)=\mathrm{E}=$

QUILOMET(S8);

EQUPERC9('S9') .. $\left(2.6 * 2 * 13^{*} 11\right)+156+\left(\mathrm{X}\left(\right.\right.$ (S9) $\left.^{\prime} / \mathrm{DENS}\left(\mathrm{S}^{\prime}\right)\right)=\mathrm{E}=$

QUILOMET('S9');

EQUPERC10(S10') .. $\left(2.6^{*} 2 * 13^{*} 11.5\right)+156+\left(\mathrm{X}\left(\mathrm{SS}^{\prime} 0^{\prime}\right) / \mathrm{DENS}\left(\mathrm{S} 10^{\prime}\right)\right)=\mathrm{E}=$ 
QUILOMET('S10');

EQUPERC11('S11) .. $(2.6 * 2 * 13 * 14)+156+\left(\mathrm{X}(\mathrm{S} 11) / \mathrm{DENS}\left(\mathrm{S} 11^{\prime}\right)\right)=\mathrm{E}=$

QUILOMET(S11');

EQUPERC12('S12') .. (2.6*2*13*14) $+156+\left(\mathrm{X}\left(\mathrm{S}^{\mathrm{S}} 12 \mathrm{2}\right) / \mathrm{DENS}\left(\mathrm{S}^{\mathrm{S}} 12^{\prime}\right)\right)=\mathrm{E}=$

QUILOMET('S12');

EQUPERC13('S13') . . $\left(2.6^{*} 2^{*} 13^{*} 14.3\right)+156+\left(\mathrm{X}\left(\mathrm{S}^{\prime} \mathrm{S}^{\prime}\right) / \mathrm{DENS}\left(\mathrm{S}^{\prime} 3^{\prime}\right)\right)=\mathrm{E}=$

QUILOMET('S13');

EQUPERC14('S14') .. $(2.6 * 2 * 13 * 13)+156+\left(\mathrm{X}\left(\mathrm{C}^{\prime} \mathbf{S}^{\prime}\right) / \mathrm{DENS}(\mathrm{S} 14)\right)=\mathrm{E}=$

QULLOMET('S14);

EQUPERC15('S15') .. $\left(2.6^{*} 2^{*} 13^{*} 15\right)+156+\left(\mathrm{X}\left(\mathrm{S}^{\prime} 15^{\prime}\right) / \mathrm{DENS}\left(\mathrm{S}^{\mathrm{S}} 15^{\prime}\right)\right)=\mathrm{E}=$

QULOMET('S15');

EQUPERC16('S16') .. $\left(2.6^{*} 2 * 13^{*} 11\right)+156+\left(\mathrm{X}\left(\mathrm{S}^{\prime} 16^{\prime}\right) / \mathrm{DENS}\left(\mathrm{S}^{\prime} 16^{\prime}\right)\right)=\mathrm{E}=$

QUILOMET('S16);

EQUPERC17('S17') .. (2.6*2*13*9) + 156 + (X('S17')/DENS('S17)) $=\mathrm{E}=$

QUILOMET(S17);

EQUPERC18('S18') .. $\left(2.6 * 2 * 13^{*} 10\right)+156+\left(\mathrm{X}\left(\mathrm{S}^{2} 18^{\prime}\right) / \mathrm{DENS}\left(\mathrm{S}^{\prime} 18^{\prime}\right)\right)=\mathrm{E}=$

QUILOMET('S18');

EQUPERC19('S19') .. $\left(2.6 * 2^{*} 13^{*} 8.7\right)+156+\left(\mathrm{X}\left(\mathrm{S}^{2} 19\right) / \mathrm{DENS}\left(\mathrm{S}^{\prime} 19^{\prime}\right)\right)=\mathrm{E}=$

QUILOMET('S19');

EQUPERC20('S20') .. (2.6*2*13*9.3) + $156+\left(\mathrm{X}\left(\mathrm{C}^{\mathrm{S} 20}\right) / \mathrm{DENS}(\mathrm{S} 20)\right)=\mathrm{E}=$

QUILOMET('S20');

EQUPERC21('S21') .. $\left(2.6 * 2^{*} 13^{*} 10.7\right)+156+\left(\mathrm{X}\left(\mathrm{S} 21^{\prime}\right) / \mathrm{DENS}\left(\mathrm{S} 211^{\prime}\right)\right)=\mathrm{E}=$

QUILOMET('S21);

EQUPERC22('S22') .. (2.6*2*13*23.3) $\left.+156+\left(\mathrm{X}\left(\mathrm{S}^{2} 22^{2}\right) / \mathrm{DENS}\left(\mathrm{S}^{2} 2\right)^{\prime}\right)\right)=\mathrm{E}=$

QUILOMET('S22');

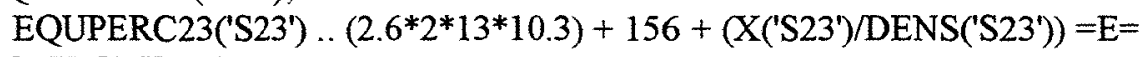

QUILOMET('S23');

EQUPERC24('S24') .. $\left(2.62^{*} 2^{*} 13^{*} 11.5\right)+156+\left(\mathrm{X}\left(\mathrm{S}^{24}\right) / \mathrm{DENS}(\mathrm{S} 24)\right)=\mathrm{E}=$

QUILOMET('S24');

EQUPERC25('S25') .. $\left(2.6^{*} 2^{*} 13^{*} 10\right)+156+\left(\mathrm{X}\left(\mathrm{S}^{2} 25^{\prime}\right) / \mathrm{DENS}\left(\mathrm{S}^{2} 5^{\prime}\right)\right)=\mathrm{E}=$

QUILOMET('S25');

EQUPERC26('S26') .. (2.6*2*13*4.6) + $156+\left(\mathrm{X}\left(\right.\right.$ ('S26 $\left.\left.^{\prime}\right) / \mathrm{DENS}\left(\mathrm{C}^{\prime} \mathrm{S} 26^{\prime}\right)\right)=\mathrm{E}=$

QUILOMET('S26);

EQUPERC27('S27) $\ldots(2.6 * 2 * 13 * 14.5)+156+(\mathrm{X}(\mathrm{S} 27) / \mathrm{DENS}(\mathrm{S} 27))=\mathrm{E}=$

QUILOMET('S2T);

EQUPERC28('S28') . $\left.\left(2.6^{*} 2^{*} 13^{*} 18\right)+156+\left(\mathrm{X}\left(\mathrm{S}^{2} 2\right)^{\prime}\right) / \mathrm{DENS}\left(\mathrm{S}^{2} 8^{\prime}\right)\right)=\mathrm{E}=$

QUILOMET('S28');

EQU2 .. X('S1')/CAPV)/(2.15*26)+(X('S2)/CAPV $/(2.15 * 26)+$

$\left(\mathrm{X}\left(\mathrm{S}^{2}\right) / \mathrm{CAPV}\right) /\left(2.15^{*} 26\right)+\left(\mathrm{X}\left(\mathrm{S} 4^{\prime}\right) / \mathrm{CAPV}\right) /\left(2.6^{*} 13\right)+\left(\mathrm{X}\left(\mathrm{S}^{\prime}\right) / \mathrm{CAPV}\right) /(2.6 * 13)+$

$\left(\mathrm{X}\left(\mathrm{S}^{\prime}\right) / \mathrm{CAPV}\right) /\left(2.6^{*} 13\right)+\left(\mathrm{X}\left(\mathrm{S}^{\mathrm{S}} \mathrm{T}\right) / \mathrm{CAPV}\right) /\left(2.6^{*} 13\right)+\left(\mathrm{X}\left(\mathrm{CS}^{8}\right) / \mathrm{CAPV}\right) /\left(2.6^{*} 13\right)+$

(X('S9)/CAPV) $/\left(2.6^{*} 13\right)+\left(\mathrm{X}\left(\mathrm{S}^{\prime} 10^{\prime}\right) / \mathrm{CAPV}\right) /\left(2.6^{*} 13\right)+\left(\mathrm{X}\left(\mathrm{S}^{\prime} 11^{\prime}\right) / \mathrm{CAPV}\right) /\left(2.6^{*} 13\right)+$

(X(S13)/CAPV) $/\left(2.6^{*} 13\right)+\left(\mathrm{X}\left(\mathrm{SS}^{2} 5^{\prime}\right) / \mathrm{CAPV}\right) /\left(2.6^{*} 13\right)+\left(\mathrm{X}\left(\mathrm{S}^{\mathrm{S}} 26^{\prime}\right) / \mathrm{CAPV}\right) /\left(2.6^{*} 13\right)+$

$(\mathrm{X}(\mathrm{S} 27) / \mathrm{CAPV}) /(2.6 * 13)=\mathrm{E}=\mathrm{VEICDP}$

EQU3..(X(S1)/CAPV)/(2.15*26)+(X('S2)/CAPV)/(2.15*26)+(X('S3)/CAPV)

$/(2.15 * 26)+\left(\mathrm{X}\left(\mathrm{S} 12^{2}\right) / \mathrm{CAPV}\right) /(2.6 * 13)+\left(\mathrm{X}\left(\mathrm{S} 14^{4}\right) / \mathrm{CAPV}\right) /\left(2.6^{*} 13\right)+(\mathrm{X}(\mathrm{S} 15)$

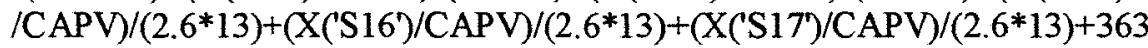

(X(S18)/CAPV) $/\left(2.6^{*} 13\right)+\left(\mathrm{X}\left(\mathrm{S} 19^{\prime}\right) / \mathrm{CAPV}\right) /\left(2.6^{*} 13\right)+(\mathrm{X}(\mathrm{S} 20) / \mathrm{CAPV}) /\left(2.6^{*} 13\right)$

$+(\mathrm{X}(\mathrm{S} 21) / \mathrm{CAPV}) /\left(2.6^{*} 13\right)+(\mathrm{X}(\mathrm{S} 22) / \mathrm{CAPV}) /(2.6 * 13)+\left(\mathrm{X}\left(\mathrm{S} 23^{\prime}\right) / \mathrm{CAPV}\right) /(2.6 * 13)$

$+\left(\mathrm{X}\left(\mathrm{S}^{\mathrm{S}} 24^{\prime}\right) / \mathrm{CAPV}\right) /\left(2.6^{*} 13\right)+\left(\mathrm{X}\left(\mathrm{C}^{\mathrm{S}} 28^{\prime}\right) / \mathrm{CAPV}\right) /\left(2.6^{*} 13\right)=\mathrm{E}=\mathrm{VEICDI} ;$

EQU6(I,J) .. Y(I)*0.197174 =E= P(I,'VIDRO');

EQU7(I,J) .. Y(I)*0.116159=E= P(I,'PET');

EQU8(I,J) .. Y(I) ${ }^{*} 0.008172=\mathrm{E}=\mathrm{P}\left(\mathrm{l}, \mathrm{\prime}^{\prime}\right.$ ALUMINIO');

EQU9(I,J) .. Y(I) ${ }^{* 0.064007=E=P(I, ' F E R R O ') ; ~}$ 
EQU10(I,J) .. Y(I) $* 0.209054=\mathrm{E}=\mathrm{P}\left(\mathrm{I},{ }^{\prime}\right.$ PAPELAO');

EQU11(I,J) .. Y(I)*0.244861 =E= P(I,'PAPEL');

EQU12(I,J) .. Y(I)*0.160574 =E= P(I,'DIVERSOS');

MEDIA1 .. SUM(I,DENS(I) $) / 28=\mathrm{E}=195.15$;

ORC_CONV(I)..CUSTCCON(I)+CUSTDCON(I)+ DESVNEG(I,'M5') - DESVPOS(I,'M5')

$=\mathrm{E}=$ OBJETIVO(I,'M5');

ORCACON(I) .. CUSTCCON(I) + CUSTDCON(I) $=\mathrm{E}=$ ORCAMENTC(I);

CUSTO1('S4) .. CUSTCCON('S4') $=E=\left(3333.34+\left(Q^{2}\right.\right.$ ULOMET('S4) $\left.\left./ 1.5 * 0.803\right)\right)$;

CUSTO2('S5).. CUSTCCON('S5') $=\mathrm{E}=\left(3333.34+\left(\mathrm{QUILOMET}\left({ }^{\prime} 5^{\prime}\right) / 1.5^{*} 0.803\right)\right)$;

CUSTO3('S6).. CUSTCCON('S6') $=\mathrm{E}=\left(3333.34+\left(\mathrm{QUILOMET}^{\prime}\left(\mathrm{S} 6^{\prime}\right) / 1.5^{*} 0.803\right)\right)$;

CUSTO4('S7) .. CUSTCCON('S7') $=\mathrm{E}=(3333.34+($ QUILOMET('S7')/1.5*0.803));

CUSTO5('S8).. CUSTCCON('S8') $=\mathrm{E}=\left(3333.34+\left(\mathrm{QUILOMET}\left(\mathrm{S}^{\prime}\right) / 1.5 * 0.803\right)\right.$ );

CUSTO6('S9') .. CUSTCCON('S9') $=\mathrm{E}=\left(3333.34+\left(\mathrm{QUILOMET}^{2}(\mathrm{~S} 9) / 1.5^{*} 0.803\right)\right.$ );

CUSTO7('S10') .. CUSTCCON('S10') $=\mathrm{E}=\left(3333.34+\left(\mathrm{QULLOMET}\left(\mathrm{S}^{\prime} 10^{\circ}\right) / 1.5^{*} 0.803\right)\right)$;

CUSTO8('S1 1') .. CUSTCCON('S11) $=\mathrm{E}=(3333.34+(\mathrm{QUILOMET}(\mathrm{S} 11) / 1.5 * 0.803))$;

CUSTO9('S12') . CUSTCCON('S12') $=\mathrm{E}=\left(3333.34+\left(\mathrm{QUULOMET}\left({ }^{\prime} \mathrm{S} 12\right) / 1.5 * 0.803\right)\right)$;

CUSTO10(S13)..CUSTCCON(S13) $=E=\left(3333.34+\left(\mathrm{QUILOMET}^{\prime}\left(\mathrm{S} 13^{\prime}\right) / 1.5^{*} 0.803\right)\right)$;

CUSTO1 ('S14')..CUSTCCON('S14) $=\mathrm{E}=\left(3333.34+\left(\mathrm{QUILOMET}^{\prime}\left(\mathrm{S} 14^{\prime}\right) / 1.5^{*} 0.803\right)\right.$ );

CUSTO12('S15) . CUSTCCON('S15') $=\mathrm{E}=\left(3333.34+\left(\mathrm{QULLOMET}\left(\mathrm{S}^{\prime} 5^{\prime}\right) / 1.5^{*} 0.803\right)\right)$;

CUSTO13('S16') . . CUSTCCON('S16') $=E=\left(3333.34+\left(\right.\right.$ QULLOMET('S16') $\left./ 1.5^{*} 0.803\right)$ );

CUSTO14('S17') .. CUSTCCON(S17') $=\mathrm{E}=\left(2908.34+\left(\mathrm{QULLOMET}^{\prime}\left(\mathrm{S} 17^{\prime}\right) / 1.5 * 0.803\right)\right)$;

CUSTO15('S18) .. CUSTCCON('S18') $=\mathrm{E}=\left(3333.34+\left(\mathrm{QULLOMET}^{\prime}\left(\mathrm{S} 18^{\prime}\right) / 1.5^{*} 0.803\right)\right)$;

CUSTO16(S19') .. CUSTCCON('S19') $=\mathrm{E}=\left(3333.34+\left(\mathrm{QUILOMET}\left({ }^{\prime} \mathrm{S} 19^{\prime}\right) / 1.5^{*} 0.803\right)\right)$;

CUSTO17(S20 ) . CUSTCCON('S20') $=E=\left(3333.34+\left(\right.\right.$ QUILOMET $\left.\left.\left(S 20^{\prime}\right) / 1.5^{*} 0.803\right)\right)$;

CUSTO18('S21 $)$.. CUSTCCON('S21') $=\mathrm{E}=\left(3333.34+\left(\mathrm{QUILOMET}^{\prime}\left(\mathrm{S} 21^{\prime}\right) / 1.5 * 0.803\right)\right.$ );

CUSTO19('S22') .. CUSTCCON(S22') $=\mathrm{E}=\left(3333.34+\left(\mathrm{QULLOMET}^{\prime}\left(\mathrm{S} 22^{\prime}\right) / 1.5^{*} 0.803\right)\right)$;

CUSTO20('S23') .. CUSTCCON(S23') $=\mathrm{E}=\left(3333.34+\left(\mathrm{QULLOMET}^{\prime}\left(\mathrm{S} 23^{\prime}\right) / 1.5^{*} 0.803\right)\right)$;

CUSTO21('S24) .. CUSTCCON(S24') $=\mathrm{E}=\left(3333.34+\left(\mathrm{QUILOMET}^{\prime}\left(\mathrm{S} 24^{\prime}\right) / 1.5^{*} 0.803\right)\right.$ );

CUSTO22('S25) . . CUSTCCON('S25') $=\mathrm{E}=\left(3333.34+\left(\mathrm{QUTLOMET}\left(\mathrm{SS}^{\prime} 5^{\prime}\right) / 1.5^{*} 0.803\right)\right)$;

CUSTO23('S26') .. CUSTCCON('S26') $=E=\left(3333.34+\left(Q^{\prime}\right.\right.$ ULOMET $\left.\left.\left(S 26^{\prime}\right) / 1.5^{*} 0.803\right)\right)$;

CUSTO24('S27).. CUSTCCON(S27) $=\mathrm{E}=\left(3333.34+\left(\mathrm{QUTLOMET}\left(\mathrm{S} 2 \mathrm{C}^{\prime}\right) / 1.5^{*} 0.803\right)\right.$ );

CUSTO25('S28') .. CUSTCCON('S28') $=\mathrm{E}=\left(3333.34+\left(\mathrm{QUILOMET}\left(\mathrm{CS}^{\prime} 8^{\prime}\right) / 1.5^{*} 0.803\right)\right.$ );

CUST('S1') .. CUSTCCON('S1) $\left.=\mathrm{E}=\left(5816.67+\left(\mathrm{QUILOMET}(\mathrm{S} 1)^{\circ}\right) / 1.5^{*} 0.803\right)\right)$;

CUST2('S2) .. CUSTCCON(S2) $=\mathrm{E}=(5816.67+(\mathrm{QUILOMET}(\mathrm{S} 2) / 1.5 * 0.803))$;

CUST3('S3) .. CUSTCCON(S3') $=\mathrm{E}=(5816.67+(\mathrm{QUILOMET}(\mathrm{S} 3) / 1.5 * 0.803)$ );

SOMATCCC .. SUM(I,CUSTCCON(I) $)=E=$ CUSTTCCON;

SOMATCS .. SUM(I, CUSTCSEL(I)) $=E=$ CUSTTCSEL;

SOMATD .. SUM(I, CUSTDCON(I) $=\mathrm{E}=$ CUSTTD;

SOMATCQU .. (QUILOMET('S4)/1.5*0.803) + (QULLOMET(S5')/1.5*0.803)

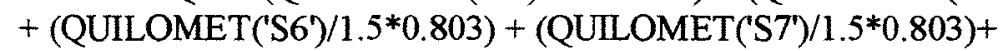

$($ QUILOMET('S8')/1.5*0.803) + (QUILOMET('S9')/1.5*0.803) +

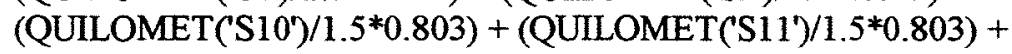

$\left(\right.$ QUILOMET(S12) $\left./ 1.5^{*} 0.803\right)+($ QULLOMET(S13)/1.5*0.803) +

$($ QULLOMET(S14')/1.5*0.803) + (QUILOMET('S15')/1.5*0.803) +

$($ QULOMET(S16 $) / 1.5 * 0.803)+($ QUILOMET(S1T) $/ 1.5 * 0.803)+$

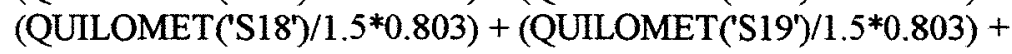

(QUILOMET(S20')/1.5*0.803) + (QUILOMET('S21) $/ 1.5 * 0.803)+$

$\left.\left(\mathrm{QUILOMET}^{(\mathrm{S} 22}\right) / 1.5^{*} 0.803\right)+\left(\mathrm{QUILOMET}\left(\mathrm{S} 23^{\prime}\right) / 1.5^{*} 0.803\right)+$

$\left.\left(\mathrm{QUILOMET}^{(} \mathrm{S} 24^{\prime}\right) / 1.5 * 0.803\right)+\left(\mathrm{QUILOMET}\left(\mathrm{S} 25^{\prime}\right) / 1.5 * 0.803\right)+$

$\left.\left(\mathrm{QUILOMET}^{\mathrm{S}} 26^{\prime}\right) / 1.5^{*} 0.803\right)+\left(\mathrm{QUILOMET}\left(\mathrm{C}^{2} 27^{\prime}\right) / 1.5 * 0.803\right)+$

$\left.\left.\left(\mathrm{QUILOMET}^{\mathrm{S}} 28^{\prime}\right) / 1.5^{*} 0.803\right)+\left(\mathrm{QUILOMET}^{\circ} \mathrm{S1}\right) / 1.5 * 0.803\right)+$

$\left(\right.$ QUILOMET('S2) $\left./ 1.5^{*} 0.803\right)+\left(\right.$ QUILOMET(S3) $\left./ 1.5^{*} 0.803\right)=$ E = CUSTQUILO;

CUSTODF(I) . . CUSTDCON(I) $=\mathrm{E}=\mathrm{X}(\mathrm{I}) * 37435.71 / \mathrm{SOMAXI}$; 
SOMA .. SOMAXI =E= SUM(I, X(I));

ORC_SEL(I) .. CUSTCSEL(I) + DESVNEG(I,'M6') - DESVPOS(I,'M6') =E= OBJETIVO(I,'M6');

CUSTO(I) .. CUSTCSEL(I) $=E=Y(T) * 44599.32 /$ SOMAYT;

SOMA3 .. SUM $(I, Y(I))=E=$ SOMAYI;

DENSIDAD(I) .. DENS(I) + DESVNEG(I, 'M8') - DESVPOS(I,'M8') =E= OBJ('M8');

PROD_COL(I).X(I)+DESVNEG(I,'M9')-DESVPOS(I,'M9') =E= OBJETIVO(I,'M9');

PRODŪT(I) .. X(I)*100/OBJETIVO(1,'M9') =E= PRODUTIV(I);

MODEL MODELO /ALL/;

MODELO.ITERLIM = 999999;

DENS.LO(T) $=100$

SOMAXI.LO $=100$;

SOMAYI.LO $=100$

SOLVE MODELO USING NLP MINIMIZING DT;

DISPLAY CUSTTCCON.L, CUSTTCSEL.L, CUSTTD.L, CUSTQUILO.L, DT.L, DT.M, DT.UP, DT.LO, DEVNEG.L, DEVNEG.M, DEVPOS.L, DEVPOS.M, DESVNEG.L, DESVNEG.M, DESVNEG.UP, DESVNEG.LO, DESVPOS.L, DESVPOS.M, DESVPOS.UP, DESVPOS.LO, X.L, X.M, X.UP, X.LO, DENS.L, DENS.M, DENS.UP, DENS.LO, QUILOMET.L, QUILOMET.M, QUILOMET.UP, QUILOMET.LO, VEICDP.L, VEICDP.M, VEICDP.UP, VEICDP.LO, VEICDI.L, VEICDI.M, VEICDI.UP, VEICDI.LO, PRODUTIV.L, Y.L, Y.M, Y.UP, Y.LO, P.L, P.M, P.UP, P.LO, ORCAMENTC.L, ORCAMENTC.M, ORCAMENTC.UP, ORCAMENTC.LO, CUSTCCON.L, CUSTDCON.L, CUSTCSEL.L, DENS.L; 


\section{Anexo K - Desvios referentes ao modelo sem prioridades}

Desvios Negativos

\begin{tabular}{lrrrrrr}
\hline Setor & \multicolumn{1}{c}{ M1 } & \multicolumn{1}{c}{ M2 } & \multicolumn{1}{c}{ M5 } & M7 & M8 & \multicolumn{1}{c}{ M9 } \\
\hline 1 & $-16.487,93$ & $-807,12$ & 0,00 & 0,00 & 0,00 & 0,00 \\
2 & 0,00 & 0,00 & $-28,23$ & 0,00 & 0,00 & 0,00 \\
3 & $-29.637,59$ & $-335,20$ & 0,00 & 0,00 & 0,00 & 0,00 \\
4 & $-74.592,92$ & 0,00 & $-1.888,05$ & 0,00 & 0,00 & 0,00 \\
5 & 0,00 & 0,00 & $-327,27$ & 0,00 & $-36,98$ & 0,00 \\
6 & 0,00 & $-329,58$ & $-102,45$ & 0,00 & $-12,97$ & 0,00 \\
7 & $-60.645,34$ & 0,00 & $-1.584,40$ & 0,00 & 0,00 & 0,00 \\
8 & 0,00 & $-415,63$ & 0,00 & 0,01 & 0,00 & $-6.303,05$ \\
9 & $-22.320,86$ & 0,00 & $-112,63$ & 0,00 & 0,00 & 0,00 \\
10 & $-87.839,81$ & 0,00 & $-3.142,54$ & 0,00 & 0,00 & 0,00 \\
11 & 0,00 & $-87,16$ & $-466,65$ & 0,00 & $-44,99$ & 0,00 \\
12 & 0,00 & $-204,11$ & $-62,78$ & 0,00 & $-12,83$ & 0,00 \\
13 & 0,00 & 0,00 & $-1.135,86$ & 0,00 & $-5,07$ & 0,00 \\
14 & 0,00 & 0,00 & $-392,46$ & 0,00 & $-50,33$ & 0,00 \\
15 & $-949,69$ & $-57,93$ & 0,00 & 0,00 & 0,00 & 0,00 \\
16 & 0,00 & $-79,07$ & 0,00 & 0,00 & 0,00 & $-10.766,28$ \\
$16 / 17$ & $-22.470,50$ & $-330,63$ & 0,00 & 0,00 & 0,00 & 0,00 \\
17 & $-7.501,53$ & $-685,26$ & 0,00 & 0,00 & 0,00 & 0,00 \\
18 & $-82.403,57$ & 0,00 & $-2.161,25$ & 0,00 & 0,00 & 0,00 \\
19 & 0,00 & $-66,35$ & $-517,22$ & 0,00 & $-43,86$ & 0,00 \\
20 & 0,00 & $-598,84$ & 0,00 & 0,00 & $-14,97$ & 0,00 \\
21 & $-2.623,40$ & $-584,48$ & 0,00 & 0,00 & 0,00 & 0,00 \\
22 & $-38.854,15$ & 0,00 & $-1.215,06$ & 0,00 & 0,00 & 0,00 \\
23 & $-3.739,21$ & 0,00 & 0,00 & 0,00 & 0,00 & 0,00 \\
24 & 0,00 & $-178,04$ & 0,00 & 0,00 & $-26,53$ & 0,00 \\
25 & 0,00 & 0,00 & $-537,21$ & 0,00 & $-18,38$ & 0,00 \\
26 & 0,00 & $-202,00$ & 0,00 & 0,01 & 0,00 & $-6.860,95$ \\
27 & 0,00 & 0,00 & $-19,66$ & 0,00 & $-27,54$ & 0,00 \\
Total & $-450.066,50$ & $-4.961,39$ & $-13.693,71$ & 0,02 & $-294,43$ & $-23.930,28$ \\
\hline & & & & & &
\end{tabular}

M3 para as $2^{\text {as }}, 4^{\text {as }}$ e $6^{\text {as. }}: 5,410$

M3 para as $3^{\text {as }}, 5^{\text {as }}$ e sábados: 5,378 
Desvios Positivos

\begin{tabular}{lrrrrr}
\hline Setor & \multicolumn{1}{c}{ M2 } & \multicolumn{1}{c}{ M5 } & \multicolumn{1}{c}{ M6 } & \multicolumn{1}{c}{ M8 } & \multicolumn{1}{c}{ M9 } \\
\hline 1 & 0,00 & $1.213,15$ & 156,54 & 50,91 & 0,00 \\
2 & 0,00 & 0,00 & 193,25 & 51,98 & $73.394,06$ \\
3 & 0,00 & 0,00 & 186,42 & 0,00 & $33.156,31$ \\
4 & 0,00 & 0,00 & 145,38 & 29,53 & 0,00 \\
5 & 0,00 & 0,00 & 129,92 & 0,00 & $50.603,08$ \\
6 & 0,00 & 0,00 & 119,48 & 0,00 & $34.423,89$ \\
7 & 0,00 & 0,00 & 136,39 & 21,95 & 0,00 \\
8 & 0,00 & 783,58 & 93,20 & 1,52 & 0,00 \\
9 & 0,00 & 0,00 & 112,64 & 0,00 & $1.502,87$ \\
10 & 0,00 & 0,00 & 185,34 & 0,00 & $48.680,38$ \\
11 & 0,00 & 0,00 & 138,91 & 0,00 & $64.550,66$ \\
12 & 0,00 & 0,00 & 122,36 & 0,00 & $38.887,12$ \\
13 & 0,00 & 0,00 & 154,74 & 0,00 & $89.098,41$ \\
14 & 0,00 & 0,00 & 130,28 & 0,00 & $51.160,99$ \\
15 & 0,00 & 719,99 & 97,88 & 5,76 & 0,00 \\
16 & 0,00 & 845,10 & 90,32 & 0,00 & 0,00 \\
$16 / 17$ & 0,00 & 216,73 & 87,44 & 0,00 & 0,00 \\
17 & 0,00 & 0,00 & 112,64 & 0,00 & $16.322,20$ \\
18 & 78,81 & 0,00 & 150,42 & 79,44 & 0,00 \\
19 & 0,00 & 0,00 & 134,95 & 0,00 & $58.413,73$ \\
20 & 0,00 & 0,00 & 116,96 & 0,00 & $30.518,56$ \\
21 & 0,00 & 968,05 & 98,96 & 5,76 & 0,00 \\
22 & 0,00 & 0,00 & 140,35 & 0,00 & $27.928,13$ \\
23 & 0,00 & 438,48 & 99,68 & 46,46 & 0,00 \\
24 & 0,00 & 0,00 & 117,32 & 0,00 & $31.076,47$ \\
25 & 0,00 & 0,00 & 127,04 & 0,00 & $46.139,86$ \\
26 & 0,00 & 886,65 & 92,84 & 1,14 & 0,00 \\
27 & 0,00 & 0,00 & 127,04 & 0,00 & $46.139,86$ \\
Total & 78,81 & $6.071,72$ & $3.598,69$ & 294,43 & $741.996,57$ \\
\hline & & & & &
\end{tabular}


Anexo L - Desvios referentes ao modelo da $1^{\text {a }}$ ordenação de prioridades

Desvios Negativos

\begin{tabular}{lrrrr}
\hline Setor & \multicolumn{1}{c}{ M2 } & \multicolumn{1}{c}{ M5 } & \multicolumn{1}{c}{ M } & \multicolumn{1}{c}{ M9 } \\
\hline 1 & 0,00 & 0,00 & $-54,58$ & 0,00 \\
2 & 0,00 & $-204,63$ & 0,00 & 0,00 \\
3 & 0,00 & 0,00 & $-21,50$ & 0,00 \\
4 & 0,00 & $-1.476,31$ & 0,00 & 0,00 \\
5 & 0,00 & $-445,86$ & $-36,98$ & 0,00 \\
6 & 0,00 & $-35,08$ & $-57,57$ & 0,00 \\
7 & 0,00 & $-1.266,25$ & 0,00 & 0,00 \\
8 & 0,00 & 0,00 & $-69,54$ & $-6.303,05$ \\
9 & 0,00 & $-52,53$ & 0,00 & 0,00 \\
10 & 0,00 & $-2.670,59$ & 0,00 & 0,00 \\
11 & $-70,01$ & $-584,27$ & $-46,77$ & 0,00 \\
12 & 0,00 & $-65,20$ & $-42,73$ & 0,00 \\
13 & 0,00 & $-1.277,12$ & $-5,07$ & 0,00 \\
14 & 0,00 & $-511,38$ & 0,00 & 0,00 \\
15 & 0,00 & 0,00 & $-7,46$ & 0,00 \\
16 & 0,00 & 0,00 & $-19,37$ & $-10.766,28$ \\
$16 / 17$ & 0,00 & 0,00 & $-46,20$ & 0,00 \\
17 & 0,00 & 0,00 & $-81,88$ & 0,00 \\
18 & 0,00 & $-1.739,30$ & 0,00 & 0,00 \\
19 & 0,00 & $-641,64$ & $-43,60$ & 0,00 \\
20 & $-68,67$ & 0,00 & $-82,19$ & 0,00 \\
21 & 0,00 & 0,00 & $-80,23$ & 0,00 \\
22 & 0,00 & $-1.059,58$ & 0,00 & 0,00 \\
23 & 0,00 & 0,00 & 0,00 & 0,00 \\
24 & 0,00 & $-11,78$ & $-50,42$ & 0,00 \\
25 & 0,00 & $-653,17$ & $-18,38$ & 0,00 \\
26 & 0,00 & 0,00 & $-41,26$ & $-6.860,95$ \\
27 & 0,00 & $-135,62$ & $-27,54$ & 0,00 \\
Total & $-138,68$ & $-12.830,31$ & $-833,25$ & $-23.930,28$ \\
\hline & & & &
\end{tabular}


Desvios Positivos

\begin{tabular}{lrrrr}
\hline Setor & \multicolumn{1}{l}{ M5 } & \multicolumn{1}{l}{ M6 } & \multicolumn{1}{c}{ M8 } & \multicolumn{1}{c}{ M9 } \\
\hline 1 & $1.622,67$ & 156,54 & 0,00 & $16.487,93$ \\
2 & 0,00 & 193,25 & 51,98 & $73.394,06$ \\
3 & 225,60 & 186,42 & 0,00 & $62.793,90$ \\
4 & 0,00 & 145,38 & 140,66 & $74.592,92$ \\
5 & 0,00 & 129,92 & 0,00 & $50.603,08$ \\
6 & 0,00 & 119,48 & 0,00 & $34.423,89$ \\
7 & 0,00 & 136,39 & 109,25 & $60.645,34$ \\
8 & 921,00 & 93,20 & 0,00 & 0,00 \\
9 & 0,00 & 112,64 & 28,60 & $23.823,73$ \\
10 & 0,00 & 185,34 & 85,93 & $136.520,19$ \\
11 & 0,00 & 138,91 & 0,00 & $64.550,66$ \\
12 & 0,00 & 122,36 & 0,00 & $38.887,12$ \\
13 & 0,00 & 154,74 & 0,00 & $89.098,41$ \\
14 & 0,00 & 130,28 & 21,31 & $51.160,99$ \\
15 & 668,58 & 97,88 & 0,00 & 949,69 \\
16 & 804,98 & 90,32 & 0,00 & 0,00 \\
$16 / 17$ & 477,91 & 87,44 & 0,00 & $22.470,50$ \\
17 & 318,78 & 112,64 & 0,00 & $23.823,73$ \\
18 & 0,00 & 150,42 & 300,64 & $82.403,57$ \\
19 & 0,00 & 134,95 & 0,00 & $58.413,73$ \\
20 & 213,82 & 116,96 & 0,00 & $30.518,57$ \\
21 & $1.209,75$ & 98,96 & 0,00 & $2.623,40$ \\
22 & 0,00 & 140,35 & 42,42 & $66.782,28$ \\
23 & 374,77 & 99,68 & 52,45 & $3.739,21$ \\
24 & 0,00 & 117,32 & 0,00 & $31.076,47$ \\
25 & 0,00 & 127,04 & 0,00 & $46.139,86$ \\
26 & 910,04 & 92,84 & 0,00 & 0,00 \\
27 & 0,00 & 127,04 & 0,00 & $46.139,86$ \\
Total & $7.747,89$ & $3.598,69$ & 833,25 & $1.192 .063,09$ \\
\hline & & & &
\end{tabular}


Anexo M - Desvios referentes ao modelo da $2^{\mathbf{a}}$ ordenação de prioridades

Desvios Negativos

\begin{tabular}{lrrr}
\hline Setor & \multicolumn{1}{c}{ M2 } & \multicolumn{1}{c}{ M5 } & \multicolumn{1}{c}{ M9 } \\
\hline 1 & $-482,80$ & 0,00 & 0,00 \\
2 & 0,00 & $-204,63$ & 0,00 \\
3 & $-183,33$ & 0,00 & 0,00 \\
4 & 0,00 & $-1.476,31$ & 0,00 \\
5 & $-241,26$ & $-445,86$ & 0,00 \\
6 & $-397,14$ & $-35,08$ & 0,00 \\
7 & 0,00 & $-1.266,25$ & 0,00 \\
8 & $-409,93$ & 0,00 & $-6303,05$ \\
9 & 0,00 & $-52,53$ & 0,00 \\
10 & 0,00 & $-2.670,59$ & 0,00 \\
11 & $-417,80$ & $-584,27$ & 0,00 \\
12 & $-272,48$ & $-65,20$ & 0,00 \\
13 & $-32,77$ & $-1.277,12$ & 0,00 \\
14 & 0,00 & $-511,38$ & 0,00 \\
15 & $-30,92$ & 0,00 & 0,00 \\
16 & $-79,07$ & 0,00 & $-10766,28$ \\
$16 / 17$ & $-215,48$ & 0,00 & 0,00 \\
17 & $-646,82$ & 0,00 & 0,00 \\
18 & 0,00 & $-1.739,30$ & 0,00 \\
19 & $-377,12$ & $-641,64$ & 0,00 \\
20 & $-676,04$ & 0,00 & 0,00 \\
21 & $-548,89$ & 0,00 & 0,00 \\
22 & 0,00 & $-1.059,58$ & 0,00 \\
23 & 0,00 & 0,00 & 0,00 \\
24 & $-324,65$ & $-11,78$ & 0,00 \\
25 & $-104,90$ & $-653,17$ & 0,00 \\
26 & $-197,74$ & 0,00 & $-6860,95$ \\
27 & $-165,85$ & $-135,62$ & 0,00 \\
Total & $-5.804,98$ & $-12.830,31$ & $-23.930,28$ \\
\hline & & &
\end{tabular}


Desvios Positivos

\begin{tabular}{|c|c|c|c|}
\hline Setor & M2 & M5 & M9 \\
\hline 1 & 0,00 & 1622,67 & 16487,93 \\
\hline 2 & 322,92 & 0,00 & 73394,06 \\
\hline 3 & 0,00 & 225,60 & 62793,9 \\
\hline 4 & 483,78 & 0,00 & 74592,92 \\
\hline 5 & 0,00 & 0,00 & 50603,08 \\
\hline 6 & 0,00 & 0,00 & 34423,89 \\
\hline 7 & 388,88 & 0,00 & 60645,34 \\
\hline 8 & 0,00 & 921,00 & 0,00 \\
\hline 9 & 114,38 & 0,00 & 23823,73 \\
\hline 10 & 450,11 & 0,00 & 136520,19 \\
\hline 11 & 0,00 & 0,00 & 64550,66 \\
\hline 12 & 0,00 & 0,00 & 38887,12 \\
\hline 13 & 0,00 & 0,00 & 89098,41 \\
\hline 14 & 113,70 & 0,00 & 51160,99 \\
\hline 15 & 0,00 & 668,58 & 949,69 \\
\hline 16 & 0,00 & 804,98 & 0,00 \\
\hline $16 / 17$ & 0,00 & 477,91 & 22470,50 \\
\hline 17 & 0,00 & 318,776 & 23823,73 \\
\hline 18 & 724,63 & 0,00 & 82403,57 \\
\hline 19 & 0,00 & 0,00 & 58413,73 \\
\hline 20 & 0,00 & 213,82 & 30518,57 \\
\hline 21 & 0,00 & 1209,75 & 2623,40 \\
\hline 22 & 199,10 & 0,00 & 66782,28 \\
\hline 23 & 167,74 & 374,77 & 3739,21 \\
\hline 24 & 0,00 & 0,00 & 31076,47 \\
\hline 25 & 0,00 & 0,00 & 46139,86 \\
\hline 26 & 0,00 & 910,04 & 0,00 \\
\hline 27 & 0,00 & 0,00 & 46139,86 \\
\hline Total & $2.965,25$ & $7.747,89$ & $1.192 .063,09$ \\
\hline
\end{tabular}


Anexo N - Desvios referentes ao modelo da $3^{\mathrm{a}}$ ordenação de prioridades

Desvios Negativos

\begin{tabular}{lrrrr}
\hline Setor & \multicolumn{1}{c}{ M1 } & \multicolumn{1}{l}{ M2 } & \multicolumn{1}{c}{ M5 } & \multicolumn{1}{c}{ M } \\
\hline 1 & $-16.487,93$ & 0,00 & 0,00 & $-64,13$ \\
2 & $-73.394,06$ & $-339,72$ & $-477,01$ & 0,00 \\
3 & $-62.793,90$ & $-477,45$ & $-49,38$ & $-4,55$ \\
4 & $-74.592,92$ & $-157,91$ & $-1.793,40$ & 0,00 \\
5 & $-50.603,08$ & 0,00 & $-517,43$ & $-76,72$ \\
6 & $-34.423,89$ & 0,00 & 0,00 & $-83,14$ \\
7 & $-60.645,34$ & 0,00 & $-1.405,21$ & 0,00 \\
8 & 0,00 & 0,00 & 0,00 & $-64,06$ \\
9 & $-23.823,73$ & 0,00 & 0,00 & $-1,93$ \\
10 & $-136.520,19$ & 0,00 & $-3.318,67$ & $-47,62$ \\
11 & $-64.550,66$ & $-13,31$ & $-719,08$ & $-95,15$ \\
12 & $-38.887,12$ & 0,00 & $-58,16$ & $-73,98$ \\
13 & $-89.098,41$ & $-651,02$ & $-1.955,51$ & 0,00 \\
14 & $-51.160,99$ & 0,00 & $-586,70$ & $-50,33$ \\
15 & $-949,69$ & $-148,01$ & 0,00 & 0,00 \\
16 & 0,00 & 0,00 & 0,00 & $-5,86$ \\
$16 / 17$ & $-22.470,50$ & 0,00 & 0,00 & $-70,89$ \\
17 & $-23.823,73$ & $-33,64$ & 0,00 & $-95,15$ \\
18 & $-82.403,57$ & 0,00 & $-2.024,26$ & 0,00 \\
19 & $-58.413,73$ & 0,00 & $-728,87$ & $-91,09$ \\
20 & $-30.518,57$ & $-97,16$ & 0,00 & $-95,15$ \\
21 & $-2.623,40$ & $-845,00$ & 0,00 & 0,00 \\
22 & $-66.782,28$ & $-143,34$ & $-1.316,45$ & 0,00 \\
23 & $-3.739,21$ & 0,00 & 0,00 & 0,00 \\
24 & $-31.076,47$ & 0,00 & 0,00 & $-75,15$ \\
25 & $-46.139,86$ & $-789,95$ & $-1.117,68$ & 0,00 \\
26 & 0,00 & $-305,78$ & 0,00 & 0,00 \\
27 & $-46.139,86$ & $-706,01$ & $-555,19$ & 0,00 \\
\hline Total & $-1.192 .063,09$ & $-4.708,30$ & $-16.623,02$ & $-994,88$ \\
\hline & & & &
\end{tabular}


Desvios Positivos

\begin{tabular}{lrrr}
\hline Setor & \multicolumn{1}{c}{ M1 } & \multicolumn{1}{c}{ M5 } & \multicolumn{1}{c}{ M } \\
\hline 1 & 0,00 & $1.914,00$ & 0,00 \\
2 & 0,00 & 0,00 & 64,09 \\
3 & 0,00 & 0,00 & 0,00 \\
4 & 0,00 & 0,00 & 98,65 \\
5 & 0,00 & 0,00 & 0,00 \\
6 & 0,00 & 1,91 & 0,00 \\
7 & 0,00 & 0,00 & 21,95 \\
8 & $6.303,05$ & $1.231,27$ & 0,00 \\
9 & 0,00 & 55,59 & 0,00 \\
10 & 0,00 & 0,00 & 0,00 \\
11 & 0,00 & 0,00 & 0,00 \\
12 & 0,00 & 0,00 & 0,00 \\
13 & 0,00 & 0,00 & 51,64 \\
14 & 0,00 & 0,00 & 0,00 \\
15 & 0,00 & 850,95 & 33,16 \\
16 & $10.766,28$ & $1.145,20$ & 0,00 \\
$16 / 17$ & 0,00 & 528,11 & 0,00 \\
17 & 0,00 & 408,88 & 0,00 \\
18 & 0,00 & 0,00 & 125,45 \\
19 & 0,00 & 0,00 & 0,00 \\
20 & 0,00 & 225,00 & 0,00 \\
21 & 0,00 & $1.007,77$ & 112,56 \\
22 & 0,00 & 0,00 & 0,06 \\
23 & 0,00 & 617,66 & 46,46 \\
24 & 0,00 & 47,67 & 0,00 \\
25 & 0,00 & 0,00 & 270,11 \\
26 & $6.860,95$ & $1.060,35$ & 44,39 \\
27 & 0,00 & 0,00 & 126,38 \\
Total & $23.930,28$ & $9.094,33$ & 994,88 \\
\hline & & &
\end{tabular}




\section{REFERÊNCIAS BIBLIOGRÁFICAS}

ACKOFF, R. L.; SASIENI, M. W. Pesquisa operacional. Rio de Janeiro: Livros Técnicos e Científicos, 1971. 523p.

AGUIAR, E. M. de. Racionalização da operação de sistemas de coleta e transporte de resíduos sólidos domiciliares para cidades de pequeno e médio porte. São Paulo, 1993. 145p. Tese (Doutorado) - Escola Politécnica, Universidade de São Paulo.

ANJOS, L. A.; BARROS, A A.; FERREIRA, J. A; OLIVEIRA, T.C.E.; SEVERINO, K. C.; SILVA, M. O.; WAISSMANN, W. Gasto energético e carga fisiológica de trabalho em coletores de lixo domiciliar do Rio de Janeiro: um estudo piloto. Rio de Janeiro: Fundação Oswaldo Cruz, 1995. (Relatório do projeto para o $\mathrm{CNPq}$ )

BIGARELLI, W. O bom lixeiro. Brasil Transportes, v.34, n.358, p.20-25, jun.jjul. 1997.

BRASIL. Governo do Distrito Federal. http://www.gdf.gov.br (08 maio 2000)

BRASIL. Ministério da Ciência e Tecnologia. Taxa de resíduos sólidos gerados por habitante. http://www.met.gov.br/clima (04 jan. 2001) 
BROOKE, A.; KENDRICK, D.; MEERAUS, A.; RAMAN, R. Gams: a user's guide. Washington: Gams Development Corporation, 1998. 262p.

BROWN, D. T. The legacy of the landfill: perspectives on the solid waste crisis. St. Catharines: Brock University. Institute of Urban and Environmental Studies, 1993. http://www.brocku.ca/epi/legacy.txt (08 ago. 2000)

CAIXETA FILHO, J. V. Avaliação do potencial de utilização de tecnologias de roteirização por empresas de coleta de resíduos sólidos urbanos. Piracicaba: USP. ESALQ, 1999. 39p. (Relatório técnico de projeto de pesquisa apoiado pelo $\mathrm{CNPq}$ )

CANASSA, E. M. Planejamento de roteiros dos veículos coletores de resíduos sólidos urbanos. Florianópolis, 1992. 134p. Dissertação (M.S.) - Universidade Federal de Santa Catarina.

CHAVES, J. R. B. Uma metodologia para o problema do carteiro chinês em redes mistas. Florianópolis, 1985. Dissertação (M.S.) - Universidade Federal de Santa Catarina.

CONSONI, A. J.; PERES, C. S.; CASTRO, A. P. Origem e composição do lixo. In: D'ALMEIDA, M. L. O.; VILHENA, A. (Coord.) Lixo municipal: manual de gerenciamento integrado. 2.ed. São Paulo: Instituto de Pesquisas Tecnológicas IPT/ Compromisso Empresarial para Reciclagem - CEMPRE, 2000. cap.2, p.2941 .

CONSONI, A. J.; SILVA, I. C.; GIMENEZ FILHO, A. Disposição final do lixo. In: D'ALMEIDA, M. L. O; VILHENA, A. (Coord.) Lixo municipal: manual de gerenciamento integrado. 2.ed. São Paulo: Instituto de Pesquisas Tecnológicas IPT/ Compromisso Empresarial para Reciclagem - CEMPRE, 2000. cap.5, p.251291. 
CORSON, W. H. (Org.) Manual global de ecologia: o que você pode fazer a respeito da crise do meio ambiente. 2.ed. São Paulo: Augustus, 1996. 413p.

COSTA, M. A B. Métodos para construção de rotas eulerianas em grafos mistos com aplicação na distribuição de bens e serviços. Campina Grande, 1982. Dissertação (M.S.) - Universidade Federal da Paraíba.

CUNHA, C. B. da; PICHLER, E. F.; SOBBRAL, F. H. de A. GIACAGLIA, M. E; CHAVES, R; SCHNEIDER, D. M. Serviços de limpeza In: D'ALMEIDA, M. L. O.; VILHENA, A. (Coord.) Lixo municipal: manual de gerenciamento integrado. São Paulo: Instituto de Pesquisas Tecnológicas - IPT / Compromisso Empresarial para Reciclagem - CEMPRE, 1995. cap.3.

D'ALMEIDA, M. L. O.; TERADA, O.; DANILAS, R. M. Tratamento (outros materiais). In: D'ALMEIDA, M. L. O; VILHENA, A. (Coord.) Lixo municipal: manual de gerenciamento integrado. São Paulo: Instituto de Pesquisas Tecnológicas - IPT / Compromisso Empresarial para Reciclagem - CEMPRE, 1995. cap.5, parte 3 , item 3.6 .

DELUQUI, K K Roteirização para veículos de coleta de resíduos sólidos domiciliares utilizando um Sistema de Informação Geográfica. São Carlos, 1998. 222p. Dissertação (M.S.) - Universidade de São Paulo, Escola de Engenharia de São Carlos.

DIÁRIO OFICIAL DA UNIÃO. Preço do óleo diesel. http://www.ntu.org.br/banco/insumos/p_od.htm (24 nov. 2000)

DUARTE, C. R. Gasto energético, ingestão calórica e condições gerais de saúde de coletores de lixo em Florianópolis. Florianópolis, 1998. Dissertação (M.S.) Universidade Federal de Santa Catarina. 
EISENSTEIN, D. D.; IYER, A. V. Garbage collection in Chicago: a dynamic scheduling model. Management Science, v.43, n.7, p.922-933, July 1997.

FERREIRA, A. B. de H. Novo dicionánio Aurélio da língua portuguesa. 41.ed. Rio de Janeiro: Nova Fronteira, 1986. 1838p.

GASS, S. I.; HARRIS, C. M. Encyclopedia of operations research \& management science. London: Kluwer Academic Publishers, 1996. 753p.

GOMES, M. J. N. O problema de planejamento e percurso de veículos na coleta do lixo urbano domiciliar. Rio de Janeiro, 1990. Dissertação (M.S.) - Universidade Federal do Rio de Janeiro.

GUIA da coleta seletiva de lixo. São Paulo: Compromisso Empresarial para Reciclagem - CEMPRE, 1999. 84p.

INSTITUTO BRASILEIRO DE GEOGRAFIA E ESTATÍSTICA Resultados Preliminares do Censo 2000. http://www.ibge.gov.br (08 out. 2000)

JARDIM, N. S.; WELLS, C.; CONSONI, A. J.; AZEVEDO, R. M. B. de. Gerenciamento integrado do lixo municipal. In: D'ALMEIDA, M. L. O; VILHENA, A (Coord.) Lixo municipal: manual de gerenciamento integrado. 2.ed. São Paulo: Instituto de Pesquisas Tecnológicas - IPT / Compromisso Empresarial para Reciclagem - CEMPRE, 2000. cap.1, p.3-25.

KADO, T. M. N. Análise do método de AS (Simulated Annealing) aplicado à roteirização de veículos coletores de resíduos sólidos urbanos domiciliares. São Carlos, 1998. 148p. Dissertação (M.S.) - Universidade de São Paulo, Escola de Engenharia de São Carlos.

KULCAR, T. Optimizing solid waste collection in Brussels. European Journal of Operational Research, n.90, p.71-77, 1996 
LEE, S. M; MOORE, L. J.; TAYLOR, B. W. Management science. 3.ed. Boston: Allyn and Bacon, 1990. 901p.

MACDONALD, M. L. A multi-attribute spatial decision support system for solid waste planning. Computers, Environment, and Urban Systems, v.20, n.1, p.1$17,1996$.

MANDL, C. Applied network optimization. New York: Academic Press, 1979. 175p.

MANSUR, G. L.; MONTEIRO, J. H. R. P. O que é preciso saber sobre limpeza urbana. Rio de Janeiro: Centro de Estudos e Pesquisas Urbanas do Instituto Brasileiro de Administração Municipal. http://www.resol.com br (20 jul. 2001)

MATION, H. Caminhos eulerianos de mínimo custo em grafos orientados. In: SIMPÓSIO BRASILEIRO DE PESQUISA OPERACIONAL; CONGRESSO LATINO AMERICANO DE PESQUISA OPERACIONAL E ENGENHARIA DE SISTEMAS, 1., Rio de Janeiro, 1982. Anais, Rio de Janeiro: Aula, 1982. v.2, p.483-92.

MINAS GERAIS. Prefeitura Municipal de Belo Horizonte. http://www.pbh.gov.br (10 ago. 2000)

MUTTIAH, R. S.; ENGEL, B. A; JONES, D. D. Waste disposal site selection using gis-based simulated annealing. Computers \& Geosciences, v.22, n.9, p.10131017, 1996.

PARRA, R; DANTAS, M. L. S.; PICHLER, E. F.; CUNHA, C. B. da Acondicionamento e Coleta do Lixo. In: D'ALMEIDA, M. L. O.; VILHENA, A (Coord.) Lixo municipal: manual de gerenciamento integrado. 2.ed. São Paulo: Instituto de Pesquisas Tecnológicas - IPT / Compromisso Empresarial para Reciclagem - CEMPRE, 2000. cap.3, p.45-77. 
PERAL, L. R. O. del. Resíduos sólidos urbanos. Madrid: Centro de Publicaciones del Ministério de Obras Públicas y Urbanismo, 1989. 78p.

PHILIPPI JUNIOR, A. Sistema de resíduos sólidos: coleta e transporte no meio urbano. São Paulo: Companhia de Tecnologia de Saneamento Ambiental CETESB, 1986. 182p.

PINTO, K C. R. Aprendendo a decidir com a pesquisa operacional: modelos e métodos de apoio à decisão. Uberlândia: Universidade Federal de Uberlândia, 2000. 109p.

PRANDINI, F. L.; D'ALMEIDA, M. L. O.; JARDIM, N. S.; MANO, V. G. T.; WELlS, C.; CASTRO, A. P. de; SCHNEIDER, D. M. O gerenciamento integrado do lixo municipal. In: D'ALMEIDA, M. L. O.; VILHENA, A. (Coord.) Lixo municipal: manual de gerenciamento integrado. São Paulo: Instituto de Pesquisas Tecnológicas - IPT / Compromisso Empresarial para Reciclagem CEMPRE, 1995. cap.1.

QUERZOLI, A Há sempre uma boa opção para o lixo urbano. Dirigente Municipal, v. 19, n.7, jul. 1988.

RAVINDRAN, A; PHILlIPS, D. T; SOLBERG, J. J. Operations research: principles and practice. 2.ed. New York: John Wiley \& Sons, 1986. 637p.

ROTH, B. W.; ISAIA, E. M. B. I.; ISAIA, T. Destinação final dos resíduos sólidos urbanos. Ciência e Ambiente, n.18, p.25-40, jan/jun. 1999.

SÃO PAULO. Prefeitura de São Paulo. Lixo: problema ou solução. http://www.prodam pmsp.sp.gov.br (19 jun. 2000) 
SUDHIR, V.; MURALEEDHARAN, V. R.; SRINIVASAN, G. Integrated solid waste management in urban India: a critical operational research framework. Socio Economic Planning Sciences, v.30, n.3, p.163-181, 1996. 